\title{
ESTUDIOS SOBRE LA UNIVERSIDAD \\ DE LÉRIDA (1561-1717)
}

RAFAEL RAMIS BARCELÓ

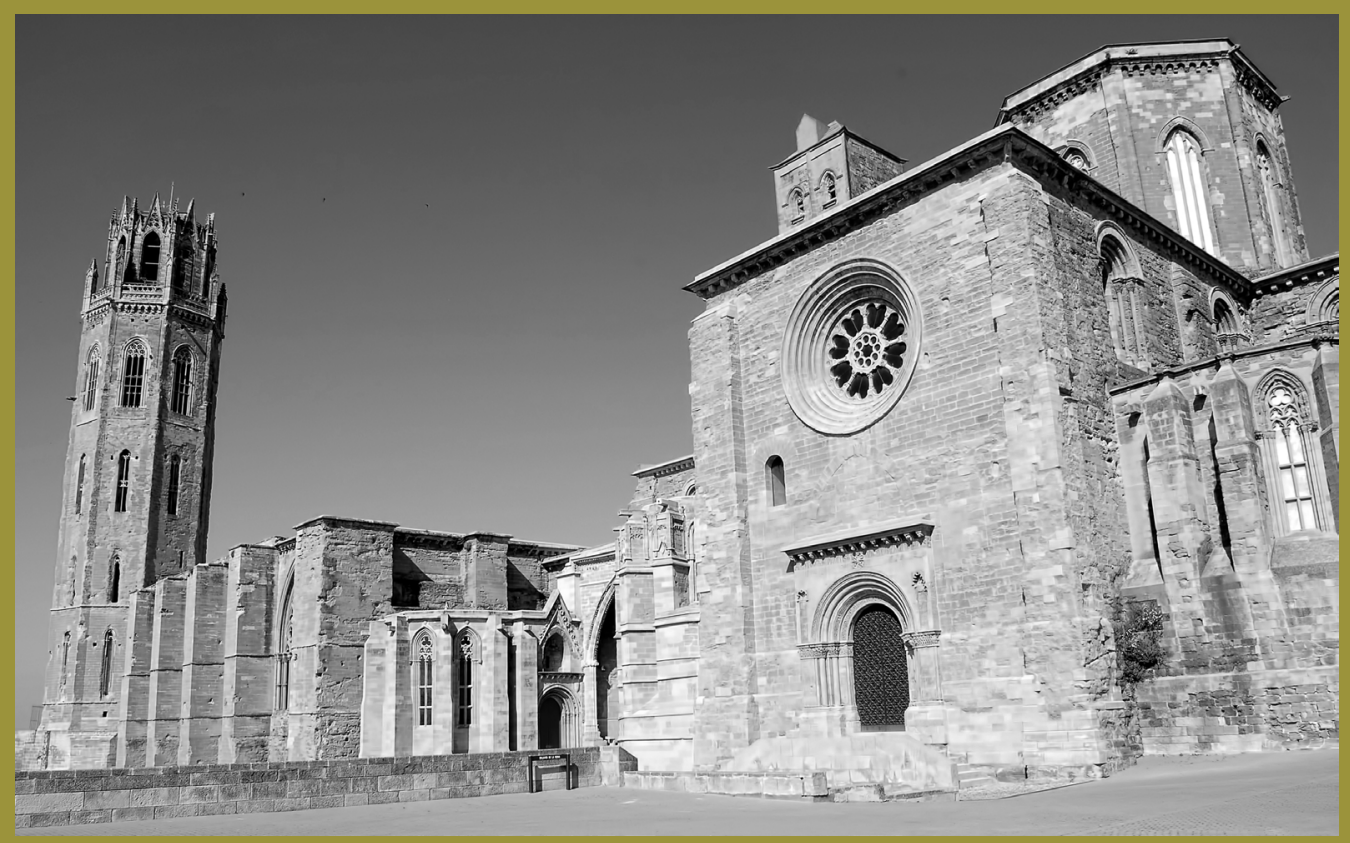



ESTUDIOS SOBRE LA UNIVERSIDAD DE LÉRIDA 
The Figuerola Institute

Programme: History of Universities

The Programme "History of Universities" of the Figuerola Institute of Social Science History -a part of the Carlos III University of Madrid- is devoted to improve the overall knowledge on the highlearning academic institutions, since their inception in the Late Middle Ages, until our days. The Programme uses an interdisciplinary approach, and it is open to all branches of related knowledge, such as the history of institutions, of science, and of cultural and social events. A number of experts from several countries have participated in the Programme, bringing in their specialized knowledge and dedication to the subject of their expertise.

To give a better visibility of its activities, the Programme has published in its Book Series a number of monographs on the different aspects of its academic discipline.

Publisher:

Carlos III University of Madrid

Book Series:

History of Universities

Editorial Committee:

Manuel Ángel Bermejo Castrillo, Universidad Carlos III de Madrid

Gianpaolo Brizzi, Alma Mater Studiorum - Università di Bologna

Elena Hernández Sandoica, Universidad Complutense de Madrid

Françoise Hiraux, Université catholique de Louvain

Manuel Martínez Neira, Universidad Carlos III de Madrid

More information at www.uc3m.es/history_universities 
ESTUDIOS SOBRE LA UNIVERSIDAD DE LÉRIDA (1561-1717)

\author{
Rafael Ramis Barceló
}

DYKINSON

2018 
Motivo de cubierta: Carme Ribes Moreno. Seu Vella, Lleida. CC BY-SA 3.o. https://commons.wikimedia.org/wiki/File:Seu_Vella.._Lleida.jpg

Historia de las Universidades, 46

ISSN: 1886-0710

(C) 2018 Rafael Ramis Barceló

Editorial Dykinson

c/ Meléndez Valdés, 61 - 28015 Madrid

Tlf. (+34) 915442846

E-mail: info@dykinson.com

http://www.dykinson.com

Preimpresión: TALLERONCE

ISBN - 978-84-9148-851-4

D.L. - M-31420-2018

Versión electrónica disponible en e-Archivo

http://hdl.handle.net/10016/27465

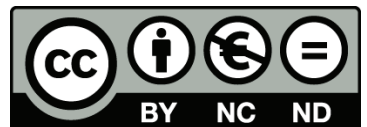

Licencia Creative Commons Atribución-NoComercial-SinDerivadas 3.o España 
Para Joan J. Busqueta, Albert Cassanyes,

Celestí Pol, Flocel Sabaté y Karen Stöber 



\section{ÍNDICE}

Introducción

1. La Universidad de Lérida durante el pontificado de Antonio Agustín (1561-1576)

2. La Facultad de Leyes y Cánones (1598-1714)

3. Las Facultades de Artes y Teología (1598-1714)

Epílogo

171

Bibliografía

175 
ACA Archivo de la Corona de Aragón

ACBE Arxiu Comarcal del Baix Ebre

ACL Arxiu Capitular de Lleida

AGN Archivo General de Navarra

AHN Archivo Histórico Nacional

AHUB Arxiu Històric de la Universitat de Barcelona

AMG Arxiu Municipal de Girona

AML Arxiu Municipal de Lleida

AMT Arxiu Muncipal de Tarragona

BC Biblioteca de Catalunya

BP Biblioteca de Poblet

BUB Biblioteca de la Universitat de Barcelona (Fondo Histórico)

DGC Dietaris de la Generalitat de Catalunya

\section{ABREVIATURAS}

Fr. Fray

O. Carm. Ordo Fratrum Beatissimae Mariae Virginis de Monte Carmelo

O. Cist. Ordo Cisterciensis

O. de M. Ordo Beatae Mariae Virginis de Redemptione Captivorum

O.F.M.Conv. Ordo Fratrum Minorum Conventualium

O. P. Ordo Praedicatorum

O.S.A. Ordo Fratrum Sancti Augustini

O.S.B. Ordo Sancti Benedicti

O. SS.T. Ordo Sanctissimae Trinitatis et Captivorum

P. Padre

Pbro. Presbítero 


\section{INTRODUCCIÓN}

En 1300, gracias a los auspicios de la oligarquía de la ciudad, Jaime II creó en Lérida una Universidad, destinada a ser la Salamanca de la Corona de Aragón. Su influencia fue muy duradera y creó un modelo universitario, de carácter municipal, que sería seguido por casi todas las Universidades de la Corona de Aragón.

En este libro estudiamos el último período de brillo de esa Universidad (el pontificado del obispo Antonio Agustín) y su progresiva decadencia hasta llegar a 1717, cuando fue transferida, junto a las demás universidades catalanas, a Cervera. Se trata de un período poco conocido, sobre el cual intentamos arrojar luz mediante tres capítulos, que pueden ser leídos de forma independiente y que, pese a ello, intentan conformar un hilo narrativo coherente. Titulamos esta obra Estudios sobre la Universidad de Lérida, puesto que, en realidad, dada la escasez de fuentes, no somos capaces de trazar una historia completa ni global sobre la institución. No tratamos la Facultad de Medicina, porque, salvo lo que indicamos en el primer capítulo, no podemos añadir mayores precisiones a la obra de Josep Lladonosa: La Facultat de Medicina de l'antiga Universitat de Lleida.

Lérida ha sido una ciudad muy castigada, y la historia, a menudo por falta de fuentes, le ha regateado su antiguo esplendor. La Guerra dels Segadors y la Guerra de Sucesión no solo mutilaron edificios y personas, sino también los archivos. El menguado material que se envió a Cervera se salvó parcialmente de los males que azotaron de nuevo a Lérida durante la Guerra Civil.

Sin embargo, la Ciudad del Segre ha contado con algunos historiadores locales que, desde la segunda mitad del siglo XX, emprendieron la hercúlea tarea de rastrear las fuentes del pasado leridano. La labor de Gayá Massot y de Lladonosa ha sido impagable. Para la historia de la Universidad, debe añadirse a Francesc Esteve Perendreu, que dedicó grandes esfuerzos a recuperar las figuras del antiguo Estudio. Sin los empeños de esta tríada de autores, este libro no se hubiera podido escribir.

Nuestra aproximación se basa sobre la suya, aunque cambia la perspectiva. No estudiamos la Universidad de Lérida desde Lérida, sino desde el contexto de la Corona de Aragón. Una vez han sido espigadas las fuentes locales, nuestra misión es la de examinar la Universidad desde un marco archivístico más amplio, buscando principalmente en los fondos del Archivo Histórico de 
la Universidad de Barcelona y en el Archivo Histórico de la Corona de Aragón. Allí hemos encontrado numerosas fuentes sobre Lérida, que no habían sido exploradas anteriormente, o que se habían analizado de manera parcial.

Asimismo, nuestros trabajos sobre otras Universidades de la Corona de Aragón nos permiten valorar con mayor precisión la relevancia de Lérida, prestando atención a algunos personajes destacados en el ámbito jurídico o teológico. Al conocer otras fuentes manuscritas de las demás Universidades, hemos podido dar sentido a algunos de los datos aislados que aparecían en los archivos de Lérida. Muchos otros han quedado en el tintero y quizás puedan ser revisados algún día con los datos que ofrecemos ahora en este libro.

El itinerario que presentamos es una historia de apogeo y decadencia, que deja un regusto doliente: la de una ciudad que, conservando aún el timbre de gloria de su primacía universitaria, ve como Barcelona poco a poco le va mermando su auctoritas, gracias a la potestas política y a la confluencia de intereses. Se transita desde los últimos rayos del humanismo (con una nómina envidiable de maestros) a la desventura del Barroco, jalonada por dos guerras que dejaron a Lérida exhausta y destruida. Mucho se ha escrito sobre la Barcelona del Barroco y sus desdichas hasta concluir la Guerra de Sucesión; las de Lérida no fueron menos y apenas han quedado datos archivísticos para atestiguarlo.

Recuperamos aquí una nómina de profesores de la época de Antonio Agustín (Capítulo 1), y constatamos con fuentes la presencia de docentes de la talla de Antoni Olibà, Pere-Joan Nunyes, Joan Moreno o Bartomeu Vilanova. En los capítulos segundo y tercero nos centramos en los estudios jurídicos, filosóficos y teológicos. Lérida fue, ante todo, una Universidad de juristas. Su prestigio, cada vez más languideciente, residía en los maestros de Leyes y Cánones. Durante el siglo XVII, Lérida quedaba alejada de las instituciones con mayor peso: el Lugarteniente, la Real Audiencia y la Diputación del General, radicadas en Barcelona. La Ciudad Condal atrajo hacia sí a los mejores juristas, que podían enseñar en su Universidad, mientras establecían una red de contactos que les permitiese un ascenso en la carrera burocrática a la que estaban destinados los catedráticos más prestigiosos. Lérida apenas podía ofrecer puestos bien remunerados en la Ciudad. Como tantas veces se dice a lo largo del libro, a duras penas podía pagar a los catedráticos.

Para los eclesiásticos, la Universidad ilerdense era una sede con menos atractivo que otras (Barcelona, Huesca, Zaragoza...), aunque con un cierto prestigio, que fue decayendo. Sin duda, la presencia de la gran mayoría de 
órdenes religiosas en la ciudad enriquecía sus perfiles, como veremos al analizar el profesorado. Sin embargo, los maestros más reputados, especialmente desde el siglo XVII, los tenemos que hallar en otras sedes. El interés en estudiar los catedráticos de Artes y Teología radica, sobre todo, en el hecho de conocer a relevantes figuras en las órdenes religiosas y en el clero secular local, que destacaron en facetas distintas (carrera eclesiástica, gobierno de sus órdenes, cuestiones políticas, literatura, pensamiento...)

La transferencia de la Universidad a Cervera supuso un grave empobrecimiento para la Ciudad: tuvo que seguir dedicando rentas al sostenimiento de la sede cervariense y no pudo recibir ningún beneficio. La situación no mejoró con el traslado de la Universidad a Barcelona. Sólo a finales del siglo XX, casi trecientos años depués, se creó la Universitat de Lleida, que ha devuelto el calor estudiantil a las riberas del Segre.

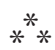

Este libro está dedicado cinco personas. Tres son profesores de la Universitat de Lleida, que me acogieron calurosamente durante mi breve estadía: Joan Josep Busqueta, Flocel Sabaté y Karen Stöber. Otro, Albert Cassanyes, es un querido colega y flamante Doctor por esa institución. Y, no menos importante, Celestí Pol i Vilagrasa, amigo y condiscípulo, hijo y nieto de juristas de Lleida, ejerce la abogacía en la ciudad, como hicieron muchos de los personajes que aparecen en el libro.

Manifestamos nuestra gratitud a las archiveras Yolanda Enjuanes Alzuria y Ana Carles Sánchez, del Arxiu de la Paeria y del Arxiu Capitular, respectivamente, por su amabilidad. Igualmente estamos en deuda con Maria Teresa Vernet Munté, del Arxiu Històric de la Universitat de Barcelona, que accedió gentilmente a digitalizar numerosas fuentes que le solicitamos. Agradecemos también al profesor Mariano Peset sus estímulos para el estudio del tema. Mi padre ha sido una ayuda inestimable para trabajar algunas fuentes de las Universidades de Barcelona, Gerona y Vic.

Una parte de este libro fue presentada como proyecto de investigación para el concurso a una plaza de Profesor contratado doctor de Historia del derecho en la Universitat de les Illes Balears. Quede constancia de nuestro agradecimiento, por sus observaciones, al Tribunal que la juzgó, compuesto por los profesores Maria Barceló i Crespí, Antoni Jordà Fernández, Tomàs de Montagut i Estragués, Antonio Planas Rosselló y Margarita Serna Vallejo. 
El libro se encuadra en los proyectos vigentes del Plan Nacional que dirigen, respectivamente, los profesores Tomàs de Montagut y José Juan Moreso, y en las líneas de investigación del Instituto de Estudios Hispánicos en la Modernidad (IEHM), Unidad asociada al CSIC.

Los anexos al final de cada capítulo ayudan a encontrar a los profesores más destacados que aparecen en el libro. Para obtener búsquedas más refinadas, los lectores interesados podrán hacerlas directamente en el PDF, colgado en internet y de libre acceso: con ello obtendrán una mayor precisión y amplitud que la que proporcionaría cualquer índice.

Por último, manifestamos nuevamente nuestra gratitud al Prof. Manuel Martínez Neira por su interés en este trabajo, que se incluye en la colección de monografías de Historia de las Universidades que dirige.

Pòrtol, septiembre de 2018. 


\title{
LA UNIVERSIDAD DE LÉRIDA DURANTE EL PONTIFICADO DE ANTONIO AGUSTÍN
}

\author{
(1561-1576)
}

Antonio Agustín Albanell (1517-1586) fue uno de los mayores humanistas y juristas de su época ${ }^{1}$. En este primer capítulo vamos a estudiar su vinculación con la Universidad de Lérida en una época central en su vida: la de su etapa como obispo de la diócesis ilerdense, en la cual tuvo un papel fundamental en la promoción del profesorado del Estudio General y en la reforma de los Estatutos de dicha institución.

Antes de adentrarnos en este período, es necesario conocer sucintamente el estado de la cuestión acerca de las fuentes y la bibliografía de la Universidad de Lérida, cuyos rasgos generales sirven también para los capítulos siguientes.

\section{Fuentes e historiografía}

Como es sabido, la mayoría de la documentación de la Universidad desapareció con el asedio que Lérida padeció en 1707 y con el traslado de la sede a Cervera. Una parte ya se había perdido durante la Guerra dels Segadors. Casi todos los datos que actualmente se poseen proceden de las labores de reconstrucción de diferentes autores, entre los que destacan Ramon Gayá Massot²

1 Véase E. Balasch (coord.), Antoni Agustí, bisbe de Lleida i arquebisbe de Tarragona, 1517-1586: aportacions entorn el marc sòcio-cultural de Catalunya en la seva època, Lleida, Publicacions dels Amics de la Seu Vella, 1995. Acerca de su obra jurídica, véase A. Jordà Fernández, "Un humanista del derecho. Antonio Agustín (1516-1517?-1586) y su obra jurídica”, e-SLegal history review, 25 (2017), pp. 1-63. Para conocer su personalidad resulta fundamental, C. Flores Sellés, Epistolario de Antonio Agustín, Salamanca, Universidad de Salamanca, 1980.

2 R. Gayá Massot, Los Valencianos en el Estudio General de Lérida, Valencia, CSICPatronato José María Quadrado, 1950; Cancilleres y rectores del Estudio General de Lérida, Lérida, La Editora Leridana, 1951; "Las Rentas del Estudio General de Lérida", Analecta Sacra Tarraconensia, 25 (1954), pp. 293-338; Los jesuitas en la Universidad de Lérida, Lérida, La Editora Leridana, 1954; "Provisión de cátedras en el Estudio General de Lérida”, Analecta Sacra Tarraconensia, 30 (1958), pp. 233-296 y “Influencia de la 
Josep Lladonosa ${ }^{3}$ y de Francesc Esteve Perendreu ${ }^{4}$ (quien consagró sus esfuerzos sobre todo a la época moderna y que, por lo tanto, es el autor más citado de este libro). Así como Lladonosa debe ser considerado el historiador de Lérida por excelencia, al haber tratado infinidad de aspectos de la vida de la ciudad, en el caso de Esteve, puede decirse que dedicó prácticamente toda su vida a la historia de la Universidad y que, con gran paciencia y laboriosidad, logró espigar datos para la reconstrucción del Estudio ilerdense.

Vicente de la Fuente ${ }^{5}$, fundador de la historiografía de las Universidades hispánicas, prestó poca atención a Lérida y se centró mucho más en las universidades mayores castellanas, y especialmente en Salamanca. En cambio, Cándido M. Ajo proporcionó mucha más información: recopiló gran cantidad de materiales heurísticos y describió fuentes impresas y manuscritas que son aún hoy de gran interés para el investigador ${ }^{6}$. Para estudiar la Universidad de Lérida, es importante seguir las indicaciones de Ajo, que se hacen eco de muchos materiales prácticamente inexplorados, si bien hay muchos otros que se hallan en volúmenes facticios, que no aparecen en su obra.

En este libro no sólo tenemos en cuenta datos aún no exhumados de los archivos de Lérida (el Archivo Capitular y el Archivo Muncipal), sino también la rica información recogida en el Archivo de la Corona de Aragón, tanto

Universidad de Salamanca en la de Lérida”, Analecta Sacra Tarraconensia, 31 (1959), pp. 101-124.

3 J. Lladonosa, La Facultat de Medicina de l'antiga Universitat de Lleida, Barcelona, Rafael Dalmau, 1969; L’Estudi General de Lleida del 1430 al 1524, Barcelona, Institut d'Estudis Catalans, 1970, "Humanisme i reformes a l'Estudi General de Lleida durant el segle XVI”, VIII Congreso de Historia de la Corona de Aragón, T. III, Vol. II, 1973, Valencia, Sucesor de Vives Mores, 1973, pp. 87-106; así como también otras obras de carácter general sobre la ciudad de Lérida, que contienen abundante información: Lérida medieval. Tomo II (siglos XIV-XV), Lleida, Dilagro, 1975; Lérida moderna. Epoca de los Austrias, Lleida, Dilagro, 1977; Lérida moderna. Época de los Borbones, Lleida, Dilagro, 1980, y muy especialmente, Història de Lleida, II, Tàrrega, F. Camps Calmet, 1975, pp. 303-324.

4 Citemos sólo las más importantes: F. Esteve Perendreu, El Régimen jurídico del Estudio General de Lleida: s. XIII/XVIII, Lleida, Publicacions de l'Estudi General de LleidaPagès, 1992; Mestrescoles i rectors de l'Estudi General de Lleida (1597-1717), Lleida, Edicions de la Universitat de Lleida, 2007 y El Col-legi universitari de l'Assumpció de Santa Maria de Lleida (segles XIV-XIX), Lleida, Universitat de Lleida, 2010.

5 V. de la Fuente, Historia de las universidades, colegios y demás establecimentos de enseñanza en España, Madrid, La viuda e hija de Fuentenebro, 1884-1887, 3 vols.

6 C. M. Ajo, Historia de las universidades hispánicas: orígenes y desarrollo desde su aparición hasta nuestros días, Ávila, CSIC, 1957-1979, 11 vols. 
en la correspondencia entre la Universidad y el Virrey, como en los asuntos relativos a ascensos, mercedes y prerrogativas de los profesores de Leyes y Cánones, así como peticiones varias correspondientes a teólogos y artistas. Asimismo, hemos tenido en cuenta la documentación que quedó depositada en el Archivo Histórico de la Universitat de Barcelona, descrita parcialmente por Ajo, que revestía un interés esencialmente económico e institucional.

Así como hay muy poca documentación del siglo XVI, el feliz hallazgo de una correspondencia y de documentación económica en los archivos ilerdenses facilita, en este primer capítulo, una reconstrucción mucho más fidedigna del profesorado. Ello nos permite conocer mejor el ambiente humanista del episcopado de Antonio Agustín.

\section{La estructura de la Universidad hasta la llegada de Antonio Agustín}

Antes de centrarnos en el estado de la Universidad durante estos años del reinado de Felipe II, conviene remontarnos a los orígenes de la institución para conocer los rasgos fundamentales de la misma, así como también dar a conocer lo que sucedía en ella unas décadas antes de la llegada del obispo canonista. Con ello podremos conocer las directrices con las que se gestó la Universidad y la progresión del Estudio General de Lérida bajo los auspicios de Carlos I.

\subsection{Los orígenes del Estudio, Constituciones y Estatutos}

La Universidad de Lérida, creada en 1300 por Jaime II, mantuvo en gran medida el modelo jurídico original durante las cuatro centurias en las que tuvo actividad 7 . Según indica Mariano Peset $^{8}$, con sus Estatutos, parcialmente similares a los de la Universidad de Bolonia, Jaime II evitó que el Estudio quedase bajo el control exclusivo de la Iglesia y lo convirtió en una estructura de poder equilibrado, que fue la base de las universidades de la Corona de Aragón, bajo un amplio poder muncipal: hay que destacar, esencialmente, el autogobierno de los escolares (mediante la elección del Rector y otras atri-

7 F. Esteve Perendreu, El régimen jurídico, pp. 117-122.

8 M. Peset, "La fundación y el fuero universitario de Lérida", Hispania, 199 (1998), pp. 515-536 y J. Pemán Gavín, "Los estatutos fundacionales de la antigua universidad Ilerdense (año 130o)”, en J. J. Busqueta (ed.), Llibre de les Constitucions i Estatuts de l'Estudi General de Lleida, Lleida, Universitat de Lleida, 2000, pp. 25-53. 
buciones); el control municipal matizado por la existencia de un gobierno académico independiente que integraba las "naciones" de la Corona; un peso eclesiástico fuerte, que podía condicionar -aunque no obligar- a las autoridades universitarias; y, por último, una vocación monopolística frente a las demás Universidades creadas con posterioridad 9.

Bonifacio VIII autorizó en 1297 a Jaime II para que crease una universidad, que el Papa quería que se basase en el modelo de Toulouse. Sin embargo, el Rey prefirió que su estructura siguiese la pauta boloñesa, en la que el Rector tenía la jurisdicción del Estudio. La documentación de $1300^{10}$ muestra la solidez del proyecto, que no sólo implicaba al monarca, sino también al Municipio, a la Iglesia, a los profesores y a los estudiantes. Peset comenta la deliberada exclusión de la Teología, puesto que ésta quedaba reservada a la Universidad de París $^{11}$.

Cuando Jaime II quiso fundar una Universidad para todos los Reinos de la Corona de Aragón, pensó en Lérida como ciudad equidistante de todos ellos ${ }^{12}$. La creación de Facultad de Leyes y Cánones de la Universidad ilerdense fue, en cierta manera, el objetivo más importante de la erección del propio Estudio por parte de la oligarquía de la ciudad ${ }^{13}$.

El cargo de Rector lo detentaba ordinariamente un estudiante legista o canonista que no fuese vecino de Lérida; la duración del cargo era anual, y su nombramiento se efectuaba por un Consejo compuesto por estudiantes de ambos derechos ${ }^{14}$. La importancia de los legistas y de los canonistas era fundamental, incluso para elegir al Rector: "Estudians en Lleys y Canons del Estudi de Lleyda, que no sien naturals de dita ciutat poden quiscun any elegir Rector de Estudi, conciliaris i vedells. El Rector de Estudi y conciliaris no

9 F. Esteve Perendreu, El régimen jurídico, pp. 117-122. M. Peset, "La fundación y el fuero", pp. 515-536. Para el tema de la jurisdicción cabe consultar también F. Esteve Perendreu, "Jurisdicció del bisbe sobre el mestrescola i eclesiàstics de l'Estudi General de Lleida” en VVAA, Església i societat a la Catalunya del segle XVIII, Cervera, UNED, 1990, vol. II, pp. 183-197.

10 Copia en AHUB, Universidad de Cervera, Caja 1, leg. 4724.

11 M. Peset, "La fundación y el fuero...", pp. 516-517.

12 M. Peset y M. Menegus Bornemann, "Localización y espacio de las universidades hispánicas”, Cuadernos del Instituto Antonio de Nebrïa, 3 (200o), pp. 189-232.

13 J. J. Busqueta, "Oligarquia urbana i ensenyament superior: Lleida, del bidell al canceller de l'Estudi General”, en F. Sabaté i Curull (coord.), L'edat mitjana: món real i món imaginari, Catarroja-Barcelona, Editorial Afers, 2012, pp. 163-169.

14 F. Esteve Perendreu, El régimen jurídico, pp. 105-116. 
han de ser nats en Lleyda ${ }^{15}$ ". Habitualmente había una alternancia entre las tres naciones: catalanes, valencianos y aragoneses ${ }^{16}$. Para Peset,

"la Universidad, por tanto, estaría constituida tan sólo por los escolares juristas foráneos: es decir, como en Bolonia la universidad ultramontana, con su rector, consiliarios y naciones, pero sin esa dualidad de la otra cismontana, que reunía a las originarios de la península itálica. Aquí se excluía a quienes eran vecinos de Lérida, que, sin duda serían más numerosos y estaban más protegidos por el derecho de la ciudad. Los estudiantes de otras materias y facultades -médicos y artistas excluidos de la elección de la universitaequedaban englobados en el estudio general, bajo el gobierno del rector, así como también los doctores y maestros, a diferencia de Bolonia ${ }^{17}$.

El Rector desempeñaba el cargo de forma gratuita, y sólo en premio de su trabajo se le conferían gratuitamente los grados de Bachiller y Doctor ${ }^{18}$. Entre sus misiones se encontraba la asistencia a todos los actos públicos y el cuidado de la disciplina escolar. Eran frecuentes los conflictos del Rector con los otros poderes que limitaban su autogobierno: el Monarca, el Muncipio y la Iglesia. Como se indica en un manuscrito, entre las obligaciones del Rector estaba "visitar las posadas de los estudiantes desde las seis a las ocho de la noche que eran las oras de vela por ver si estudiauan y estan recullidos ${ }^{19}$ ".

Indica Peset que "la Universidad o estudio debe lograr un espacio propio, cierta jurisdicción para velar por su existencia y sus privilegios, si no quieren verse sometidos al dominio municipal, con la desventaja de ser extranjeros y no ciudadanos ${ }^{20}$ ". En Tolosa, el problema se resolvía al someter la Universidad a la jurisdicción eclesiástica, si bien en Lérida, como hemos dicho, se siguió el modelo boloñés. El Rector fue juez del estudio hasta 1585, cuando, siguiendo el modelo salmantino, cedió estas prerrogativas al Cancelario o Maestrescuela ${ }^{21}$.

Según Esteve, el Rector, como órgano unipersonal, y el Rector-Consejo General, y el Rector Consejo-Particular, en tanto que órganos colegiados, tenían la potestad de representar y de regir la Universidad, de acuerdo con las competencias atribuidas a cada uno de ellos ${ }^{22}$.

15 ACL, P7_M2_P3_Co3, s.f.

16 Llibre de les Constitucions i Estatuts de l'Estudi General de Lleida, pp. 76-78.

17 M. Peset, "La fundación y el fuero...", p. 527.

18 Llibre de les Constitucions i Estatuts de l'Estudi General de Lleida, pp. 81-82.

19 AHUB, Universidad de Cervera, Caja 147, leg. 1226.

20 M. Peset, "La fundación y el fuero...", p. 527.

21 F. Esteve Perendreu, El régimen jurídico, pp. 123-125.

22 Ibidem, p. 118. 
En cuanto al Canciller, en tanto que representante de la Iglesia ${ }^{23}$, hay que destacar que no tenía ninguna función de gobierno en el Estudio: era un cargo honorífico de designación real, que recaía en un canónigo de Lérida, que tenía carácter vitalicio y presidía y confería los grados, con autoridad apostólica y real, con la excepción de los de Bachiller en Leyes y Cánones, que los confería el Rector ${ }^{24}$.

De los bedeles, se decía en un manuscrito que "asistian en dicha Universidad y al Retor siempre que salia en publico con sus masas" y en cuanto al "oficio de secretario valia muchos ducados por estar unido este al de Secretario de la Ciudad ${ }^{25}$ ".

Los escolares de la Universidad de Lérida disfrutaban de multitud de privilegios, conferidos todos en el decreto de fundación ${ }^{26}$. Tal vez los más importantes eran el no poder ser presos ni detenidos, ni vendidos sus bienes por deudas contraídas antes de pasar a la ciudad de Lérida ni como principales ni como fiadores, cuya inmunidad se hacía también extensiva a los mercaderes de libros que se trasladaran a Lérida para el ejercicio de su oficio; que en ninguna casa o habitación de Doctores, Maestros y Escolares pudieran practicarse pesquisas por los oficiales de Justicia en busca de delincuentes, a no ser que éstos merecieran pena corporal o que se hubieran ocultado perseguidos por aquellos oficiales en dichas casas (lo que conllevaba gravísimas penas, incluso la de horca, a los infractores de aquella ley).

Normalmente los monarcas nombraban visitadores a los obispos de Lérida $^{27}$, si bien, como veremos, en ocasiones fueron otros prelados los responsables de la visita y reforma del Estudio General, que era una institución aquejada siempre de escasez económica y, muchas veces, de alumnado. Los altercados entre los estudiantes, que afectaban también a la población de la ciudad, o a los profesores, eran muy frecuentes. De ahí que fuese tan importante el establecimiento de una jurisdicción fuerte, a fin de atajar los escopetazos, las riñas y los tumultos.

En la provisión de cátedras tenían voto, en los primeros años de establecimiento de la Universidad, todos los estudiantes de las Facultades respectivas, con tal que tuviesen aprobado un curso y se hallaran matriculados; luego esta

23 M. Peset, "La fundación y el fuero...”, pp. 522-523.

24 Llibre de les Constitucions i Estatuts de l'Estudi General de Lleida, pp. 82-85.

25 AHUB, Universidad de Cervera, Caja 147, leg. 1226.

26 F. Esteve Perendreu, El régimen jurídico, pp. 147-149.

27 F. Esteve Perendreu, Mestrescoles i rectors..., pp. 52-53. 
disposición fue restringida. En Lérida, como en las ciudades universitarias, había dos clases de maestros: los pagados por la Ciudad, y aquellos que ejercían la enseñanza privadamente. Aquí nos referiremos solamente a los primeros, que tenían el rango de catedráticos ${ }^{28}$. Los lectores de las catedrillas tenían un sueldo muy limitado, pero solían ascender de forma mucho más rápida hacia cátedras mejor remuneradas. El curso terminaba el día 14 de abril y en dicho día se congregaban todos los Catedráticos, aprobando cada uno en su Facultad el curso a los estudiantes.

Las Rentas de que gozaba el Estudio General fueron variables a lo largo del tiempo ${ }^{29}$ : las que tuvieron mayor estabilidad fueron dos pensiones sobre la Mitra de Lérida que sumaban $1480 £$; una pensión de $110 £$ sobre la Colegiata de Ager; una pensión de $50 £$ sobre la hacienda del Duque de Alba; otra de $129 £$ sobre la "marmesoría" de Gallart; dos que componían $100 £$ sobre la Ciudad de Lérida y los Oncenillos de Aragón y Cataluña, que consistían en la undécima parte del diezmo sobre determinados lugares que eran del Arcediano Mayor de Lérida, que a la supresión de esta dignidad fueron aplicadas a la Universidad. En 1607 el Rey aplicó las rentas de la Abadía premonstratense de las Avellanas a los salarios de la Universidad ${ }^{30}$. En un manuscrito de 1630 se señalan los devengos de las Rentas del Estudio:

"La Renta de la Universidad consiste en una pension sobre la mensa episcopal de mil y treinta libras cada año.

El Arrendamiento del derecho del vino que esta oy arrendado en seys cientas y sinquenta libras.

De los censeros de la Maestrescolia sacan tres cientas y sesenta libras.

De la Catreda de Conchillos sesenta libras

De la haçienda de Çervero para una catreda de filosophia Ciento y treynta libras ${ }^{31 "}$.

Las cantidades cambiaron muy sensiblemente a lo largo del siglo XVII ${ }^{32}$. En un manuscrito que detalla las rentas tras la extinción de la Universidad, se indica que eran: de la mitra de Lérida dos pensiones perpetuas, una de 700 y otra de 300 ducados de oro anuales; $100 £$ de la pensión del Duque de Alba

28 F. Esteve Perendreu, El régimen jurídico, pp. 151-163.

29 Ibidem, pp. 165-174.

30 ACA, Consejo de Aragón, leg. 282, n. 48/6. El Síndico de la Universidad escribía al Rey en 1608 quejándose de que aún no habían percibido esas rentas.

31 ACA, Consejo de Aragón, leg. 282, n. 48/11.

32 F. Esteve Perendreu, El régimen jurídico, pp. 172-173. 
por los derechos que percibía en Castelló de Farfanya; de los administradores del albaceazgo de Gallart, de la fundación del obispo Conchillos y de la imposición que tenía la Ciudad sobre el vino. Todo ello, en total, suponían $2179 £$ barcelonesas para pagar los salarios de los catedráticos, el síndico, el clavario, el secretario, el bedel, el impresor y la limosna de misas que en la Iglesia de la Universidad había fundadas, y otros cargos subalternos. Para los doce catedráticos existían unos aumentos de salario, que se repartían proporcionalmente según su sueldo ${ }^{33}$.

Fueron muy constantes los conflictos entre los síndicos del Estudio General y cada una de estas instituciones, por el pago de las rentas. En este sentido, como ha subrayado Mariano Peset que,

“como no dispone de rentas, ni el pontífice se las otorga, confió el Estudio general a la paeria de Lérida para que lo financiase y nombrase sus profesores, para que lo regulara de acuerdo con el rector y escolares... De este modo, apareció la primera universidad municipal, modelo que, con los años, se implantó en la costa mediterránea: Gerona y Barcelona lo adoptaron, con mayor dependencia de sus Ayuntamientos, como después Valencia o Vic. Incluso se extendería a Messina ${ }^{34 "}$.

\subsection{La Universidad de Lérida bajo Carlos I}

La Universidad de Lérida, que había sido protegida y privilegiada por los diferentes monarcas, tuvo una fuerte competencia tanto de las Universidades fundadas en el siglo XV como de las sedes nuevas que habían emergido desde 1550, especialmente Barcelona y Zaragoza. El hecho de que Barcelona fuera Cap $i$ casal y que la administración del Principado hubiera crecido y estuviese fuertemente centralizada en la Ciudad Condal, favoreció las aspiraciones del Estudio General barcelonés ${ }^{35}$, que fue adquiriendo cada vez más estudiantes de Artes y Medicina, y poco a poco fueron consolidando los estudios jurídicos y teológicos ${ }^{36}$.

33 AHUB, Universidad de Cervera, Caja 147, leg. 1226.

34 M. Peset, "La fundación y el fuero...", p. 535.

35 A. Fernández Luzón, La Universidad de Barcelona en el siglo XVI, Barcelona, Universitat de Barcelona, 2005.

36 R. Ramis Barceló, "Los graduados en Leyes y Cánones de la Universidad de Barcelona durante el siglo XVI”, Anuario de Historia del Derecho Español, 85 (2015), pp. 475496 y R. Ramis Barceló, "Los grados en teología en la Universidad de Barcelona durante el siglo XVI”, Anuario de Historia de la Iglesia, 24 (2015), pp. 291-309. 
Lérida experimentó, a lo largo del siglo XVI, un crecimiento demográfico pausado, aunque progresivo ${ }^{37}$, que contribuyó al florecimiento de la ciudad. Pese al atractivo que ejercía sobre los estudiantes foráneos, tenía que luchar contra la competencia, pues a mediados del siglo XVI ya no tenía la situación privilegiada de la que había gozado en las centurias anteriores. La Universidad de Huesca asimismo le privó de alumnos del Reino de Aragón e incluso atrajo hacía ella a muchos catalanes. Así como Carlos I había favorecido mucho la Ciudad Condal y su interés había resultado decisivo para desencallar las tensiones internas para la puesta en funcionamiento de su Estudio General, su hijo Felipe II apoyó claramente la Universidad de Lérida ${ }^{38}$ como sede tradicional, especialmente como medio de protección frente las herejías ${ }^{39}$.

Sin embargo, en las Cortes de Monzón de 1541, Carlos I había accedido al aumento de los salarios de los catedráticos del Estudio General ilerdense, "lo qual es molt famos, $y$ dell han proceit molts Doctors famosos en totas las ditas facultats, los quals han servit i servexen a vostra Majestat, y a vostres predecessors en la bona administratio de la justitia, y altrament ${ }^{40 "}$.

Tenemos escasos datos de los profesores ilerdenses en la época de Carlos I, si bien hemos podido espigar una nómina de 1535: Ferran de Cardona, Pere Soler, Pere Oriol, Pau Jordà, Miquel Miralles, Pere Robio, Onofre Urgelles, Doctores en Derecho; Joan Ozoro, Pere Joan Vilaplana, Gabriel Babot, Simó Pla, Joan Mascaro, Doctores en Artes y Medicina ${ }^{41}$. En 1536, como es sabido, se dio un gran impulso a la Facultad de Teología con la creación de la llamada cátedra de Conchillos ${ }^{42}$. Su promotor había sido el obispo Jaime Conchillos (1513-1542). De él escribió Lladonosa que: "Lleida gaudirà durant trenta anys d'un prelat resident $i$ reformista $i$ amb una mentalitat oberta, tant com ho podrà ésser un home del Renaixement peninsular43".

37 Véase M. J. Vilalta i Escobar, "La societat de Lleida en l'època moderna", en C. Martínez Shaw (coord.), Historia Moderna, Historia en construcción, Vol. II, Lleida, Milenio, 1999, pp. 329-350.

38 S. Sánchez-Lauro Pérez, "L’Estudi General de Lleida davant un moment històric d'inflexió renovadora: peticions locals d'intervenció regi a Felip II”, Revista de Dret Històric Català, 9 (2009), pp. 253-269.

39 J. Lladonosa, Història de Lleida, vol. II, p. 307.

40 Constitutions y altres drets de Cathalunya..., Barcelona, en casa de Joan Pau Marti y Joseph Llopis, 1704, p. 37.

41 ACL, P7_M2_P3_Co6, s.f.

42 ACL, P7_M2_P3_Co4, cuadernillo, s.f.

43 J. Lladonosa, Història de Lleida, II, p. 143. 
Ferran de Cardona, Pere Soler, Pere Oriol, Pau Jordà, Miquel Miralles y Pere Robio eran Doctores en Derecho y estuvieron presentes en la supresión de la provisión de la cátedra de Teología en $1535^{44}$. Pere Soler, Vicario General, había llevado a cabo la visita pastoral en 1535 por mandato del obispo Conchillos ${ }^{45}$. Pau Jordà y Pere Molí se ocuparon de gestionar el "redreç" de la Universidad en $1534^{46}$. Tal vez el jurista más destacado fuese Onofre Urgelles, que, tras ocupar diversos cargos, llegó a ser Regente de la Cancillería del Consejo de Aragón en 154577. Indiquemos también que Simó Pla, Doctor en Medicina, fue insaculado como diputado de la Ciudad de Lérida ${ }^{48}$.

Dicho lo anterior, volvamos a la cátedra del obispo Conchillos, erigida en 1536, que vino a sustituir la cátedra de teología anterior, suprimida en 1535 , en el marco de la reforma de los estudios aprobada por el mismo Emperador ${ }^{49}$. El primer catedrático fue Nicolau Moratell, Doctor en Artes y en Teología, beneficiado de la Catedral y buen conocedor de las lenguas clásicas. Tras su fallecimiento en 1545, fue nombrado Fr. Joan Escapolat Prades, trinitario, Doctor en Teología, que detentó la cátedra entre 1546 y $1549^{50}$. Desde este último año, y durante diferentes lapsos, la ocupó Fr. Joan Moreno, franciscano, de quien volveremos a ocuparnos posteriormente. El agustino Fr. Joan Baptista Burgos la detentó durante los años 1552-1555 y el trinitario Fr. Joan Bertran lo hizo en 1556. Onofre Ximeno, Maestro en Teología leyó la cátedra de Conchillos en 1560, y entre 1566 y 1569 lo hizo Agustí Gascón. La cátedra que fundó el obispo fue leída desde 1570 hasta 1578 por Pere Salas, Doctor en Teología y Rector de la Iglesia Parroquial de Sant Joan ${ }^{51}$.

44 F. Esteve Perendreu, El Col-legi universitari de l'Assumpció..., p. 55.

45 J. Lladonosa, Història de Lleida, II, p. 230.

46 Ibidem, p. 235.

47 T. Canet Aparisi, "Entre la visita y la sucesión. La resistencia a la virreinalización administrativa en Valencia entre Carlos V y Felipe II”, Estudis. Revista de Historia Moderna, 28 (2002), pp. 205-240, especialmente, p. 208.

48 E. Serra i Puig, Els Llibres de l'Ànima de la Diputació del General de Catalunya (1493-1714), II, Barcelona, IEC, 2015, p. 268.

49 F. Esteve Perendreu, "La docència de la teologia a Lleida, la càtedra del bisbe Conchillos i les altres càtedres teològiques de l'Estudi General” en X. Company (ed.), El bisbe Jaume Conchillos, l'humanisme a Catalunya, Lleida, Amics de la Seu Vella, 1993, p. 153.

50 P. Sanahuja, "La Universidad de Lérida y los franciscanos", Archivo Ibero-americano, 7 (1947), p. 204.

51 Tomamos los datos de F. Esteve Perendreu, "La docència de la teologia a Lleida...", pp. 158-159. 
Pedro Sanahuja aporta una nómina profesoral incompleta del año $1557^{52}$. En ella figuran dos catedráticos de Teología, lo cual hace suponer que con anterioridad se había creado otra cátedra, llamada de Prima. En 1560 se fundó una tercera cátedra, que fue encomendada al maestro Ripoll. Ese mismo año, el catedrático de Prima era Fr. Joan de Nus, franciscano ${ }^{53}$.

Miquel Despuig, Doctor en ambos Derechos y Obispo de Lérida desde 1556, murió el 21 de noviembre de 1559 y no pudo acabar la reforma que había proyectado. Poco antes de su fallecimiento había fundado el Colegio de la Purísima Concepción y había promulgado unos Estatutos para la reforma de la Universidad ${ }^{54}$.

Los paheres mandaron a Fr. Juan Moreno, catedrático de Prima de Teología, y a Melchor Munyós ${ }^{55}$, que era ciudadano honrado ${ }^{56}$ y paher segundo de Lérida $^{57}$, a la Corte de Felipe II, a fin de obtener del monarca una sustanciosa pensión sobre la mitra de Lérida a favor del Estudio General ${ }^{58}$.

Ante la necesidad de un prelado experto para resolver la problemática del

52 P. Sanahuja, "La Universidad de Lérida y los franciscanos”, p. 206. "Según canta esta libreta, hubo en dicho año 1557, cinco asignaturas o facultades: Teología, Cánones, Leyes, Medicina y Artes.

Facultades, horas de clase y catedráticos:

Teología: Octava, Fr. Juan Moreno; Cuarta, (Onofre) Ximeno.

Cánones: Sexta, Suñer; Séptima (Pedro) Moli; Octava, (Pedro) Segarra; Nona, Tristany; Secunda, (Bartolomé) Gomar, doctores en Derecho; Tercia, (Pedro) Ribes; Cuarta, Bordalva.

Leyes: Sexta, (Martin Juan) Franquesa; Sétima, (Pedro) Rubio o Gaço; Octava, (Francisco) Botella; Nona, (Pedro) Rubio o Robio; Secunda, (Jerónimo) Pascual; Tercia, Jordá; Cuarta, (Juan) Amell.

Medicina: Séptima, Pardina; Octava, Benach; Secunda, Scalona.

Artes: Séptima, Vilanova: Séptima; Séptima [sic]; Segunda, Vilanova, Segunda; Segunda [sic]".

53 F. Esteve Perendreu, "La docència de la teologia a Lleida...”, pp. 155-156 y 159.

54 F. Esteve Perendreu, "Rentas y reformas del Estudio General de Lérida", Analecta Sacra Tarraconensia, 69 (1996), pp. 29-86, especialmente, 69-73.

55 ACL, P7_M2_P3_Co6, Llibre del Studi, f. 18r.

56 ACA, Real Patrimonio, Procesos, 1547-1548, n. 1.

57 F. J. Morales Roca, Ciudadanos y burgueses honrados habilitados como Síndicos del Brazo Real en las Cortes del Principado de Cataluña: dinastías de Trastámara y de Austria, siglos XVy XVI, 1410-1599, Madrid, Hidalguía, 1995, p. 212.

58 P. Sanahuja, "La Universidad de Lérida y los franciscanos", véase especialmente, pp. 210-238. 
Estudio, Felipe II nombró a Antonio Agustín, natural de Zaragoza, que a la sazón era auditor de la Rota ${ }^{59}$. El Obispo, que había sido Visitador de Sicilia por encargo del monarca, agradeció rápidamente la merced a Felipe $\mathrm{II}^{60}$. Sin embargo, no se dirigió directamente a Lérida, sino que encaminó sus pasos hacia Trento, donde tuvo una presencia muy activa en la última fase del Concilio $^{61}$. Llegó finalmente a la Ciudad del Segre en 1564, e intentó aplicar allí las novedades tridentinas ${ }^{62}$.

El paso de Antonio Agustín ${ }^{63}$ por la mitra ilerdense ha sido estudiado en un sentido más histórico-filológico e histórico-artístico ${ }^{64}$ que en su dimensión religiosa, educativa e institucional. Es cierto que Lladonosa ${ }^{65}$ había indicado con acierto que la presencia de Antonio Agustín había favorecido el humanismo en el Estudio de Lérida, aunque no había precisado la nómina de los profesores ni la vinculación que tuvo con ellos. La documentación universitaria que examinaremos seguidamente permite conocer a algunos de sus más estrechos colaboradores.

Volviendo al hilo cronológico, recordemos que en 1562, Felipe II había asignado setecientos ducados sobre los frutos del Obispado de Lérida, a favor del Estudio General ${ }^{66}$. Estos ducados los percibía en vida el clérigo Juan Hurtado de Mendoza, y tras su fallecimiento, se acordó que Fr. Juan Moreno se trasladase a la Corte para solicitar que se hiciese efectiva la pensión de los

59 Véase P. Molas, “El bisbe Antoni Agustí: política i erudició al segle XVI”, en M. Esther Balasch (coord.), Antoni Agustí..., pp. 13-19.

60 C. Gutiérrez, Trento, un problema: la última convocación del concilio (15521562), V, Madrid, Universidad Pontificia de Comillas, 2000, pp. 216-217.

61 J. Bada i Elias, "Aportacions doctrinals d'Antoni Agustín a la tercera etapa del Concili de Trento (1562-1563)”, Revista Catalana de Teologia, 12/1 (1987), pp. 125-139.

62 J. F. Alcina Rovira, “Antonio Agustín y el índice de libros prohibidos del Concilio de Trento (Roma, 1564)”, Calamvs renascens: Revista de humanismo y tradición clásica, 3 (2002), pp. 7-14.

63 Para una biografía de Antonio Agustín, véase J. Carbonell i Manils, Epigrafia i numismàtica a l'epistolari d'Antonio Agustín (1551-1563), Bellaterra, Universitat Autònoma de Barcelona, [Tesis doctoral], 1992, especialmente, pp. 1-72.

64 J. F. Alcina Rovira, "El Humanismo de Antonio Agustín”, en A. Egido y J. E. Laplana (coord.), Mecenazgo y Humanidades en tiempos de Lastanosa: Homenaje a Domingo Ynduráin, Zaragoza, Institución Fernando el Católico e Instituto de Estudios Altoaragoneses, 2008, pp. 31-50.

65 J. Lladonosa, "Humanisme i Reformes a l'Estudi General de Lleida durant el segle XVI”, pp. 87-106.

66 ACA, Cancillería, Reg. 4298, ff. 113r-v. 
setecientos ducados a favor del Estudio, con los correspondientes abonos de los atrasos. Finalmente, el 9 de junio de 1565, el papa Pío IV concedió los setecientos ducados sobre la mitra de Lérida a favor del Estudio General ${ }^{67}$. Asimismo, el 28 de junio de 1568 Felipe II aprobó la unión de las rentas del Priorato de Lérida al Estudio ilerdense ${ }^{68}$.

Tres meses después, el 19 de septiembre de 1565, Felipe II, mediante Real Cédula, le encargó a Antonio Agustín la reforma del Estudio General de Lérida, concediéndole amplísimos poderes para inspeccionar, sancionar y elaborar nuevos estatutos. Como veremos, dichos poderes causaron recelo a las autoridades ilerdenses y crearon una situación muy problemática.

\section{Los profesores del Estudio (1564-1673) ${ }^{69}$}

Gracias a unas muy escuetas notas de pagos, contenidas en el Llibre del Studi que se conserva en el Archivo Capitular de Lérida tenemos una documentación inédita acerca del profesorado del Estudio General cuando llegó el obispo Antonio Agustín, que complementan el trabajo de Pedro Sanahuja sobre las ápocas de pago anteriores ${ }^{70}$.

Hay que indicar, antes de entrar en la nómina de lectores, que en el manuscrito se mezclan las cátedras doctorales con las de bachiller. Esta distinción sólo es importante para los juristas, ya que había tres cátedras de Leyes y tres de Cánones, cuatro catedrillas de Leyes y cuatro de Cánones, así como una cátedra de Instituta, que podía leer tanto un Bachiller como un Doctor. Había asimismo cuatro cátedras de Teología, tres de Medicina, dos de Filosofía y dos de Gramática. Estas cátedras, como veremos, quedaron definitivamente asentadas tras la reforma de Antonio Agustín de 1575.

La documentación manuscrita indica que a través de la "marmessoria de Berenguer Gallart ${ }^{71}$ " se pudo hacer el pago desde San Lucas a la vigilia de

67 F. Esteve Perendreu, "Rentas y reformas...”, 44-45. Véase ACA, Cancillería, Reg. 4303, ff. $115 \mathrm{v}-116 \mathrm{v}$.

68 ACA, Cancillería, Reg. 4301, ff. 286r-287r y ACA, Cancillería, Reg. 4302, ff. 195v$196 \mathrm{v}$.

69 En los apartados siguientes se amplía nuestro estudio: R. Ramis Barceló, "La Universidad de Lérida durante el pontificado de Antonio Agustín (1561-1576)”, Cauriensia, 12 (2017), pp. 599-626.

70 P. Sanahuja, “La Universidad de Lérida y los franciscanos”, pp. 204-205.

71 ACL, Llibre del Studi, ff. 1-2. 
San Tomás apóstol y la otra paga de Navidad hasta San Juan. Estos frutos del albaceazgo de Berenguer Gallart ascendían a cuatrocientos florines, que, gracias a una bula del papa Benedicto XIII de 1413, estaban incoporados a la Universidad. Indica Lladonosa que hasta el año 1564 esta cantidad se repartió entre $237 £$ catalanas pagaderas en las dos tandas antes indicadas y $30 £$ más que los albaceas solían pagar anualmente para la composición de la Bula del Estudio $^{72}$.

Para el curso de 1564, las notas de pagos proporcionan los siguientes nombres de lectores, que hemos reunido aquí73: Pere Molí, Pere Segarra, Bartomeu Gomar, Pere Rubio (Pere Aguiló, sustituto), Francesc Botella, Hieronim Pasqual, Agustí Gascón, Gabriel Babot, Francesc Riber, Fernando Gil Scalona, Jaume Mir, Antoni Oliba, Luis Copons, Llorens Cellers, Andreu Rius, Salvador Mor, Miquel Ferrer, Fra Joan Ginebrosa, Mestre Pere Llopico, Thomas Carrera, Barthomeu Serret y Pere Esteve ${ }^{74}$.

Hay que recordar, en primer lugar, que el catedrático de Prima de Teología, Fr. Juan Moreno -que leía, según Sanahuja y Vázquez Janeiro, desde $1549^{75}$ - se hallaba en la Corte para negociar las rentas de la Universidad. Moreno era franciscano conventual, nacido en Monzón ${ }^{76}$, había leído durante muchos años en Lérida y a la sazón se desempeñaba como confesor de Isabel de Valois. De ahí que no conste el pago de su sueldo hasta 1568, año de la muerte de la reina. Desde el momento en que los conventuales ilerdenses tuvieron que dejar su cenobio a los observantes, Sanahuja no tenía más noticias de Moreno ${ }^{77}$. Gracias a la documentación que aquí describimos podemos saber que este religioso siguió como catedrático durante algunos años más.

Pere Molí, Pere Segarra y Bartomeu Gomar ${ }^{78}$ eran Doctores en Derecho

72 J. Lladonosa, L'Estudi General de Lleida del 1430 al 1524, p. 39.

73 Mantenemos la grafía original, que sólo alteramos en contados casos en la que es necesario hacerlo para que resulte comprensible. Las anotaciones entre paréntesis son aclaraciones que aparecen en el propio texto manuscrito.

74 ACL, Llibre del Studi, ff. 27r-28r.

75 I. Vázquez Janeiro, "Repertorio de franciscanos españoles graduados en teología durante la Edad Media”, en Repertorio de Historia de las Ciencias Eclesiásticas de España, vol. 3: Siglos XIII- XVI, Salamanca, UPSA, 1971, p. 282.

76 F. de Latassa, Biblioteca Nueva de los escritores aragoneses: que florecieron desde el año de 1500 hasta 1599, Vol. 1, Pamplona, en la oficina de Joaquín Domingo, 1798, pp. 309-311.

77 P. Sanahuja, "La Universidad de Lérida y los franciscanos”, p. 238.

78 Insculado como Oidor real, E. Serra i Puig, Els Llibres de l’Ànima..., p. 198. 
canónico y catedráticos de dicha Facultad, mientras que Pere Rubión 79 , Francesc Botella ${ }^{80}$ y Jeroni Pasqual eran Doctores y catedráticos de Leyes, que ya estuvieron presentes en la reforma de los Estatutos de la Universidad realizada por el obispo Despuig en $1559^{81}$. Agustí Gascó era Doctor y catedrático de Teología ${ }^{82}$. Gabriel Babot era catedrático de Medicina, al igual que Gil Escalona $^{83}$, que leyó muchos años en la Facultad. Francesc Riber también era catedrático de Medicina ${ }^{84}$.

Antoni d'Olibà (o Oliba) estudió en Lérida, era catedrático de Leyes como mínimo desde ese curso ${ }^{85} \mathrm{y}$ fue un destacado jurisconsulto, como después veremos. Andreu Rius fue insaculado como Oidor y diputado real, años después en calidad de Doctor en Leyes por la ciudad de Tortosa ${ }^{86}$, mientras que Tomás Carrera lo fue por la ciudad de Barcelona ${ }^{87}$. Hallamos también como joven profesor a Lluís de Copons, quien, con el tiempo, llegó a ser Abogado Fiscal de la Generalitat ${ }^{88}$. Fr. Joan Ginebrosa era un dominico, Bachiller en Artes por la Universidad de Barcelona ${ }^{89}$, destinado en aquel momento para enseñar

79 Insaculado como Oidor y diputado real, E. Serra i Puig, Els Llibres de l'Ànima..., p. 379. Aparece en P. Guiso, Historia de las Heroycas virtudes, relacion de los portentosos milagros: Vida, muerte, y culto del B. Salvador de Horta..., Caller, en Santo Domingo, 1732, p. 27: "Salia en cierta ocasion el Santo para ver los concurrentes, como solia, y llegandose a el una mujer, que lo era del Doctor Rubios Cathedratico en Leyes de la Universidad de Lerida, le rogò encarecidamente implicase a Nuestro Señor le concediese para su mayor servicio un hijo varon. Respondiola el Siervo de Dios: tu frequentas tanto el juego de naypes, que el Señor no te dara hijos asta que le dexes. Si eso es (repondió ella) no tan solamente me abstendre de essa diversion enadelante; pero ni aun los tomaré con la mano".

80 Insaculado como Oidor y diputado real, E. Serra i Puig, Els Llibres de l'Ànima..., p. 67.

81 F. Esteve Perendreu, El Col-legi universitari de l'Assumpció..., p. 58.

82 F. Esteve Perendreu, "La docència de la teologia a Lleida...", p. 159.

83 J. Lladonosa, La Facultat de Medicina, p. 46.

84 Ibidem.

85 F. Esteve Perendreu, El Col-legi universitari de l'Assumpció..., p. 58.

86 Insaculado como Oidor y diputado real, E. Serra i Puig, Els Llibres de l'Ànima..., p. 364 .

87 Insaculado como diputado real, E. Serra i Puig, Els Llibres de l’Ànima..., p. 94.

88 M. A. Martínez Rodríguez, "Linaje y poder en la Cataluña foral: la actividad política de los Copons", Cuadernos de Historia Moderna, 22 (1999), pp. 11-31, especialmente, p. 18.

89 J. M. Madurell Marimon, "Luis Juan Vileta”, Analecta Sacra Tarraconensia, 37 (1964), p. 15 . 
Artes en Lérida. Indiquemos que Bartomeu Serret era canónigo de Lérida ${ }^{90}$ y profesor de Cánones, y que también enseñaba derecho canónico Pere Esteve, que había sido profesor de Derecho canónico en la Universidad de Huesca durante el curso 1563-1564 ${ }^{91}$.

Sabemos que en 1565 el cajero del Estudio era Bartomeu Gomar y que el 25 de mayo de 1565 el Clavario mayor depositaba en el Sagrario, por mandato de los Paheres, $43 £$, correspondientes a la primera paga de las catedrillas. Los dineros fueron puestos en saquitos de estopa y estos dentro de una caja. Los sueldos eran muy menguados: Pere Molí cobró $19 £$ por 38 lecciones y Pere de Segarra cobró, por 29 lecciones, $14 £$ y 10 sueldos $^{92}$.

En 1565 la nómina de profesores estaba compuesta por Pere Molí, Pere Segarra, Bartomeu Gomar, Pere Rubio (Pere Aguiló, sustituto), Francesc Botella, Hieronim Pasqual, Agustí Gascó, Pere Salas, Gabriel Babot, Francesc Riber, Fernando Gil Scalona, Jaume Mir, Antoni Oliba, Joan Garcia, Llorens Cellers, Barthomeu Serret, Andreu Riu, Salvador Mor, Thomas Carrera, Miquel Ferrer, Joan Ginebrosa, Pere Llopico, Pere Esteve y el "pare Boneta, lector d'Arts ${ }^{93 "}$.

Este último era el mercedario Jerónimo Boneta, que enseñó Artes en Lérida y fue catedrático de Teología en la Universidad de Huesca entre 1578 y $1585^{94}$. De Pere Salas podemos decir que fue Doctor en Teología y Rector de la Iglesia parroquial de Sant Joan de la Plaça ${ }^{95}$, así como también examinador de libros para el Santo Oficio ${ }^{96}$. A continuación, en el manuscrito se indica la nómina de los Bachilleres en Leyes y Cánones:

"Mes avant se continuen asi los bachillers ordinaris qui llegiran per la conducta tant

90 R. Viola i González, “Un testament canonical (16 d'agost de 1561)”, Analecta Sacra Tarraconensia, 71 (1998), p. 915.

91 A. Durán Gudiol, "Notas para la historia de la Universidad de Huesca en el siglo XVI”, Hispania Sacra, 21 (1968), pp. 87-150. Véase especialmente, p. 153.

92 J. Lladonosa, Història de Lleida, II, p. 305.

93 ACL, Llibre del Studi, ff. 29r-3or.

94 A. Durán Gudiol, "Notas para la historia de la Universidad de Huesca...”, p. 150. Véase J. M. Lahoz Finestres y L. García Torrecilla, "Graduados en teología en la Universidad de Huesca”, Miscelánea Alfonso IX. Centro de Historia Universitaria, Salamanca, Universidad de Salamanca, 2001, p. 228.

95 F. Esteve Perendreu, "La docència de la teologia...”, 199.

96 [Mariano Aguiló], Catálogo de obras en lengua catalana impresas desde 1474 hasta el presente, s.l, 1865, p. 168. 
en canons com en lleys, los quals han de llegir quaranta lliçons qui son en dies legibles a raho tres sous per lliçons, los quals lectors son los seguents y es la lectura del primer any.

Primo $\mathrm{M}^{\mathrm{O}}$ Barthomeu Serret. Andreu Rius, Llorenç Sellers, Salvador Mor, Jaume Mir, Antoni Oliba, Thomas Carrera, Joan Garcia97".

Nuevos detalles aparecen en la nómina de lectores de 1566: Pere Molí, Pere Sagarra, Bartomeu Gomar, Francesc Botella, Pere Aguiló, Francesc Bonet, Miquel Montornés, Gabriel Babot, Francesc Riber, Jaume Mir, Antoni Oliba, Francesc de Sinistere i Francesc Bafart, Llorenç Sellers, Bartomeu Serret, Pere Esteva, Salvador Mor, Tomas Carrera, Jeroni Boneta, Bartomeu Vilanova (lectura de Artes), Joan Sanz, Gabriel Maçot (Gramática) ${ }^{98}$.

En primer lugar hay que destacar que Pere Aguiló ${ }^{99}$ consolidó la cátedra de segunda de Leyes y que Francesc Bonet ${ }^{100}$ pasó a ser catedrático en lugar de Jeroni Pasqual. Tenemos una breve noticia de Miguel Montornés, que después fue presbítero y vicario de Leciñena, y que fue acuchillado en 1572 por Antonio Clavero, agricultor y habitante en dicha localidad ${ }^{101}$. Aparece ya en esta nómina Francesc Bafart, colegial y Prior del Colegio de la Asunción ${ }^{102}$, que a la sazón era lector de Leyes. Hay que destacar que Bartomeu Vilanova era un reputado estudioso de Aristóteles, que había enseñado previamente en la Universidad de Valencia y que, tras su paso por Lérida, lo hizo en la de Barcelona $^{103}$. Hasta ahora no se sabía qué años había leído Vilanova en Lérida, aunque era considerado por la historiografía uno de los metafísicos más notables de la Corona de Aragón ${ }^{104}$.

En cuanto a los lectores de 1567, la documentación manuscrita proporciona los siguientes nombres: "Joan Moreno y a ell mestre Jaume Come lector de taulogia”, Agustí Gascón, que leía la cátedra de Conchillos, Francesc Berenguer, Pere Salas, Pere Molí (lector en Cánones), Pere Sagarra, Bartomeu

97 ACL, Llibre del Studi, f. $30 v$.

98 ACL, Llibre del Studi, ff. 33r-34r.

99 Insaculado como diputado real, vid. E. Serra i Puig, Els Llibres de l'Ànima..., p. 10. 100 Insaculado como Oidor real, vid. E. Serra i Puig, Els Llibres de l’Ànima..., p. 62.

101 Se abrió un proceso penal. Véase M. I. Falcón Pérez, M. A. Motis Dolader, Procesos criminales en el Arzobispado de Zaragoza, Zaragoza, Gobierno de Aragón, 2000, p. 115.

102 F. Esteve Perendreu, El Col-legi universitari de l'Assumpció..., p. 57.

103 A. Fernández Luzón, La Universidad de Barcelona..., pp. 155, 314-315.

104 J. Gallego Salvadores, "La metafísica en España durante el siglo XVI", en $R e$ pertorio de las ciencias eclesiásticas en España, Vol. VII, Salamanca, UPSA, 1979, pp. 229-230. 
Gomar, Salvador Mor (Bachiller), Bartomeu Serret, Llorenç Cellers, Pere Esteve, Botella (lector de Leyes), Pere Aguiló, Micer Bonet, Antoni Oliba (Bachiller), Jaume Mir, Thomas Carrera, Baffart, Gabriel Babot (lector en Medicina), Francesc Riber, Fernando Scalona, Miquel Llupia ${ }^{105}$ (para leer las faltas de los otros doctores de la Facultad de Medicina), Bartomeu Vilanova (lector en Artes), Joan Sans, Celedoni Prunyonosa (lector de Gramática) y Antoni Seran (ayudante de Prunyonosa) ${ }^{106}$.

Indiquemos que Francesc de la Torre Berenguer era canónigo de la catedral de Lérida y catedrático de Teología, mientras que Pedro Salas era Doctor en Teología y catedrático de dicha disciplina. En 1573 eran, respectivamente, catedráticos de Prima y de Segunda de Teología, tal y como consta en la aprobación del Libro llamado Consuelo de Nuestra Peregrinación de Fr. Andrés Capilla $^{107}$. Jaume Coma puede ser identificado con el Arcediano mayor y canónigo de la Catedral de Vic ${ }^{108}$.

En 1568 hubo los siguientes lectores sustitutos: Miquel Tristany (sustituto de Molí), a quien no se le debía nada, porque en realidad no había leído ("nihil, quia non legit”); Pere Bordalba (sustituto de Micer Sagarra); Miquel Ribes (sustituto de Gomar); Tomas Carrera (sustituto en Leyes); Antoni Benach (sustituto del maestro Babot); Miquel Llupia (sustituto del maestro Riber); Lluys Fuster (Bachiller sustituto en Cánones); Melchor Punster (sustituto en Leyes); Rafael Monço y Josep Calaf (sustitutos en Leyes) ${ }^{109}$. Recordemos que Miquel Tristany, Doctor en Derechos, había enseñado Cánones en la Universidad de Huesca durante los años 1560-1562 ${ }^{110}$, y fue conservador del Estudio General en junio de $1568^{111}$ y que los demás, mediado el tiempo, devinieron catedráticos del Estudio General.

En el curso 1568-1569 encontramos los siguientes lectores: Joan Moreno, Agustí Gascó (Conchillos), Francesc Berenguer, Pere Salas, Pere Molí (lector de Cánones), Pere Segarra, Bartomeu Gomar, Francesc Gomar (lector de Leyes), Pere Aguiló, Francesc Bonet, Pere Joan Benach (lector de Medicina),

105 J. Lladonosa, La Facultat de Medicina, p. 46.

106 ACL, Llibre del Studi, ff. 37r-v.

107 A. Capilla, Libro llamado Consuelo de Nuestra Peregrinación de grande utilidad y consolaciòn para todos los fieles, en que se trata de la dignidad y exellencia de la Religión Christiana, Lerida, Pedro de Nobles y Juan de Villanueva, 1574.

108 E. Serra i Puig, Els Llibres de l'Ànima..., I, p. 120.

109 ACL, Llibre del Studi, ff. 41v-42v.

110 A. Durán Gudiol, “Notas para la historia de la Universidad de Huesca...”, p. 153.

111 F. Esteve Perendreu, Mestrescoles i rectors..., p. 32. 
Francesc Riber, Ferrando Gil de Ascalona, Joan Sans, Fra Boneta, Fr. Francesc Salvador (que leía las horas del maestro Vilanova), Pere Joan Nunyes, Pere Bordalba (sustituto de Pere Sagarra), Miquel Ribes (sustituto de Bartomeu Gomar, al cual no se le pagó nada, porque no leyó), Pere Estamper, Jaume Roig, Jaume Calbis ${ }^{12}$, Gaspar Punster, Tomas Carrera, Francesc Bafart, Joan Mur, Melchor Punster, Luis Fuster (sustituto en Cánones), Rafel Montsó (sustituto en Leyes del maestro Carrera), Francesc Descamps (sustituto en Leyes del maestro Carrera) y Pere Plana (sustituto de Baffart) ${ }^{113}$.

Ha sobrevivido el grado de Doctor en Teología que el 20 de octubre de 1568 se concedió a Miquel Bonet, canónigo de Barcelona ${ }^{114}$. Sabemos asimismo que Joan Mur fue colegial de la Asunción y Rector del Estudio durante el curso de 1567-1568 y Pere Plana era también colegial de la Asunción ${ }^{115}$. Pere Esteve fue elegido Rector de la Universidad el día 1 de abril de $1569^{116}$.

Con todo, el profesor más interesante, desde el prisma historiográfico, es Pere Joan Nunyes (1522-1602). Sin duda, Nunyes, seguidor de Ramus ${ }^{117}$, era uno de los humanistas hispanos más prestigiosos a la sazón y, al parecer, tras haber impartido clases en diferentes universidades, encontró protección en casa de su amigo Antonio Agustín. Procedente de la Universidad de Zaragoza, indica Pilar Barbeito que "lo cierto es que en 1568 lo encontramos en Lérida, en casa de Antonio Agustín, obispo de la diócesis desde 1561, con quien le unía una buena amistad que no hizo sino estrecharse con los años ${ }^{118}$ ".

En la tesis doctoral de Ferran Grau $^{119}$ se sugería que Nunyes probablemen-

112 Conocemos a un personaje llamado Jaume Calbis o Calvís. Era natural de Montblanc. Tomó el hábito en Montserrat el 12 de setembre de 1584. Fue abad de Sant Genís de Fontanes (1607-08) y luego de Sant Benet de Bages (¿1621-1625?). Véase J. Galobart i Soler, "Les actes de visita dels abats de Montserrat al monestir de Sant Benet de Bages. I. 1627-1725”, Studia monastica, 45/1 (2003), p. 92 y E. Zaragoza Pascual, Abaciologi benedictí de la Tarraconense, Barcelona, Ed. Balmes, 2002, pp. 58 y 179.

113 ACL, Llibre del Studi, ff. 46r-47r.

114 ACA, Diversos, Monistrol, Perg. n. 1170.

115 F. Esteve Perendreu, El Col-legi universitari de l'Assumpció..., p. 58.

116 ACL, Llibre del Studi, ff. 50 y 53.

117 J. F. Alcina Rovira, "Los inicios del ramismo en España”, en J. Pérez Dura y J. M. Estellés (eds.), Los humanistas valencianos y sus relaciones con Europa, Valencia, Ajuntament de Valencia, 1998, pp. 117-136.

118 M. P. Barbeito Díez, Pedro Juan Núñez, humanista valenciano, Madrid, Universidad Complutense, [Tesis doctoral], 1996, p. 57.

119 F. Grau, Las Retóricas de Pedro Juan Núñez, Valencia, Universidad de Valencia, [Tesis doctoral], 1994, pp. LXXIII-LXXV. 
te tuvo relación con el Estudio General ilerdense. Gracias al manuscrito del que damos cuenta sabemos que Nunyes enseñó Artes durante varios cursos en Lérida. Indicaba Pilar Barbeito que "tras estas noticias de la estancia en Lérida de 1568 se pierde de nuevo la pista de Núñez, aunque es probable que entre 1568 y 1574 -año en que lo encontramos de nuevo en Zaragoza- pasara algún periodo en la Universidad de Barcelona ${ }^{120}$ ". Antonio Fernández Luzón indica en la nómina de profesores del Estudio barcelonés que Nunyes enseñó Retórica y Griego desde el curso 1572-1573 hasta 1579-1580 ${ }^{121}$.

La documentación del Estudio de Lérida concuerda completamente, pues -como veremos- hemos documentado allí a Nunyes hasta el año 1571. No hay duda de que el humanista fue a la ciudad del Segre atraído por la amistad de Antonio Agustín, que le hospedó y le dejó cultivarse y recrearse en su biblioteca personal. Hay que conjeturar que la creciente presión de los Paheres hacia el Obispo y el carácter sensible de Nunyes motivaron su traslado a la Universidad de Barcelona que, como veremos, acogió a muchos profesores del Estudio de Lérida en esta década de $157 \mathrm{O}^{122}$, especialmente tras algunos incidentes entre el Rector, los Paheres y el Obispo.

Pasemos a detallar la nómina de los lectores ordinarios que percibieron la paga de San Juan de 1570: Joan Moreno, Francesc de la Torre alias Berenguer, Pere Sales (cátedra de Conchillos), Joan Tarros, Gaspar Sahona, Pere Moli, Pere Segarra, Bartomeu Gomar, Francesc Botella, Pere Aguiló, Francesc Bonet, Antoni Joan Benach, Francesc Riber, Ferrando Gil de Escalona, Joan Sans (Artes), Pere Joan Nunyez (Artes), Pere Joan Nunyez (lectura de Gramática), P. Salvador (lectura de Artes), Pere Esteve (lector en Cánones), Gaspar Punster, Antoni Oliba, Tomas Carrera, Francesc Baffart, Melchior

120 P. Barbeito Díez, Pedro Juan Núñez..., p. 60.

121 A. Fernández Luzón, La Universidad de Barcelona..., p. 311.

122 También sucedió en la década siguiente, DGC, III, p. 462: "Phelip Dimas Montaner té denou anys de pràtica en la Real Audiència, és estat cathedràtich de cànones en Lleyda en l'any 82 y 83, y en la universitat de Barcelona ha llegit setse anys, en lo qual temps ha obtingudas las càtedras menors y las dos majors de lleys y cànones..."; "Micer Francesch Tristany és de edat de ... anys, doctor de la Real Audiència en l'any 1593, té deu anys de pràtica, ha llegit en Leyda tot l'any 90 com ha substitut ordinari de la càtedra de tercera de Doctor en lleys, en la universitat de Barcelona obtingué una càthedra en competència de dos altres doctors en l'any 93...”; “Lo magnífic misser Miquel Olzina és assessor ordinari del General, de edat de 37 anys, molt pràtic y expert en negocis de la Generalitat y privilegis del present Principat, celós de la justícia y propria consciència, lo qual té més de deu anys de pràtica y ha llegit dos anys de canones en Lleyda...” 
Punster, Lluis Fuster (que ha leído por Jaume Roig) y Miquel Ferrer (por el resto de las lecturas) $)^{123}$.

De estos profesores, cabe destacar especialmente a Joan Tarròs, a quien identificamos con el futuro Abad de Poblet (1598-1602). De él sabemos que fue Rector del Colegio de Poblet en Lérida en 1570 y Maestro en Sagrada Teología ${ }^{124}$. Tarròs es el primer exponente del Colegio de San Bernardo en Lérida, fundado por la comunidad de Poblet en la Ciudad del Segre en $1568^{125}$. Tarròs era natural de Albatàrrec (el Segrià) y llegó a ser Vicario General de la Orden en 1601, un cargo que ocupó hasta su fallecimiento, ocurrido en 1602. También sobresalió Fr. Gaspar Sahona (o Saona), natural de Mota del Cuervo, Maestro en Sagrada Teología, lector de la Catedral y más adelante Provincial de la Orden de San Agustín en la Provincia de la Corona de Aragón ${ }^{126}$, y reformador de la Orden de Cataluña, hasta su fallecimiento, en $1596^{127}$.

Detengámonos también en la figura de Miquel Ferrer, cuyo nombre ha aparecido ya antes. Aparece aquí como profesor del resto de lecturas y la razón es que daba clase tanto de Artes como de Medicina. Fue autor de una útil Recollectio casuum. Mètodo y art molt clar pera apendrer la gramàtica de la llengua llatina, publicada en Lérida en $1578^{128}$. En una carta al obispo Antonio Agustín le exponía su plan de formación humanística dirigida a los discípulos ilerdeneses ${ }^{129}$. La orientación humanística del Estudio, durante estos años, fue muy marcada.

En la nómina de profesores en la festividad de San Juan de 1571 aparecen: Joan Moreno, Francesc de la Torre, Pere Salas, Antoni Pont, Joan Tarros, Gaspar Saona, Pere Moli, Pere Sagarra, Bartomeu Gomar, Botella, Pere Aguiló, Bonet, Fernando Gil de Escalona, Pere Arnau de Sant Marti, Joan Sans, Pere Joan Nunyez, Montserrat Capdevila, Gabriel Massot (leyó la Gramática de Nunyes), Pere Bordalba, Miquel Ribes, Tomas Carrera, Melchior Punster,

123 ACL, Llibre del Studi, ff. 55r-56r.

124 J. Finestres y de Monsalvo, Historia del Real Monasterio de Poblet, vol. 4, Tarragona, Joseph Barber, 1756, p. 220.

125 J. Lladonosa Pujol, Lérida y sus relaciones con el Monasterio de Poblet, Lleida, Tipografia Selecta, 1954, p. 14. Véase también A. Altisent, Història de Poblet, Tarragona, Abadia de Poblet, 1974, pp. 262-263, 455 y 465.

126 J. Massot, Compendio Historial de los Hermitaños de nuestro Padre San Agustín del Principado de Cataluña, Barcelona, Juan Jolis, 1699, pp. 71-73.

127 J. Lladonosa i Pujol, Història de Lleida, vol. II, p. 431.

128 J. Lladonosa, "Humanisme i Reformes...", p. 95.

129 F. Esteve Perendreu, Mestrescoles i rectors..., p. 152. 
Francesc Boldu (sustituto de Riber), Miquel Ferrer (sustituto de Scalona), Agusti Calaf (sustituto de Sant Marti), Matheu Pla, Lluis Fuster, Joseph Calaf, Cristofol Capero, Antoni Oliba, Rafael Monço, Pere Plana, Francesc Moliner, Miquel Ferrer, Josep Morata (como sustituto de Joseph Calaf en Cánones) ${ }^{130}$.

Por un lado, creemos que Antoni Pont fue el célebre trinitario mallorquín, estudioso de la obra de Ramon Llull ${ }^{131}$. Al haber sido profesor en el Estudio de Lérida durante su juventud, y al tenerlo localizado en Lérida desde 1567 hasta 1577 nos parece probable que se trate del mismo. Por otro lado, Agustí Calaf fue Doctor en Leyes ${ }^{132}$ y catedrático del Estudio General e hijo de un homónimo ciudadano honrado y Paer de Lérida ${ }^{133}$. Francesc Moliner fue jurista, insaculado después como diputado militar en la veguería de Lérida en lugar del ya citado Jeroni Botella ${ }^{134}$.

Tenemos también los salarios de los lectores en la Festividad de San Juan de 1572. La nómina esta compuesta por Joan Moreno, Francesc de la Torre, Pere Salas (cátedra del obispo Conchillos), Antoni Pont, Joan Tarros, Gaspar Sahona, Pere Moli, Pere Sagarra, Bartomeu Gomar, Francesc Botella, Pere Aguiló, Francesc Bonet, Francesc Riber, Fernando Escalona, Pere Arnau Sant Marti, Montserrat Capdevila (curso), Nofre Serra (curso), Siurana (lectura de Gramática), Pere Bordalba (sustituto de Molí), Miquel Ribes (sustituto de Segarra), Serret (sustituto de Gomar), Tomas Carrera (sustituto de Botella), Melchior Punster (sustituto de Aguiló), Miquel Ferrer (sustituto de Riber); Lluis Fuster, Cristofol Capero, Pere Mollan, Rafel Monço, Pere Plana, Francesc Moli, Jeronim Pradell (sustituto de Fuster), Josep Morata (sustituto de Capero), Francesc Tormo (sustituto de Saona), Josep Coria (sustituto de Oliba), Miquel Berart (sustituto), Joan Crespo (sustituto), Pere Montserrat (sustituto), Luis Sans (sustituto) ${ }^{135}$.

130 ACL, Llibre del Studi, ff. 62r-63r.

131 J. M. Bover, Biblioteca de autores baleares, vol. 2, Palma, Gelabert, 1868, p. 129. Oriundo de Selva (Mallorca), Antoni Pont nació hacia 1500 tomó el hábito trinitario en 1518 y fue a estudiar a Lérida, donde fue maestro y lector -al decir de Bover y otros- por espacio de veintidós años. Regresó en 1553 y de allí fue destinado a Murviedro, para pasar a Lérida como ministro en 1567 hasta que en 1577 tuvo la misma dignidad en Mallorca. Felipe II promovió su elección como arzobispo de Orestano, a la que renunció. Murió en Palma en 1580.

132 DGC, Vol. 3, p. 126.

133 F. J. Morales Roca, Ciudadanos y burgueses honrados..., p. 88.

134 E. Serra i Puig, Els Llibres de l'Ànima..., I, p. 170.

135 ACL, Llibre del Studi, ff. 71r-73r. 
Tenemos los horarios de algunos profesores del año 1572, al igual que del curso $1568^{136}$. La documentación nos indica asimismo que Miquel Ferrer era profesor de Medicina de segundo curso, mientras que Pere Arnau de Sant Martí enseñaba en primero ${ }^{137}$. Cristòfol Capero figuró, a comienzos del siglo XVII, como asesor de Joan de Pròxida, lugarteniente del Maestrazgo ${ }^{138}$.

Resulta llamativo el caso de Nofre Serra. Recordemos que hasta el curso anterior había leído Nunyes. ¿Podría ser este Nofre Serra el célebre Onofre Serra, profesor de Artes en la Universidad de Valencia? No pasa de ser una conjetura: sabemos que el Patriarca Ribera había intervenido duramente en la Universidad de Valencia y había encarcelado en la prisión eclesiástica a varios catedráticos (entre los que se hallaba Serra), que fueron liberados en 1571, si bien el proceso inquisitorial se prolongó hasta febrero de $1572^{139}$. ¿Es posible que Serra hubiera pasado a Lérida huyendo de estos problemas, buscando un ambiente humanístico menos enconado? Otro nombre llamativo es el de Vicent Ciurana, que identificamos con el homónomo gramático y erudito valenciano ${ }^{140}$.

Aparece en esta nómina por primera vez el arcediano Pere Mollan, destacado humanista, gran amigo de Antonio Agustín y síndico suyo en Roma, citado en su correspondencia en temas de erudición jurídica ${ }^{141}$ y también en otras cuestiones más bien prosaicas (de carácter pecuniario). Mollán era también valenciano y fue albacea testamentario de Pedro Chacón ${ }^{142}$.

Desde el punto de vista del saber jurídico, el personaje más interesante es el Dr. Francesc Molí, hijo del ya citado Pere Molí. Tras haber sido profesor en la Universidad de Lérida, fue nombrado Oidor en la Real Audiencia de Mallorca $^{143}$. Posteriormente regresó a Lérida, donde volvió a enseñar. Fue autor

136 ACL, P7_M2_P3_Co3, n. 8.

137 ACL, P7_M2_P3_Co3, s.f.

138 J. Ferreres Nos, "El bandolerisme català dels segles XVI i XVII a les terres del Maestrat Vell de Montesa”, Recerca, 9 (2005), pp. 67-104.

139 A. Felipo Orts, La Universidad de Valencia durante el siglo XVI (1499-1611), Valencia, Universidad de Valencia, 1993, p. 45.

140 J. P. Fuster, Biblioteca Valenciana de los escritores que florecieron hasta nuestros dias, Vol. 1, Valencia, Ximeno, 1827, p. 189.

141 Antonii Augustini archiepiscopi Tarraconensis Opera omnia, Vol. 7, Lucae, Typis Josephi Rochii, 1772, p. 229.

142 E. Ruiz, "Los años romanos de Pedro Chacón”, Cuadernos de Filología Clásica, 10 (1976), pp. 189-247, especialmente, p. 209.

143 A. Planas Rosselló, La Real Audiencia de Mallorca en la época de los Austrias 
de varios libros sobre derecho civil y canónico (sobre los pactos matrimoniales, y sobre las juridicciones secular y eclesiástica ${ }^{144}$ ). Creemos asimismo que el citado Joan Crespo fue, mediado el tiempo, el homónimo Oidor de la Audiencia de Mallorca, que falleció al poco de tomar posesión de su plaza ${ }^{145}$.

Es posible que Pere Montserrat, Doctor en Derecho, fuese el diputado insaculado por Barcelona en 1581 y que aparece como fallecido en $1588^{146}$. En cuanto a Lluís Sans, cabe examinar la posibilidad de que fuese Lluís Sans i Còdol, el futuro canónigo de la Seu d'Urgell, obispo electo de Elna, primer obispo de Solsona y posteriormente obispo de Barcelona. Sabemos que se doctoró en ambos Derechos en Roma el 30 de abril de $1576^{147}$.

La última nómina completa que tenemos es la de San Juan de 1573. En ella hallamos a los siguientes lectores: Joan Moreno, Francesc de la Torre, Pere Sales, Antoni Pont, Joan Terros, Gaspar Assahona, Barthomeu Gomar, Pere Bordalba, Bartomeu Serret, Francesc Botella, Pere Aguiló, Francesc Bonet, Francesc Riber, Fernando Gil de Escalona, Pere Arnau de Sant Marti, Onofre Serra, Ramon Cirera, Antoni Mani, Vicent Ciurana (maestro de Gramática), Miquel Ferrer (maestro de Gramática), el maestro Armeda (sustituto del maestro Berenguer), Francesc Pastor (sustituto del maestro Aguiló por enfermedad), Pere Esteve (sustituto del maestro Bordalba), Tomas de la Carrera (sustituto del maestro Botella), Lluis Fuster (ordinario en cánones), Joseph Calaf (enfermo), Cristofol Capero, Pere Mollan, Antoni de Oliba, Pere Plana, Francesc Moli, Joan Crespo, Lluis Sans, Josep Morata, Francesc Tormo, Je-

(1571-1715), Barcelona, Publicacions de la Universitat Pompeu Fabra, 2010, p. 320, aporta los siguientes datos: "Nombrado Oidor de Mallorca el 16 de enero de 1585. Realizó sendas visitas a los oficiales e instituciones de la isla de Menorca en 1587-1588 y 1596-1597. Fue suspendido del cargo en 1597 como consecuencia de un procedimiento de visita en el que se le imputaron los delitos de concubinato, violación y estupro de menores. En julio de aquel año partió hacia la Corte para defenderse. Fue privado de la plaza y condenado a una multa de 1.500 ducados".

144 F. Molini, De brachio seculari Ecclesiae praestando et mutuis iudicum auxiliis celeberrimi commentarij: in tres libros distincti; his accessit liber singularis De sacra homicidio amittenda immunitate nec ne, Barcelona, Ioannem Simon, 1607; Tractatus celebris, et insignis de ritu nuptiarum, et pactis in matrimonio conuentis, Barcelona, Laurentij Déu, 1617.

145 A. Planas Rosselló, La Real Audiencia de Mallorca..., p. 312.

146 E. Serra i Puig, Els Llibres de l’Ànima..., I, p. 254.

147 R. Ramis Barceló, Doctores hispanos en Leyes y Cánones por la Universidad de la Sapienza de Roma (1549-1774), Madrid, Dykinson, 2017, p. 73. 
roni Pintor (sustituto) ${ }^{148}$, Pere Monserrat (sustituto), Joan Castello (sustituto), Joan Baptista Boyl (sustituto), Lois Vilallonga (sustituto) ${ }^{149}$.

Más allá de los maestros que ya hemos comentado, hay que mencionar a Ramon Cirera, un autor que nos permite abundar en la conexión valenciana, pues hallamos a un personaje homónimo en la colación de grados en la Universidad de Valencia, junto al ya citado Onofre Serra, en el lustro de 1566-1571 ${ }^{150}$. En cuanto a Antoni Maní, beneficiado de la Catedral, hay que suponer que a la sazón leía Artes o Filosofía. Desde 1578 detentó una cátedra de Teología y más adelante fue canónigo penitenciario, hasta su muerte acaecida en $1610^{151}$.

Hay que descartar, por razones cronológicas, que este Francesc Pastor fuese el futuro maestrescuela del Estudio. En lo tocante a Joan Baptista Boil fue, como veremos, Rector del Estudio durante el curso 1574-1575. Y en cuanto a Joan Castelló, se trataba de un destacado jurista, más tarde profesor en la Universidad de Barcelona y que llegó a ser juez de la Real Audiencia ${ }^{152}$. Participaba de los ideales humanistas y su biblioteca estaba bien surtida con las obras de Tito Livio, Cicerón, Virgilio, Herodoto... ${ }^{153}$

Se conservan en la Biblioteca de Poblet unos fragmentos de apuntes de Leyes y de Cánones del curso 1573, extraídos de las lecciones de Nicolau Freixenet (sobre el testamento inoficioso de acuerdo con las Instituta) y de Pere Mollan (sobre la sentencia y la cosa juzgada) ${ }^{154}$. Sobre Freixenet tendremos ocasión de extendernos con detalle en el capítulo siguiente.

A partir de 1573 dejamos de tener datos del profesorado de Lérida. Desde entonces, como veremos, se puso de manifiesto una gravísima tensión entre el Estudio, los Paheres y el Obispo. Lo cierto es que, en paralelo a la gestación de este conflicto, en 1573 empezó un éxodo hacia la Universidad de Barcelona de un grupo muy representativo de estos profesores.

148 Se conserva un Memorial en fet per la ciutat de Barcelona conrta [sic] Geronym Pintor, Barcinone, apud Sebastianum et Iacobum Matevat..., 1638.

149 ACL, Llibre del Studi, ff. 8or-83r.

150 A. Felipo Orts, F. J. Peris Felipo, F. Miralles Vives, Estudiantes y probanzas de cursos en la Universidad de València (1561-1707), Valencia, Universidad de Valencia, 2013, p. 411.

151 F. Esteve Perendreu, Mestrescoles i rectors..., p. 155.

152 A. Fernández Luzón, La Universidad de Barcelona..., p. 277.

153 C. Narváez Cases, "El patronatge de les noves oligarquies urbanes a l'art català dels segles XVI i XVII”, Recerques, 51 (2005), p. 18.

154 BP, Ms. 156, ff. 1-11. 


\section{El conflicto sobre la reforma de la Universidad (1572-1575)}

Pese a que Antonio Agustín había recibido el encargo específico de reformar la Universidad, lo cierto es que las medidas concretas no llegaban. Buena parte de la historiografía (Villanueva ${ }^{155}$, Sainz de Baranda ${ }^{156}$, Poch ${ }^{157}$, Esteve Perendreu ${ }^{158}$ ) achaca el enfado de los Paheres a la poca celeridad del Obispo, mientras que Lladonosa ${ }^{159}$ considera que hubo desencuentros personales, incomprensión y falta de entendimiento, que desembocaron en una situación muy tensa.

Pese a que los incidentes de los últimos años del pontificado hayan sido ya tratados por los autores mencionados, queremos aportar aquí nueva documentación, que tal vez sirva para esclarecer un poco más la situación. Más allá de los documentos que fue transcribiendo y publicando José Poch, hay que tener en cuenta la riqueza de la correspondencia que se ha conservado de los Paheres, que dan noticias indirectas del conflicto.

Ya el 16 de julio de 1568, Felipe II había insistido en que se llevase a cabo la reforma definitiva del Estudio. Pese a las reiteradas peticiones de los Paheres y del Rector, el Obispo no había hecho ninguna intervención decisiva en él, aunque había acogido a diversos profesores humanistas y les había facilitado su estadía en Lérida. El Dr. Francesc Molí fue enviado a la Corte con una letra de presentación el 27 de marzo de 1572 para el "redreç" (enderezamiento) de la Universidad ${ }^{160}$.

La tensión llegó al cénit en abril de 1573 cuando se eligió como Rector del Estudio al bachiller Gil Gironza, y poco después se llevó a cabo otra elección que recayó en Gaspar Beranuy. Los Paheres entendieron que la primera se había hecho de acuerdo con los privilegios y estatutos del Estudio, mientras que el Obispo visitador-reformador consideró que los privilegios se habían observado solamente en la segunda elección. Las

155 J. Villanueva, Viage literario a las iglesias de España, T. XVII, Madrid, Imprenta de la Real Academia de la Historia, 1851, pp. 56-58.

156 P. Sainz de Baranda, España Sagrada, T. XLVII, Madrid, Imprenta de la Real Academia de la Historia, 1850, p. 93.

157 J. Poch, "Del Estudio General de la Universidad de Lérida. Carta de los Paheres a Felipe 11 (17 agosto 1574)", Ciudad, 26 (1974), p. 120; J. Poch, "El rectorado del Estudio General de Lérida en la anualidad 1573-1574”, Ciudad, 27 (1975), s.n.

158 F. Esteve Perendreu, "Rentas y reformas...”, pp. 39-51.

159 J. Lladonosa, "Humanisme i Reformes...", p. 92.

160 AMP, Reg. 850 (1572-1574), f. 56r. 
autoridades confirieron el Rectorado a Gironza, mientras que Agustín sólo reconocía a Beranuy ${ }^{161}$.

La decisión del Obispo fue impugnada por los Paheres ante el Virrey de Cataluña, Fernando de Toledo, manifestando que no se le diese posesión a Gaspar Beranuy, porque era una persona muy violenta y conflictiva. Escribieron los Paheres al virrey el 28 de abril de 1573, indicando que "dit Beranuy ha comensat havent manasat pegar unes bastonades a un estudiant dels electors de dit rector de la ciutat de Barbastre anomenat Leonardo ${ }^{162 "}$. El asunto llegó a la Real Audiencia.

Mientras tanto, el embajador de Lérida, "por ser los salarios que estan señalados para los cathedraticos pequeños" y porque tenían miedo de que se fuesen a otras universidades y no se encontrarían personas adecuadas para leer, pedía al Rey un aumento de las Rentas del Estudio. Felipe II respondió el 21 de mayo de dicho año, ordenando que, si quedaban rentas vacantes, se diesen a la Universidad Ilerdense ${ }^{163}$.

La Audiencia de Barcelona falló el 22 de mayo, confirmando la decisión del Obispo visitador-reformador sobre el Rector. Los Paheres volvieron a escribir al Virrey el 10 de junio indicando que, sobre el caso de Beranuy, "per ser persona tan escandalosa", habían pedido consejo al Dr. Gomar, lector de Prima $^{164}$. Con todo, al final, el 10 de noviembre el Virrey ratificó la decisión de la Real Audiencia.

Esta decisión, lejos de calmar los ánimos, los encendió aún más. Juan Bautista Bohil fue elegido Rector para el curso 1574-1575 y tomó posesión el primer día de marzo. Como el Obispo no llevaba a cabo la reforma, los Paheres, a la vista de los problemas, decidieron escribir directamente a Felipe II. En su carta de 17 de agosto indicaban que:

“...vista la gran ruhina y total perdicio causades en la Universitat del Studi per lo Reverent pare en Crist bisbe de aquesta ciutat havent nos portat sembre ab rahons bones sperant y nou o deu anys que ha que te lo carrech y V. M. de visitador y reformador de dita Universitat reformes aquella haventlo y infinides voltes pregat y tambe donada la carta de V. Majestat de 16 de juliol de 1568 ab la qual fent nos la mentres ei manave fes dita reformacio dins lo termini de sis mesos ${ }^{165}$ ".

161 F. Esteve Perendreu, "Rentas y reformas...”, p. 49.

162 AMP, Reg. 850 (1572-1574), f. 62r.

163 ACA, Cancillería, Reg. 4305, ff. 94v-95r.

164 AMP, Reg. 850 (1572-1574), f. 64 r.

165 AMP, Reg. 850 (1572-1574), ff. 86v-87r. 
Los Paheres se quejaban también de que el Obispo no había llegado a hacer la ansiada reforma y que cada vez había menos estudiantes. Pedían también al Rey que las cátedras se diesen por votos. Esta misma idea fue repetida en tres cartas enviadas el mismo día a Pau Pla (Abad de Sant Pere de Galligants, canónigo de la Catedral de Barcelona y Doctor del Real Consejo Civil), al vicecanciller Bernardo de Bolea y al abogado fiscal Miquel Terça ${ }^{166}$.

A principios de septiembre, el Obispo, deslegitimando a Bohil como Rector ${ }^{167}$, mandó a algunos hombres armados para que lo capturaran y le quitaran las insignias rectorales ${ }^{168}$. Los Paheres escribieron a Fernando de Toledo el 4 de septiembre para referirle los hechos y también a Miquel Revert, Síndico de la Ciudad de Lérida, indicándole que el Rector iba al Estudio para la colación de un grado y que el Obispo mandó "a uns criats armats ab penyals ${ }^{169}$ ", le quitaron las insignias rectorales y se lo llevaron preso al Palacio Episcopal. De inmediato, mucha gente de la ciudad la emprendió contra Agustín y éste, temiendo una rebelión, dejó salir libre al Rector.

Los Paheres escribieron el 8 de septiembre al virrey Fernando de Toledo para que intercediese ante el Rey a fin de lograr la reforma de la Universidad, indicándole que el Obispo había puesto en libertad al Rector ${ }^{170}$. El 23 del mismo mes escribieron al Rey para pedir de nuevo el redreç de la Universidad ${ }^{111}$.

En una nueva misiva de los Paheres al monarca, fechada el 7 de octubre de 1574, se quejaban de que -a causa del conflicto desatado- los estudiantes venían de muy lejos y no podían graduarse en la sede del Estudio, sino en la Catedral. Los Paheres solicitaron la intervención del Rey, a fin de que los grados se diesen de nuevo en la Universidad y que calmase los ánimos del cabildo catedralicio ${ }^{172}$, que mantenía una relación difícil con el Obispo.

Pocos días después, el 11 de octubre, escribían congratulándose de la buena elección del Magnífico Señor Cordelles "per a fer bon asiento del Estudi $i^{173}$ ". Miguel de Cordelles, ciudadano honrado y Doctor en Derecho, llegó a ser Regente de la Cancillería, y fue enviado a Lérida para inspeccionar per-

\footnotetext{
166 AMP, Reg. 850 (1572-1574), ff. 87v-9or.

167 J. Poch, “Del Estudio General...”, p. 120.

168 AMP, Reg. 850 (1572-1574), f. 92r.

169 AMP, Reg. 850 (1572-1574), f. 93r.

170 AMP, Reg. 850 (1572-1574), ff. 93v-94r.

171 AMP, Reg. 850 (1572-1574), ff. 99v-10or.

172 AMP, Reg. 850 (1572-1574), ff. 101v-102v.

173 AMP, Reg. 850 (1572-1574), ff. 103r-104r.
} 
sonalmente la problemática de la Universidad ${ }^{174}$. Mediante la misiva de los Paheres sabemos que a la sazón el Obispo estaba ausente de la Ciudad. Se había refugiado en Monzón, donde -según indica Lladonosa ${ }^{175}$ - acudían los prelados cuando tenían problemas con las autoridades civiles y eclesiásticas.

Para agravar más la situación, Bartomeu Serret, canónigo y catedrático de Tercia de Cánones, hizo un grave menosprecio al Rector del Estudio. Ello generó un pleito por parte del Rector Joan Baptista Bohil ${ }^{176}$. Vistas las circunstancias, el canónigo y Vicario General Onofre Moliner consideró que Serret merecía por ello ser suspendido de su cátedra ${ }^{177}$.

El Rector y Consejo de la Universidad de Lérida escribieron al Rey el 13 de septiembre de 1574 para que mandase "remediar vn tant gran dany $y$ com ara haiam entes la voluntat de Vostra Magestat y es que dita Universitat torne a son bo $y$ antic stament ${ }^{178}$ ". Asimismo, los Paheres escribieron de nuevo al virrey Fernando de Toledo indicando que no llegaba el redreç de la Universidad y que el Señor Cordelles ya se había marchado. Se quejaban amargamente de la actitud del Obispo: "les malicies grans y odis que lo Sr. Bisbe y los officials an pres tot aquest poble y haver volgut traura la ma a tornar lo Studi al que soli $e^{179 "}$.

Los Paheres escribieron el 25 de noviembre de 1574 indicando que el Rector Juan Bautista Bohil había emprendido el viaje hacía dos días, en nombre del Estudio General, hacia la Corte para dar explicaciones directamente al Rey. Pedían al Virrey y al Rey que atendiesen a Bohil y le indicaban los problemas más acuciantes: los lectores tenían que cobrar su salario por Navidad y no sabían si el Obispo querría pagar su parte. Los Paheres recalcaban asimismo la necesidad de nombrar administradores para el Estudio ${ }^{180}$.

La situación era muy tensa. Las diferencias entre el Obispo, el Rector y la Ciudad parecían irresolubles, tal y como se desprende de la correspondencia entre el Virrey y el vicecanciller Bernardo de Bolea en los primeros meses de $1575^{181}$. Lo cierto es que, al final, Agustín concluyó los Estatutos, que fueron

174 F. J. Morales Roca, Próceres habilitados en las Cortes del Principado de Cataluña, siglo XVII: 1599-1713, Vol. 1, Madrid, Hidalguía, 1983, p. 206.

175 J. Lladonosa, “Humanisme i Reformes...”, p. 92.

176 ACL, P7_M2_P3_Co6, s.f.

177 AMP, Reg. 850 (1572-1574), f. 106v.

178 S. Sánchez-Lauro Pérez, “L’Estudi General de Lleida...”, p. 268.

179 AMP, Reg. 850 (1572-1574), f. 108r.

180 AMP, Reg. 850 (1572-1574), f. 113r.

181 F. Esteve Perendreu, "Rentas y reformas...”, p. 50. 
aprobados y sancionados por Felipe II el 27 de julio de dicho año ${ }^{182}$, destacando que "Studi de Leyda es del mes principals de España y dell han eixit homens insignes que han servit al Señor Rey, y a sus antecessors en los govern dels Reynes ${ }^{183}$ ". Nada podemos añadir ya a lo que se ha dicho sobre los estatutos ilerdenses de Antonio Agustín. Han sido comentados con detalle por Esteve Perendreu ${ }^{184}$ y otros y, sin duda, representan una estructuración definitiva de la Universidad, ahondando en las reformas del obispo Despuig.

Solamente diremos que, de acuerdo con esta reforma, tanto las cátedras mayores como las menores tenían que ser provistas por oposición y votadas por los estudiantes en lección pública; que las cátedras doctorales se tenían que proveer por votos de bachilleres y estudiantes que hubieran cursado un mínimo de tres años en aquella Facultad; que las catedrillas de bachiller se tenían que proveer por un espacio de dos años mediante los votos de los estudiantes de la Facultad, que hubieran cursado un año y estuviesen matriculados. Asimismo se ordenó que las lecturas empezasen en San Lucas y que llegasen hasta la Virgen de Agosto, con excepción del catedrático de Instituta, que tenía que leer todo el año.

Felipe II, en la letra real que declaraba los Estatutos de 1575, añadió a todo lo anterior que los catedráticos tenían que leer personalmente, y no mediante sustituto, salvo en casos de enfermedad o de ausencia necesaria, y que el sustituto de un Doctor tenía que ser Doctor, mientras que el del Bachiller debía ser Bachiller. Asimismo dispuso que los catedráticos que faltasen un mes a la lectura sin licencia del Rector y del Consejo fuesen privados de su cátedra ${ }^{185}$.

Como premio a tan ardua labor, Antonio Agustín, que estaba muy bien considerado y mantenía un sostenido epistolario ${ }^{186}$ tanto con Felipe II como con Gregorio XIII, consiguió de ambos su remoción de aquella incómoda sede de Lérida y su promoción al arzobispado de Tarragona. Éste estaba vacante por la muerte del cardenal Cervantes, quien había puesto las bases de la Uni-

182 AMP, Libre del Studi, Reg. 23, ff. 93-98v.

183 F. Esteve Perendreu, El régimen jurídico, p. 197.

184 Véase F. Esteve Perendreu, El Régimen jurídico..., pp. 197-199, y también "Rentas y reformas...”, pp. 51-55, con abundante bibliografía.

185 F. Esteve Perendreu, El régimen jurídico, pp. 230-231.

186 J. Carbonell Manils, "La relación epistolar inédita entre Antonio Agustín y el Papa Gregorio XIII”, Faventia, 22/2 (2000), p. 131. Así le agradeció Agustín al Santo Padre su traslado de Lérida: "placuit Philippo Regi nostro Catholico a S(anctita)te V(estra) postulare ut me, qui in hoc minore grege Ilerdensi operam inutilem consumpsi, ceteris praeferat et provinciae totius oves committat". 
versidad de Tarragona, a la que Antonio Agustín acabó de dar fisonomía y que fungió como Seminario-Universidad y como lugar de graduación de muchos clérigos de las diócesis vecinas ${ }^{187}$.

Sentado lo anterior, cabe reflexionar sobre por qué se dio dicho conflicto entre Antonio Agustín y las autoridades ilerdenses. Hay que pensar que, junto con las circunstancias personales, incomprensiones y rencillas, Agustín atrajo a Lérida a muchos humanistas y que se rodeó de ellos durante unos años en los que hubo una gran actividad intelectual en el Estudio. Su concepción de la Universidad estaba muy influenciada por el retorno italiano al cultivo de los clásicos grecolatinos y quería para la Universidad de Lérida una nómina de profesores eruditos, procedentes de toda la Corona de Aragón.

De la relación de profesores, desconocida hasta ahora, se desprende que Agustín tuvo una concepción intervencionista con respecto a la gestión y a la enseñanza en el Estudio, y que ello dio motivo a quejas por parte de las autoridades civiles y universitarias. Cabe pensar que los Paheres consideraron que el Obispo visitador-reformador se extralimitaba en sus atribuciones, si bien la fama intelectual que tenía era, en sí misma, una atracción y un reclamo para los estudiosos, que -bajo la protección episcopal- fueron luego profesores en la Universidad.

Pese a que no haya quedado constancia manuscrita de su influencia en la promoción académica de Pere Joan Nunyes, Pere Mollan y otros eruditos valencianos mencionados, lo cierto es que el criterio episcopal debió de tener mucho peso, en un Estudio que cada vez tenía una proyección más bien local. De hecho, en la Universidad de Lérida desde la reforma de Antonio Agustín hasta su transferencia a Cervera encontramos un profesorado de renombre más bien local o regional, frente a la brillante nómina de lectores que se congregaron cabe el Segre durante el período que hemos tratado aquí.

Sin duda, el enfrentamiento entre Agustín, los canónigos, los Paheres y el Rector fue la chispa que facilitó la marcha de muchos docentes a la Universidad de Barcelona. Con un ambiente hostil y un obispo cuestionado (e incluso exiliado en Monzón), no es de extrañar que algunos de los profesores más reconocidos aceptasen la tentadora oferta de la pujante Universidad barcelonesa, que no sólo les ofrecía buenas condiciones económicas, sino también una cercanía con las instituciones de gobierno que facilitaba su propia promoción. Recordemos que en el curso 1573-1574 enseñaron Leyes en la Uni-

187 R. Ramis Barceló, “Grados mayores en la Universidad de Tarragona (1580-1624)”, Analecta Sacra Tarraconensia, 90 (2017), pp. 131-155. 
versidad de Barcelona Jaume Mir, Antoni Olibà y Lluís Fuster y -desde el curso 1575-1576- Joan Castelló, todos ellos procedentes de Lérida ${ }^{188}$. Éstos se añaden a los ya citados (Nunyes, Vilanova...)

En definitiva, no es casual que cuando empezaron los enfrentamientos más serios entre Antonio Agustín, los Paheres y el Estudio General, los profesores se marcharan a otras sedes, particularmente a la de Barcelona, que empezaba a emprender su vuelo y que estaba deseosa de competir con (y vencer a) la aneja Universidad ilerdense.

Asimismo podemos afirmar que la presencia de Antonio Agustín en Lérida significó un momento dorado en cuanto a la nómina de profesores del Estudio. Sin duda, ninguna otra universidad hispánica -hecha la salvedad de Salamanca, y quizás de Alcalá- gozó de un profesorado tan reputado en aquellos años. Sin embargo, el carácter del Obispo, su intervencionismo y sus ideas humanísticas chocaron con la voluntad de muchos estudiantes y de los Paheres, que tenían una visión pragmática que anteponía los equilibrios de poder local (e incluso entre las tres nationes) sobre los ideales del prelado zaragozano.

Al final, Antonio Agustín, tras una dura lucha con las autoridades locales (que tenían unos argumentos económicos y sociales muy convincentes y realistas) concluyó su pontificado reformando la Universidad, consolidando las cátedras existentes y dotándola de una estabilidad institucional que duró - con pequeñas modificaciones- hasta su transferencia a Cervera. El nacimiento de nuevas sedes universitarias (Zaragoza, Tarragona, Vic, Tortosa, Solsona...), la voluntad oligárquica de la Pahería sobre el control del profesorado y las guerras impidieron otro período de esplendor docente como el de aquellos años.

\section{El Estudio, tras la marcha de Antonio Agustín}

Observemos que, tras la marcha de Agustín, la Universidad de Huesca inició un ascenso en casi todas las Facultades, al tiempo que Lérida entró en decadencia. Un estudio de Lahoz Finestres ${ }^{189}$ detalla el número de grados en la Universidad sertoriana y arroja unas cifras que deben tenerse muy en cuenta: en la década de 1560-1570 hubo 2 graduados de Bachiller y 11 de Licenciado

188 A. Fernández Luzón, La Universidad de Barcelona..., p. 320.

189 J. M. Lahoz Finestres, "Un estudio sobre los graduados de la Universidad de Huesca”, Argensola: Revista de Ciencias Sociales del Instituto de Estudios Altoaragoneses, 115 (2005), pp. 245-282, especialmente p. 281. 
en Teología; 22 de Bachiller y 18 en Cánones; 12 de Bachiller y 10 de Licenciado en Leyes; 2 de Bachiller y 10 de Licenciado en Medicina y sólo 3 Licenciados en Artes. Si observamos los datos de la década siguiente (1570-1580), el crecimiento es espectacular: 40 graduados de Bachiller y 22 de Licenciado en Teología; 96 de Bachiller y 49 en Cánones; 53 de Bachiller y 22 de Licenciado en Leyes; 35 de Bachiller y 23 de Licenciado en Medicina; 83 Bachilleres y 7 Licenciados en Artes. Esta tendencia se consolidó en las décadas siguientes. Más allá del desarrollo de la institución, Huesca se convirtió en la principal competencia de Lérida, tal y como podremos corroborar en los capítulos siguientes.

Así como Huesca atrajo estudiantes de Aragón, Navarra, Valencia, Baleares y Cataluña, la naciente Universidad de Barcelona no representó en estos años una seria competencia para la Universidad de Lérida, puesto que los grados de las Facultades mayores fueron muy escasos. Básicamente, el Estudio barcelonés sirvió para la colación de más de un millar de grados de Bachiller en Artes $^{190}$, si bien en el siglo XVII se fue convirtiendo, paulatinamente, en el centro de referencia para los estudiantes catalanes, en detrimento de Lérida.

La Universidad de Huesca atrajo también a algunos profesores, como Fr. Felipe Hernández de Monreal, agustino, que había sido, según indican algunas fuentes, catedrático de Prima de Teología en Lérida ${ }^{191}$, antes de pasar a Huesca, donde Gudiol le localiza en los cursos 1582-1583 y 1585-1587 $7^{192}$.

La situación en Lérida se complicó de nuevo con una disputa que tuvo lugar en 1578 en el aula de Leyes entre los profesores Jeroni Valls, Jeroni i Lluís de Gomar, que creó un gran escándalo ${ }^{193}$ y obligó a que el rector Francesc Capdevila tuviese que promulgar unos estatutos en $1579^{194}$. El mismo estado de postración y decadencia lo confirma el informe del licenciado Burgués, quien en 1581 era el profesor de Gramática. Lamentándose de las faltas de disciplina de los estudios y la ruina del edificio, recomendaba que la enseñanza de la latinidad estuviera en manos de la Compañía de Jesús ${ }^{195}$, algo que acabó sucediendo al cabo de dos décadas.

190 A. Fernández Luzón, La Universidad de Barcelona..., p. 304.

191 F. D. de Aynsa y de Iriarte, Fundacion, excelencias, grandezas, y cosas memorables de la antiquissima ciudad de Huesca, assi en lo temporal, como en lo espiritual, Huesca, por Pedro Cabarte, 1619, p. 574.

192 A. Durán Gudiol, “Notas para la historia de la Universidad de Huesca...”, p. 151.

193 J. Lladonosa, Història de Lleida, II, pp. 307-308.

194 F. Esteve Perendreu, El régimen jurídico, pp. 229-230.

195 ACL, P7_M2_P3_Co3, n. 5. 
El 18 de abril de 1584, Felipe II ordenó una reforma del Estudio de Lérida, en la cual mandaba, entre otros puntos, que los catedráticos de Leyes y de Cánones no pudiesen leer teniendo un cuaderno delante, sino una nota o sumario del texto que tenían que explicar; que todos los catedráticos que faltasen a las lecturas tenían que ser apuntados y multados; que si vacaba alguna cátedra durante el curso no se hiciese provisión hasta las primeras vacaciones, y que mientras tanto se diese un sustituto temporal; que los monjes y los religiosos hábiles podían oponerse a las cátedras aunque no fuesen doctores, pero si ganasen la cátedra se tenían que graduar en dos meses ${ }^{196}$.

Apuntemos sólo que Felipe II, en las Cortes de Monzón, junto a la Maestrescolía y las rentas, en el marco de las reformas de la institución, mandó a Miquel Ferrero a Lérida para que presenciase los votos de las cátedras de Bachiller:

"A supplicatio de alguns estudiants de aqueixa Universitat manarem ab nostra real lletra al Doctor Miquel Ferrero del nostre Consell Criminal que assistis a la provisio que conforme a la reformatio ultima de la dita Universitat se te de fer per Vots de estudiants de les Cathedres de Bachiller a fi de que no suscitassen questions ni diferencias, y perque lo dit Micer Ferrero per sa absencia no porra assistir dit dia en la Universitat, reuocant la commissio a aquell donada sens nota de infamia vos encarregam, manam y cometem que vos assistau dit dia en dites competencias y prouisions de Cathedres, Provehint que lo dit acta se faça ab la pau y quietut que a nostre seruei, y al be de la dita Universitat conue, Decidint los duptes que en la prestatio dels uots se mouran, e inseguint en tot, lo que esta disposat amb nostra real reformacio, y altres prouisions apres de aquella per nostros llochtenents generals y de dita universitat fetes, encarregant vos que en tot lo sobre dit vos empleeu amb la industria y diligencia que de vos se confia, Dat en Monço a 25 de setembre, MDLXXXV'197".

Cinco días, después, el 30 septiembre de 1585, el Rey recuerda a Ferrero que: "Y quant a les appelacions ques son interpossades y es la materia subjecta de la prouisio de las catedras no suffre que tinguen effecte suspensiu procuraren lo consell proceescha a la habilitacio, o inhabilitaçio predita no obstant las ditas appellacions ${ }^{198 ”}$.

La maestrescolía se erigió por "no hauer hagut fins assí, persona ab bastant poder, y plena auctoritat, pera corregir, castigar, y tenir ab la deguda disciplina scolastica, als estudiants, y altres persones del dit general studi

196 F. Esteve Perendreu, El régimen jurídico, pp. 199-200.

197 ACA, Cancillería, Reg. 4309, f. 224v.

198 ACA, Cancillería, Reg. 4310, f. 25v. 
de Leyda' ${ }^{199 ”}$. Para atajar los desórdenes de armas y otros inconvienientes, los tres brazos pidieron a Felipe II que nombrase

"Maestre Scuela, lo qual sia de nacio Cathala, y haje de residir personalment, en la ciutat de Leyda, y perpetuament priuatiue, a tots altres jutges, aixi Ecclesiastichs, com Seculars, sie superior, y jutge competent y tingue tota jurisdictio ciuil, y criminal, mer, y mixt imperi sobre tots los cathedratichs, y estudiants, y ministres del dis estudi... ${ }^{200 "}$

El Maestrescuela debía tener un alguacil con la capacidad de "portar bastor llarch, y hage de ser home de honor" y que "en crim flagrant pugue entrar en qualsevol cases encara que no sien subjectes a la jurisdictio del Maestre Scuela, pera pendre y capturar los estudiants, y als que se alegren dels priuilegis de estudiants tan solament... ${ }^{201}$

Con el Maestrescuela se daba inicio a otro capítulo de la historia de la Universidad ilerdense. Los conflictos de jurisdicción a partir de entonces jalonaron la evolución del Estudio y fueron constantes en el siglo XVII, como tendremos ocasión de comprobar en los capítulos siguientes.

\section{Conclusiones}

Hasta ahora se sabía -aunque de forma general e imprecisa- que Antonio Agustín había influido en el Estudio General de Lérida y que se había rodeado de humanistas. Gracias a la documentación manuscrita que aquí hemos analizado conocemos una nómina bastante exacta de los profesores durante su pontificado y, efectivamente, constatamos los vínculos del Obispo con muchos de ellos.

Las tres contribuciones más relevantes de este capítulo son la nómina de profesores, la constatación de la presencia de importantes humanistas ligados con Antonio Agustín, y la aportación de nuevos datos al enfrentamiento que sustuvieron el Obispo, los Paheres y las autoridades del Estudio General.

Conocemos mejor ahora la trayectoria de algunos afamados teólogos como Fr. Juan Moreno o Fr. Antoni Pont, y aportamos nuevos datos sobre la ejecutoria de destacados juristas como Antoni Oliba, Pere Mollan, Lluís Fuster, Pere y Francesc Molí, así como también de relevantes filósofos, gramáticos y

199 Constitutions fetes per la Sacra Catholica Real Magestat del Rey Don Phelip..., Barcelona, Casa de Damia Bages, 1586, p. 45v.

200 Ibidem, p. 45v.

201 Idem, p. 46r. 
humanistas, como Miquel Ferrer, Gabriel Massot, Bartomeu Vilanova... De todos ellos tenemos información desconocida acerca de sus lecturas o faltas en ellas.

Apuntamos también la posible conexión valenciana, con el caso especial de Pere Joan Nunyes (de quien confirmamos su estadía en Lérida como lector de Artes y de Gramática), así como también de Onofre Serra y Vicent Ciurana, de quienes conjeturamos su identificación. A lo largo de este estudio hemos apuntado también los vínculos que unieron a las Universidades de Lérida y de Huesca, especialmente en el profesorado que enseñó en las dos sedes a lo largo de la segunda mitad del siglo XVI.

Sin duda, el Estudio de Lérida tuvo durante el pontificado de Antonio Agustín los mejores profesores de la Corona de Aragón, algunos de los cuales acudieron allí expresamente atraídos por la personalidad cultivada del Obispo. El humanismo intuido y esbozado por Lladonosa puede confirmarse definitivamente con esta nómina, que no deja lugar a dudas.

Y el desencuentro entre el Obispo y las autoridades acabó pasando factura al profesorado local o foráneo, que terminó marchándose a la Universidad de Barcelona (Jaume Mir, Antoni Oliba y Lluís Fuster, Joan Castelló, Bartomeu Vilanova...) o a otras. Les llevó a Lérida la búsqueda de nuevos horizontes y de libertad, amparada por Antonio Agustín, y la perdieron cuando el Obispo empezó a ser cuestionado por las autoridades del Estudio General, los estudiantes y los Paheres. Todos los datos apuntan a que el Obispo facilitó la estabilización de algunos renombrados amigos y colaboradores suyos como profesores en el Estudio General, y que el prelado no tenía prisa en la reforma del mismo, sino que prefería atraer a docentes afamados.

Las autoridades querían asegurarse el pago de las rentas que gravaban sobre la mitra, y ansiaban el control de la institución, que desempeñaba un papel importante en la promoción de la oligarquía de la ciudad. Lo que empezó como una desavenencia de intereses y de sensibilidades acabó desencadenando un conflicto que, a la postre, acabó con la promulgación de unos Estatutos que blindaban las competencias y las cátedras de la Universidad, y con la remoción del prelado.

Lladonosa interpretó acertadamente la falta de entendimiento de las partes y subrayó la gravedad del conflicto, al involucrar al Rector y a los Paheres, así como también a canónigos, estudiantes, maestros... todos ellos tomaron cartas en un conflicto que concluyó de la mejor forma posible para el Estudio y que fue el final de una etapa, que podría calificarse de tardohumanista, en Lérida. 
En este sentido, se puede afirmar que desde la fundación de la cátedra de teología del obispo Conchillos se vivió una época de esplendor, que se incrementó con las reformas del obispo Despuig y que llegó a su cénit en el pontificado de Antonio Agustín, lapso que -en cuanto a la notoriedad de su profesorado- podemos estimar que fue una época dorada. En los años siguientes, el escolasticismo se sobrepuso al humanismo, el localismo al universalismo y los equilibrios de poder a la auctoritas del prelado aragonés.

Por la defensa acérrima que Felipe II hizo del Estudio de Lérida, podemos decir que la institución pudo sobreponerse parcialmente de la crisis de la década de 1570, y que siguió contando con algunos maestros universitarios notables, de quienes tenemos algunos datos aislados gracias a los trabajos de Lladonosa y especialmente de Esteve Perendreu. El hallazgo de más materiales inéditos, espigando en diferentes fuentes, quizás nos permita conocer el ambiente en el Estudio en los años finales del reinado de Felipe II, en los que se creó la maestrescolía y se consolidaron algunas reformas llevadas a cabo por Antonio Agustín.

De todas formas, como hemos podido ver, el Rey consideraba en las Cortes de Monzón que la Universidad de Lérida seguía siendo muy problemática y estaba especialmente preocupado por las oposiciones a cátedra y por los conflictos con los estudiantes. De ahí que la creación de la Maestrescolía fuese, en buena manera, una manera de reforzar la autoridad en el Estudio General. Con ello, nos introducimos en la Lérida del Barroco, que trataremos en los capítulos siguientes. 
PROFESORES

(1564-1573)

\begin{tabular}{|c|c|c|}
\hline Nombre & $\begin{array}{l}\text { Fecha de } \\
\text { comienzo }\end{array}$ & Facultad \\
\hline Aguiló, Pere & 1564 & Leyes \\
\hline Armeda, [-] & 1573 & - \\
\hline Babot, Gabriel & 1564 & Medicina \\
\hline Bafart, Francesc & 1566 & Leyes \\
\hline Benach, Antoni & 1568 & Medicina \\
\hline Benach, Pere Joan & 1569 & Medicina \\
\hline Berart, Miquel & 1572 & [Sustituto] \\
\hline Berenguer, Francesc & 1567 & Teología \\
\hline Boil, Joan Baptista & 1573 & Leyes \\
\hline Boldú, Francesc & 1571 & Medicina \\
\hline Bonet, Francesc & 1566 & Leyes \\
\hline Boneta, Jeroni, O. de M. & 1565 & Teología \\
\hline Bordalba, Pere & 1568 & Cánones \\
\hline Botella, Francesc & 1564 & Leyes \\
\hline Calaf, Agustí & 1571 & Medicina \\
\hline Calaf, Josep & 1571 & Leyes \\
\hline Calvís, Jaume, O.S.B.? & 1568 & - \\
\hline Capdevila, Montserrat & 1571 & Artes \\
\hline Capero, Cristòfol & 1571 & Leyes/Cánones \\
\hline Carrera, Tomàs & 1564 & Leyes \\
\hline Castelló, Joan & 1573 & Leyes \\
\hline Cellers, Llorenç & 1564 & Leyes \\
\hline Cirera, Ramon & 1573 & Artes \\
\hline Coma, Joan & 1567 & Teología \\
\hline Copons, Lluís & 1564 & Leyes \\
\hline Coria, Josep & 1572 & Leyes \\
\hline Crespo, Joan & 1572 & Leyes/Cánones \\
\hline Descamps, Francesc & 1568 & Leyes \\
\hline Estapé, Pere & 1568 & Leyes \\
\hline Esteve, Pere & 1564 & Cánones \\
\hline
\end{tabular}




\begin{tabular}{|c|c|c|}
\hline Ferrer, Miquel & 1564 & Artes/Medicina \\
\hline Fuster, Lluís & 1568 & Cánones \\
\hline Garcia, Joan & 1565 & Leyes \\
\hline Gascón, Agustí & 1564 & Teología \\
\hline Gil Escalona, Fernando & 1564 & Medicina \\
\hline Ginebrosa, Joan, O. P. & 1564 & Artes \\
\hline Gomar, Bartomeu & 1564 & Cánones \\
\hline Llopico, Pere & 1564 & - \\
\hline Llupià, Miquel & 1567 & Medicina \\
\hline Maní, Antoni & 1573 & Teología \\
\hline Massot, Gabriel & 1566 & Artes \\
\hline Moreno, Joan, OFM Conv. & 1567 & Teología \\
\hline Montserrat, Pere & 1572 & Leyes \\
\hline Mir, Jaume & 1564 & Leyes \\
\hline Molí, Pere & 1564 & Cánones \\
\hline Mollan, Pere & 1573 & Cánones \\
\hline Montornés, Miquel & 1566 & Teología \\
\hline Montsó, Rafel & 1568 & Leyes \\
\hline Mor, Salvador & 1564 & - \\
\hline Morata, Josep & 1571 & Cánones \\
\hline Nunyes, Pere Joan & 1568 & Artes \\
\hline Oliba, Antoni & 1564 & Leyes \\
\hline Pasqual, Jeroni & 1564 & Leyes \\
\hline Pla, Mateu & 1571 & - \\
\hline Plana, Pere & 1568 & Leyes \\
\hline Pastor, Francesc & 1573 & Leyes \\
\hline Pintor, Jeroni & 1573 & [Sustituto] \\
\hline Pont, Antoni, O.SS.T. & 1571 & Teología \\
\hline Pradell, Jeroni & 1572 & Cánones \\
\hline Prunyonosa, Celedoni & 1567 & Artes \\
\hline Punster, Melcior & 1568 & Leyes \\
\hline Punster, Gaspar & 1568 & Leyes \\
\hline Riber, Francesc & 1564 & Medicina \\
\hline Ribes, Miquel & 1568 & Cánones \\
\hline Rius, Andreu & 1564 & Leyes \\
\hline
\end{tabular}




\begin{tabular}{|l|c|c|}
\hline Roig, Jaume & 1568 & Cánones \\
\hline Rubio, Pere & 1564 & Leyes \\
\hline Sans, Joan & 1566 & Artes \\
\hline Sans, Lluís & 1572 & [Sustituto] \\
\hline Salas, Pere & 1565 & Teología \\
\hline Salvador, Francesc & 1568 & Artes \\
\hline Sahona, Gaspar, O.S.A. & 1572 & Teología \\
\hline Sant Martí, Pere Arnau de & 1571 & Medicina \\
\hline Segarra, Pere & 1564 & Cánones \\
\hline Seran, Antoni & 1567 & Artes \\
\hline Serra, Onofre & 1571 & Artes \\
\hline Serret, Bartomeu & 1564 & Cánones \\
\hline Sinistere, Francesc de & 1566 & - \\
\hline Siurana, Vicent & 1572 & Artes \\
\hline Tarròs, Joan, O. Cist. & 1570 & Teología \\
\hline Tormo, Francesc & 1572 & Teología \\
\hline Tristany, Miquel & 1568 & Cánones \\
\hline Vilanova, Bartomeu & 1566 & Artes \\
\hline Vilallonga, Lluís & 1573 & [Sustituto] \\
\hline
\end{tabular}




\section{LA FACULTAD DE LEYES Y CÁNONES}

(1598-1714)

En las páginas anteriores hemos analizado la época central del siglo XVI y hemos podido conocer los avatares de la Universidad hasta las reformas llevadas a cabo por Antonio Agustín. En este capítulo vamos a estudiar la etapa final de esa Facultad ilerdense, desde las transformaciones que se produjeron a finales del siglo XVI hasta que la Universidad fue transferida, junto con las demás del Principado, a Cervera. Nuestro objetivo es doble: por una parte, examinar la estructura institucional de la Universidad y sus grandes reformas y, por otra, profundizar en el conocimiento de los profesores de Leyes y Cánones y la enseñanza del derecho, a través del análisis de las vicisitudes ocurridas desde el comienzo del reinado de Felipe III al de Felipe V, que decidió acabar con la histórica sede universitaria.

Pretendemos trazar, por vez primera, un cuadro unitario del funcionamiento de aquella Facultad de Leyes y Cánones, haciendo especial hincapié en los perfiles del profesorado (su formación y promoción), así como también de la incidencia de los avatares históricos del momento en la vida universitaria.

\section{La estructura de la Facultad en su contexto}

Como hemos visto en el capítulo anterior, el Estudio de Lérida, desde su fundación, era esencialmente un centro para la formación de juristas. Sin duda, los maestros legistas y canonistas fueron los docentes más prestigiosos de cuantos enseñaron durante cuatro siglos cabe el Segre.

Durante el pontificado de Antonio Agustín el Estudio tuvo un profesorado muy afamado (Pere Molí, Francesc Molí, Pere Sagarra, Antoni d’Olibà...) aunque, como hemos visto, hubo muchísimas tensiones entre el Obispo y los Paheres sobre la reforma del Estudio ${ }^{1}$. Los Paheres conocían, con todo, los límites de la institución y el estado de decadencia y postración que tenían muchas de las Facultades del Estudio leridano, especialmente tras la muerte de Felipe II, que siempre había apostado por esta sede universitaria.

1 ACL, Reg. 850, Correspondencia, ff. 62-64 y 86v-94r. 
Como hemos indicado en las páginas precedentes, a petición de los tres brazos en las Cortes de Monzón, se solicitó la creación de la maestrescolía. El 22 de agosto de 1592, Clemente VIII erigía en la Catedral de Lérida la dignidad de Maestrescuela, en sustitución del Archidiácono mayor y a sus funciones se le unió también la Cancillería de la Universidad ${ }^{2}$. El Maestrescuela era, en definitiva, un juez escolástico, con jurisdicción real y apostólica, civil y criminal, y con un carácter independiente, para que se ocupase del orden interno de la Universidad ${ }^{3}$. Felipe II expidió la provisión de Maestrescuela a favor de Matías Ferrer en 1597, aunque se inició un conflicto ${ }^{4}$, en el que se vieron implicados el Rector, el Cabildo, y los Paheres, que no concluyó hasta 1605, cuando se hizo una concordia para que la jurisdicción del Rector sobre los estudiantes se extendiese acumulativamente a la del Maestrescuela. Con todo, los conflictos de jurisdicción fueron muy habituales a lo largo del siglo XVII.

El número de cátedras de la Facultad de Leyes y Cánones de la Universidad de Lérida tuvo algunos cambios durante el siglo XVI, hasta la reforma definitiva de Antonio Agustín. A partir de ese momento, dispuso de un total de seis cátedras mayores (Prima, Secunda y Tercia de Leyes y de Cánones), así como de cuatro catedrillas menores de Leyes y otras tantas de Cánones, más una cátedra menor de Instituta ${ }^{5}$. Las cátedras de Prima estaban dotadas con $120 £$, mientras que las demás tenían un sueldo de $100 £$. Las catedrillas (que leían los graduados de Bachiller) estaban provistas con un sueldo de $50 £$, salvo la de Instituta, cuyo titular percibía solamente $40 £^{6}$.

Un manuscrito de mediados del siglo XVII ${ }^{7}$ nos confirma estas mismas cifras, sin bien dice que algunas cátedras tenían algunos aumentos: los catedráticos de Prima de Leyes y Prima de Cánones recibían un aumento de $37 £$ cada uno, y los catedráticos de Vísperas, Decreto y Código percibían un aumento de $33^{£}$. El resto de cátedras no tenían derecho a estas percepciones extraordinarias.

La documentación manuscrita consigna que, en el momento de la extinción de la Universidad, había las cátedras antes citadas, todas ellas con un

2 AHUB, Universidad de Cervera, Caja 2, leg. 4805.

3 J. Lladonosa i Pujol, Història de Lleida, II, p. 310.

4 F. Esteve Perendreu, Mestrescoles i rectors..., pp. 35-38.

5 F. Esteve Perendreu, "Rentas y reformas...", p. 52.

6 F. Esteve Perendreu, El Régimen jurídico..., p. 159.

7 ACA, Consejo de Aragón, leg. 282, n. 48/11. 
salario de 128 ducados, y que había una catedrilla de Leyes con un salario de 67 ducados y dos catedrillas de Leyes que recibían como salario el grado de Doctor $^{8}$. Con el paso de las décadas, había existido una ligera mejora de los salarios, si bien eran menguados y no resultaban ventajosos, especialmente con otros cargos de la burocracia regia.

En cuanto a las lecturas de Cánones, hay que recordar que la cátedra de Prima se dictaba de 7 a 8 h. de la mañana, la de Decreto de 8 a 9, las de bachiller de 9 a 10 y de 10 a 11, mientras que la cátedra de Vísperas se leía de 2 a 3 y las de bachiller de 3 a 4 y de 4 a 5 . Las lecturas de Leyes estaban dispuestas de la siguiente manera: la de Prima de 7 a 8, la de Segunda de 8 a 9, los bachilleres explicaban de 9 a 10 y de 10 a 11, y el catedrático de Instituta lo hacía de 1 a 2; por la tarde, leía en primer lugar el catedrático de Vísperas de 2 a 3 , mientras que de 3 a 4 y de 4 a 5 lo hacían los bachilleres ${ }^{9}$.

La elección de los catedráticos recaía en los Paheres, si bien tenían que atender a los votos de los estudiantes, una limitación que, como subrayó Gayá Massot $^{10}$, acarreó muchos problemas. Indica Esteve Perendreu que, con la reforma de Antonio Agustín, "oída la lección por los bachilleres y estudiantes de la respectiva Facultad (Cánones o Leyes) y con tres años de estudio, votarán las cátedras mayores. Las catedrillas las votarán los estudiantes con un año cursado y también de la facultad respectiva ${ }^{11}$ ”.

En cuanto a las reformas efectuadas por Juan de Zúñiga, hay que indicar, según Esteve Perendreu, que los catedráticos tenían que explicar la hora completa. Los de Leyes y Canones debían explicar la lección sin tener el libro de texto delante, aunque podían valerse de notas-resumen. Debía existir asimismo un control de los catedráticos que faltasen a su lectura, para que fuesen debidamente multados. Los catedráticos que renunciasen a sus cátedras antes de terminar el tiempo comprometido de su lectura, tendrían que jurar que no lo hacían dolosamente ni por interés ${ }^{12}$.

Ciertamente, en la Universidad de Lérida existió una menor movilidad del profesorado que en otras universidades, bien porque buena parte de los docentes eran eclesiásticos que ocupaban una dignidad aneja, bien porque la

8 AHUB, Universidad de Cervera, Caja 147, leg. 1226.

9 ACL, Llibre del Studi, ff. 44-59. Véase F. Esteve Perendreu, El Régimen jurídico..., p. 162.

10 R. Gayá Massot, "Provisión de cátedras...” p. 273.

11 F. Esteve Perendreu, "Rentas y reformas...” p. 53.

12 Ibidem, p. 65. 
abundancia de cargos que había a menudo en Zaragoza, Valencia o Barcelona, no podía darse en Lérida, que tenía una administración burocrática más sencilla, y, como no era capital de Reino, no poseía sede de la Audiencia ni tantos órganos asamblearios.

En las universidades cercanas había un número similar de cátedras jurídicas, que jamás llegaban a las que tenía la Universidad de Salamanca ${ }^{13}$. En la de Huesca, que atrajo a muchos graduados catalanes ${ }^{14}$, había a finales del siglo XVI cinco cátedras de Leyes (Prima, Vísperas, Código, Instituta, Bachiller) y otras tantas de Cánones (Prima, Vísperas, Decreto, Sexto, Bachiller) ${ }^{15}$, bien remuneradas, según Lahoz ${ }^{16}$. La competencia entre Huesca y Lérida fue cada vez en aumento.

En las reformas universitarias de 1645 de la Universidad de Zaragoza se establecieron también cinco cátedras de cada disciplina (Prima, Vísperas, Decreto, Sexto y Bachiller, en la de Cánones; y Prima, Vísperas, Código, Instituta y Bachiller, en Leyes $)^{17}$. Valencia tuvo, a lo largo del siglo XVI, una política algo indecisa en la creación de cátedras y pavordías, lo cual dejó un balance pobre en cuanto al alcance de la Facultad de Leyes y Cánones ${ }^{18}$.

Y en Barcelona, a finales de la centuria, había un total de seis cátedras: dos de ellas eran mayores y cuatro eran menores ${ }^{19}$. Las mayores eran vitalicias

13 L. E. Rodríguez-Sampedro Bezares, La Universidad salmantina del Barroco, periodo 1598-1625, Tomo II, Salamanca, Universidad de Salamanca, 1986, p. 21.

14 J. M. Lahoz Finestres, "Graduados catalanes en las facultades de Leyes y Cánones de la Universidad de Huesca”, Estudis històrics i documents dels arxius de protocols, 15 (1997), pp. 167-220.

15 A. Durán Gudiol, "Notas para la historia de la Universidad de Huesca...”, pp. 126139.

16 J. M. Lahoz Finestres, Las Facultades de Leyes y Cánones de la Universidad de Huesca, siglos XIV a XIX, 3 vols., Zaragoza, Universidad de Zaragoza, [Tesis doctoral], 1994. Véase un resumen en J. M. Lahoz Finestres, "Esbozo de los graduados de la universidad de Huesca (1541-1845)”, en AAVV, Aulas y Saberes, vol. II, Valencia, Universidad de Valencia, 2003, pp. 29-43, especialmente pp. 34-35.

17 G. Redondo Veintemillas, "La Universidad de Zaragoza”, en J. J. Busqueta Riu y J. Pemán Gavín (coords.), Les universitats de la Corona d’Aragó, pp. 239-287, especialmente p. 279.

18 A. Felipo, La Universidad de Valencia durante el siglo XVI, pp. 176-184. Véase también. A. Felipo Orts y E. Callado Estela, Entre la cátedra y el púlpito. Los pavordes de la Universidad de Valencia (siglos XVI-XVII), Valencia, Universitat de València, 2016.

19 AHUB, Ordinacions de la Universitat Literària de Barcelona de 1638 i 1656, ff. 24r-v. Véase R. Ramis Barceló, "La Facultad de Leyes y Cánones de la Universidad de 
y las menores tenían una duración trienal. Las cátedras mayores eran la de Cánones (cuyo titular percibía $120 £$ anuales ${ }^{20}$ ) y la de Leyes (denominada también de Digesto inforciado, remunerada con 100£). Había una cátedra menor de Cánones, llamada también de Decreto, remunerada con 90£. Las tres cátedras menores de Leyes eran las de Digesto viejo ( $80 £$ ), la de Instituta (70£) y la de Código (60£). Había asimismo catedrillas de bachiller para la lectura de "los quatra Llibres de la Instituta Civil"1".

La Facultad de Lérida, así pues, estaba compuesta a la sazón por seis catedráticos mayores, un catedrático menor de Instituta, y otros bachilleres o doctores que regentaban lectorados o "catedrillas", tal y como sucedía en otras universidades como la de Barcelona, en los que se ejercitaban en la lectura de los diferentes textos jurídicos. Muchos de ellos empezaban a explicar en catedrillas o lectorados con el rango de Bachiller y al poco eran creados Doctores.

Durante el siglo XVII, los juristas hispanos tenían en las cátedras universitarias un trampolín que, con suerte y constancia, les podía catapultar a los lugares mejor remunerados de la administración de la Monarquía. Tal y como señaló Kagan ${ }^{22}$, la docencia universitaria era a finales del siglo XVII un primer paso casi imprescindible en la carrera de los legistas y los canonistas ${ }^{23}$.

Lérida no pudo rivalizar jamás con las Universidades mayores de Castilla, y particularmente con la Universidad de Salamanca. Ésta, especialmente por sus colegios mayores -cada vez más poderosos, como base de reclutamiento de la alta burocracia de la Monarquía hispana ${ }^{24}$ - y por la fama de los profeso-

Barcelona a comienzos del siglo XVIII", Anuario de Historia del Derecho Español, 86 (2016), pp. 385-408.

20 BC, Ms. 304, Llibre de las Sedulas del Estudi General 1705, ff. 1-2.

21 AHUB, Ordinacions de la Universitat Literària de Barcelona de 1638 i 1656, f. 25 r.

22 R. L. Kagan, Universidad y sociedad en la España moderna, Madrid, Taurus, 1981, pp. 211-212.

23 M. A. Martínez Rodríguez, "Els oïdors de la Sala Tercera de l'Audiència de Catalunya a la segona meitat del segle XVII", Estudis històrics i documents dels Arxius de Protocols, 20 (2002), pp. 205-228.

24 Así se veía, por ejemplo, desde Roma, cf. R. Ramis Barceló, "La Universidad de Salamanca vista desde La Sapienza en el siglo XVII”, en J. Correa Ballester (ed.), Universidad y Sociedad: Historia y pervivencias, Valencia, Publicaciones de la Universidad de Valencia, 2018, pp. 513-525. Sobre la carrera de los profesores, véase M. P. Alonso Romero, "Catedráticos salmantinos de Leyes y Cánones en las Chancillerías y Audiencias regias 
res, ejercía un enorme atractivo entre los estudiantes. Hubo muy pocos colegiales mayores catalanes ${ }^{25}$, aunque según Rodríguez-Sampedro, "la atracción ejercida por la Salamanca del siglo XVII sobre los estudiantes manteístas del conjunto de la Corona de Aragón resulta significativamente jurídica y predominante en cánones ${ }^{26 "}$.

En Lérida, muchos de los profesores de Leyes compatibilizaban sus cátedras con algunos cargos municipales, tales como la defensa jurídica de la ciudad, algo que, por ejemplo, estaba vetado en Barcelona. De hecho, como recuerda Gras, los abogados ordinarios de la ciudad "havien d'ésser doctors en Cànons o Lleis per la Universitat de Lleida, i haver obtingut càtedra major de dites facultats en la mateixa escola, o almenys haver verificat oposicions $^{27}$ ". Sin embargo, el desempeño de cargos representativos en la Pahería era del todo incompatible con la lectura de las cátedras, de manera que tenían que llamar a sustitutos para que se ocupasen de las mismas.

También había muchos profesores eclesiásticos, que poseían al mismo tiempo una canongía u otro beneficio. Buena parte de estos clérigos habían ido a Roma por cuestiones derivadas de la gestión de sus beneficios y algunos de ellos se habían doctorado en La Sapienza e incorporado su título a la Universidad de Lérida, pues el doctorado romano se consideraba más prestigioso.

La Sapienza era una de las pocas universidades que Felipe II había tolerado, al establecer el cordón sanitario ${ }^{28}$. La presencia en las Universidades italianas de legistas y canonistas que habían cursado algunos años en Lérida

durante el siglo XVII", en Salamanca, escuela de juristas, Madrid, Dykinson, 2012, pp. 375-398.

25 D. de Lario, "La variante catalana" en Al hilo del tiempo. Controles y poderes de una España imperial, Valencia, Universidad de Valencia, 2004, pp. 141-147.

26 L. E. Rodríguez-Sampedro Bezares, "La Corona de Aragón en la Universidad de Salamanca: siglos XVII y XVIII”, en Aulas y Saberes: VI Congreso Internacional de Historia de las universidades hispánicas, vol. II, Valencia, Universidad de Valencia, 2003, p. 401.

27 R. Gras de Esteva, La Paheria de Lérida. Organización municipal 1149-1707, Lleida, Imprenta y litografía Sol y Benet, 1909. Hay una reedición en catalán de 1988, por la que citamos. La referencia está en la p. 80.

28 Véase D. de Lario Ramírez y J. García Martín, "La impermeabilización ideológica de Felipe II: cronología de una coyuntura (1558-1571)", Estudis: revista de historia moderna, 40 (2014), pp. 31-70. 
fue decayendo a medida que avanzaba el siglo $\mathrm{XVI}^{29}$. Como excepción, documentamos en su momento muchos juristas catalanes, aragoneses y mallorquines que habían frecuentado el Estudio Ilerdense antes de doctorarse en la Universidad de Pisa $^{30}$. Podemos afirmar que la Universidad de Lérida fue el punto de procedencia mayoritario de los hispanos que acudieron a doctorarse a Pisa, entre los que deben incluirse algunos canónigos y Rectores del Estudio. La presencia de estos juristas en Italia fue constante hasta finales del reinado de Felipe III, cuando pasó a ser mucho más esporádica.

Recordemos que el número de Universidades hispánicas había ido creciendo desde la época de los Reyes Católicos, aunque durante los reinados de Felipe II y Felipe III se incrementó aún mucho más ${ }^{31}$. En la Corona de Aragón había enseñanza de derecho en las Universidades antes citadas, así como también en las de Gandía ${ }^{32}$ y Orihuela ${ }^{33}$, de escasa reputación académica, y con una visión mucho más laxa en el tema de la concesión de grados. La Universidad Luliana y Literaria de Mallorca empezó a graduar en $1692^{34}$, de manera que no fue rival de la Universidad de Lérida, si bien, al tener Universidad en Palma, muchos insulares dejaron de frecuentar la Península, y el flujo de estudiantes mallorquines descendión ${ }^{35}$.

29 Puede verse un análisis en R. Ramis Barceló, "Peregrinatio academica: Legistas y canonistas de la Corona de Aragón en las Universidades italianas durante el Renacimiento", Miscellanea historico-iuridica, 12 (2014), pp. 35-66.

30 R. Ramis Barceló, "Estudiantes hispanos de leyes y cánones en la Universidad de Pisa (1543-1665)”, Glossae. European Journal of Legal History, 10 (2013), pp. 524-544.

31 Puede consultarse R. Ramis Barceló, "La política universitaria de los Austrias en la Península Ibérica” en G. P. Brizzi y A. Mattone (ed.), Le origini dello Studio Generale sassarese nel mondo universitario europeo dell'eta moderna, Bolonia, CLUEB, 2013, pp. $103-116$.

32 Véase P. García Trobat, "La Universidad de Gandía”, en M. Peset; M. F. Mancebo; M. Martínez Gomis; P. García Trobat, Historia de las universidades valencianas, II, Alicante, Instituto Juan Gil-Albert, 1993, pp. 153-221.

33 M. Martínez Gomis, La universidad de Orihuela (1610-1807): un centro de estudios superiores entre el Barroco y la Ilustración, Alicante, Universidad de Alicante, 1986. Para leyes y cánones, R. Ramis Barceló, “La Facultad de Leyes y Cánones de la Universidad de Orihuela en el siglo XVII”, Cuadernos de historia del derecho, 24 (2017), pp. 161-185.

34 A. Planas Rosselló y R. Ramis Barceló, La Facultad de Leyes y Cánones de la Universidad Luliana y Literaria de Mallorca, Madrid, Dykinson, 2011.

35 A. Cassanyes Roig y R. Ramis Barceló, "Graduados en Leyes y Cánones en la Universidad Luliana y Literaria de Mallorca (1692-1831)”, e-legal history review, 16 (2013), pp. 1-62. 
El caso extremo de laxitud fue la Universidad de Solsona ${ }^{36}$, un Colegio de dominicos ${ }^{37}$ transformado en expendeduría de títulos a precio módico, que graduó a un sinfín de estudiantes catalanes y baleares, pese a las airadas protestas y memoriales enviados por la Universidades de Barcelona y Lérida. Para ambas instituciones, representó una competencia desleal, que desequilibró la pugna e introdujo una práctica que desprestigiaba el estudio y la enseñanza del derecho.

Aunque Torroella haga mención de algunas cátedras de Leyes $^{38}$ en Gerona, nuestro estudio de las fuentes manuscritas nos permite descartar su funcionamiento. En cuanto a la Universidad de $\mathrm{Vic}^{39}$, hay que subrayar que pudo colacionar grados en derecho durante los primeros años del siglo $\mathrm{XVIII}^{40}$, sin que hayan sido estudiados aún ni los profesores ni los alumnos. Mientras tanto, las de Tortosa ${ }^{41}$ y Tarragona ${ }^{42}$ solamente tenían Facultades de Artes y Teología, y eran lugares de formación casi exclusivamente clerical, como veremos en el capítulo siguiente.

El nivel general de las Universidades catalanas era muy bajo. Cuando la

36 R. Ramis Barceló, "Sobre los privilegios de la Universidad de Solsona y los grados en leyes, cánones y medicina durante el siglo XVII”, Glossae. European Journal of Legal History, 12 (2015), pp. 661-678 y R. Ramis Barceló y P. Ramis Serra, "Los últimos grados de la Universidad de Solsona (1701-1715)”, Historia. Instituciones. Documentos, 44 (2017), pp. 313-349.

37 V. Beltrán de Heredia, "Catálogo de los colegiales, lectores y rectores del Colegio de San Miguel de Solsona (1615-1835)”, Analecta Sacra Tarraconensia, 31 (1958), pp. $125-137$.

38 J. B. Torroella, El Estudi general ó Universitat Literaria de Girona. Ensaig histórich-crítich, Girona, Impr. P. Torres, 1906. Véase también S. Marqués, "L'Estudi General de Girona”, en J. J. Busqueta Riu y J. Pemán Gavín (coords.), Les universitats de la Corona d'Aragó, ahir i avui..., pp. 125-146.

39 Véase R. Rial i Carbonell, L'Ensenyament superior a la Catalunya central entre els segles XVII i XIX: de la Universitat literària de Vic (1599-1717) al Seminari Conciliar de Vic (1749-1868), Barcelona, Facultat de Teologia de Catalunya, 2003, pp. 71-77.

40 AHUB, Universidad de Cervera, Caja 3040/1 y Caja 328, n. 320.

41 E. Querol Coll, L'Antiga Universitat a Tortosa (1529-1824), Tortosa, Antena Cultural Tortosa-Universitat Rovira i Virgili, 2013 y R. Ramis Barceló, "Estudiantes y grados en la Universidad de Tortosa durante el siglo XVII”, en J. M. Calderón Ortega, M. Casado Arboniés, A. Díez Torre (coord.), Historia universitaria de España y América, Alcalá, Universidad de Alcalá de Henares, 2016, pp. 253-268.

42 A. del Arco, La antigua Universidad de Tarragona: apuntes y documentos para su historia, Tarragona, Tip. de F. Sugrañes, 1918. 
Universidad de Tarragona solicitó poder conceder grados en Leyes, Cánones y Medicina, el Duque de Feria, Virrey de Cataluña a la sazón, afirmó claramente que

"todos conformes sienten que esto seria una cosa muy perjudicial y no serviria de mas que de autorizar con titulos honrosos a estudiantes ygnorantes como se hace en Barcelona y Perpiñan y lo procuran los de Girona, y que no solamente se debe negar esta facultad, pero aún convendria si fuese posible, que se acabasen todas las Universidades, excepto la de Lerida ${ }^{43}$ ".

Es decir, que a comienzos del período que estudiamos la Universidad de Lérida aún conservaba cierto prestigio sobre las demás universidades catalanas, cuya puesta en funcionamiento había sido más reciente. Sin embargo, Barcelona superaba a Lérida ampliamente en número de estudiantes. De hecho, el jesuita Pere Gil, en su Geografia de Catalunya, indicó que:

“...Y sent un principat com es no molt gran, te quatre universitats y estudis Generals, es à saber la Universitat de Leyda, en la qual estudian mes de siscents estudiants: la de Barcelona en la qual son ensenyats noucents ò mil estudiants, la de Perpinya en la qual estudian quatrecents estudiants; y la de Tarragona e la qual ouen dos cents estudiants pochs mes ò manco...4"

En los otros Reinos peninsulares se abrieron nuevas Facultades de Leyes y Cánones e incluso algunas Universidades graduaron de todas las materias, sin que se hubiese erigido la Facultad, ni hubiera enseñanza regular. Un ejemplo sería la Universidad de Irache ${ }^{45}$, que graduó desde 1613 a laicos y seglares de todos los Reinos en todas las disciplinas, especialmente en derecho canónico. Entre los egresados en Irache había muchos aragoneses, aunque los catalanes fueron excepción. La diferencia con Solsona residía en que Irache era una Universidad válidamente constituida, con privilegios reales y pontificios.

Con todo, cabe recordar que desde la segunda mitad del siglo XVI se asistió a una proliferación universitaria, que permitió una mayor picaresca por parte de los alumnos. Por todo lo que hemos dicho, queda claro que a comienzos del siglo XVII, los estudiantes tenían otras alternativas novedosas -más

43 Reproducido en A. Fernández Luzón, La Universidad de Barcelona..., p. 296.

44 Véase J. Iglesies, Pere Gil, S.I. (1551-1622) i la seva Geografia de Catalunya, Barcelona, Institut d'Estudis Catalans, 2002, p. 269.

45 R. Ramis Barceló y P. Ramis Serra, "Grados de la Universidad de Irache (16131620)”, Studia monastica, 6o/1 (2018), pp. 119-180. 
económicas y laxas- antes de graduarse en Lérida, lo cual contribuyó que la Universidad ilerdense tuviese una dimensión cada vez más local.

\section{Los profesores}

Se poseen pocos datos sobre la docencia en la Facultad de Leyes y Cánones de Lérida, aunque, dada su importancia, se conservan muchos más que de las demás Facultades de la institución. Al haber muchos catedráticos (en cátedras mayores y menores), han quedado algunos de sus nombres en documentos sueltos que, hasta cierto punto, facilitan su reconstrucción ${ }^{46}$.

Como sucedía en las demás Universidades del momento, la enseñanza del derecho estaba, en gran medida, en manos de clérigos y seglares procedentes de un reducido grupo de familias, que habitualmente estaban emparentadas entre sí. Los Biosca, Freixenet, Segarra o Maranyosa son ejemplos de familias con notable ascendiente en el Estudio. Muchas de ellas habían ascendido socialmente gracias a la formación jurídica de algunos de sus vástagos, los cuales habían podido solicitar luego el privilegio militar y ser insaculados para el ejercicio de algunos cargos representativos.

Asimismo, como sucedía en otras Facultades, la enseñanza del derecho canónico y del derecho civil ocupaba indistintamente a laicos y a eclesiásticos, que accedían libremente a las diversas cátedras. Sin embargo, el carácter endogámico de la Facultad estuvo presente en todas las épocas, en la que encontramos -como clérigos o como seglares- a padres, hijos, tíos y sobrinos. Algunos estudios sobre la oligarquía ilerdense ${ }^{47}$, así como también sobre el ennoblecimiento en la ciudad, resultan clave para entender la endogamia, sobre todo en el siglo XVII, cuando la Universidad de Lérida dejó de gozar de una proyección en toda la Corona de Aragón y pasó a tener profesores casi exclusivamente de la misma diócesis.

Era muy habitual que los profesores empezasen su cursus honorum académico por las llamadas cátedras menores y progresaran hacia las de Prima, mejor remuneradas. La de Instituta, de lectura bienal, fue, en muchas

46 Una buena base de datos la proporciona E. Ribera, "Figuras del Estudio General de Lérida en el Archivo Parroquial de San Juan Bautista”, en AAVV, Miscelanea de Trabajos sobre el Estudio General de Lérida, Lleida, Institut d'Estudis Ilerdencs, I, 1949, pp. 65-120.

47 Resulta fundamental la obra de A. Passola Tejedor, Oligarquia i poder a la Lleida dels Austria: una elit municipal catalana en la formació de l'estat modern, Lleida, Pagès, 1997. 
ocasiones, el punto de arranque de la carrera académica. Las cátedras de Prima y de Vísperas dictaban las materias más enjundiosas. En Leyes, los catedráticos de Prima y Vísperas se repartían la lectura del Digesto (Nuevo, Viejo e Inforciado). La segunda cátedra de Leyes estaba destinada fundamentalmente a la exégesis del Código. En cuanto al derecho canónico, en las cátedras de Prima y Vísperas se leían las Decretales y el libro Sexto, mientras que la segunda cátedra estaba específicamente destinada al Decreto de Graciano.

Los profesores desempeñaban un papel fundamental en la vida de la ciudad, no sólo en su actividad docente, sino también como consejeros en múltiples facetas. Por ejemplo, los catedráticos de Prima de Leyes y Cánones tenían que examinar a los candidatos que aspirasen al cargo de notario ${ }^{48}$.

La vida universitaria anduvo muy inquieta durante estos primeros años del siglo XVII, en los que las injerencias del Maestrescuela en las competencias del Rector y los claustros dieron lugar a diversos altercados ${ }^{49}$. Lérida, más incluso que otras ciudades universitarias, fue pródiga en conflictos entre estudiantes, especialmente de Leyes y Cánones ${ }^{50}$.

Resulta descorazonador que haya tan poca información sobre una Facultad tan compleja y que se hayan perdido los expedientes de oposición y los libros de grados. Intentaremos aquí una reconstucción de la nómina de catedráticos, de los cuales indicaremos también -hasta donde conocemos- sus actividades paralelas como abogados, síndicos, paheres o si fueron insaculados para algún otro cargo representativo. Excluiremos a los lectores de las catedrillas, de carácter más bien circunstancial, y nos centraremos en las siete cátedras ya citadas (Prima, Segunda y Tercia, de leyes y de cánones, y la de Instituta).

Podemos reconstruir buena parte del profesorado de finales del siglo XVI gracias a los datos que aparecen diferentes documentos sueltos, fruto de la

48 R. Gras de Esteva, La Paheria de Lérida..., p. 81.

49 Asimismo, durante estas fechas los juristas de la Universidad promovieron diferentes concordias con los acreedores de las rentas del Estudio Ilerdense para promover y facilitar su sostén económico: ACA, Cancillería, Ms. 4893, ff. 241-242v y ACA, Cancillería, Ms. 4894, ff. 82r-v, sobre la concordia de la Universidad con el Arcipreste de Ager.

50 La serie de los Llibres de crims, conservada en el AML, aporta mucha información al respecto. Buena parte de esa documentación ha llegado en mal estado y es de difícil consulta. Con todo, se trata de un conjunto de fuentes imprescindible para seguir trabajando. El estudio de R. Gort Riera, L'Estudi General de Lleida al segle XIV, Lleida, Edicions de la Universitat de Lleida, 2016, se basa, esencialmente, en esta serie. 
investigación en diversos archivos, que se unen a los proporcionados por Lladonosa y Esteve Perendreu ${ }^{51}$. Hay que constatar que en muchos memoriales presentados para ejercer cargos en la administración se indica, muchas veces, con poca precisión, que los interesados desempeñaron alguna cátedra en Lérida. Hay que recordar que, hasta que la Universidad de Barcelona empezó a colacionar con frecuencia los grados mayores, una parte importante de los Doctores en Leyes o Cánones provenían del Estudio ilerdense.

\subsection{Los comienzos del siglo XVIII}

Juan Francisco de Gracia, aragonés, Bachiller en Derechos y catedrático de Cánones fue elegido Rector del Estudio en ${ }^{1598^{52}}$. Hay autores que incluyen en esta época al canónigo Gaspar Fabrici de Vallbona i de Mediona entre los profesores de Leyes. Residente en Roma, era "un dels professors de dret més egregis de l'Estudi General; residí molts anys a la cúria romana ${ }^{53}$ ". En aquellas fechas también era catedrático en Lérida José de Sesse i Piñol, quien después fue Lugarteniente del Justicia de Aragón, Consejero del Senado Real del Reino, Consultor del Santo Oficio y Regente de la Real Cancillería de Aragón ${ }^{54}$. Dejó varios libros publicados entre los que destacan las Decisiones sacri senatus regii regni Aragonum et curiae Domini justitiae Aragonum, en varios volúmenes.

Sabemos que en 1593 era catedrático de Vísperas de Cánones el aragonés Juan Izquierdo y Aznar, nacido en Vililla (cerca de Calatayud), en $1562^{55}$. En 1598 aún figuraba como catedrático, como Vicario general del Arcedianado de Calatayud, por mandato de Pedro Cerbuna, y como capellán de Su Majestad ${ }^{56}$.

Antonio Carmona, según el memorial que presentó glosando su trayec-

51 F. Esteve Perendreu, Mestrescoles i rectors..., p. 155.

52 Ibidem. Cabe suponer que detentaba una catedrilla.

53 J. J. Piquer i Jover, Abaciologi de Vallbona (1153-1977), Santes Creus, Fundació Roger de Ballfort, 1978, p. 218. Véase también J. Lladonosa i Pujol, Història de Lleida, II, p. 442.

54 V. Blasco de Lanuza, Historias eclesiasticas y seculares de Aragon, desde el año 1556 hasta el de 1618, vol. II, Çaragoça, por Iuan de Lanaia y Quartanet, 1622, p. 559.

55 F. de Latassa y Ortin, Biblioteca nueva de los escritores aragoneses: que florecieron desde el año de 1600 hasta 1640, Vol. 2, Pamplona, Joaquín Domingo, 1799, p. 369.

56 M. Martínez del Villar, Tratado del Patronado, antiguedades, gouierno, y varones illustres de la ciudad, y Comunidad de Calatayud, y su Arcedianado, Çaragoça, Lorenço de Robles, 1598, aprobación. 
toria ${ }^{57}$, leyó una cátedra en la Universidad ilerdense, años antes de ser escogido Canciller, en sustitución del Dr. Jaume d'Agullana ${ }^{58}$. Este personaje, según indica Miguel Ángel Martínez, fue Vicario General de Barcelona y de Valencia ${ }^{59}$. El arzobispo Aliaga, en febrero de 1613, nombró comisario de un proceso de beatificación a "Antonio Carmona, presbítero, doctor en ambos derechos y abad electo de la abadía de San Pedro de Rodes de la diócesis de Gerona ${ }^{60}$. En efecto, tenemos constancia de que Carmona fue Abad desde 1614 hasta $1615^{61}$.

Asimismo, en un manuscrito ${ }^{62}$ se indica que Josep Simó, tiempo después canónigo y Vicario general del cardenal Spinola en Tortosa, había desempeñado una cátedra de derecho en Lérida, sin que podamos precisar los años.

Los últimos años del reinado de Felipe II fueron convulsos, pues en 1596, el Procurador fiscal inició un proceso contra el Rector y el Consejo del Estudio de Lérida ${ }^{63}$, sobre la escribanía, cuestión polémica, como veremos después. El Monarca escribió al Duque de Maqueda en noviembre de dicho año, para insistir en que debían aplicarse sin demora todas las reformas de Antonio Agustín ${ }^{64}$.

En las Cortes de 1599, Felipe III, favoreciendo la permanencia de los estudiosos del derecho en Lérida, y favoreciendo a sus egresados, decidió:

"que tots los Doctors y Batchillers que passats sis anys se detendran en la Vniversitat del studi general de Leyda llegint en aquella, o pretenent cathedra, o exercitantse en llur facultat continuant los studis sian vists praticar en la real Audientia, aixi com los qui pratican en aquella, y manarem tenir compte en les persones que en dita Vniuersitat residiran exercitantse en llur facultat quant se offeriran prouisions de llochs del real Consell, e altres officis, per animar aquells en continuar sos studis ${ }^{65}$ ".

57 M. A. Martínez Rodríguez, Felip IV i Catalunya, Lleida, Pagès, 2013, p. 25.

58 J. H. Elliott, La revolta catalana, 1598-1640: Un estudi sobre la decadència d'Espanya, [1963], València, Universitat de València, p. 564.

59 M. A. Martínez Rodríguez, Felip IV i Catalunya, p. 25.

60 A. Felipo Orts, "La actitud institucional ante el proceso de beatificación de Francisco Jerónimo Simón durante el siglo XVII”, Estudis: Revista de historia moderna, 23 (1997), pp. 117-148. La cita está en la p. 119.

61 E. Zaragoza Pascual, Catàleg dels monestirs catalans, Montserrat, Abadia de Montserrat, 1997, p. 194.

62 ACA, Consejo de Aragón, leg. 271, n. 46.

63 ACA, Real Patrimonio, Procesos, 1596, n. 1.

64 ACA, Consejo de Aragón, leg. 264, n. 72.

65 Constitutions fetes per la S.C.R. Magestat del Rey Don Phelip Segon, Barcelona, en casa de Gabriel Graels y Giraldo Dotil, 1603, p. 11. 
En 1599, el catedrático de Prima de Cánones era el aragonés Felipe Gaço ${ }^{66}$ (o Gazo), el de Segunda, Joan Guillem Ivars y el de Tercia, Jeroni Biosca. En Leyes, el catedrático de Prima era Nicolau Freixenet, el de Segunda, Joan Soler y el de Tercia, Josep Sabata. Ocupaba asimismo otra cátedra Francesc Bafart i Farrús, ciudadano honrado, insaculado como Oidor real ${ }^{67}$. Sabemos que en 1600 se habían preparado $237 £$ de buena moneda para pagar a los catedráticos y $30 £$ para la composición de la bula del Estudio ${ }^{68}$. En 1600, tenemos constancia de que Domènec Miravet i Balaguer, Rector de la Universidad, era Bachiller en cánones y profesor ordinario ${ }^{69}$.

A la sazón, el maestrescuela mandó fijar en el Aula de Cánones unos edictos que prohibían los torneos y otros actos festivos, porque resultaban una distracción a los estudiantes y un dispendio para los padres. Fijó pena de excomunión a los que transgrediesen esta norma. El catedrático Joan Guillem Ivars (fallecido en $1606^{\circ}$ ) fue consultado por el Rector acerca de si el Maestrescuela podía llevar a cabo legalmente tal actuación. El Rector decidió romper los edictos, y fue excomulgado, por lo que se iniciaron unos años de convivencia muy difícil hasta la concordia de 1605, que dibujó con mayor precisión las competencias del Rector y del Maestrescuela. Esta concordia fue firmada por el maestrescuela Anton Gallart y el rector Pau Pocorull, con la presencia de Pere Pineda, Bachiller en Derechos y catedrático ordinario ${ }^{71}$.

Una parte importante del profesorado (por ejemplo, de los citados, Freixenet y Bafart) procedía del Colegio de la Asunción ${ }^{72}$, que -como es sabidoacogía a muchos estudiantes de Leyes y de Cánones. Freixenet fue promovido a una plaza a la Real Audiencia en $1599^{73}$ por el ascenso del Dr. Joan de Sabater al cargo de Regente de la Cancillería ${ }^{74}$. Freixenet, que había sido síndico de Lérida $^{75}$, insaculado para el cargo de Oidor real ${ }^{76}$, murió en 1601 y su cátedra

66 V. Blasco de Lanuza, Historias Ecclesiasticas, vol. I, p. 229.

67 E. Serra i Puig, Els Llibres de l'Ànima, II, p. 40.

68 ACL, P7_M2_P3_Co6, Llibre del Studi, s. f.

69 F. Esteve Perendreu, Mestrescoles i rectors..., p. 43.

70 E. Ribera, "Figuras del Estudio General...", p. 69.

71 F. Esteve Perendreu, Mestrescoles i rectors..., pp. 43-44.

72 F. Esteve Perendreu, El Col-legi universitari de l'Assumpció..., pp. 58-59.

73 M. A. Martínez Rodríguez, "Els assessors del governador de Catalunya als segles XVI i XVII”, Pedralbes, 23 (2003), pp. 98 y 106.

74 ACA, Consejo de Aragón, leg. 225, n. 63.

75 F. J. Morales Roca, Ciudadanos y burgueses honrados..., p. 151.

76 E. Serra i Puig, Els Llibres de l'Ànima..., p. 185. 
pasó ser ocupada por Gaspar de Sagarra. Para esta oposición se planteó un cambio en el sistema de elección de los catedráticos, indicando lo siguiente:

"Segons la experiencia ha amostrat ha mal reheixit fer la dita catreda y la de prima y segona de canones perpetues, per moltes causes y senyaladament, que com les dites catredes se confereyxen a vots dels estudiants, si se inclinen a hu que no sera tant benemerit com un altre lo posaran en la catreda y a aquella obtindra tota la vida sens fer fruyt algu, y sera privat lo estudi que altre benemerit farie, sia cap dels tres anys que dita catreda vacarie la obtenia, y tambe ab confiansa que son perpetues, considerant que nols ne poden llansar, ab facilitat se descuyden de treballar ${ }^{77}$.

El Dr. Gaspar de Sagarra continuó leyendo en la Universidad de Lérida, y sumó veintidós años como profesor en el Estudio. Tras desempeñar otros cargos, en 1629 fue escogido asesor de la Diputación del General ${ }^{8}$.

En 1603, la cátedra de Vísperas la poseía Francesc Monfar i Sorts, que fue también Arcediano de la Catedral de Lérida ${ }^{79}$; y la de Instituta, Francesc Josep Messeguer ${ }^{80}$. En un informe del Obispo a Felipe III, le indicaba al monarca en 1603 que los estudios de derecho estaban en mal estado y que en la provisión de cátedras había muchas corruptelas:

“...En ellas no se leen por cada catedratico cien lecciones en un año y essas no llegaran a media hora cada una, impidiendolo los estudiantes... Quando vienen a probar los cursos los estudiantes, todos son abilitados, aian oido o no lo necessario, porque unos testifican por otros y ellos se avienen, pues, en dar el grado que antiguamente solia ser de tanta authoridad, el de Doctor. En esta Universidad, en Derechos, andan tan floxos que no ay hombre por poco que aia estudiado que no se atreva a graduarse, y assí ha perdido el grado de Doctor de su honor y authoridad. En dar las Cáthedras de Doctores y bachilleres por competencias ay tan grandes abusos y acen offensas de nuestro Señor que sería de muy grande servicio suyo que esto se remediasse... ${ }^{81}$

En realidad, por lo que puede verse en un curso manuscrito conservado

77 ACL, P7_M2_P3_Co6, s.f.

78 DGC, V, p. 288, “...diu sia elegit en assessor un solempne doctor, nomenam al doctor misser Gaspar de Sagarra, cavaller qui ja és estat per residuum en temps atràs un any y mesos assessor; oÿdor de comptes un trienni; 22 anys cathedràtich de prima y vespres en la universitat de Leyda; 14 anys assessor de la governació, y tants anys de pràtiga..."

79 E. Serra i Puig, Els Llibres de l’Ànima..., p. 279. En 1614 fue electo Visitador del General, véase DGC, IV, p. 167.

80 F. Esteve Perendreu, Mestrescoles i rectors..., p. 161.

81 Ibidem, p. 361. 
en la Biblioteca de Catalunya, la enseñanza era la clásica exposición del mos italicus, explicada cada vez en un sentido más laxo, y complementada con algunos ejemplos de la práctica forense catalana. En este curso aparecen las lecciones dictadas por los catedráticos Segarra, Sabata y Freixenet. Este último debía de ser Josep Freixenet, insaculado como Oidor real ${ }^{82}$, quien detentó la cátedra de Vísperas de Leyes hasta su muerte, acaecida en $1618^{83}$. El curso del Dr. Sagarra era una exposición de rúbricas escogidas del Digesto inforciado ${ }^{84}$, mientras que el del Dr. Sabata contenía el comentario a algunas rúbricas del Digesto Viejo ${ }^{85}$.

La fortuna ha hecho que no se perdiese una parte del libro de matrículas en Leyes, desde 1607 hasta $1624^{86}$, que da algunos datos de interés sobre el número de los estudiantes, los maestros y su procedencia. Con ello, puede saberse que los alumnos matriculados eran más bien pocos: unos cuarenta cada año, una cifra que progresivamente se redujo en beneficio de la Universidad de Huesca y de la pujante Facultad de la Universidad de Barcelona ${ }^{87}$, que tuvo un crecimiento sostenido desde los primeros lustros del siglo XVII hasta la Guerra dels Segadors.

En la Facultad, tal y como consta en diferentes documentos, había durante aquellos años mucha violencia y el maestrescuela quería excomulgar a quienes tuviesen armas y pedernales, un tema que llegó hasta la Diputación del General $^{88}$. De hecho, el 20 de septiembre de 1608 el Rector del Estudio, Ma-

82 E. Serra i Puig, Els Llibres de l'Ànima..., p. 185.

83 F. Esteve Perendreu, Mestrescoles i rectors..., p. 182.

84 BC, Ms. 3497, ff. 1r-181v.

85 BC, Ms. 3497, ff. 182r-277r.

86 A. Hernández Palmés, "Matriculatio legistarum Universitaris Generalis Studii Ilerdensis (1607-1624)”, en AAVV, Miscelánea de Trabajos sobre el Estudio General de Lérida, vol. II, Lérida, Editora Leridana, 1950, pp. 71-178.

87 Para un análisis de los grados, véase R. Ramis Barceló, "Apuntes sobre los grados en leyes y cánones en la Universidad de Barcelona a comienzos del siglo XVII”, en A. Murillo Villar, A. Calzada González y S. Castán Pérez-Gómez (eds.), Homenaje al Profesor Armando Torrent, Madrid, Dykinson, 2016, pp. 753-763.

88 DGC, III, p. 846. "Aserca del negoci del mestre escuela de Lleyda, avisí als senyors diputats ab carta de 3 de octubre 1603 com dit mestre escuela procuraria que sa Santedat posàs una excomunicació major contra los estudiants de la universitat de Lleyda que aportassen en dita ciutat pedrenyals o altres armes. Y tement jo no fos assò en perjudici de les llibertats de Cathalunya, y per consegüent aguessen vostres senyories de exir a la deffensa d'elles, procurí parlar ab lo prcurador de dit mestre scuela, lo que tenia aquest negoci a càrrech, representant-li com ho havien de sentir en aquest consistori...” 
teu Martí, Doctor en Leyes, murió de un escopetazo. El Vicerrector, Dr. Macià Sabata acudió a Barcelona para exponer el problema ante los diputados del General ${ }^{89}$.

Hay constancia de que en 1608 Jeroni Pastor era profesor de derecho ${ }^{90}$. En 1611 el Dr. Felip Gaço, que había sido catedrático de Vísperas de Leyes en la Universidad de Huesca durante el curso 1589-1590 ${ }^{91}$, había pasado a catedrático de Prima de Cánones en la Universidad de Zaragoza ${ }^{92}$.

En 1611, el catedrático Gaspar Sagarra renunció a la cátedra de Prima de Leyes, sin que conozcamos los motivos. Sabemos, con todo, que el Dr. Sagarra fue nombrado, años después, ya en $1614^{93}$, Asesor del Gobernador de Cataluña ${ }^{94}$. El Virrey, Marqués de Almazán, se arrogó el derecho de nombrar a su sustituto en la cátedra, un hecho que levantó un gran descontento, pues se hacía en contra de los Estatutos de la Universidad. Hubo altercados violentos y el canónigo Paul Josep Oriol, Doctor en Cánones ${ }^{95}$, fue asesinado de un escopetazo el 1 de enero de 1612.

En el momento de retomar las lecturas, hubo un motín estudiantil, que impidió el comienzo de las clases. El Dr. Montfar fue el comisionado para suplicar al Virrey que celebrasen las oposiciones de la forma prescrita ${ }^{96}$. La situación en la Universidad (reflejo, por otra parte, de lo que sucedía en la

89 DGC, III, p. 606. "Lo doctor Mathià Sabata, vice-rector de la universitat de Leyda en dies passats amb embaxada per part de dita universitat representa als deputats del present Principat com per la unió de la ciutat de Leyda fou mort lo doctor Matheu Martí, rector de dita universitat, que anava per a repetir uns studiants presos per dita unió, y explica en dita embaxada lo sentiment tenia de un cas tant atrós, y lo quant convenia per la quietut d'ella y de la dita ciutat, fossen castigats los culpables. Y axí considerant los deputats la gravetat del dit cas y molts altres perpetrats per los de la unió, han determinat que de sa part vinguessen a supplicar a vostra excel-lència extrajudicialment los faça mercè de manar ab la prestesa possible castigar dit cas y altres excessos comesos per los de la unió”.

90 F. Esteve Perendreu, Mestrescoles i rectors..., p. 96, n. 280.

91 A. Durán Gudiol, "Notas para la historia de la Universidad de Huesca”, p. 151.

92 I. de Camón y Tramullas, Memorias Literarias de Zaragoza, II, en Zaragoza, Imprenta de Francisco Moreno, 1768, p. 114.

93 M. A. Martínez Rodríguez, "Els assessors del governador de Catalunya...”, pp. 99-100.

94 ACA, Cancillería, Ms. 4870, f. 251.

95 R. Ramis Barceló, Doctores hispanos..., pp. 100-101.

96 DGC, IV, p. 48. El Dr. Montfar obtuvo en 1612, por provisión real, el arcedianato de Ribagorza. 
ciudad $^{97}$ ) debía de ser muy tensa, pues hubo de nuevo un motín de los estudiantes, que se quejaban porque no se había provisto la cátedra de Prima de Leyes e incluso, tiempo más tarde, el Rector recibió en un tumulto un escopetazo, del cual quedó herido ${ }^{98}$.

En vista de esta situación, el Rey ordenó al Obispo de Lérida, Francesc Virgili, que visitase y reformase la Universidad. Virgili concluyó su visita y redactó nuevos Estatutos en $1613^{99}$, que fueron aprobados por Felipe III el 20 de diciembre de dicho año ${ }^{100}$. Cabe destacar que en esta reforma se tomaron algunas medidas complementarias, destinadas a reforzar las que había establecido Antonio Agustín. Se dispuso que los catedráticos de Leyes tenían que leer hasta la vigilia de San Juan Bautista, y que después, en las Facultades de Leyes y Cánones, tenían que leer un Doctor y un Bachiller de cada Facultad hasta el 15 de septiembre ${ }^{101}$.

Tenemos datos incompletos sobre el profesorado de esta época. Sabemos que Joan Pau Nin, Rector en 1617-1618, fue profesor de Derecho ${ }^{102}$, y luego Arcediano mayor de la Catedral de Tarragona ${ }^{103}$. Cabe pensar que el sucesor del Dr. Sagarra fue finalmente el Dr. Joan Soler, quien murió en 1617, siendo catedrático de Prima ${ }^{104}$. En 1618, como hemos indicado ya, murió el Dr. Josep Freixenet, que había detentado la cátedra de Vísperas de Leyes. Sabemos que Cristòfol Puigredó ${ }^{105}$ era profesor de Cánones y que Francesc Frígola ${ }^{106}$, Bachiller en Derecho, era catedrático ${ }^{107}$.

El Virrey, Duque de Alburquerque, mandó en 1617 a Montserrat Ramon,

97 Véase J. Lladonosa, Lérida moderna. Epoca de los Austrias, pp. 89-92.

98 F. Esteve Perendreu, Mestrescoles i rectors..., pp. 169-171.

99 ACA, Cancillería, Ms. 4895, ff. 83r-125v.

100 Decreta Regia pro reformatione Universitatis Studii Generalis Illerdae, edita in illius visitatione de anno M.DC.XIII, Apud Ludouicum Manescal, 1614.

101 F. Esteve Perendreu, El Régimen jurídico..., p. 202.

102 F. Esteve Perendreu, Mestrescoles i rectors..., pp. 179-181.

103 S. Capdevila, "La Seu de Tarragona", Analecta Sacra Tarraconensia, 10 (1934), p. 148.

104 E. Ribera, "Figuras del Estudio General...", p. 70.

105 Un personaje homónimo figura como Abad de la canónica del Castillo de Cardona (1617-1646).Véase E. Zaragoza Pascual, Catàleg dels monestirs catalans, p. 66.

106 Francesc Frigola i de Lordat, presbítero, se mantuvo fiel a Felipe IV en la Guerra dels Segadors y fue luego agente y síndico en Roma. Véase D. Carrió-Invernizzi, "Los catalanes en Roma y la iglesia de Santa María de Montserrat (1640-1670)", Pedralbes, 28 (2008), p. 582.

107 F. Esteve Perendreu, Mestrescoles i rectors..., p. 179, n. 577. 
Magistrado de la Real Audiencia, para que cortara los abusos en las provisiones de las cátedras y pusiese orden en los desmanes estudiantiles ${ }^{108}$. Al parecer, la situación económica era asimismo muy precaria y el Síndico Fr. Juan de Mur ${ }^{109}$ pidió al Rey, en nombre de la Universidad, que "por ser muy cortas las rentas della y salarios de los cathedraticos padecen mucha necesidad $y$ no pueden acudir a sus obligaciones" intercediese ante el Papa para que éste uniera a sus rentas las de las rectorías rurales que había en el obispado de Lérida y en el de Urgel ${ }^{110}$.

Por una alegación tenemos constancia que en 1619 se produjo una disputa $^{111}$ de Francesc Agramunt, catedrático de Prima contra Joaquim Frigola i de Lordat, canónigo de la Catedral ${ }^{112}$. Constatamos la presencia, en estos años, del Dr. Jacint Salavert, que Gayá Massot cuenta entre los catedráticos de Derecho canónico en $1616^{113}$. Al parecer, dicho Salavert era un noble francés afincado en Lérida, para quien se solicitó un privilegio militar en $1624^{114} \mathrm{y}$ del que no tenemos más noticias.

El 22 de junio de 1622 murió Francesc Josep Messeguer, catedrático de Segunda de Leyes ${ }^{115}$. En 1623, el catedrático de Prima de Cánones era Francesc Agramunt, mientras que Francesc Farro, presbítero, se desempeñaba como catedrático de Decretos, y Joan Baptista Pollina era el catedrático de Tercera de Cánones. Josep Sabata, insaculado para diversos cargos ${ }^{116}$, era el catedrático de Prima de Leyes; Francesc Freixenet, el de Segunda; Gaspar Sabadia, el de Tercera; y Joan Baptista Monjo ${ }^{117}$ detentaba la cátedra de

108 Ibidem, pp. 180-181.

109 Había sido profesor de Leyes en la Universidad de Huesca entre 1568 y 1572. Véase A. Durán Gudiol, "Notas para la historia de la Universidad de Huesca...”, p. 152.

110 ACA, Cancillería, Reg. 4900, ff. 269r-270r. La cita está en el f. $269 \mathrm{v}$.

111 Responsum pro Petro Francisco Agramunt D.D. Cathedratico Primario Canonum Vniversi[tatis] gener[alis] studij Ilerden[sis]: contra oppositionem Ioachimi Frigola, Illerdae, apud Ludouicum Manescal, 1619.

112 E. Serra i Puig, Els Llibres de l'Ànima..., p. 186.

113 R. Gayá Massot, Los Jesuitas en la Universidad de Lérida, pp. 114-115.

114 ACA, Consejo de Aragón, leg. 274, n. 12.

115 E. Ribera, "Figuras del Estudio General...”, p. 71.

116 E. Serra i Puig, Els Llibres de l’Ànima..., p. 380.

117 Ciudadano honrado de Lérida. Siendo Doctor en Artes, se matriculó en Derecho civil. Véase A. Hernández Palmés, "Matriculatio legistarum...”, p. 99. En 1622 solicitó un privilegio de caballero. ACA, Consejo de Aragón, leg. 272, n. 1, en el cual indicaba que algunos de sus familiares ya habían sido profesores de leyes de la Universidad de Lérida. 
Instituta ${ }^{118}$. Francesc Freixenet, Doctor en Derechos, fue insaculado para los cargos de Oidor real y Diputado real ${ }^{119}$. El 31 de mayo de 1623 se enfrentaron para una catedrilla de Leyes Joan Baptista Canet y Joan Baptista Cortiada. Hubo incidentes en las votaciones, intentos de soborno y de retención de un estudiante, aunque al final la cátedra fue para Cortiada $^{120}$. Aparecen también en la documentación los nombres de los doctores Jeroni Canet, Montserrat Castelló, Joan Pau Corbella, Pere Joan Perendreu, Dídac Cisteller y Joan Baptista Canet $^{121}$.

El 19 de junio de 1624, Francesc Rialp, Doctor en Cánones, y Rector de la Universidad $^{122}$, escribió al Virrey quejándose porque no había sido admitido a la oposición de Instituta, por no ser Doctor en Leyes, y alegando que a ella se podían presentar indistintamente los legistas y los canonistas ${ }^{123}$.

El Obispo, Pedro Antón Serra, capturó ese año a Gaspar Monçó, "persona

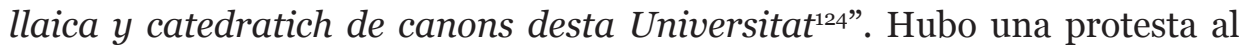
Rey porque la jurisdicción pertenecía al Maestrescuela, quien también fue capturado por el prelado. La Ciudad decidió hacer una embajada para visitar al Obispo y pedirle la liberación del Maestrescuela ${ }^{125}$. En paralelo, el virrey Joan Sentís fue informado de que la cátedra de Instituta se intentó proveer antes del plazo prefijado ${ }^{126}$. Las misivas entre la Ciudad, el Obispo y el Virrey fueron constantes, en tonos a menudo dramáticos.

El 26 de noviembre de 1625 murió el Dr. Agramunt, catedrático de Prima y el 1 de agosto de 1626 lo hizo el Dr. Francesc Farro ${ }^{127}$. Sabemos asimismo que el Dr. Joan Baptista Pollina i Ciurana fue designado Vicario general de Baltasar de Borja ${ }^{128}$, Obispo de Mallorca desde 1625.

En las Cortes de 1626, los doctores Alexandre Calaf i Soldevila y Josep Sa-

118 F. Esteve Perendreu, Mestrescoles i rectors..., p. 186.

119 E. Serra i Puig, Els Llibres de l'Ànima..., p. 185.

120 ACL, P7_M2_P3_Co6, s.f. Véase la explicación del suceso en J. Lladonosa, Anecdotari de l'antiga Universitat de Lleida, Barcelona, Barcino, 1957, pp. 175-182.

121 F. Esteve Perendreu, Mestrescoles i rectors..., p. 189.

122 Ibidem, p. 186.

123 ACA, Cancillería, Reg. 5498, ff. 194v-195r.

124 ACL, P7_M2_P3_Co3, s.f.

125 AHUB, Universidad de Cervera, Caja 57, leg. 3090.

126 AML, Reg. 851, Cartes Reials, s.f.

127 AML, Reg. 851, Cartes Reials, s.f.

128 A. Despuig y Dameto, Vida de la beata Catalina Tomás, Mallorca, Imprenta de Felipe Guasp, 1816, p. 82, n.1. 
bata, Síndicos de la Ciudad de Lérida en Cortes, suplicaron al Rey que mandase publicar una consulta hecha sobre la reforma de la Universidad de Lérida, que estaba en poder de Jaume Mir, Doctor del Real Consejo, y ponerla en ejecución ${ }^{129}$.

También en 1626, el Virrey, tras sostener una copiosa correspondencia con las instituciones y los particulares, dio órdenes para reorganizar las cátedras vacantes, en contra de los Estatutos: la de Prima de Cánones tenía que ser ocupada por el Dr. Joaquim Frígola; la Segunda, por el Dr. Pollina; la Tercera, por el Dr. Joan Perat; y la cátedra de Instituta, por el Dr. Joan Rialp. Perat era un antiguo alumno de la Facultad, matriculado en $1619^{130}$, que antes había leído en las catedrillas y posteriormente fue nombrado canónigo, provisor y Vicario general de Zaragoza ${ }^{131}$. En cuanto a las demás cátedras, el Virrey ordenó que la de Segunda de Leyes la leyese el Dr. Gaspar Sabadia y la de Vísperas el Dr. Joan Baptista Monjo, así como también mandó que "les cathedrillas vacants se proveeescan conforme la regia reformatio ${ }^{132}$ ". Poco sabemos de la actividad docente del Dr. Dídac (Diego) de Cisteller ${ }^{133}$, alumno desde 1618 a $1628^{134}$, quien, en una alegación jurídica, indicó que era Doctor en ambos derechos y que había detentado las cátedras de Instituta y de Decreto $^{135}$, y que pidió infructuosamente la de Prima, como veremos después.

Durante esta época los virreyes tuvieron una fuerte actividad intervencionista en el Estudio y, en particular, en la Facultad de Leyes y Cánones, lo cual generó un gran descontento en el Claustro profesoral y en la Pahería. Miguel Santos de San Pedro, Virrey y Obispo de Solsona, dando solución a las quejas constantes, mandó el 18 de mayo de 1628 que: "la provisio de la cathedra

129 ACA, Consejo de Aragón, leg. 282, n. 48/7.

130 A. Hernández Palmés, “Matriculatio legistarum...”, pp. 154-155.

131 F. de Latassa y Ortin, Biblioteca nueva de los escritores aragoneses, Vol. 2, p. 576.

132 AML, Reg. 851, Cartes Reials, s.f.

133 Ha sido muy conocido por su Memorial, en defensa de la lengua catalana, para que se predique en ella en Cataluña, dedicado a los Muy Illustres Señores Diputados del Principado de Cataluña, padres de la Patria, Tarragona, en casa Gabriel Roberto, 1636.

134 A. Agustí i Farreny, "Els concilis de la Tarraconense. Algunes aportacions a la història de la llengua catalana”, en Miscel-lània Jordi Carbonell, Barcelona, 1993, p. 80.

135 Alegacion en derecho contra el D. Francisco Martí y Viladamor... en justificación de los procedimientos hechos por el muy Illustre, y noble Lugarteniente de Bayle General, y su Consistorio, a peticion del Procurador Fiscal del R. Patrimonio de la B.G., Barcelona, por la Viuda Déu, 1647. 
de Instituta se fassa y haya de fer en doctor legista y no canonista segons la consuetut de tants anys atrás observada ${ }^{136 " . ~ E n ~ n o v i e m b r e ~ d e ~ d i c h o ~ a n ̃ o ~}$ también ordenó que no se representasen comedias mientras hubiese lecturas en la Universidad, a fin de que no hubiese distracciones para los estudiantes ${ }^{137}$.

A punto de empezar el curso, el 17 de octubre de 1627, el Consejo General de la Ciudad se quejó de que los estudiantes, especialmente los de Leyes y Cánones, se marchaban a otras universidades, principalmente a la de Huesca, y resolvió poder remedio a esta situación:

"mes fonch proposat a tots es cosa molt notoria que la Universitat del General Studi de la present Ciutat es una de les mes riques joies y de major stima que aquesta Ciutat haje tingut y pot tenir la qual al dia de vuy esta tan decaiguda y acabada per lo poch concurs de studiants principalment en les facultats de Lleis y Canones, que son les que mes la ilustren y fan flori, que apenes y ha studiants en dites facultats de tal manera que si de prompte no se dona remey sera forsos haverse de deixar de legir los mestres y catedratichs que no tindran quils hoje perque tots se dirigeixen en altres parts y en particular a la Universitat de Guesca la qual al mateix to que aquesta nostra se va destruhint, aquella se va augmentant y florint.... ${ }^{138 "}$

Por desgracia, no poseemos los grados de la Universidad de Lérida, aunque sí los de Huesca, en los que podemos ver un crecimiento sostenido, muy especialmente entre los juristas, tanto legistas como canonistas: si observamos la progresión, constatamos que en la década de 1590-1600 hubo 154 Bachilleres en Cánones y 43 Licenciados, mientras que en la Facultad de Leyes se dieron 42 grados de Bachiller y 11 de Licenciado; en la década de 1600-1610 hubo 99 Bachilleres en Cánones y 28 licenciados; mientras que los Bachilleratos en Leyes ascendieron a 100 y los licenciados a 15; en la década de 1610-1620 fueron 105 los Bachilleres en Cánones y 17 los Licenciados, mientras que los Bachilleres en Leyes eran 106 y los Licenciados eran 15; por último, los Bachilleres en Cánones en la década de 1620-1630 eran 124 y los licenciados 13, al tiempo que los Bachilleres en Leyes eran 123 y los licenciados $24^{139}$. Las quejas, por lo tanto, parecen fundadas, pues la Universidad de Huesca experimentaba un continuo florecimiento.

136 AML, Reg. 851, Cartes Reials, s.f.

137 AML, Reg. 851, Cartes Reials, s.f.

138 AML, Reg. 438, Llibre d'Actes (1622-1628), f. 227.

139 J. M. Lahoz Finestres, "Un estudio sobre los graduados de la Universidad de Huesca”, p. 281. 
Observó Lladonosa que desde 1628 hasta 1639 se realizaron varias reformas edilicias en el Estudio, principalmente, la de desmontar los arcos góticos de las Aulas de Leyes y Cánones, que fueron sustituidas por bigas gruesas que permitían la construcción de dos plantas más, en las que tenían que establecer las Aulas de Medicina, Artes, Teología y Gramática, a las cuales se podría acceder a través de una escalera exterior que comunicaba con el claustro $^{140}$. Por desgracia, estas reformas fueron asoladas por la Guerra dels Segadors.

Una vez indicado lo anterior, sigamos con la evolución de las cátedras de Leyes y Cánones. El Dr. Joaquim de Frígola i de Lordat, canónigo de Tortosa ${ }^{141}$, que se había doctorado en ambos Derechos en Roma el 12 de octubre de $1617^{142}$, obtuvo el 12 de abril de 1630 los dineros para pagar los quindenios de la Universidad ilerdense en Roma ${ }^{143}$. Murió el 20 de junio de ese año y se publicaron edictos para la provisión de la cátedra de Prima que poseía ${ }^{144}$. De inmediato, el Duque de Feria, a la sazón Virrey de Cataluña, ordenó al Rector que no se proveyese la cátedra de Frígola porque antes tenía que hacerse una reforma ${ }^{145}$. Asimismo, el 10 de septiembre de $1631 \mathrm{mu}$ rió Gaspar Sagarra, doncel, que había sido catedrático hasta su renuncia en $1611^{146}$ y luego había sido nombrado Asesor de la Generalitat en $1629^{147}$. En septiembre del año siguiente fallecieron dos catedráticos más: Josep Sabata y Gaspar Sabadia ${ }^{148}$.

En paralelo, la cátedra de Prima de Leyes, que había pertenecido al Dr. Sabata, fue solicitada por el Dr. Diego de Cisteller en un memorial ${ }^{149}$. Cisteller había pedido al Rey, en primer lugar, su nombramiento como asistente del Veguer de la ciudad, cargo que que recayó finalmente en Joan Baptista Bafart. Al recibir la denegación, pidió de nuevo que se le diera la cátedra de Prima, sin necesidad de hacer oposiciones, como "obra de caridad por ser muy po-

\footnotetext{
140 J. Lladonosa i Pujol, Història de Lleida, vol. II, p. 419.

141 F. J. Morales Roca, Próceres habilitados..., p. 98.

142 R. Ramis Barceló, Doctores hispanos..., p. 134.

143 ACL, P7_M2_P3_Co6, s.f.

144 AML, Reg. 851, Cartes Reials, s.f.

145 AML, Reg. 851, Cartes Reials, s.f.

146 F. Esteve Perendreu, Mestrescoles i rectors..., p. 199.

147 DGC, V, p. 288.

148 E. Ribera, "Figuras del Estudio General...”, p. 75.

149 ACA, Consejo de Aragón, leg. 282, n. 48/1.
} 
$b r e^{150}$. Dicha petición fue examinada por las autoridades de la Universidad, que indicaron que las razones eran buenas, "pero no tan grandes que obliguen a V. A. a darle la Cathedra sin opposicion".

Cisteller siguió insistiendo y finalmente fue nombrado en 1646 Abogado fiscal de la Bailía General de Cataluña, en lugar de Francesc Martí i Viladamor, que había sido privado del oficio. Por lo que nos indican los Dietaris de la Generalitat, Cisteller también tenía "provisión de captura ${ }^{151}$ ", aunque ocupó la plaza y fue difamado por Martí y Vilademor, un personaje controvertido, y cada vez más vencido hacia el poder francés. De ahí la alegación que hemos citado antes, que nos informa de estas circunstancias, en la que Cisteller acusaba a Martí de fraude y de deslealtad, en términos muy ásperos ${ }^{152}$. Apuntamos sólo estos datos para dar cuenta de la ejecutoria de este catedrático de la Universidad de Lérida, uno de los más pintorescos y estudiados por la historiografía.

\subsection{Una década convulsa: memoriales y propuestas de reforma}

La compleja relación del Estudio con la Compañía de Jesús se analiza en el capítulo siguiente. Sin embargo, hay que dejar constancia de que en 1629 se creó una cátedra de Teología moral en el Colegio de los jesuitas. Por lo visto, fue muy importante para el enriquecimiento de los estudios jurídicos, pues "como en esta Universidad las sciencias que mas se profesan son Canones y Leyes, havia grande necessidad desta cathedra, porque si bien en la Universidad hay dos de Theologia, leense siempre materias escolasticas y los alumnos se quedavan ayunos en la Moral, que mas han menester ${ }^{153}$ ".

150 ACA, Consejo de Aragón, leg. 282, n. 48/12.

151 DGC, VI, p. 776. "Vuy, antes de migdia, estant ajuntats los senyors consellers per a posar en execució la deliberació feta per vostra senyoria lo dia de aÿr en quant al donar pocessió a micer Diego Cistaller del offici de la Ballia General, en lo qual fonch extret per privació del doctor micer Francisco Martí y Viladamor, és arribat a sa presència Francesch Joseph Fontana, síndich de la present casa, dient que a sa notícia era pervingut que dit senyor Cisteller tenia provisió de captura en la règia cort per mal effecte a sa majestat, que Déu guarde".

152 Esta cuestión se estudia en J. Anton Pelayo y M. Jiménez Sureda, "Francisco Martí i Viladamor: un profrancés durante la guerra dels Segadors”, Manuscrits, 9 (1991), pp. 289-304.

153 Citado en R. Gayá Massot, Los Jesuitas en la Universidad de Lérida, p. 133. 
Tras una visita al Rector y al Mestrescuela de la Universidad ilerdense, el Virrey, Enrique de Aragón y Cardona, se quejaba a Felipe IV de que se hubiesen puesto en funcionamiento otras universidades en la Corona de Aragón, especialmente en Zaragoza y en Valencia, lo cual iba en merma de la calidad de los estudios jurídicos en Lérida. Querían que en estas ciudades "se prohibiesen las Cathedras de Leyes y Canones, reservandoles la de la instituta ${ }^{154}$ " y solicitando una vuelta al estado universitario anterior, de manera que para la Real Audiencia "no se admitan firmas de Doctores que no lo sean por Salamanca o Lerida que con este haura como en tiempos passados personas eminentes en letras de quien V. M. se podra servir". La crítica de este memorial del Virrey a la situación de los estudiantes de Derecho en la Universidad de Lérida no podía ser más dura:

“...los estudiantes de Leyes y Canones, no solo no acuden a la obligacion de sus estudios, pero aprenden a vivir con notable soltura inquietando no solo las escuelas pero toda la Ciudad con su livertad, y lo peor es que sin haver estudiado, ora sea por cudiçia de los graduantes, ora sea por favor de los Padres y deudos se graduan de Doctores, aquí, en gran numero, de manera que ay muchos que solo les sirve de goçar de Privilegio militar, y de entrar con el Gobierno de las casa de la Ciudad y Diputacion, y los que abogan no estan en lo que haçen en gran daño de las partes y esto á llegado á estado, que hoy esta reduçida esta plaça a cinco o seis Abogados, de manera que si se ofreçe haver de proponer y o ternar para las Plaças del serviçio de Vuestra Magestad no quedara abogado que lo sea para el bien de la Republica...155"

Hubo varios memoriales de los visitadores comisionados por el rey para cambiar el funcionamiento de la Universidad, y muy particularmente de los estudios de Leyes y Cánones. Criticaban asismismo el exceso de Universidades. Tiempo atrás, los estudiantes de Leyes y Cánones de Lérida ocupaban, al graduarse, puestos relevantes en la Administración, pero la competencia había limitado mucho su promoción:

"Salieron tan bien estos studios que los serenissimos Reyes sus successores para su gobierno ansi para cargos majores y menores en Audientias y otro officios se han valido de los sujettos que se crian en aquellos studios y han sido de exemplar doctrina.

Esto se ha continuado hasta haora en las demas plaças que se occupan en los Consejos de su Majestad en las Audiencias de la Corona son hijos y han studiado en dicha Universidad hase venido a menoscabar esto en dos cosas, la una porque el Maestre esquelas que

154 ACA, Consejo de Aragón, leg. 282, n. 48/4.

155 ACA, Consejo de Aragón, leg. 282, n. 48/4. 
hauia de animar a los studiantes, desde que ha entrado el Canonigo Pastor por su mucho interesse, poco cuydado y mal exemplo, ha sido causa de que no van studiantes.

La otra ha sido porque en Valencia, Çaragoça y Barcelona se han puestos studios a donde por la comodidad de no salir de sus casas studian en dichas Universidades, pero como en estas Ciudades ay tantos entretenimientos ni se studia ni se haçe cosa buena ${ }^{156 ”}$.

A la sazón, la estructura de la Facultad era la siguiente: el catedrático de Prima de Cánones era el Dr. Pollina; el de Segunda, el Dr. Perat; el de Prima de Leyes era el Dr. Joan Baptista Monjo y el de Segunda el Dr. Francesc de Sagarra. Las acusaciones contra la ligereza de los profesores y los examinadores eran muy claras, aunque ni el Estudio ni Pahería parecían muy interesados en revertir la situación. Al parecer, al conceder los grados, no se hacía votando las calidades, tal y como estaba preceptuado, sino que se daba una calificación genérica:

"En quanto a los grados de los dotores de leyes y canones ay grandes faltas en no guardarse con puntualidad la regia Reformacion del obispo don Francisco Virgilio que dispone en el titulo de collegio doctorum que si se hallara tener el graduador sinco havas negras se le quite el Primer Et y si se hallaren siete se le quete la otra Et. Si passa de siete se le de en el grado tan solamente (Creamus te doctorem sin los Et) lo qual antiguamente se acostumbrava hasiendo differentias de grados pero ahora todos salen con el grado comun aunque tengan muchas havas negras y para que se animen a studiar conviene se mande se observe este Capitulo con mucho rigor.

Tambien en el Collegio de los letrados el primer apunctuante gasta mas de media hora o tres quartos letendo sobre la licion de que ha leido el graduante lo que mas sirve para susttentation que para examen del que se gradua y al fin puestas algunas difficultades no quieren que responda a ellas lo que resulta en no poderse conocer bien la erudition del doctorando ni del que preside y assi le auria de quitar del todo este grado abuso guardandose lo que dispone sobre dicha regia reformatio en el mismo titulo empeçando donde luego con argumentos graves y prosiguiendolos.

Seria muy conveniente que los grados de Bachiller y Dotor se hagan dentro el claustro de la Universidad por ser auto de ella proprio y lo que se paga oy por el lugar del Capitulo de dicha Ciudad se de al arca de la universidad de lo qual se obtuvo la prouilegio siendo visorey el maestre de Montesa.

Que caso que el numero de legistas y canonistas se redusga a un numero menor de los que ay en dicha Ciudad no sean excluidos de este numero los Catredaticos aunque no lean de los mas Antiguos antes bien estos hande ser los primeros en dicho numero porque estos tratan las cosas scolasticas y lecturas y assi son mas abtos y tiene mas disposition para ser apuntuantes presidir y arguir ${ }^{157}$.

156 ACA, Consejo de Aragón, leg. 282, n. 48/5.

157 ACA, Consejo de Aragón, leg. 282, n. 48/7. 
La situación de los estudios, sin duda, debía de ser muy laxa. El Consejo General de la Universidad, para evitar el fraude, exigió en 1636 que, para que los alumnos de Leyes y Cánones tuviesen la aprobación del curso, tenían que entregar sus códices a fin de que el Rector y los profesores los pudiesen examinar detenidamente y comprobar que, como rezaban los Estatutos, "se audivisse lectiones et scripsisse materias manu propia in qualibet lectione vel maiore illarum parte ${ }^{15}$ ".

En el memorial que hemos indicado antes, se dice también que "para que los catredaticos attiendan solo a leer y studiar lo que no pueden haser ahora por la tenuidad de los salarios se ha de servir su Magistad le augmente los salarios de las catedras de leyes y canones...159".

Y, en una acusación velada al estado del Colegio de la Asunción, aconsejaba asimismo a Felipe IV que estableciese

“...un collegio en dicha universidad para que de todas las veguerias de Cataluña según la tacha que se hora entre en el los quales Collegiales ajan de de continuar sus studios de leyes y canones en dichas universidad dies años continuos sin poder salir del dicho collegio sino con licencia del Retor en causa justa [...] con esto dandoles nominationes de sus lugares respective a las veguerias según la forma aparecen a la Corte saldran hombres doctissimos y gravissimos de dicho collegio ${ }^{160 "}$.

Con respecto al Maestrescuela y a su jurisdicción, había no pocas críticas, por la falta de tacto y los problemas que ocasionaba. El memorial decía:

"Que sera muy acertado que para maestre scuela se elija persona de letras y otras buenas partes que ame y stime los studiantes visite por su persona los comunes de ellos les aha leer en puntos delante su presntia sea cabeça de la Congregation de ellos animandoles a toda virtud y que en ninguna manera sean castigados en la bolsa sino en pena corporal y con benignidad como de Padre a hijos y lo que huuieren de pagar por entrar en la prision sea muy poco y tassado porque ha echado a perder esta uniuersidad haserles pagar compositiones y los salarios de los officiales del maestre scuela y assi se han ido a otros studios ${ }^{161}$ ".

En dicho memorial también se hicieron algunas precisiones acerca del oficio del Vicerrector ${ }^{162}$, que vale la pena reproducir aquí:

158 F. Esteve Perendreu, Mestrescoles i rectors..., p. 203.

159 ACA, Consejo de Aragón, leg. 282, n. 48/7.

160 ACA, Consejo de Aragón, leg. 282, n. 48/7.

161 ACA, Consejo de Aragón, leg. 282, n. 48/7.

162 F. Esteve Perendreu, El régimen jurídico, pp. 116-117. 
"Que lo mismo haga el Retor en la prouision de viceretor ordinario el qual deuia nombrar dentro de un mes como es costumbre porque en esto suele hauer grande daño de dadiuas y dineros y que tenga de aprouarle el concejo con scrutinio y tenga las mismas prerogatiyas que le dan los statutos.

Que no pueda nombrar vicerretor para tres dias porque de ordinario se base por segundas intentiones y nunca faltara retor o viceretor ordinario o cathedratico mas Antiguo.

Que faltando el vicerretor ordinario desde el principio de esta universidad ha sido vicerretor el catredatico mas Antigo como consta en el statuto 14. Titulo de officio rectoris y en el statuto 3 titulo de officio vicerretoris y esta muy puesto en rason el ser vicerrector el mas Antiguo como en otras universidades es el Decano por tener mas notitia de las cosas de la Universidad ${ }^{163 "}$.

El síndico de la Universidad, responsable de la gestión de los negocios del Estudio $^{164}$, informaba al Rey de que era importante que vigilase los juegos de los estudiantes y que los amonestase cuando fuera necesario:

"Conviene tambien mucho que ningunos dias de licion aunque sean horas extraordinarias y que no se lee no jueguen los studiantes a pelota de que ay grande abuso y assi cansados o, no van a oir, o ojen de muy mala gana y no pueden studiar al tiempo de la Candela y para esto se ordene al aguasil los amoneste y la segunda vez los ponga en la Carcel sino obedecieron y ni mas y menos si a las horas de la licion anduuieren diuagando por la Ciudad y no assistieren en la Scuela y no stuvieren recogidos por las noches a las horas que los statutos dispone $\mathrm{e}^{165}$.

Asimismo, a fin de evitar los abusos y los sobornos en la provisión de las cátedras, el memorial indicaba lo siguiente:

"En lo que toca a la prouision de las Catredas de aquella Uniuersidad es immemorial el proveerse por votos de los studiantes en todas las regias reformationes del obispo Puig don Antonio Agustin don Francisco Virgilio se ha echado de ver ser esto mas conveniente porque casi siempre sucede proveherse los mas abiles y quando no lo sean se animan studiando los pretendientes y de ordinario studian mucho mas para poder pretender Catredas lo que no hasen se sabe que por mano superior se han de Proveher y tienen esto los studiantes tan en el alma y coraçon que les parece quitarles todo su ser porque assi sin stimados de sus maestros y les scuchan en el porte y les ojen y responden y entre si tienen mas amistad y correspondentia lo que no hasen si saben que no han de ser votos para sus Catedras y assi la experientia ha mostrado que en nuestra Universidad no han querido oir los Catredaticos proueidos por los señores de la junta que mando haser su Magestad antes

163 ACA, Consejo de Aragón, leg. 282, n. 48/7.

164 F. Esteve Perendreu, El régimen jurídico, pp. 130-131.

165 ACA, Consejo de Aragón, leg. 282, n. 48/7. 
bien les han inquietado quitandoles las scaleras de los pulpitos sin bastar a refrenarles ni remediarlos el Retor ni el maestre scuelas y el dar las Catredas los dotores en cada facultad a mas que no se quitan los inconuenientes dichos se siguen otros peores porque [...] seran pocos y de la tierra stando subornados lleuara las catredas los que tendra mas parientes en la Ciudad.

El modo de votar se podria haser para huir inconvenientes que se habilitassen los votos despues de las liciones de puntos juntandose los abilitadores sacados a suerte en la forma que dispone la Regia Reformation de don Francisco Virgilio y que allo habiliten sin salir de la aula porque habilitando antes quedan los votos y los opositores tan libres y sueltos que sin ningun empacho y publicamente gastan en comidas y beuidas dandoles facultad que tomen de las tiendas confituras y otras cosas que antes de votar se promulgue sententia de excomunication para los que antes huuieren recebido algo de los oppositores o per interpuestas personas y que assi mismo el uicerector y alguasil reconoscan los studiantes entre tanto que se vota o se hase dicha habilitation traen a dicha aula de canones comidas y beuidas a effecto de subornar y finalmente que el juramento que hasen antes de votar expressamente se ponga que no han recibido dineros ni otras cosas de los oppositores no de otro por ellos ${ }^{166 "}$.

Los profesores eran un colectivo privilegiado, si bien en muchas ocasiones no ponía suficiente interés en su labor. De ahí que en el Memorial se recomendase que:

“Tambien conuiene que cada Catredatico respectivamente tenga Conclusiones de las materias que va leyendo el sabado siguiente aunque sea de fiesta o feriado y que assistan los dotores de dicha facultad y argujan tres o quatro studiantes segun el tiempo assistiendo en ellas el catredatico mas Antigo como presidente sin que le pague por ellas al retor uedeles ni dotores cosa alguna antes bien los dotores que faltare de dicha professio que no esten justamente impedidos paguen cada ves sinco Reales pero non se dexe de leer por la mañana de dicho dia ni tampoco el jueves que suele ser feriado y se quiten muchas ferias que ay en los Cursos ${ }^{167}$.

Recomendaba también el memorial que si el Rey quería que no hubiese ninguna cátedra de propiedad, parecía que los doctores que hubiesen leído por espacio de veinte años interpoladamente o dieciséis continuamente (que estaban sirviendo en la Universidad con esa buena fe) deberían recibir la recompensa de estar inmunes a cualquier concurso y competencias de cáte$\operatorname{dras}^{168}$. El memorial indicaba asimismo que "se pueda opponer un bachiller

166 ACA, Consejo de Aragón, leg. 282, n. 48/7.

167 ACA, Consejo de Aragón, leg. 282, n. 48/7.

168 ACA, Consejo de Aragón, leg. 282, n. 48/7. 
a catreda dotoral prestada caution que dentro de quatro meses se graduara de dotor si lleva la catreda como Antiguamente se hacia y esta puesto en razon porque con este se animaran los studiantes ${ }^{169}$ ".

Pese a los buenos consejos, nada se hizo al respecto, aunque desde la Corte, eludiendo los problemas, se pidió el 31 de octubre de 1633 a los Paheres que "façon lo esforç possible en que los dits cathedratichs tingan satisfaccio de sos salaris, procurant alentar y animarlos, per a que ab lo degut fervor continuen ses lectures com sempre se ha acostumat ${ }^{170 "}$.

El 15 de abril de 1632 se había ordenado el sobreseimiento de la provisión de las cátedras doctorales ${ }^{171}$. En aquel momento, el catedrático de Vísperas de Leyes era Onofre Anglesill, que a la sazón cobraba las rentas de los legados píos inciertos ${ }^{172}$. En enero de 1632, el Deán de la Catedral se dirigió al Virrey para quejarse de que el Rector impedía la lectura del Dr. Martín de Ripalta, catedrático de Leyes, por “ciertos intereses particulares”. El Deán le indicaba que el Dr. Ripalta hacía ocho años que leía Leyes y que sustentaba todos los actos públicos de conclusiones, de modo que la decisión del Rector resultaba muy perjudicial para los estudiantes ${ }^{173}$. Sabemos también que Joan Baptista Maranyosa i Toló, Doctor en Derecho y catedrático del Estudio General, ostentaba el cargo de Oficial general del obispo en 1633 y que falleció en $1634^{174}$.

El Consejo General de la Universidad aprobó el 15 de marzo de 1636 un nuevo estatuto sobre la forma de aprobar los cursos de Leyes y Cánones: tenían que examinar los códices de los estudiantes y así,

"Rector et Cathedratici penes se remanere codices scholarium ob evitandam fraudem hactenus inventam, quod uni aliis codices comodabant, et ultra praedicta Doctores et Bacalaurei Cathedratici voveant per fabas albas et nigras an sic cursus tali scholari probandus, et si apareat, maiorem partem votorum habere, scribatur talis scholaris per notarium Universitatis in libro probationum cursum in praesentia praedictorum... ${ }^{175}$ "

El 27 de enero de 1637 murió el Dr. Pollina ${ }^{176}$, quien debió de ser reem-

169 ACA, Consejo de Aragón, leg. 282, n. 48/7.

170 AML, Reg. 851, Cartes Reials, s.f.

171 AML, Reg. 851, Cartes Reials, s.f.

172 ACL, P7_M2_P3_Co6, s.f.

173 F. Esteve Perendreu, Mestrescoles i rectors..., p. 199-200.

174 Ibidem, p. 201.

175 AML, Llibre de l'Estudi, f. 106v.

176 E. Ribera, "Figuras del Estudio General...", p. 76. 
plazado en la cátedra de Prima de Cánones por el Dr. Francesc Perandreu. El Virrey, Duque de Cardona y de Segorbe, mandó que se leyesen las lecciones de dicha cátedra durante el tiempo que tardase en votarse la cátedra por parte de los estudiantes ${ }^{177}$. La cátedra de Segunda de Leyes debió de ser ocupada por Onofre Anglasill, insaculado como Oidor real ${ }^{178}$, aunque la información de esta época es muy dispersa. Los Dietarios de la Generalitat nos informan de que Anglesill fue votado y elegido Doctor del Real Consejo en 1641, en sustitución de micer Codina ${ }^{179}$.

En diciembre de 1639 figuraba como catedrático de Vísperas Mateu de Monbilia i Pauls, colegial de la Asunción, por renuncia de Miguel de Aroztegui, también colegial, quien pasaba a ser Rector del Estudio (1639-1640) ${ }^{180}$. Sabemos que Llorenç Espígol y Pau Escolà, Bachilleres en Cánones y colegiales de La Asunción, detentaban sendas catedrillas en $1640^{181}$.

\subsection{La Guerra dels Segadors}

El conflicto que se desencadenó durante la Guerra dels Segadors acabó desestructurando aún más el frágil equilibrio de poderes de la Universidad. Se ha conservado parte de la tensa correspondencia mantenida entre los Paheres, el Estudio General y el Virrey Santa Coloma. En 1638, los Paheres escribían al Virrey describiendo los incidentes escolares, riñas y escopetazos en un ambiente cada vez más violento ${ }^{182}$. Y el Maestrescuela, Jaume Magre, denunció en julio varios desórdenes entre profesores y estudiantes en la provisión de cátedras ${ }^{183}$.

177 AML, Reg. 851, Cartes Reials, s.f.

178 E. Serra i Puig, Els Llibres de l'Ànima..., p. 567.

179 DGC, V, p. 1188, “...fonch anomenat lo doctor micer Onoffre Anglasill, Doctor en drets de la ciutat de Balaguer, lo qual ha molts anys és cathedràtich de la ciutat de Leyda, en lo qual concorren letras y parts per occupar aqueix y majors puestos, y que lo senyor deputat real ha referit que tot lo temps que ha estat en la ciutat de Leyda li ha sempre assistit en auditor general y és estat molt gran part de la quiettut de aquella ciutat y frontera y que sa senyoria fos servit votar-lo y honrar-lo en dit càrrech, lo qual encontinent fonch votat per escrutini; y acabat de votar fonch trobat hàbil per a occupar dit càrrech de altre dels magnífichs doctors de la província micer Onoffre Anglasil de la ciutat de Leyda”.

$180 \quad$ F. Esteve Perendreu, El Col-legi universitari de l'Assumpció..., p. 62.

181 Ibidem.

182 ACA, Generalitat, Correspondencia del virrey Conde de Santa Coloma, carta n. 1224, s.f.

183 ACA, Consejo de Aragón, leg. 281, n. 96. 
Debido al fallecimiento del Obispo de Vic ${ }^{184}$, el día 22 de noviembre de 1638 el rey comisionó al Obispo de Urgel para la reforma de la Universidad ${ }^{185}$, con muchas consecuencias para la vida universitaria. Según Pau Duran, Obispo de Urgel, las cátedras de Prima tenían que ser perpetuas y también tenían que serlo las cátedras de Facultades mayores en propiedad que hubiesen sido leídas por doce años consecutivos o interpolados por el mismo profesor. Ordenó asimismo que las demás cátedras se proveyesen cada tres años, con la excepción de la de Instituta, que debía hacerse cada dos y que se tenía que instaurar también una cátedra de Sexto (que al final de no se creó). En cuanto a la votación, no podía ser directa, y tenía que hacerse por “calidades", es decir, por voto ponderado dependiendo de los años de estudio y los grados de los electores ${ }^{186}$.

Ese año el Rector y el Consejo de la Universidad solicitaron la provisión de las cátedras y aún en abril de 1640 no se habían designado ${ }^{187}$. Todo ello obedecía a un grave conflicto con la actuación de Pau Duran, quien, con el cargo de visitador del Estudio, paralizó las oposiciones ${ }^{188}$ e hizo capturar al catedrático de Prima de Cánones, Dr. Francesc de Sagarra. Como éste se escondiera y no quisiera comparecer, el Obispo mandó que leyese en la Facultad como sustituto el canónigo coadjutor Francesc Perandreu i Cabacés ${ }^{189}$. Una vez concluida la visita de Pau Duran, Sagarra salió del escondite y pidió volver a su cátedra. El Vicerrector de la Universidad escribió al Virrey en 1641, quejándose de la injerencia del Obispo y solicitando la confirmación del catedrático de Prima de Cánones y la convocatoria de las cátedras vacantes ${ }^{190}$. No obstante, se confirmó como catedrático de Prima a Francesc Perandreu ${ }^{191}$, quien tomó posesión definitiva de su canonicato en 1641 y fue Arcediano mayor de la Catedral de Lérida. Asimismo fue Maestrescuela de la Universidad desde 1653

184 ACA, Consejo de Aragón, leg. 281, n. 101.

185 AML, Reg. 851, Cartes Reials, s.f.

186 F. Esteve Perendreu, El Régimen jurídico..., pp. 156-157.

187 ACA, Generalitat, Correspondencia del virrey Conde de Santa Coloma, carta n. 9555, s.f.

188 ACA, Consejo de Aragón, leg. 283, n. 143.

189 ACA, Generalitat, Correspondencia del virrey Conde de Santa Coloma, carta n. 11315 , s.f.

190 ACA, Generalitat, Correspondencia del virrey Conde de Santa Coloma, carta n. 12381 , s.f.

191 Sobre el personaje, véase F. Esteve Perendreu, "El doctor Francisco Perandreu Maestrescuela del Estudio General de Lérida" en Miscel-lània. Les Terres de Lleida al segle XVII, Lleida, Institut d'Estudis Ilerdencs, 1984, pp. 165-214. 
a $1665^{192}$, y asumió un papel muy destacado en la reactivación de los estudios tras el fin de la guerra. Fue presentado en 1664 para la mitra ilerdense, aunque el elegido fue Brauli Sunyer ${ }^{193}$.

El 13 de abril de 1641, la Ciudad de Lérida, con el voto decisivo de Francesc de Sagarra, se adhirió a la propuesta de unión con Francia ${ }^{194}$ y se sometió a la jurisdicción de Luis XIII. El Dr. Onofre Anglasill fue nombrado juez de la provincia $^{195}$. El catedrático de Prima de Leyes en 1641 era Joan Baptista Monjo, autor de la censura y de un soneto que puede leerse en Cataluña defendida de sus emulos ${ }^{196}$.

En esta época tenemos algunas noticias dispersas de Miquel Cortiada, quien fue con posterioridad uno de los juristas más reconocidos de su tiempo. En sus escritos afirmaba que había sido catedrático de Prima de Leyes, si bien no sabemos exactamente durante cuántos años detentó el puesto ${ }^{197}$. No sabemos si, por causa de la guerra, Cortiada efectivamente llegó a tener alumnos en el Estudio. No hay duda de que fue catedrático, al igual que Joan Baptista Canet $^{198}$, pues ambos fueron comisionados como tales para atender algunas de las urgencias de la Universidad ${ }^{199}$. Este último, insaculado como Oidor y diputado real ${ }^{200}$, solicitó en 1644 una plaza en la Real Audiencia de Cataluña, que no se le concedió $^{201}$. También en estos años aparece como catedrático de cánones Pere Claver, Prior asimismo del Colegio Viejo ${ }^{202}$, así como también Miquel Ondarro, profesor de Cánones y lugarteniente del Prior del Colegio de la Asunción ${ }^{203}$.

192 F. Esteve Perendreu, Mestrescoles i rectors..., pp. 94-108.

193 ACA, Consejo de Aragón, leg. 574, n. 16.

194 J. Lladonosa, Lleida durant la Guerra dels Segadors, Barcelona, Rafael Dalmau Editor, 1971, p. 14 .

195 DGC, V, p. 1188.

196 A. Marqués, Cataluña defendida de sus emulos illustrada con sus hechos fidelidad y servicios a sus reyes, Lérida, por Enrique Castañ, 1641.

197 M. A. Martínez Rodríguez, "Los regentes la Cancillería en la Cataluña de los últimos Austrias”, Manuscrits, 23 (2005), p. 116, indica que fue catedrático en 1650.

198 DGC, VI, p. 1453, “...se ha averiguat que de altra part dit reverendíssim senyor col-lector, a 23 del mes de agost del any 1643, consignà al magnífich doctor Joan Baptista Canet com a síndich y procurador de la universitat del studi general de la ciutat de Lleyda sinc-centes lliures, pagadores per los deputats y oïdors...”

199 F. Esteve Perendreu, Mestrescoles i rectors..., pp. 214-216.

200 E. Serra i Puig, Els Llibres de l'Ànima..., p. 86.

201 ACA, Consejo de Aragón, leg. 278, n. 145.

202 F. Esteve Perendreu, Mestrescoles i rectors..., p. 216.

203 F. Esteve Perendreu, El Col-legi universitari de l'Assumpció..., p. 66. 
En el contexto bélico se agravaron aún más los problemas económicos y los Paheres escribieron al Estudio para tratar el problema de los frutos de la mensa episcopal ${ }^{204}$ y también al Rey para que se preocupase de los problemas de la Universidad, representada por Fr. Francesc Reguera, catedrático de Prima de Teología y por Joan Baptista Canet, catedrático de Prima de Leyes ${ }^{205}$. El Dr. Canet, en tanto que catedrático más antiguo, era el Vicerrector y suplía las labores rectorales en esta época de guerra, en la que muchos de los estudiantes habían regresado a sus lugares de origen ${ }^{206}$.

En 1644, la Universidad de Lérida pretendió que no se haciese merced de oficios y beneficios de provisión real en el Principado de Cataluña y Condados de Rosellón y Cerdaña a quien no fuese graduado de Doctor por el Estudio ilerdense. El Virrey, tras una consulta ${ }^{207}$, no aceptó dicha pretensión. El 7 de julio de 1644 se produjo un motín felipista dentro de la ciudad en el que falleció, entre otros, el Dr. Onofre Anglesill, quien a la sazón era el consejero real y asistente del gobernador, Mr. de Chaussy. Anglesill fue asesinado por el notario Josep Algueró, Clavario mayor de la Ciudad, quien le asestó varias puñaladas ${ }^{208}$.

En 1645, en una misiva dirigida al Rey, el Rector y el Claustro de la Universidad pidieron que se desocupasen las aulas, que permanecían con abundante material de artillería, a fin de que de pudiesen reanudar las lecciones y que se acordase de los catedráticos de Lérida a la hora de establecer la provisión de las cinco plazas vacantes en la Real Audiencia ${ }^{209}$.

En 1646, los catedráticos eran los siguientes: el Dr. Joan Baptista Canet detentaba la cátedra de Prima de Leyes, el Dr. Miquel Cortiada era el catedrático de Segunda y su hermano, el Dr. Francesc Cortiada, era el de Tercera. El Dr. Francesc Perandreu era el catedrático de Prima de Cánones, el Dr. Andreu Rovert (o Revert) era el de Segunda y el Dr. Josep Sabata i Castells, el de Vísperas ${ }^{210}$. Josep Sanou i Domènech era el catedrático de Instituta ${ }^{211}$. Este último personaje puede ser identificado con el homónimo vicario de la Iglesia de Sant Llorenç ${ }^{212}$.

204 AML, Reg. 856, Correspondencia, f. $10 \mathrm{v}$.

205 AML, Reg. 856, Correspondencia, f. 116r-v.

206 F. Esteve Perendreu, Mestrescoles i rectors..., p. 217.

207 ACA, Consejo de Aragón, leg. 278, n. 116.

208 F. Esteve Perendreu, Mestrescoles i rectors..., p. 97.

209 ACA, Consejo de Aragón, leg. 511, s.n.

210 F. Esteve Perendreu, Mestrescoles i rectors..., p. 221.

211 ACA, Consejo de Aragón, leg. 220, n. 29.

212 J. Lladonosa i Pujol, Història de Lleida, vol. II, p. 489. 
Durante la Guerra dels Segadors, entre los profesores en activo y los antiguos catedráticos había serias divergencias políticas: el Dr. Canet era más bien moderado y filipista ${ }^{213}$, al igual que Josep Sabata, mientras que, como hemos visto, el Dr. Anglesill falleció como víctima de su colaboración con el poder francés, y el Dr. Francesc de Sagarra debe ser considerado un partidario acérrimo de Luis XIII ${ }^{214}$. Sagarra fue nombrado miembro del Consejo Criminal de la Audiencia de Cataluña por Pèire de Marca. Su actuación contra los afectos al rey Felipe fue muy contundente. Acabó exiliado en Francia y Luis XIV le nombró Gobernador del Rosellón ${ }^{215}$.

Asimismo, la participación de los profesores en la administración de la Ciudad era continua ${ }^{216}$, y sus cátedras tenían que ser leídas por sustitutos. Andreu Revert fue nombrado asesor trienal del Veguer en 1647, una plaza que había solicitado también el Dr. Sanou ${ }^{217}$, y fue sustituido por el Dr. Tomàs Arqués. El Dr. Sabata fue Paer en cap en $1651-1652^{218}$. Y a la sazón el Dr. Miquel Cortiada estaba en la Corte, como Síndico de la Ciudad de Lérida ${ }^{219}$.

La época en la que Cortiada hubiera podido enseñar era tan convulsa, que no sabemos si llegó dictar lecciones. Por lo que hemos visto, los encargos le mantuvieron ocupado fuera de las aulas, si bien siempre mantuvo un gran afecto hacia el Estudio General de Lérida, del cual decía -con gran orgulloque había sido catedrático. Años después, en su decisión CXXXV, aprovechó las circunstancias para hacer un homenaje a la que había sido su Alma mater: "Inter celebres Universitates Studiorum generalium insignis est in juris scientia, nostra Illerdensis ${ }^{200}$ ". En los párrafos siguientes podemos leer los nombres de los eminentes juristas del Estudio de Lérida, muchos de los cuales han aparecido en el capítulo anterior y en el presente: Miquel Ferrer,

213 Ibidem, p. 469.

214 Q. Casals Bergés, Polítics de Lleida. El poder local i les seves mutacions a través del temps (1716-1868), Lleida, Pagès, 2014, p. 98.

215 O. Jané Checa, “Aspectes de la relació identitària de Catalunya amb França a l'època de Lluís XIV”, Manuscrits, 19 (2001), pp. 103-136, especialmente, p. 120.

216 J. Lladonosa, Lérida moderna. Epoca de los Austrias, pp. 55-57.

217 ACA, Consejo de Aragón, leg. 220, n. 29. Fue insaculado en 1654 como diputado real. Véase E. Serra i Puig, Els Llibres de l’Ànima..., p. 395.

218 Q. Casals Bergés, Polítics de Lleida..., p. 105.

219 AML, Reg. 856, Correspondencia, f. 208r.

220 M. de Cortiada, Decisiones cancellarii et sacri regii senatus Cathaloniae siue Praxis contentionum et competentiarum, tomo III, Lugduni, sumptibus Anisson et Posuel, 1699, p. 130. 
Francesc Molí, Pere Molí, Miquel Miralles, Andreu Roig, Josep Ramon, Nicolau Freixenet, Francesc Ferrer, José de Sese, Bernat de Pons, Josep Romeu de Ferrer...

En 1652 constan como catedráticos: Tomás Arqués, Doctor en Cánones y Catedrático de Decreto ${ }^{221}$; Josep Sanou, Doctor en ambos Derechos; Josep de Gomar, Doctor en Leyes ${ }^{222}$; y Francesc Nogués, Doctor en Cánones, canónigo y catedrático de Instituta ${ }^{223}$. Todos ellos, junto con los demás catedráticos, nombraron síndicos a Joan Perat, canónigo de la Catedral de Zaragoza, y a Josep Costrán, residente también en Zaragoza, a fin de que procurasen la percepción de las rentas de la Universidad ${ }^{224}$.

Sin duda, las dificultades económicas impidieron una recuperación más rápida del Estudio, puesto que no recibía las rentas que le correspondían de la mitra. El Rey mandó el 14 de octubre de 1654 que se embargasen las rentas de la Cámara Apostólica para el pago de los catedráticos ${ }^{225}$. Junto al problema económico, se añadía que las aulas aún estaban ocupadas con material de guerra. Tras varias tentativas sin éxito, en el curso 1654-1655 se hicieron los preparativos para reiniciar la actividad académica. Los Paheres escribieron al Rey el 9 de agosto de 1654, indicando que

"per les ocurrents guerres que ha patit esta ciutat y frontera, ha deixat alguns anys de cunplirse y com lo unic remey de la restauracio de dita ciutat sie tornarla en son pristino estat, havem per tots camins procurat se comence a llegir lo dia de Sant Lluch de aquest any ${ }^{226 "}$.

El final de la Guerra dels Segadors, unido a la peste, no permitió recuperar plenamente la actividad académica hasta el curso 1656-1657. Algunos profesores, como el Dr. Miquel Cortiada, habían sido ya promovidos a otros

221 J. C. de Vargas Machuca, Decisiones vtriusq[ue] supremi tribunalis Regni Aragoniae, placitis et sententiis supremorum tribunalium Regni Neapolis, Neapoli, Typis et expensis Aegidii Longo, 1676, pp. 49-50.

222 Josep de Gomar i Espígol fue doncel y ciudadano honrado de Lérida, Consejero Real, Asesor de la Diputación de la Generalitat (1665). Véase F. J. Morales Roca, “Officialium Catalonia, IV, Regidores del Ayuntamiento de Lérida, Dinastía de Borbón, 17161833”, Hidalguía, 316-317 (2006), p. 457. El árbol genealógico de los Gomar puede verse en Q. Casals Bergés, Polítics de Lleida..., p. 299.

223 J. C. de Vargas Machuca, Decisiones vtriusq[ue] supremi..., p. 50.

224 F. Esteve Perendreu, Mestrescoles i rectors..., p. 228.

225 AML, Reg. 851, Cartes Reials, s.f. y ACA, Consejo de Aragón, leg. 308, n. 9

226 AML, Reg. 856, Correspondencia, ff. 289r-v. 
cargos: en su caso, a Abogado en el Regio Concilio de Cerdeña, y después Abogado del Patrimonio en la Audiencia de Cataluña, donde empezó a publicar sus Decisiones cancellarii et Sacri Regni Senatus Cathaloniae y otras obras, frecuentemente reimpresas en las más afamadas prensas europeas ${ }^{227}$. Mediado el tiempo, en 1681, pese a ser según algunos "poco afecto a la causa de Felipe IV durante la Guerra de los Segadores'228", llegó a Regente de la Cancillería de Cataluña ${ }^{229}$. Sin duda, fue el catedrático más importante de la Universidad de Lérida durante esta centuria, y uno de los juristas más destacados de la Corona de Aragón.

Su cátedra fue leída por el Dr. Josep de Melianta i Moratón ${ }^{230}$, insaculado como Oidor real y Oidor militar ${ }^{231}$. En 1660, Melianta era profesor de Código, pues se conserva un curso suyo manuscrito, iniciado el 26 de octubre ${ }^{232}$. A la sazón, el Vicerrector era el catedrático de Vísperas de Cánones, Josep Sabata. El catedrático de Decreto era el Dr. Medardo Montanuy, racionero de la villa de Benavarre. La Universidad escribió el 2 de noviembre de 1657 a los Jurados de dicha villa pidiendo que le dejasen ausentarse y le diesen licencia para estar en Lérida y leer su cátedra ${ }^{233}$. La respuesta debió de ser negativa, porque no le volvemos a encontrar en la documentación ${ }^{234}$.

\subsection{La recuperación}

Progresivamente se fueron ocupando las vacantes: la cátedra de Instituta fue ocupada por el agustino Fr. Juan de Enciso, Prior del convento de San Agustín de Lérida, y la cátedra de Decreto fue detentada finalmente por Fr.

227 O. Oleart, "Diputación del General y libros jurídicos en Cataluña (siglos XVIXVIII): la publicación de las Decisiones del doctor Miquel de Cortiada”, en M. Á. González de San Segundo (coord.), Un jurista aragonés y su tiempo. El doctor Juan Luis López, primer marqués del Risco (1644-1703), Zaragoza, Gobierno de Aragón, 2007, pp. 505-591.

228 Su trayectoria puede verse en M. A. Martínez Rodríguez, "Los regentes la Cancillería...”, pp. 109-130. La cita está en la p. 118.

229 ACA, Consejo de Aragón, leg. 225, n. 95.

230 F. Esteve Perendreu, Mestrescoles i rectors..., p. 240.

231 E. Serra i Puig, Els Llibres de l'Ànima..., p. 260.

232 AHCB, Ms. A-8o, ff. 252-273.

233 AML, Reg. 856, Correspondencia, f. 351r.

234 Mediante una alegación sabemos que fue nombrado Vicario General y visitador con el encargo que visitase "las Iglesias del Abadiado de la O”. Véase F. de Blasco y Lanuza, Respuesta al presente mandato, con sus erratas a la margen, [s.l.], [1654], p. 2. 
Gabriel Hernández Alegre ${ }^{235}$, también de la Orden de San Agustín. Este último, nacido en Montalbán en 1608, era Doctor en Teología por la Universidad de Huesca y en Cánones por la Universidad de Lérida. Había sido previamente catedrático de Escritura en Huesca. Fue Examinador sinodal del obispado de Huesca y Calificador de la Inquisición de Aragón. Se conservan varios sermones suyos. Murió en el convento de Zaragoza en $1672^{236}$.

Al poner en marcha de nuevo la Universidad, los Paheres, solicitando protección para los egresados del Estudio ilerdense, pidieron al Rey,

"mandar con Real Decreto que en adelante nadie sea consultado ni admitido a los honores y cargos de la Provincia que requieren el grado de Dotor o de Bachiller, sino se ha obtenido en dicha universidad, o por lo menos cursado en ella dos cursos de la Facultad legitimamente aprobados ${ }^{237}$.

Los Paheres, al parecer, estaban satisfechos con la enseñanza de Fr. Gabriel Hernández, pues se había graduado en ambos Derechos y había predicado tres cuaresmas. La Ciudad pidió al Inquisidor General en 1658 que le hiciese calificador del Santo Oficio ${ }^{238}$.

En 1658 aparecen como profesores de Leyes y Cánones los siguientes: Joan [Medardo] Montanuy, Doctor en Cánones; Melcior Vallés, Doctor en Leyes $^{239}$; Josep Gomar, Doctor en Leyes; Fr. Juan de Enciso, Doctor en Cánones; Pere Poca ${ }^{240}$, Bachiller en Leyes; Bernat Miró ${ }^{241}$, Bachiller en Cánones ${ }^{242}$;

235 F. Esteve Perendreu, Mestrescoles i rectors..., p. 237 n. 745. Fr. Gabriel Hernández (1608-1672) Era un buen amigo del P. Baltasar Gracián, quien había sido catedrático de Teología moral en Lérida. Véase J. M. Ayala Martínez, "La admiración de Baltasar Gracián por San Agustín”, Ciudad de Dios, 217/1 (2004), pp. 261-281, especialmente p. 276.

236 F. de Latassa, Biblioteca Nueva de los escritores aragoneses..., II, pp. 431-432. Lladonosa le llamó Gabriel Alegre, lo cual dificulta su identificación. Véase J. Lladonosa i Pujol, Història de Lleida, II, p. 536.

237 ACL, P7_M2_P3_Co6, s.f.

238 AML, Reg. 856, Correspondencia, f. 356.

239 Fue extraído para Abogado Fiscal, pero no juró. DGC, VI, p. 1469.

240 Fue canónigo y sustituto del maestrescuela en 1668. Véase F. Esteve Perendreu, El Col-legi universitari de l'Assumpció..., p. 82.

241 Luego fue canónigo penitenciario de la Catedral de Lérida. Falleció el 27 de febrero de 1701. F. Esteve Perendreu, Mestrescoles i rectors..., p. 306.

242 Se graduó en la Universidad de Huesca en 1657. Véase J. M. Lahoz Finestres, “Graduados catalanes...", p. 199. 
Francesc de Pedrolo ${ }^{243}$, profesor de Leyes; Simó Vicent ${ }^{244}$, Dionís Roca, Antoni Berenguer ${ }^{245}$, Josep Fillat ${ }^{246}$ y Josep March ${ }^{247}$, profesores de Cánones ${ }^{248}$. En 1661, Josep Aguiló era Prior del Colegio de la Asunción y profesor de Leyes ${ }^{249}$.

Tras una visita realizada a la Universidad por el obispo Fr. Miguel de Escartín, Felipe IV ordenó el 12 de mayo de 1662 una reforma de los Estatutos ${ }^{25}$. En ella se ordenó que el Rector confiriese los grados de Bachiller de Leyes y Cánones, y que para expedir sus privilegios se tenía que valer del Notario de la Universidad. Por lo demás, el Notario del Maestrescuela conservaba el derecho a la expedición de privilegios de todos los demás grados de todas las Facultades. En esta reforma, se suprimió el voto ponderado de los estudiantes,

243 Francesc de Pedrolo i Desclergue nació en 1640, procedente de una familia noble. Según S. Albertí, "Esquema històric del llinatge Pedrolo", Urtx, 7 (1995), p. 69, "Cursa lleis al Col-legi de la Concepció de la Universitat de Lleida, on es graduarà. Del 15 de febrer de 1658 al 16 d'abril de 1659 hi actua, amb un altre company, de rector o prior. [...] El cas es que, mentre l'ocupa encara, tenint divuit anys o dinou de ben justos, Francesc de Pedrolo i Desclergue es casa amb una noia de casa bona: Anna Maria Ratera Riber i Robuster, d'una família de Tarrega que sol traginar el tercer cognom a honor d'un parent il-lustre dels seus avantpassats, el bisbe Francesc Robuster (1544-1607), que va ser-ho d'Elna i de Vic. La parella te un sol fill, almenys amb bona supervivencia: Antoni, batejat a Montblanc el 20 de novembre de 1659. Mes tard, Francesc de Pedrolo i Desclergue es doctora en Dret. Aconsegueix la plaça d'assessor jurídic del lloctinent per a Montblanc del Batlle General de Catalunya”.

244 Era Colegial de la Asunción. Véase F. Esteve Perendreu, El Col-legi universitari de l'Assumpció..., pp. 70-74.

245 Antoni Francesc de Berenguer i Novell fue Oidor Real de la Generalitat de Catalunya (1689-1690), y obtuvo el privilegio nobiliario en 1692. Participó en las Cortes de 1701. Fidelísimo austracista, Participó en la Junta de Brazos de Cataluña celebrada en julio de 1713 por la cual el Principado declaró la continuación de la guerra. Fue extraído diputado militar de la Generalidad de Cataluña el 22 de julio de 1713, cargo que aceptó pese a su provecta edad. Al final de la guerra, sus propiedades fueron secuestradas. Véase F. de Castellví, Narraciones Históricas desde el año 1700 hasta el año 1725, III, 2002, Madrid, Fundación Francisco Elías de Tejada y Erasmo Pèrcopo, pp. 709 y 837 y F. J. Morales Roca, Próceres habilitados..., Vol. II, p. 154.

246 Era Colegial de la Asunción. Véase F. Esteve Perendreu, El Col-legi universitari de l'Assumpció..., pp. 72-74.

247 Josep March i Agustí fue Colegial (1654-1660) y Prior de la Asunción. Fue elegido Rector de la Universidad para el curso 1659-1660. Véase F. Esteve Perendreu, El Col-legi universitari de l'Assumpció..., pp. 70-74.

248 F. Esteve Perendreu, Mestrescoles i rectors..., pp. 235-236.

249 F. Esteve Perendreu, El Col-legi universitari de l'Assumpció..., p. 74.

250 AML, Fondo Municipal, Perg. n. 260 y ACA, Consejo de Aragón, leg. 314, n. 80. 
instituido por Pau Duran, y se volvió al sufragio individual ${ }^{251}$. Un año antes, ante las continuas presiones, se había determinado con exactitud la provisión del oficio de Bedel y portero del Estudio ${ }^{252}$. En este sentido reformista, el 1 de abril de 1663 los Paheres pidieron al Rey que las cátedras de Prima de Leyes y Cánones fuesen trienales ${ }^{253}$, aunque no lo consiguieron.

En 1662 sabemos que el catedrático de Instituta era Jaume Biosca, nacido en 1636, hijo de Tomàs Biosca, Doctor en Leyes ${ }^{254}$. En 1672 contrajo nupcias con Clementina Anglesill, hija del ya citado catedrático Dr. Onofre Anglesill. Bendijo la unión el catedrático de Prima de Cánones, Dr. Joan Pau Molner, canónigo ${ }^{255}$. Con tales alianzas, no es de extrañar que su promoción fuese rápida. En 1665, Biosca ya era catedrático de Prima de Leyes ${ }^{256}$, asesor del Maestrescuela ${ }^{257}$ y fue insaculado como Oidor y Diputado real ${ }^{258}$. A la sazón, el catedrático de Prima de Cánones era Josep Guarga Gil, y el de Vísperas de Cánones, Tomàs de Maranyosa ${ }^{259}$. Podemos añadir los nombres de algunos catedráticos de Bachiller: Josep Sornosa, Antoni Puig ${ }^{260}$ y Josep Toda ${ }^{261}$.

Los Paheres pidieron al Rey una merced para el citado Tomàs de Maranyosa el 26 de enero a 1665, en atención a sus méritos, que había expuesto en un memorial impreso ${ }^{262}$. El 31 de mayo de 1667 se presentaron a la cátedra

251 F. Esteve Perendreu, El Régimen jurídico..., p. 157.

252 ACA, Consejo de Aragón, leg. 316, n. 16.

253 AML, Reg. 863, Correspondencia, f. 65, pliego intercalado.

254 V. de Cadenas y Vicent, Extracto de los Expedientes de la Orden de Carlos III. 1771-1847, Tomo IV, Madrid, Hidalguía, 1982, p. 222.

255 Véase F. Esteve Perendreu, Mestrescoles i rectors..., p. 262.

256 Antes había desempeñado la cátedra de Código. Véase F. Esteve Perendreu, El Col-legi universitari de l'Assumpció..., p. 74 y 88-89.

257 E. Casellas, Iurisdiccion regia y pontificia que sobre la Universidad y Estudios Generales de Lerida y singulares personas de aquella, tiene el maestre-escuelas de dicha Universidad, s.n., 1687?, p. 5 .

258 E. Serra i Puig, Els Llibres de l'Ànima..., p. 54.

259 F. Esteve Perendreu, Mestrescoles i rectors..., p. 248.

260 Se refiere a Antoni Puig Vivero, consejero militar y paer en cap en los años 1673, 1697 y 1704. Véase Q. Casals Bergés, Polítics de Lleida..., p. 279. Fue también veguer de Lérida. Cf. A. Simón i Tarrés, Del 1650 al 1705. L'autogovern de Catalunya i la classe dirigent catalana en el joc de la política internacional europea, València, Universitat de València, 2011, p. 145.

261 Profesor de Leyes y síndico de la Universidad. Véase F. Esteve Perendreu, Mestrescoles i rectors..., p. 249.

262 AML, Reg. 863, Correspondencia, f. 96. 
de Instituta dos opositores: Bernat Enveja y Lluís Rey ${ }^{263}$. Obtuvo más votos el primero, que fue nombrado catedrático. Bernat Enveja i Marcer fue Doctor en ambos Derechos y Prior de la Iglesia y Colegiata de Santa Ana ${ }^{264}$, al tiempo que defensor de sus derechos en la obra Triumphus veritatis multiplici antiquitatis splendore coronatus (Barcelona, Iosephi Llopis, 1688).

En aquellos momentos, el Dr. Guarga, canónigo doctoral de la Catedral de Huesca y luego Vicerrector de la Universidad Sertoriana ${ }^{265}$, en cuya fábrica participó activamente, fue sustituido por Joan Pau Molner i Farran, que se había doctorado en 1666, que fue Arcediano de Ribagorza y detentó la cátedra de Prima de Cánones desde 1668 hasta su muerte, acaecida en $1688^{266}$. El catedrático de Decreto era Fr. Juan de Enciso $^{267}$, mientras que la cátedra de Vísperas de Leyes la obtuvo en 1668 el Dr. Aleix Novell, quien había leído Instituta hasta entonces. Esta última cátedra fue cubierta por el Dr. Manuel Pallarés, que fue nombrado Rector de la Universidad el 27 de octubre de $1668^{268}$. El catedrático de Código era, a la sazón, el Dr. Ramon Queraltó i Aiguamolsa, quien había recibido el título de Bachiller el 2 de abril de $1661^{269}$, y que enlazó matrimonialmente con la familia Sabata (la cual había dado varios profesores universitarios), y que fue insaculado después como Diputado real ${ }^{270}$. Sabemos también que en estos años Josep Bullfarines, miembro de una familia destacada, fue catedrático en el Estudio ${ }^{271}$.

263 AML, Reg. 447, Llibre d'Actes (1665-1676), f. 56v.

264 A. Pérez Santamaría, "L'escultor guixolenc Domènec Rovira (1608-1678)”, Estudis del Baix Empordà, 31 (2012), p. 85.

265 L. Alins Rami, "La nueva fábrica de la Universidad Sertoriana (1690)", Argensola: Revista de Ciencias Sociales del Instituto de Estudios Altoaragoneses, 92 (1981), p. 270. Fue catedrático de Vísperas de Cánones de la Universidad de Huesca hasta su jubilación.

266 Sobre este personaje, véase F. Esteve Perendreu, "Llibreria jurídica de Joan Pau Molner, catedràtic de l'Estudi i ardiaca de la Seu”, a Seu Vella. Anuari d'Història i Cultura, 3, Lleida, Amics de la Seu Vella, 2001, pp. 325-358.

267 F. Esteve Perendreu, Mestrescoles i rectors..., p. 255.

268 Ibidem, p. 257.

269 J. M. Clarisó Martí, La economía de la nobleza de Lleida en el siglo XVIII, Madrid, UNED, [Tesis doctoral], 2015, pp. 326-329. El autor, entre muchas otras aportaciones, deshace el malentendido sobre el segundo apellido de este personaje y traza su genealogía.

270 E. Serra i Puig, Els Llibres de l'Ànima..., p. 350.

271 Véase J. Lladonosa i Pujol, Història de Lleida, II, p. 510. Fue Doctor en Leyes y Paer en dos ocasiones (1668 y 1674). Véase R. Cerro Nargánez, "Los alcaldes mayores del corregimiento de Lérida en el siglo XVIII”, Cuadernos dieciochistas, 2 (2001), p. 40. 
Lladonosa indica que Fr. Ramon Berart, dominico, fue catedrático del Estudio entre los años 1675 y $1680^{272}$. Berart fue Definidor y Procurador General de la Provincia del Santo Rosario de las Islas Filipinas, Doctor en ambos derechos, teólogo y Examinador de la Nunciatura de España, y Sinodal del Arzobispo de Manila y Obispado de Lérida. En varios lugares aparece que había sido catedrático de Cánones en la Universidad de Lérida. En realidad, cuando tomó el hábito se llamaba Abdón Berart; era Doctor en Derecho civil y canónico por las Universidades de Lérida y Barcelona; y consta que en esta última obtuvo por oposición una cátedra de cánones ${ }^{273}$. Por lo tanto, su trayectoria docente fue anterior a su profesión en la Orden de Predicadores, de manera que los datos aportados por Lladonosa no concuerdan, aunque es posible que hubiera enseñado algunos años antes en Lérida. Digamos, por último, que Berart desempeñó una importante labor como asesor jurídico ${ }^{274}$.

La estructura de las cátedras mayores en 1671 era la siguiente: el Dr. Molner se desempeñaba como catedrático de Prima de Cánones; el Dr. Joan Sentís, de Decreto; y el Dr. Tomàs de Maranyosa, de Vísperas; el Dr. Biosca era catedrático de Prima de Leyes; el Dr. Queraltó, de Código y el Dr. Novell, de Vísperas. Esta fue una época de bastante estabilidad de los profesores en sus respectivas cátedras, lo que favoreció un cierto florecimiento de la Facultad.

El Rector, Martín Antonio Baylin, pidió en 1672 la provisión de las cátedras vacantes ${ }^{275}$. Queraltó quiso perpetuarse en la cátedra de Código, que había ganado en 1663, pero no la había ocupado ininterrumpidamente, sino que había leído otras cátedras mejor remuneradas y no había cumplido los doce años previstos para perpetuarse. Los Paheres pidieron que se convocase la oposición, a la que se presentaron también Joan Josep Casanoves y Bartomeu Mesonada, y que ganó nuevamente Queraltón ${ }^{276}$.

272 J. Lladonosa i Pujol, Història de Lleida, II, p. 536.

273 V. T. Gómez, “Aportación del convento dominicano de Santa Catalina de Barcelona a la evangelización de América y el Extremo Oriente” en J. Barrado Barquilla (coord.), Actas del II Congreso Internacional sobre los Dominicos y el Nuevo Mundo, Salamanca, 28 de marzo-1 de abril de 1989, Salamanca, San Esteban, 1990, pp. 929-930.

274 Se conserva un importante escrito suyo: Manifiesto por la justificacion de D. Fr. Phelipe Pardo, Arzobispo de Manila en orden o la absolucion y penitencia del Maestre de Campo D. Juan de Vargas Hurtado, y exhumacion de los cuerpos de dos ministros togados, [s.l.].

275 AML, Reg. 863, Correspondencia, f. 209v.

276 AML, Reg. 863, Correspondencia, ff. 280r-v. 
Por óbito, en 1674, del Dr. Aleix Novell, que había sido asesor del Veguer $^{277}$, accedió a la cátedra de Vísperas de Leyes en 1675 el Dr. Joan Josep Casanovas i Mercer ${ }^{278}$ quien, insaculado como Diputado real ${ }^{279}$, ocupó un destacado papel en la Universidad y en la Pahería ${ }^{280}$. En 1680, Casanovas fue nombrado abogado del Cabildo, junto con el Dr. Biosca, catedrático de Prima de Leyes ${ }^{281}$. Tomàs de Maranyosa ${ }^{282}$ ejerció como abogado, especialmente tras dejar la cátedra el 2 de febrero de $1673^{283}$, y quedan escritos un conjunto de alegaciones y de discursos ${ }^{284}$ especialmente de su época como Procurador Fiscal de la Bailía General de Cataluña, puesto que ocupó desde $1673^{285}$ hasta su muerte, acaecida en $1694^{286}$.

Sabemos también que, en 1674, Agustí Pallàs ${ }^{287}$ ocupaba una cátedra menor de Leyes, mientras que en 1675 lo hacía Matías (Macià) Pujol ${ }^{288}$. Sabemos que Josep Teixidor, de Vilafranca del Panadés, era profesor de Leyes en $1674^{289}$. En la nómina de docentes de Leyes de 1676 debe añadirse a Pere Talau y Gaietà Aguiló, ambos colegiales y priores del Colegio de la Asunción ${ }^{290}$.

277 F. Esteve Perendreu, "El tribunal de coltellades de Lleida. Procediment i dictàmens mèdics”, Gimbernat, 30 (1999), pp. 165-174, especialmente p. 166.

278 F. Esteve Perendreu, “Joan Josep Casanoves, el final d'una època”, en X. Eritja et alii (coords.), Lleida al segle XVIII: el naixement d'una nova ciutat, Lleida, Ateneu Popular de Ponent, 2002, pp. 75-116.

279 E. Serra i Puig, Els Llibres de l’Ànima..., p. 98.

280 Fue notario público, abogado del Cabildo y paer segon en 1585. Véase A. Passola Tejedor, Oligarquia i poder a la Lleida dels Austria, p. 360.

281 F. Esteve Perendreu, Mestrescoles i rectors..., p. 268.

282 Se ha conservado un expediente de limpieza de sangre para ser oficial de la Inquisición de Zaragoza. Véase AHN, Consejo de la Inquisición, leg. 226, doc. 47.

283 AML, Reg. 863, Correspondencia, f. 221r.

284 Posiblemente el más destacado sea Pro syndico et clavario civitatis Barcinonae contra rectorem et operarios termini et parrochiae Sancti Martini de Provensals territorij Barcinone, s.f., s.d.

285 ACA, Consejo de Aragón, leg. 225, n. 88.

286 ACA, Consejo de Aragón, leg. 226, n. 47.

287 Agustí Pallàs Solé fue Colegial de la Asunción. Véase F. Esteve Perendreu, El Col-legi universitari de l'Assumpció..., pp. 80-82. Procedente de una familia payesa, alcanzó el grado de Doctor en Leyes. Véase Q. Casals Bergés, Polítics de Lleida..., p. 109.

288 F. Esteve Perendreu, Mestrescoles i rectors..., p. 266.

289 F. Esteve Perendreu, El Col-legi universitari de l'Assumpció..., p. 118.

290 Ibidem, p. 81. 
Sabemos también que Josep de Cau y Miquel Sanui eran colegiales de la Asunción y profesores de Leyes en $168 \mathrm{O}^{291}$.

El Decreto de Visita de la Universidad de 1677 declaró que tenían que fundarse dos cátedrillas de Instituta, a la que solamente podían oponerse los doctores. Tanto estas dos catedrillas como las de Leyes y Cánones que ya existían, tenían que ser bienales. Para las tres catedrillas de Leyes se tenían que dar los puntos de la Instituta y a la de Cánones, de las Decretales. El pago de estos profesores -al igual que sucedía en otras universidades, como la de Barcelona- era la colación gratuita del grado de Doctor en Leyes o en Cánones. Los posesores de estas catedrillas tenían que presidir academias de Instituta todos los domingos del curso, por turno, bajo pena de diez sueldos ${ }^{292}$.

El catedrático de Vísperas de Cánones en 1680 era el Dr. Antoni Burgada, quien murió en $1685^{293}$ y el catedrático de Instituta era el Dr. Josep Llopis, abogado de la ciudad ${ }^{294}$ e insaculado como Oidor y diputado real ${ }^{295}$. Llopis pasó a la cátedra de Prima de Leyes por la muerte del Dr. Joan Pau Molner, acaecida en 1688.

Aparece también como catedrático de Cánones en 1681 el Dr. Martín de Viñuales, aragonés, que había sido vicerrector en el curso $1672-1673^{296}$. Viñuales fue con posterioridad catedrático de Cánones en la Universidad de Huesca, Canciller de competencias del Reino de Aragón y Vicario General de Zaragoza $^{297}$. Devino asimismo un miembro destacado entre los austracistas aragoneses: designado en 1706 por el archiduque Carlos para la Junta Eclesiástica de Secuestros y Confiscaciones de Aragón, de la que fue Presidente, obtuvo presentación para la mitra de Huesca por parte del proclamado Carlos III, el 5 de septiembre de 1707, y fue obispo electo, ya que jamás llego a ser confirmado por el Papa ${ }^{298}$.

Asimismo figuraba como catedrático de Instituta el Dr. Josep Joan de Fe-

291 Idem, p. 82.

292 F. Esteve Perendreu, El Régimen jurídico..., pp. 219-220.

293 F. Esteve Perendreu, Mestrescoles i rectors..., p. 276.

294 Ibidem, p. 279.

295 E. Serra i Puig, Els Llibres de l'Ànima..., p. 231.

296 F. Esteve Perendreu, Mestrescoles i rectors..., p. 261.

297 J. Solís, "Las Juntas de secuestros y confiscaciones del Archiduque Carlos en Cataluña, Aragón y Valencia”, Anuario de Historia del Derecho Español, 69 (1999), p. 434.

298 J. Solís, "La organización del Santo Oficio y el nombramiento de Inquisidor General por el archiduque Carlos (1709-1715)”, Hispania, 65/2 (2005), pp. 534-535. 
rran $^{299}$, doncel, luego Juez de apelaciones y Gobernador del Campo de Tarragona, asesor del Veguer y asesor único del Corregidor de Barcelona. El Dr. Ferran había nacido en Valmoll en 1653, había sido catedrático por oposición de la catedrilla de Bachillerato de Leyes ${ }^{300}$ y había contraído matrimonio en 1691 con Maria Biosca, hija de Jaume Biosca, el catedrático de Prima de Leyes ${ }^{301}$.

Pese a la estabilidad de las cátedras, la conflictividad en la Universidad no cesaba y había continuos conflictos de jurisdicción entre el Maestrescuela, los profesores, los alumnos y las autoridades civiles y eclesiásticas. Un memorial del maestrescuela Esteve Caselles, escrito tras haber consultado al Dr. Jaume Biosca, catedrático de Prima de Leyes y al Dr. Ramon Queraltó, catedrático de Código jubilado, fue elevado al Rey el 20 de agosto de $1681^{302}$. En él se reflejaba claramente la violencia escolar ${ }^{303}$ y la corrupción en la provisión de las cátedras ${ }^{304}$ y denunciaba un estado general de postración de la Universidad:

"El Maestre-Escuelas, como a Superior Ecclesiastico, y Real, que es de la Vniversidad de Lerida, y singulares personas de ella, ha de corregir lo que se hallare que enmendar; esta es su obligacion. Halla desde el dia que entro en la Dignidad de su govierno descaida su Universidad, no tanto de las ruinas de la antigua gerra [sic], como de la que con sus discordias la derriban los professores della, y no solo con discordias de animos, sino del coraçon de las reglas, y estatutos, que es lo peor [...]

299 Esta noticia aparece en una carta inserta en M. M. de Ribera, Centuria primera del Real y Militar Instituto de la inclita religion de Nuestra Señora de la Merced Redempcion de Cautivos christianos, Barcelona, por Pablo Campins, 1726, s.f. En compensación a su fidelidad, el duque de Berwick le nombró en septiembre de 1714 asesor letrado de la curia del veguer. Falleció en 1727. Véase R. Cerro Nargánez, "Los alcaldes mayores del corregimiento de Tarragona (1717-1808)”, Cuadernos de investigación histórica, 20 (2003), p. 305 .

300 F. Esteve Perendreu, Mestrescoles i rectors..., p. 263.

301 V. de Cadenas y Vicent, Extracto de los Expedientes de la Orden de Carlos III, p. 222.

302 AML, Reg. 863, Correspondencia, ff. 403v-404r.

303 E. Casellas, Iurisdiccion regia, p. 21 “...quantas vezes desde el año 1680 han visto al Maestre-Escuelas dentro de la Vniverfidad exerciendo su jurisdicion, mandando poner estudiantes inquietos à la carcel, reconocer el Alguazil en su prefencia, y fin ella, las aulas, y los estudiantes si llevavan puñales, o pistolas".

304 Ibidem, p. 30 “...sobre que haviendo el Vice Retor Dotor Jayme Biosca, hecho avisar, para juntar consejo en el dia aseñalado por los estatutos, para hazer las elecciones, no se pudo juntar el consejo, por haver algunos Cathedraticos subornado a otros, que no asistiessen á consejo por los fines, que se tenian, por las Cathedrillas, y Cathedras que se havian de proveher". 
En esta manera de sabiduria se aplican esta Vniversidad de Lerida muchos, aunque en sus facultades todos; en llegando a materia de empenyos, y pretenciones por Cathedras, la recta intencion esta condenada, juramentos, estatutos, y meritos no obligan; en esta educacion exercitan la juventud, y les passa en habito, quando hombres, que harto lo experimentan en la Ciudad...305".

El conflicto de jurisdicción fue bien estudiado por Francesc Esteve, a quien remitimos ${ }^{306}$. En cuanto a los exámenes de Latinidad y el ingreso a la Universidad, tema que enfrentó al Maestrescuelas con el rector Pere Terrer, será analizado en el capítulo siguiente ${ }^{307}$.

En los Dietarios de la Generalitat aparece en 1683 un "Petrus Martyr Llebrer, doctoris, gerens cathedra Illerde ${ }^{308}$ ", en un dictamen que firma con otros catedráticos de la Universidad de Barcelona (Francesc Portell, Josep Delfauo, Pere Potau). No tenemos más información de este personaje. En cambio, sabemos que en 1684 Ignasi de Gomar era profesor de Leyes ${ }^{309}$ y que en 1686 Pere Terrer, Rector en el curso 1687-1688, figuraba como profesor de Derecho civil, mientras que Joan Llobera enseñaba Derecho canónico ${ }^{310}$. Sabemos también que Josep Fraga fue colegial y Prior de la Asunción y que en 1692 era profesor de Derecho canónico ${ }^{311}$.

Indica Esteve Perendreu ${ }^{312}$ que el Dr. Joan Josep Casanoves concluyó en 1691 el Libre Vert de la ciutat de Leyda, que servía para completar los Privilegis, estatuts i ordinacions de la ciutat de Lleida, llamado también Llibre verd petit. Es una muestra muy elocuente de la simbiosis entre el ius commune y el derecho catalán.

Ésta se encuentra también en la obra del jurista ilerdense Antoni de Vilaplana, autor de Illustrationes feudales et emphyteuticales ${ }^{313}$, que completaba el estudio de Lluís de Peguera y de otras obras. En la censura a las Proposiciones Christianas y iuridicas de Vilaplana se dice que "es el Autor en todo

305 Idem, pp. 2 у 3.

306 F. Esteve Perendreu, "Jurisdicció del bisbe sobre el mestrescola i eclesiàstics de l'Estudi General de Lleida”, pp. 183-197.

307 F. Esteve Perendreu, Mestrescoles i rectors..., pp. 116-130.

308 DGC, VIII, p. 1593.

309 F. Esteve Perendreu, Mestrescoles i rectors..., p. 273.

310 Ibidem.

311 F. Esteve Perendreu, El Col-legi universitari de l'Assumpció..., p. 87.

312 F. Esteve Perendreu, Mestrescoles i rectors..., p. 283.

313 Bacinone, sumptibus Raphaëlis Figuerò, Vincentij Surià et Iosephi Llopis, 1687. 
singular, $y$ ha sido acrehedor de las aclamaciones en las lineas de sabio, y virtuoso, en la Universidad de Lerida....14" El propio Vilaplana, en dicha obra escribió que "este es el sentir uniforme de los Dotores Theoricos, y de esse modo lo leí en la Cathedra de nuestra Real, y precelsa Vniversidad de Lerida $^{315 " .}$

No conocemos exactamente en qué momento Vilaplana leyó Derecho civil en Lérida. Sabemos que Vilaplana había pedido plaza de Oidor militar en cualquier veguería en los años 1674 y $1675^{316}$, fue nombrado juez de reclamos en $1686^{317}$, juez de corte en $1687^{318}$, estuvo en la terna para la provisión de la Real Audiencia de $1691^{319}$, y sustituyó a Jaume de Potau en la Real Audiencia en $1693^{320}$. Sin duda, con la excepción de Cortiada, Vilaplana fue el jurista más ambicioso, en el ámbito de la dogmática y en la praxis, de cuantos salieron del estudio ilerdense en la segunda mitad del siglo XVII.

El 18 de noviembre de 1693 se hizo la última reforma de los Estatutos de la Universidad, preparada por el obispo Fr. Miguel de Molina, Consejero real y Visitador del Estudio ${ }^{321}$. Hay que destacar que en ella se preceptuaba que para los grados de Doctor se tenían que leer tres cuartos del primer punto, sin que el padrino estuviese cerca. Se obligaba a que se midiese el tiempo de la exposición con un reloj de arena. Se prohibía que los doctorandos diesen propinas de confitura y de refresco. Asimismo se ordenó la extinción de la catedrilla de Cánones ${ }^{322}$.

En aquellos años el catedrático de Decreto era el Dr. Llorenç Gondi$\mathrm{no}^{323}$, canónigo y limosnero mayor de la Iglesia de Roda, Vicario general del Obispo visitador del Estudio, Miquel Jeroni de Molina, quien quería reformar la Universidad con unos nuevos estatutos pensados por el Dr. Joan Josep Casanoves. Cesó el Dr. Gondino y pasó a ocupar la cátedra el

314 A. de Vilaplana, Proposiciones Christianas y iuridicas, Barcelona, Iacinto Andreu, 1679, aprobación.

315 Ibidem, p. 152.

316 ACA, Consejo de Aragón, leg. 243, n. 7.

317 ACA, Consejo de Aragón, leg. 225, n. 102.

318 ACA, Consejo de Aragón, leg. 225, n. 92.

319 ACA, Consejo de Aragón, leg. 226, n. 41.

320 ACA, Consejo de Aragón, leg. 225, n. 78.

321 ACL, Llibre vert de la ciutat de Lleyda, ff. 979-1009.

322 F. Esteve Perendreu, El Régimen jurídico..., p. 234.

323 F. Esteve Perendreu, Mestrescoles i rectors..., p. 288. 
Deán de la Catedral, Dr. Pau Ferrer ${ }^{324}$, que fue asimismo diputado eclesiástico ${ }^{325}$.

El exrector Joan Baptista Morata (1691-1692), colegial que fue de la Asunción $^{326}$, regentó por oposición la cátedra menor de Instituta y que fue sustituto en otras de Leyes y Cánones ${ }^{327}$. Sabemos también que Esteve Serradó y Joan Baptista Sabata fueron profesores de Derecho canónico en $1695^{328}$. Este último fue ciudadano honrado y, con posterioridad, consejero borbónico de Lérida, nombrado el 15 de junio de $1711^{329}$.

Por las numerosas ocupaciones del Dr. Josep Llopis ${ }^{330}$, Paer segon desde $1696^{331}$, su cátedra fue leída por sustitutos: los hermanos Francesc i Bonaventura Goli la desempeñaron sucesivamente desde 1696 hasta 1698, año en que empezó a leer el Dr. Ignasi de Maranyosa i Granada ${ }^{332}$, vástago de una destacada familia ilerdense y protagonista destacado de la Guerra de Sucesión.

Los Paheres se dirigieron al Rey en 1698, explicándole el gran desorden que se producía en la provisión de cátedras a través de los votos de los estudiantes. Por ello, entre otras súplicas, solicitaban a Carlos II que las cátedras mayores fueran provistas por el Consejo de Aragón:

"En fin a que en otros tiempos se havia atendido para que los Estudiantes fuessen Juezes de las Cathedras, era para que los Cathedraticos, dependiendo de ellos, tuviessen mayor aplicación a su aprovechamiento; y a mas de las lecciones ordinarias, les assistiesen con repasso; pero ni este provechoso fin se quita, asumiendose V. Magestad en el modo dicho de la provision de las Cathedras mayores, que es donde nacen todos los inconvenientes; pues aun les quedan las provisiones de las Cathedras de Philosophia, Instituta y de las Cathedrillas, o Cathedras menores de Theologia, Leyes y Canones, siendo mas proprio de los que ocupan estas Cathedras el aplicarse a los repasos ${ }^{333}$ ".

324 Ibidem, p. 293.

325 E. Serra i Puig, Els Llibres de l'Ànima..., p. 170.

326 F. Esteve Perendreu, El Col-legi universitari de l'Assumpció..., p. 87.

327 F. Esteve Perendreu, Mestrescoles i rectors..., p. 282.

328 F. Esteve Perendreu, El Col-legi universitari de l'Assumpció..., p. 88.

329 AML, Reg. 472, Manual dels actes (1707-1715), f. 16r.

330 DGC, IX, p. 1752, informa de que Llopis era ciudadano honrado de Barcelona y de Lérida, y que poseía una casa "en dita ciutat de Lleyda y parròquia de Sant Llorens, a la plasa de la Palma”.

331 Q. Casals Bergés, Polítics de Lleida..., p. 96.

332 F. Esteve Perendreu, Mestrescoles i rectors..., p. 295.

333 Ibidem, p. 408. 
Al cabo de dos años esta cuestión aún no había sido zanjada y los síndicos del Estudio la volvieron a plantear. En 1700 fue elegido Rector Josep Motes, que era Bachiller en Teología y en Cánones, y profesor de ambas disciplinas ${ }^{334}$. Sabemos que también a la sazón enseñaba cánones Bonaventura de Montserrat ${ }^{335}$, Rector del Colegio de la Concepción.

\subsection{Cambio de dinastía}

El 11 de agosto de 1700 había muerto el Dr. Jaume Biosca ${ }^{336}$ y la Real Cancillería suspendió las oposiciones que se habían convocado a la cátedra de Prima ${ }^{337}$. Los síndicos del Estudio, Ignasi de Maranyosa y Ramon Queraltó, buscaron el apoyo del Cabildo para escribir al Canciller, preocupados por los problemas que acarrearía dicha suspensión. El Virrey Jorge, Landgrave de Hasia, escribió una misiva al Rector el 25 de agosto de 1700 en la que ordenaba la provisión de las cátedras excepto las de Instituta y Escritura ${ }^{338}$. Tras las gestiones de los Paheres, la cátedra se proveyó al Dr. Joan Josep Casanoves, que había detentado durante veinticinco años la de Vísperas ${ }^{339}$. Asimismo, el Dr. Josep Llopis obtuvo una plaza de Juez en la Real Audiencia de Cataluña ${ }^{340}$ y dejó la cátedra en 1704. Posteriormente ocupó otros cargos ${ }^{341}$ hasta llegar al Consejo de Castilla ${ }^{342}$.

334 Idem, p. 299.

335 Creemos que se trata de Josep Bonaventura de Montserrat i Brossa, caballero, natural de Cervera. Participó en la Junta de Brazos de 1713. Véase F. J. Morales Roca, Próceres habilitados..., Vol. II, p. 322.

336 E. Ribera, "Figuras del Estudio General...”, p. 81.

337 AML, Reg. 870, Correspondencia, s.f.

338 ACL, P7_M2_P3_Co6, Llibre del Studi, s. f.

339 F. Esteve Perendreu, Mestrescoles i rectors..., pp. 300-302.

340 J. Solís, "La magistratura austracista en la Corona de Aragón", Manuscrits, 23 (2005), pp. 131-150, especialmente p. 134.

341 AHN, Consejos, leg. 6.804, n. 52 y 128.

342 R. Cerro Nargánez, "Assessors del veguer i alcaldes majors: una transició problemàtica per a Barcelona (1714-1720)”, Barcelona. Quaderns d'Història, 7 (2002), pp. 119135, especialmente p. 134. P. Molas, “Aragón’ en el Consejo de Castilla”, Cuadernos dieciochistas, 2 (2001), p. 20, resume su trayectoria de la siguiente forma: "El leridano José Llopis había pertecido a las instancias de poder de la Cataluña foral. Había sido cabeza del municipio de Lérida en 1697 y diputado de la Generalitat por el brazo real en 1700. Exiliado en 1706, se le nombró alcalde de Casa y Corte, cargo que ocupó hasta 1721. Solicitó plaza de fiscal de Castilla pero se le concedió de consejero de Hacienda (1722). Nombrado consejero de Castilla en 1726, murió dos años más tarde”. 
Felipe V fue recibido con gran alborozo en Lérida en septiembre de 1701, y mandó instrucciones para modificar la estructura de las cátedras. La de Prima, que dejó el Dr. Llopis, fue provista por oposición a finales de 1704, a la que se presentaron el Dr. Joan Pau Ferrer, Deán y catedrático de Decreto, y el Dr. Ignasi de Maranyosa, catedrático de Vísperas, apoyado éste por su poderoso hermano Ramon ${ }^{343}$. Al final, obtuvieron cuatro votos cada uno y el empate fue decidido por el obispo Francesc Solís, quien dio su voto al Dr. Maranyosa. El nombramiento fue impugnado por el Dr. Ferrer, y por el Dr. Ignasi de Gomar i de Vilaplana ${ }^{344}$, a la sazón sustituto de la cátedra de Prima de Cánones, pero fue ratificado el vencedor y tomó posesión de la cátedra ${ }^{345}$. Figuran también como catedráticos a la sazón el Dr. Anastasi Biosca i Anglesill $^{346}$, hijo del fallecido catedrático de Prima Jaume Biosca, y el Dr. Bartomeu Messonada, insaculado como Oidor y Diputado real ${ }^{347}$.

Con ello podemos completar la nómina de los profesores de estos momentos previos a la Guerra de Sucesión: el Dr. Ignasi de Maranyosa detentaba la cátedra de Prima de Cánones; el Dr. Pau Ferrer era el catedrático de Decreto; y el de Vísperas, el Dr. Josep Mallada i Pedret, que se desempeñó como Paer $\operatorname{segon}^{348}$. El catedrático de Prima de Leyes era el Dr. Joan Josep Casanoves; el de Código, el Dr. Ramon Queraltó y el de Vísperas, el Dr. Anastasi Biosca, ciudadano honrado y Paer de Lérida, así como síndico de Cortes por el Brazo Real en $1701^{349}$. El Dr. Messonada era el catedrático de Instituta ${ }^{350}$. En 17011702 constatamos que Ignasi de Maranyosa i de Granada era Paer en cap ${ }^{351}$. La mayoría de los citados fue de fidelidad austracista, como veremos a continuación, aunque se acomodaron después a la situación posterior a la guerra.

Los últimos profesores de los que tenemos constancia en 1705 son: Ignasi de Maranyosa i de Granada, catedrático de Prima de Cánones; Joan Josep Casanoves, catedrático de Prima de Leyes; Josep Mallada, de Vísperas de Cá-

343 J. Lladonosa, Lérida moderna. Época de los Borbones, p. 27.

344 Murió el 17 de enero de 1715. Véase F. Pifarré San Agustín, Aspectes sanitaris de l'arxiu parroquial de Sant Joan de Lleida, segles XVIII i XIX, Lleida, [Tesis doctoral], 2007, s.f.

345 F. Esteve Perendreu, Mestrescoles i rectors..., p. 310.

346 F. J. Morales Roca, Próceres habilitados..., Vol. II, p. 178.

347 E. Serra i Puig, Els Llibres de l'Ànima..., p. 263.

348 Q. Casals Bergés, Polítics de Lleida..., p. 106.

349 F. J. Morales Roca, "Officialium Catalonia”, p. 459.

350 F. Esteve Perendreu, Mestrescoles i rectors..., pp. 312-313.

351 F. Pifarré San Agustín, Aspectes sanitaris..., s.f. 
nones; Pau Ferrer, de Decreto; Ramon de Queraltó, de Código; Anastasi Biosca, de Vísperas de Leyes; y Bartomeu Mesonada, de Instituta ${ }^{352}$. La cátedra menor de Instituta la leyó también Fr. Joan Cancer, benedictino ${ }^{353}$.

A partir de entonces empezaron las turbas populares y el 21 de septiembre de 1705 se determinó la capitulación de Lérida, negociada por Francesc Cubells, Ignasi Maranyosa, Anastasi Biosca y el Dr. Juan Bautista Bullfarines i Sangrà, ciudadano honrado y síndico. Esa misma tarde, las tropas austracistas ocuparon la Puerta de San Antonio ${ }^{354}$.

El 27 de septiembre la ciudad envió a Ignasi Maranyosa y a Anastasi Biosca para jurar obediencia a Carlos de Austria ${ }^{355}$. Como premio, el Dr. Maranyosa fue nombrado Juez del Real Senado el 25 de noviembre de ese año ${ }^{356}$. Entre los que portaron el palio cuando el rey Carlos III fue aclamado en Lérida el 7 de julio de 1706 estaban los Paheres y los catedráticos Bartomeu Messonada y Josep Mallada ${ }^{357}$. Mallada, natural de Lérida, había nacido en 1674, hijo de un Doctor en Medicina. Sabemos que se doctoró en Leyes y en Cánones y que en 1701 había sido asesor ordinario del Veguer ${ }^{358}$.

De nuevo hubo conflicto de jurisdicción entre el Obispo y el Maestrescuela, pues éste pretendía tener jurisdicción privativa y sustraerse de la eclesiástica. El 25 de agosto de 1705 se firmó una Demostración jurídica manuscrita, en la que el Obispo de Lérida fundaba sus derechos ${ }^{359}$.

Según Esteve Perendreu, en 1706 se extinguió de facto la Universidad, pues sus aulas fueron ocupadas el 9 de junio por un regimiento de caballería ${ }^{360}$. Sabemos que ese año aún leyó Simó Pocurull ${ }^{361}$. Los Vicerrectores de

352 F. Esteve Perendreu, Mestrescoles i rectors..., pp. 313 y 320.

353 Ibidem, p. 314. Recordemos que los benedictinos eran una de las pocas órdenes religiosas que tenían estudiantes de Leyes y de Cánones. J. L. Llaquet de Entrambasaguas, La Facultad de Cánones de la Universidad de Cervera (ss. XVIII-XIX), Barcelona, Universidad de Barcelona, [Tesis doctoral], 2001, p. 594, indica que a los benedictinos sólo se les estaba permitido graduarse en cánones.

354 F. de Castellví, Narraciones Históricas, I, p. 583.

355 Ibidem, p. 585 .

356 Idem, p. 625.

357 M. de Riquer, Quinze generacions d’una família catalana, Barcelona, Quaderns Crema, 1998, p. 217.

358 F. Esteve Perendreu, Mestrescoles i rectors..., p. 320.

359 AHUB, Universidad de Cervera, Caja 57, leg. 3090.

360 F. Esteve Perendreu, Mestrescoles i rectors..., p. 322.

361 Idem, p. 323. F. Pifarré San Agustín, Aspectes sanitaris..., s.f. proporciona algu- 
la misma durante el tiempo de suspensión de la actividad académica fueron Joan Josep Casanoves y Ramon Queraltó. El primero, que formó parte de la junta de guerra y era Paer segon ${ }^{362}$, falleció el 30 de septiembre de $1711^{363}$ y el segundo, que quedó como único Vicerrector, pidió en vano la restauración de los estudios, junto con Marià Biosca i Anglesill, catedrático de Instituta ${ }^{364} \mathrm{y}$ hermano del citado Anastasi. Ramon de Queraltó y Josep Mallada pasaron a formar parte de la junta de gobierno municipal, constituida el 14 de junio de 1711 con fidelidad a Felipe V ${ }^{365}$.

No sabemos dónde situar a Juan Balcazar de Burgos, que en 1746 firmó una censura a un libro como "Cathedratico que fuè de Prima de Canones en la Universidad de Lerida ${ }^{366}$ ". Simplemente, dejamos constancia del dato y de que, en su caso, debió de desempeñar dicha cátedra en la época final de la institución.

La erección de la Universidad de Cervera ha sido muy estudiada y sobre ella hay diversas interpretaciones ${ }^{367}$. Rubió y Borrás estudió con detalle la transferencia de Lérida a Cervera, y dio cuenta de la correspondencia entre los Diputados que escribían desde la Corte y los Paheres de Cervera. Se pidió

"que se digne Su Majestad trasladar la Universidad Real y Estudio General de Lérida con los dos Colegios de Beca existentes en dicha Ciudad, a la de Cervera, con todas las rentas que poseen, no pudiendo cursarse las enseñanzas de Leyes, Cánones ni Medicina en otra Universidad de Cataluña, como asimismo graduarse de Doctor ni Bachiller; interponiendo cerca de Su Santidad la necesaria influencia para el traslado a Cervera de la

nos detalles sobre su vida y confirma que figura en la documentación como profesor de leyes: contrajo matrimonio en 1706 y falleció el 19 de febrero de 1743.

362 AML, Reg. 472, Manual dels actes (1707-1715), f. 16r.

363 F. Pifarré San Agustín, Aspectes sanitaris..., s.f.

364 F. Esteve Perendreu, El Col-legi universitari de l'Assumpció..., p. 92.

365 AML, Reg. 472, Manual dels actes (1707-1715), f. 16r.

366 S. de Acuña, Dissertaciones sobre el orden que los medicos deben observar en las juntas para evitar discordia, y conservar la autoridad, y prerrogativa, de que goza cada uno; en defensa de las Universidades de España, del Real Protho-Medicato, de los Medicos de Camara de su Magestad y de los de su Real Familia, Madrid, Librerìa de Luis de Correa, 1746.

367 Véase especialmente J. Prats, La Universitat de Cervera i el reformisme borbònic, Lleida, Pagès, 1993, que se hace eco de las diversas propuestas interpretativas. Según su lectura, muy bien respaldada en la documentación archivística, Felipe $\mathrm{V}$ no obró tanto por represalia como por la voluntad reformista, que luego intentó aplicar a muchas universidades hispánicas, con poco éxito. 
dignidad de Maestrescuela, como también para las Rentas Eclesiásticas de que disfruta la Universidad de Lérida ${ }^{368}$ ".

Dicho memorial continuaba con un plan alternativo, que subrayaba la idea de que la Universidad de Cervera tenía que erigirse según el modelo de Lérida y se destacaba, sobre todo, la enseñanza del derecho:

"Si no pudiera conseguirse lo anterior, debe suplicarse a Su Majestad se digne mandar y disponer la erección en Cervera de una Universidad como la de Lérida y para el sostenimiento de las Cátedras, que serán tres de Teología, tres de Cánones, cuatro de Leyes, tres de Medicina y tres de Filosofía, el Rector y demás Oficiales, sean señaladas cuatro mil libras, moneda barcelonesa, consignadas del tercio que se acostumbra imponer a las Mitras en Cataluña; o de donde tenga Su Majestad por más conveniente, en la misma forma que fué concedido a la Universidad de Lérida y otras; y que en ninguna de las otras Universidades de Cataluña, se puedan leer Cátedras de Leyes, ni Cánones, gozando el Rector de dicha Universidad de la misma autoridad que el Maestrescuela de Lérida ${ }^{369 ”}$.

Felipe V escogió como maestrescuela de la Universidad de Cervera a Francesc de Queralt, que se presentó ante el cabildo de la Catedral de Lérida para pedir que se le diese posesión de dicho cargo, hecho que logró el 14 de julio de 1716. Finalmente, el 11 de mayo de 1717 se erigió formalmente la Universidad de Cervera y todas las demás universidades catalanas fueron transferidas a dicho centro ${ }^{370}$. Asimismo, las rentas de la Universidad de Lérida fueron aplicadas a la de Cervera ${ }^{371}$, como veremos en el capítulo siguiente. El Ayuntamiento de Cervera inició un proceso contra el Ayuntamiento de Lérida para el devengo del sueldo de los catedráticos ${ }^{372}$.

A diferencia de lo sucedido en la Universidad de Barcelona, de la que Felipe $\mathrm{V}$ extrajo a algunos catedráticos afectos para la de Cervera, en la Facultad de Leyes y Cánones ilerdense apenas un profesor pudo continuar con la do-

368 M. Rubió y Borrás, Historia de la Real y Pontificia Universidad de Cervera, I, Barcelona, Librería Verdaguer, 1915, pp. 100-101.

369 Ibidem, p. 101.

370 Idem, p. 318. "Mando que absolutamente queden extinctas assi la dicha Universidad de Gerona como las de Lérida y Barcelona y otra qualquiera que haya en aquel Principado, y que en ninguna de ellas desde la publicación del referido Decreto se pueda hauer conferido ni conferir grado literario de Bachiller, Maestro, Licenciado o Doctor”. Véase también F. Esteve Perendreu, Mestrescoles i rectors..., pp. 323-325.

371 AHUB, Universidad de Cervera, Caja 1, Legs. 4768-4769.

372 ACA, Real Patrimonio, Procesos, 1717, n. 1. 
cencia, y no de forma inmediata. Sin embargo, el Dr. Jaume Aran, catedrático de Medicina en Lérida, fue nombrado catedrático de Prima de Medicina de Cervera $^{373}$. Los catedráticos de Leyes y Cánones leridanos tuvieron, desde entonces, una suerte y trayectoria dispar.

Por su parte, Ignasi de Maranyosa, durante la guerra, fue destinado por el Archiduque Carlos a las fronteras de Urgel y se mostró favorable a la resistencia de Barcelona. Tuvo que exiliarse y en 1717 ejercía como Juez de la Real Audiencia de Cerdeña, donde fue capturado durante la invasión borbónica de la isla ${ }^{374}$.

En cambio, Marià Biosca i Anglesill y Josep Mallada i Pedret, síndicos diputados, a la sazón fervientes austracistas, formaron parte de la comitiva que fue a dar la bienvenida a Felipe V en Fraga, mostrándose desde entonces fidelísimos a este monarca. Ambos fueron recompensados. Cuando el Rey designó en 1727 los oficios para la nueva estructura del Ayuntamiento, Josep Mallada fue regidor y se le asignó el cargo de Abogado Ordinario de la Ciudad ${ }^{375}$. En cuanto a Biosca, hijo y nieto de catedráticos, fue nombrado catedrático de Decretales en la Universidad de Cervera en $1719^{376}$. Posteriormente, durante los años 1723 a 1727 fue Alcalde Mayor de Lérida ${ }^{377}$ y, desde ese año hasta su fallecimiento en 1745, fue edil vitalicio del nuevo Ayuntamiento borbónico, y el primero en ocupar esta posición entre los que con anterioridad no poseían la condición de caballero ${ }^{378}$.

373 F. Esteve Perendreu, Mestrescoles i rectors..., p. 149.

374 F. de Castellví, Narraciones Históricas..., IV, p. 610.

375 J. M. Clarisó Martí, La economía de la nobleza..., p. 444.

376 J. L. Llaquet de Entrambasaguas, La Facultad de Cánones de la Universidad de Cervera (ss. XVIII-XIX), p. 239.

377 F. J. Morales Roca, "Officialium Catalonia, IV, Regidores del Ayuntamiento de Lérida...”, p. 459.

378 Q. Casals Bergés, Polítics de Lleida..., p. 104. Para J. M. Clarisó Martí, La economía de la nobleza..., pp. 444-445, se trataba de "otro proceso de ennoblecimiento casi idéntico a los que venimos explicando repetidamente: una familia que había acumulado la suficiente riqueza para colocar un hijo en religión y promocionarlo a la élite eclesiástica; enviar otro descendiente a la Universidad para su graduación como doctor; y una vez graduado doctor, los siguientes pasos eran la obtención de una plaza como catedrático en la Unversidad y solicitar la incorporación en la matrícula de ciudadanos honrados de Lleida en la Paeria”. 


\section{Conclusiones}

El período que abarca desde 1598 hasta 1714 representa la última etapa de la Universidad de Lérida, una época caracterizada por la inestabilidad institucional, y jalonada por dos guerras que marcaron el devenir de la institución. De hecho, podríamos dividir la historia de la Universidad desde la muerte de Felipe II y la creación de la Maestrescolía hasta la Guerra dels Segadors y, desde ésta hasta la Guerra de Sucesión.

La Facultad de Leyes y Cánones fue, sin duda, la más prestigiosa del Estudio ilerdense, si bien, en los poco más de cien años que aquí estudiamos, asistimos a su progresiva decadencia y regionalización. La decadencia vino, sobre todo, por la pujanza y la competencia de las universidades vecinas, y discurrió en paralelo al ascenso de la Universidad de Barcelona, que se beneficiaba del poder de la Ciudad Condal, Cap i casal y centro de la administración del Principado. Al desarrollo de las Universidades de Barcelona y de Zaragoza desde finales del siglo XVI, debe sumarse el de las nuevas Facultades de Mallorca y Vic, que empezaron a conceder grados en derecho poco antes de la Guerra de Sucesión.

Hubo, por lo tanto, una multiplicación de la competencia, sin que ello se tradujese en la calidad de la enseñanza. En este sentido podemos leer las críticas vertidas por Josep Finestres ${ }^{379}$, educado en el Colegio de Cordelles y en la Universidad de Barcelona, hacia el Estudio de Lérida, al que consideraba vulgar y que no supo emprender el vuelo tras las reformas del obispo Agustín. Y es que, en definitiva, tras las reformas del gran humanista, al decir de Gayá Massot, "el Estudio estaba ya en la pendiente de su decadencia ${ }^{380 " . ~}$

Lérida adquirió una cierta fama cuando tuvo poca competencia, es decir, hasta mediados del siglo XVI, si bien sus borlas eran menos preciadas que las de Tolosa, Padua, Roma, Pisa o Bolonia. Pese a ser la Universidad más antigua de la Corona de Aragón, jamás gozó del peso que tuvo Salamanca, y sus profesores y egresados tuvieron, en su mayoría, un cursus honorum más bien circunscrito al Principado, o incluso meramente local. Las peticiones, por parte de la Universidad, de restringir los oficios públicos de provisión real a los doctores de Lérida tienen que entenderse como medidas tendentes a frenar tanto la decadencia como la competencia.

379 I. Casasnovas, Josep Finestres: estudis biográfics, Barcelona, Biblioteca Balmes, 1931, p. 172.

380 R. Gayá Massot, Los Jesuitas en la Universidad de Lérida, p. 113. 
En definitiva, el establecimiento de nuevas Universidades (Zaragoza, Barcelona, Tarragona, Solsona, Tortosa, Vic, Mallorca...) hizo que Lérida perdiese cada vez más su atractivo, especialmente cuando algunas de ellas, como Solsona, Orihuela o Irache, concedían los grados con especial laxitud.

Los factores político y económico, como hemos señalado, fueron muy relevantes, aunque la propia institución jamás gozó de suficientes rentas, hecho que le obligó a estar pleiteando continuamente, y pidiendo ayuda para pagar los salarios. Por esta razón, los profesores querían dejar la docencia y pasar a cargos más estables y mejor remunerados. De ahí también que los catedráticos tuviesen cada vez más una trayectoria local. Mientras que en los reinados de Felipe III y Felipe IV observamos aún una preeminencia de los profesores de Lérida sobre los de Huesca y Zaragoza, en el reinado de Carlos II, repuesta ya la Universidad de la Guerra dels Segadors, se logró una cierta estabilidad institucional, aunque a costa de perder esa dimensión de prima inter pares de la que gozaba anteriormente.

Como corolario de lo anterior, podemos ver que, a medida que avanzaba la centuria, las plazas de profesor eran ocupadas mayoritariamente por vástagos de las familias mejor situadas de Lérida. Los Biosca, los Maranyosa, los Sabata... a menudo emparentaron entre sí y desempeñaron las cátedras y los diferentes oficios representativos de la ciudad. Puede decirse que, en esta última etapa, la Universidad de Lérida pasó de ser la sede histórica de la Corona de Aragón a una universidad de ámbito local, modelada según las oligarquías de la ciudad, en una endogamia cada vez más clara ${ }^{381}$.

La carrera de los profesores empezaba a menudo a través de la cooptación de los colegiales de la Asunción o como vástagos de una familia de la oligarquía ilerdense. Tras unos años de lectura en las cátedras de Bachiller, pasaban a realizar sustituciones en las cátedras de Prima, Segunda, Tercia o de Instituta. El cursus honorum, especialmente para los candidatos de promoción local, era el ascenso desde Instituta o Tercia, a Segunda y de ésta a Prima.

Pese a que los catedráticos mandaban memoriales para lograr una promoción en la Administración, lo cierto es que, si la comparamos con la Universidad de Barcelona, pocos profesores de Lérida llegaron a detentar cargos en las Reales Audiencias durante el período estudiado, especialmente si lo contrastamos con el siglo XVI. La figura más destacada fue, sin duda, el Dr. Miquel de Cortiada, catedrático en una época tan convulsa como la Guerra dels Segadors, y que luego tuvo una promoción muy relevante, tanto como

381 A. Passola Tejedor, Oligarquia i poder a la Lleida dels Austria, pp. 349-362. 
magistrado y regente, cuanto como jurisconsulto teórico y práctico. Añadamos también a Antoni de Vilaplana, que también dejó escritos de gran valía y logró una promoción notable. Debemos hacer mención a otros que ocuparon cargos en la Bailía General de Cataluña: el Dr. Dídac Cisteller (abogado fiscal), Joan Josep Casanoves o Tomàs de Maranyosa (procuradores fiscales).

Los catedráticos de ambos derechos fueron sensibles al poder político, y tomaron partido durante las guerras. Francesc de Sagarra, por ejemplo, fue totalmente contrario a Felipe IV y acabó exiliado en Francia, mientras que otros eran más acomodaticios, pues buscaban la promoción. La Guerra de Sucesión hizo que muchos profesores virasen hacia ambos bandos: el Archiduque Carlos recibió la fidelidad de la Ciudad y de sus profesores, si bien luego Felipe V, con la Universidad prácticamente extinguida, los atrajera mayoritariamente hacia sí. Uno de ellos, Marià Biosca, fue nombrado catedrático de Decretales en la Universidad de Cervera. Recordemos también la ejecutoria de Josep Llopis, filipista exiliado, que, tras ocupar numerosos cargos, llegó a Consejero de Castilla.

En cuanto a la enseñanza, sólo tenemos datos indirectos, a partir de unos pocos manuscritos de las lecciones y de un manuscrito parcial sobre las matrículas. No han sobrevivido los libros de grados ni otros similares, de manera que tenemos que estimar la docencia a partir de las escasas noticias que podamos espigar. Al parecer, no hubo ninguna variación con respecto al plan de estudios tradicional, basado en el ius commune, si bien los profesores descendían en algunas ocasiones a glosar la práctica jurídica del derecho catalán.

El nivel de los estudiantes, como se ha visto, era muy bajo, y el ambiente era muy violento, propenso a las riñas y a los tumultos, como en la mayoría de las ciudades universitarias. El Estudio General era un espejo de las tensiones políticas y sociales de la ciudad. La inestabilidad política contagió especialmente el devenir de los legistas y los canonistas, que vindicaban continuamente una protección de los egresados ilerdenses frente a los de las demás universidades catalanas.

En definitiva, en este capítulo hemos podido identificar a los profesores de Leyes y Cánones de la Universidad de Lérida, conocer sus perfiles y promoción y tener una visión de conjunto del devenir universitario desde la muerte de Felipe II hasta la extinción del Estudio ilerdense y su transferencia a Cervera. En el capítulo siguiente analizaremos las Facultades de Artes y Teología. 


\section{RELACIÓN DE LOS PRINCIPALES CATEDRÁTICOS CITADOS}

[Salvo Instituta, se excluyen las cátedras menores]

\begin{tabular}{|l|l|}
\hline \multicolumn{1}{|c|}{ NomBRE } & \multicolumn{1}{c|}{ FACULTAD } \\
\hline Agramunt, Francesc & Cánones \\
\hline Anglesill, Onofre & Leyes \\
\hline Arqués, Tomàs & Cánones \\
\hline Bafart i Farrús, Francesc & Leyes \\
\hline Berart, Ramon & Cánones \\
\hline Biosca i Anglesill, Anastasi & Leyes \\
\hline Biosca, Jaume & Leyes \\
\hline Biosca, Jeroni & Cánones \\
\hline Burgada, Antoni & Cánones \\
\hline Canet, Joan Baptista & Leyes \\
\hline Casanoves i Mercer, Joan Josep & Leyes \\
\hline Cisteller, Dídac de & Leyes - Cánones \\
\hline Cortiada, Francesc & Leyes \\
\hline Cortiada, Miquel & Leyes \\
\hline Enciso, Juan de, O.S.A. & Leyes - Cánones \\
\hline Enveja i Marcer, Bernat & Leyes \\
\hline Farro, Francesc & Cánones \\
\hline Ferran, Josep Joan de & Leyes \\
\hline Ferrer, Joan Pau & Cánones \\
\hline Freixenet, Francesc & Leyes \\
\hline Freixenet, Josep & Leyes \\
\hline Freixenet, Nicolau & Leyes \\
\hline Frígola i de Lordat, Joaquim de & Cánones \\
\hline Gaço, Felipe & Cánones \\
\hline Gomar, Josep de & Leyes \\
\hline Gomar i de Vilaplana, Ignasi de & Leyes - Cánones \\
\hline Gondino, Llorenç & Cánones \\
\hline Guarga, Josep & Cánones \\
\hline Hernández Alegre, Gabriel, O.S.A. & Cánones \\
\hline Ivars, Joan Guillem & Cánones \\
\hline Izquerdo y Aznar, Juan & Cánones \\
\hline & \\
\hline
\end{tabular}




\begin{tabular}{|l|l|}
\hline Llopis, Josep & Leyes \\
\hline Mallada i Pedret, Josep & Cánones \\
\hline Maranyosa i Granada, Ignasi de & Leyes \\
\hline Maranyosa i Toló, Joan Baptista & Leyes \\
\hline Maranyosa, Tomàs de & Cánones \\
\hline Melianta i Morató, Josep de & Leyes \\
\hline Messeguer, Francesc Josep & Leyes \\
\hline Messonada, Bartomeu & Leyes \\
\hline Molner i Farran, Joan Pau & Cánones \\
\hline Monbilia i Pauls, Mateu de & Leyes \\
\hline Monjo, Joan Baptista & Leyes \\
\hline Montanuy, Medardo & Cánones \\
\hline Montfar i Sorts, Francesc & Leyes \\
\hline Morata, Joan Baptista & Leyes \\
\hline Nogués, Francesc & Leyes \\
\hline Novell, Aleix & Leyes \\
\hline Pallarés, Manuel & Leyes \\
\hline Perandreu i Cabacés, Francesc & Cánones \\
\hline Perat, Joan & Cánones \\
\hline Pollina i Ciurana, Joan Baptista & Cánones \\
\hline Queraltó, Ramon & Leyes \\
\hline Revert, Andreu & Cánones \\
\hline Rialp, Joan & Leyes \\
\hline Ripalta, Martín de & Leyes \\
\hline Sabadia, Gaspar & Leyes \\
\hline Sabata i Castells, Josep & Cánones \\
\hline Sabata, Josep & Leyes \\
\hline Sagarra, Francesc de & Leyes - Cánones \\
\hline Sagarra, Gaspar de & Leyes \\
\hline Sanou i Domènech, Josep & Leyes \\
\hline Sentís, Joan & Cánones \\
\hline Soler, Joan & Leyes \\
\hline Vallés, Melcior & Leyes \\
\hline Vilaplana, Antoni de & Leyes \\
\hline Viñuales, Martín de & Cánones \\
\hline
\end{tabular}




\begin{tabular}{|c|c|c|}
\hline 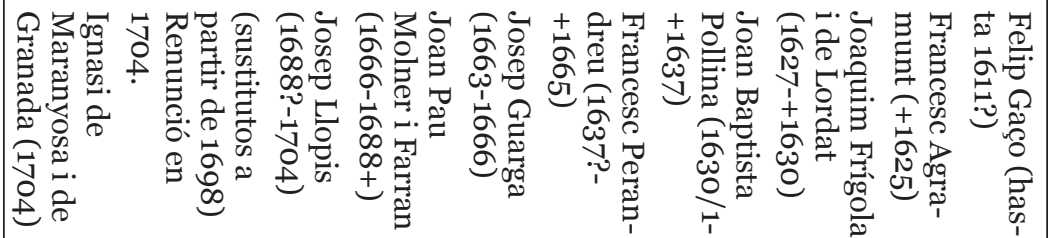 & 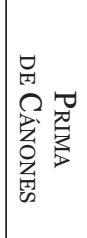 & \\
\hline 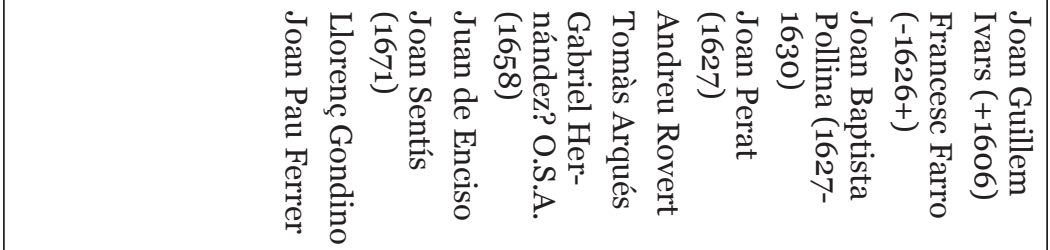 & 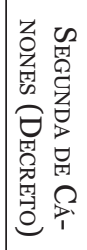 & \\
\hline 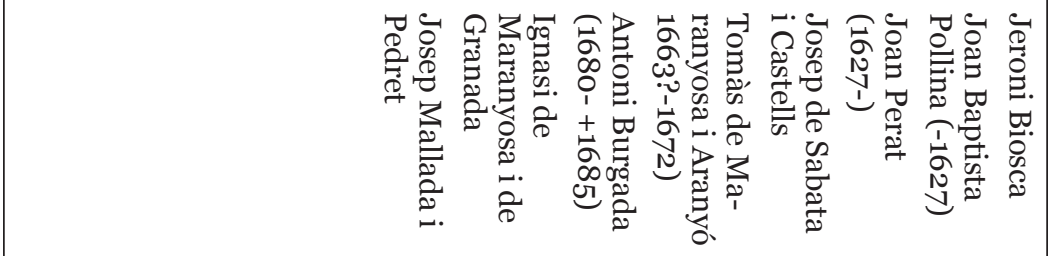 & 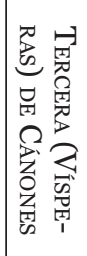 & 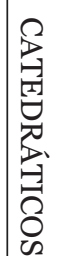 \\
\hline 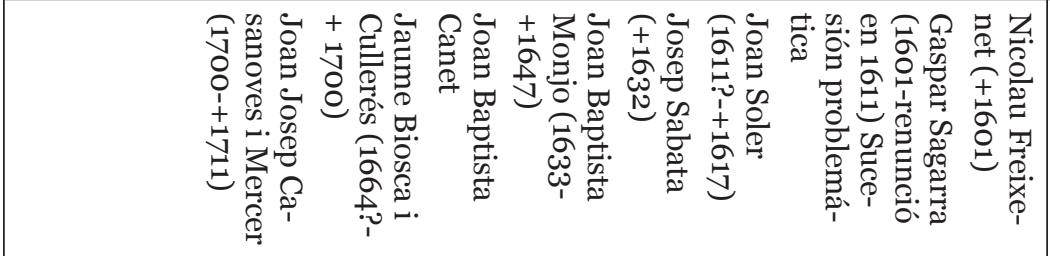 & 恶 & 尝 \\
\hline 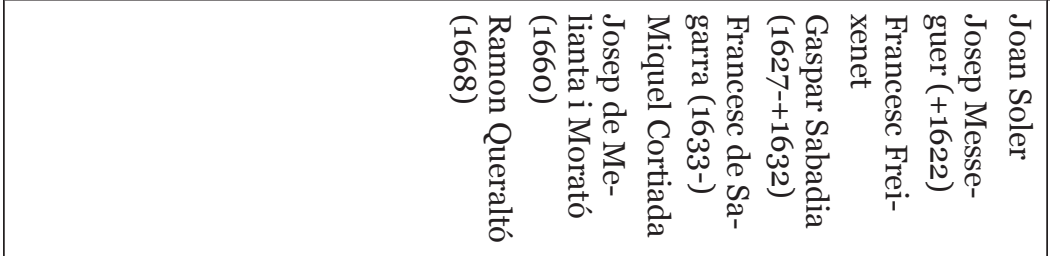 & 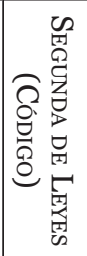 & 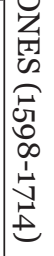 \\
\hline 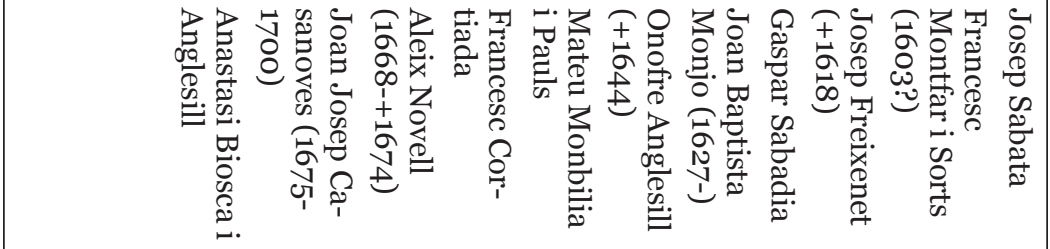 & 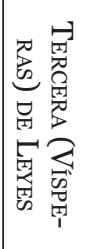 & \\
\hline 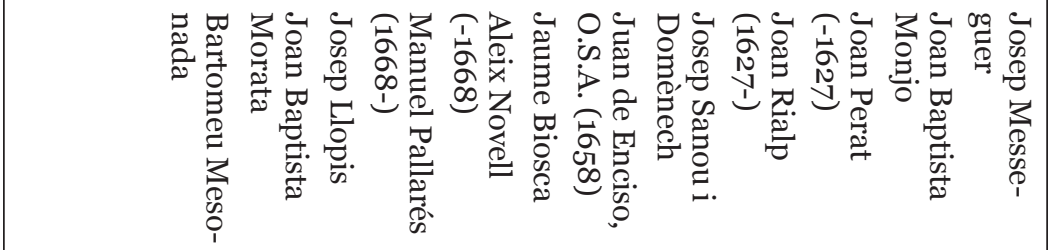 & 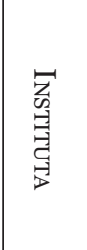 & \\
\hline
\end{tabular}




\section{LAS FACULTADES DE ARTES Y TEOLOGÍA (1598-1714)}

Tras haber estudiado en el capítulo anterior la evolución de la Facultad de Leyes y Cánones, el auténtico corazón de la Universidad, nos centraremos en este en las Facultades de Artes y de Teología del Estudio Ilerdense desde el fallecimiento de Felipe II hasta la transferencia de la Universidad a Cervera. Antes de entrar a comentar con detalle lo que sabemos acerca de la configuración de los estudios, las cátedras, los profesores y los alumnos, conviene tener una perspectiva general sobre estas Facultades en las Universidades de la Corona de Aragón.

1. El estudio de las Artes y la Teología en Lérida y en las Universidades de la Corona de Aragón

A diferencia de lo que sucedía con la Facultad de Leyes y Cánones, la implantación de las cátedras de Teología en Lérida fue tardía. Hemos visto en el primer capítulo la instauración de las cátedras de Conchillos, Prima y Vísperas. La reforma de Antonio Agustín consagró dos cátedras de Gramática dotadas con $100 £$, sendas cátedras de Filosofía, con unos emulumentos de $80 £$, una cátedra de Prima de Teología, con 60£, dos cátedras adicionales de Teología (una de ellas dotada con $60 £$ y la otra con $50 £$ ) y finalmente la llamada cátedra de Conchillos, con una remuneración de $60 £^{1}$. En un manuscrito de 1630 señala que "De Philosophia ay dos catredas que vale cada una ciento y treynta libras”. En el mismo manuscrito se indican los aumentos que percibían los catedráticos de teología:

"De Theologia sin la Catreda de prima ay quatro catredas, las tres valen a ochenta libras cada una sin los augmentos, y la de escritura, que se llama la catreda de Conchillos, vale sesenta libras y no entra en los augmentos. Estas tres Catredas tienen de augmento veynte y seys libras ocho sueldos cada una ${ }^{2}$ ".

En otro manuscrito se detalla la composición de las cátedras de Teología

1 F. Esteve Perendreu, El Régimen jurídico..., p. 159.

2 ACA, Consejo de Aragón, leg. 282, n. 48/11. 
en el momento de la extinción: Prima de Teología ( 85 ducados), Santo Tomás (120 ducados), Durando (6o ducados), Vísperas (6o ducados) y Escritura (6o ducados). La Ciudad solamente pagaba esta última cátedra.

Se trataba de una estructura prácticamente idéntica a la que había en la Universidad de Zaragoza y muy cercana a las de Huesca y Barcelona. Junto con tres cátedras de Medicina, "con cortissimo salario", había tres más de Filosofía, con una percepción de 120 ducados $^{3}$. Esas tres cátedras representaban una estructura muy básica, pensada para cubrir los cursos trienales. Antes de 1666, solo había dos cátedras de Filosofía. El montante total de las cátedras de las cuatro Facultades era, en el momento de la transferencia a Cervera, de 1600 ducados. Había 600 ducados más, procedentes del derecho de oncenillos, que se repartían entre los claustrales como aumentos.

La competencia de las demás universidades catalanas y aragonesas era muy dura. La Universidad de Huesca tenía cinco cátedras de Teología: Prima, Sagrada Escritura, Escoto, Vísperas y Durando. Los de Prima y Vísperas leían a Santo Tomás ${ }^{4}$. La recién creada Universidad de Zaragoza tenía también cinco cátedras: Prima, Vísperas, Escritura, Durando y Santo Tomás ${ }^{5}$.

Las Universidades catalanas eran menos dadas a la pluralidad de vías. Los estudios teológicos estaban muy vinculados a las necesidades de las diócesis y todas ellas (salvo la Seo de Urgel) tuvieron una Facultad en el siglo XVII. Lérida tuvo que luchar desde finales del siglo XVI con la dispersión y las facilidades dadas en las demás universidades del Principado, muy controladas por los cabildos y los dominicos.

En el curso 1571-1572 se habían establecido seis cátedras en el Estudio General de Barcelona: tres de ellas dedicadas a Santo Tomás, una a Pedro Lombardo y otras dos dedicadas respectivamente al Antiguo y al Nuevo Testamento ${ }^{6}$. La presión ejercida por los catedráticos de Santo Tomás acabó por eliminar las cátedras de Antiguo y Nuevo Testamento, dejando una sola de Sagrada Escritura en 1588. En cambio, se logró implantar una cátedra de Durando, regentada de forma bianual. Asimismo se promovió otra cátedra dotada por Doña Marina de Aragón, en la que también fue obligatorio leer a Santo Tomás7.

3 AHUB, Universidad de Cervera, Caja 147, leg. 1226.

4 A. Durán Gudiol, "Notas para la historia de la Universidad de Huesca”, p. 120.

5 G. Redondo Veintemillas, "La Universidad de Zaragoza”, en J. J. Busqueta Riu y J. Pemán Gavín (coords.), Les universitats de la Corona d’Aragó, p. 263.

6 A. Fernández Luzón, La Universidad de Barcelona..., pp. 236-237.

7 Ibidem, pp. 237-239. 
Las Ordenaciones de 1638 de la Universidad consagraron estas cátedras, que se mantuvieron hasta $1714^{8}$ : tres mayores y tres menores. Las mayores eran vitalicias y las menores tenían una duración trienal. Entre las cátedras mayores había dos de teología escolástica (ambas con una remuneración de $55 £$ dos veces cada año) y una de Sagrada Escritura (cuyo titular percibía asimismo semestralmente 60£). Las cátedras menores eran las del Maestro de las Sentencias (con un pago semestral de 45£), de Doña Marina de Aragón (cuyo titular recibía $35 £$ bianualmente) y de Durando (que percibía $40 £$ también dos veces al año ${ }^{9}$ ).

En cuanto a la organización de la Facultad de Artes barcelonesa, podemos decir que tenía un total de quince cátedras: seis de Filosofía, cuatro de Gramática y una de Hebreo, Griego, Matemáticas, Cirugía, y Retórica. Sin duda, las cátedras de Artes mantenían la vertiente humanística, mientras que las de Filosofía eran más tradicionales ${ }^{10}$. Si comparamos la riqueza de cátedras de Artes y Filosofía en Barcelona y la pobre estructura de Lérida (solamente con dos cátedras de Filosofía), podemos concluir que -especialmente tras la marcha de Antonio Agustín- en la ciudad del Segre no se prestó apenas atención a los estudios humanísticos y filosóficos.

La Universidad de Gerona comenzó a funcionar, en un primer momento, con tres cátedras de Gramática. En 1601, se crearon tres cátedras de Filosofía $^{11}$, aunque no se ocuparon de inmediato. Hasta la década de 1630 no se leyeron las tres cátedras de Teología y, desde 1663, se modificó la estructura de las mismas. Desde entonces, en la Universidad gerundense hubo cinco cátedras y dos catedrillas de Teología: la de Prima (de siete a las ocho de la mañana); de Expositiva (de ocho a nueve); de Adroher (de nueve a diez); de Vísperas (de dos a tres); y otra, llamada de Pasqual (de tres a cuatro). Las catedrillas se leían en horas que no se enseñaban las otras materias. Dichas cinco cátedras de Teología eran trienales, y las catedrillas, bienales ${ }^{12}$.

En la Universidad de Vic, confirmada por Felipe III en 1599, se había pre-

8 R. Ramis Barceló, "La Facultad de Teología de la Universidad de Barcelona a comienzos del siglo XVIII”, Revue d'Histoire Ecclésiastique, 112/1-2 (2017), pp. 185-214.

9 BC, Llibre de las Sedulas del Estudi General, ff. 1-2.

10 R. Ramis Barceló, "La defensa del tomismo frente al suarismo: la Facultad de Artes y Filosofía de la Universidad de Barcelona a comienzos del siglo XVIII”, Espíritu, 155 (2018), pp. 81-106.

11 AMG, Manual d'Acords (1601), Reg. 17694, ff. 203r-v.

12 AMG, Llibre d'actes o manual d'acords del Consell de la ciutat (1686), Reg. 17438, f. 6 . 
visto la lectura de la Filosofía según los comentarios de Vileta a Aristóteles ${ }^{13}$. Los estudios de Latinidad se basaban en las obras de Virgilio, Terencio, Cicerón y Erasmo. La Teología se basaba exclusivamente sobre Santo Tomás ${ }^{14}$. De hecho, a la vera de la Universidad nació, al igual que sucedió en Barcelona años después, una Academia de Santo Tomás, para la exaltación del Aquinate como opinión propia de la Universidad ${ }^{15}$.

El tomismo también fue la opinión en la Universidad de Tortosa, en manos de los dominicos, en cuyos estatutos leemos:

"Qualquier que se graduare en esta Universidad despues de hecha la profession de la fee, antes de recibir el grado ò insignias, jure en manos del Canciller, que defendera la doctrina del Angelico Dotor Santo Thomas de Aquino, y los privilegios y estatutos desta Universidad ${ }^{16 ”}$.

Tortosa fue asimismo un Convento-Universidad dominicano, aunque con mayor fama, que graduó a clérigos de Aragón, Cataluña, Baleares y Valencia. El caso extremo de laxitud era la Universidad de Solsona, un Colegio de dominicos que, como hemos indicado en el capítulo anterior, concedía grados en todas las Facultades sin tener privilegios ni estudios mínimamente reglados.

Con la excepción de Solsona y Tortosa, las demás Universidades, salvo la de Tarragona, eran municipales y el peso de los canónigos fue determinante en el establecimiento de un statu quo muy conservador, enraizado casi siempre en el tomismo y opuesto a las novedades. Las Universidades hacían las veces de seminarios y los formadores a menudo eran canónigos o prebendados que tenían como obligación o percepción anexa el desempeño de algunas cátedras ${ }^{17}$, así como jóvenes clérigos que, como hemos indicado, buscaban su promoción a través de la lectura de una cátedra menor. La formación teológica en estas universidades municipales era reducida y se basaba fundamen-

13 El maestro Vileta había sido catedrático en la Universidad de Barcelona, y un reputado conocedor de la obra de Aristóteles y de Llull. Véase J. M. Madurell Marimon, “Luis Juan Vileta”, pp. 19-76 y R. Ramis Barceló, “Aristotelismo, lulismo y ramismo en Barcelona durante el siglo XVI: Joan-Lluís Vileta y sus discípulos”, Cauriensia, 10 (2015), pp. 385-407.

14 J. Gudiol i Cunill, La Universitat Literària de Vic, Vic, Patronat d'Estudis Osonencs, 1991, [1924], pp. 51-66.

15 Ibidem, Cap. XVII.

16 BC, Ms. 3918, Libro de la Universidad..., f. 4v.

17 Un rápido resumen puede verse en J. Bada i Elias, "L'ensenyament superior a Catalunya en el segle XVII", Ausa, 143 (1999), pp. 499-518. 
talmente en el estudio de la escolástica tomista, aderezada a veces con algún curso según la opinión de Durando y otro de Sagrada Escritura.

La Universidad de Orihuela, fundada sobre el Colegio de los dominicos, se distinguió por su defensa del tomismo en Teología ${ }^{18}$. En cambio, la Universidad de Gandía estaba en manos de la Compañía de Jesús, que se ocupó de la enseñanza de las Artes y de la Teología ${ }^{19}$.

Hay que indicar que, doctrinalmente, Lérida tuvo mayor parentesco con las Universidades de Zaragoza, Huesca, Valencia y Mallorca que con las catalanas. En Valencia se produjeron difíciles equilibrios para mantener las opiniones distintas del tomismo, aunque nunca se perdió una cierta pluralidad en la teología escolástica ${ }^{20}$ y fue uno de los núcleos de mayor pujanza del suarismo. El caso de Mallorca es distinto, porque se erigió la Universidad en 1692 y se hizo ya de acuerdo con el sentir reformista de Carlos II y con la participación de las principales órdenes religiosas (dominicos, jesuitas y franciscanos), de manera que se podía estudiar teología siguiendo las vías luliana, escotista, tomista o suarista ${ }^{21}$.

Una circunstancia que distinguió a Lérida frente a las demás universidades de Cataluña fue que se admitió, como después veremos, que los jesuitas se ocupasen de la enseñanza de la Gramática en la Universidad, algo que permitió una participación relativamente temprana de la Compañía de Jesús en el Estudio, que acabó consolidándose en el siglo XVIII.

18 Para Artes, Medicina y Teología, véase R. Ramis Barceló y P. Ramis Serra, "Los primeros grados de la Universidad de Orihuela (1610-1643)", Estudis. Revista de Historia Moderna, 43 (2017), pp. 235-26o.

19 P. García Trobat, "Los grados de la universidad de Gandía (1630-1772)”, en AAVV, Universidades españolas y americanas, Valencia, Universidad de Valencia, 1987, pp. 175186.

20 Véase la exposición de la estructura de las cátedras de A. Felipo, La Universidad de Valencia durante el siglo XVI, pp. 156-176.

21 Véanse los estudios de Rafael Ramis Barceló, "Las cátedras escotistas de la Universidad Luliana y Literaria de Mallorca (1692-1824)", Archivum Franciscanum Historicum, 108/1-2 (2015), pp. 301-317; "Las cátedras suaristas de la Universidad Luliana y Literaria de Mallorca (1692-1767)”, Archivum Historicum Societatis Iesu, 164/2 (2014), pp. 399-426; "Las cátedras lulianas de la Universidad de Mallorca (1692-1824)", Bolletí de la Societat Arqueològica Lul-liana, 70 (2014), pp. 185-205; y "Las cátedras tomistas de la Universidad Luliana y Literaria de Mallorca (1692-1824)”, Archivum Fratrum Praedicatorum, 83 (2013), pp. 345-368. 


\section{Las cátedras y los catedráticos de Artes y Teología}

El principal objetivo de las páginas siguientes es dar a conocer las visicitudes de las cátedras y los catedráticos de Artes y Teología de la Universidad de Lérida. Esteve Perendreu dedicó varios trabajos a recopilar las noticias más relevantes que había encontrado. Nosotros aportaremos los datos adicionales que hemos podido espigar en los archivos de Lérida, en el Archivo de la Corona de Aragón y, sobre todo, en el estudio de las fuentes que permiten conocer la movilidad del clero regular. Con ello procuraremos mostrar la relación de la Universidad de Lérida con las de su entorno.

La presencia de los dominicos en la Universidad durante estos años fue bastante escasa. Sabemos ahora el motivo, pues en el capítulo provincial de la Orden de Predicadores, celebrado en Valencia en 1596, se indicó que: "In studio conventus Ilerdensis nulla sit prouisio, declarauit en Reuerend. non esse computandum inter Vniversitates Prouintiae ${ }^{22 "}$. De todas formas, en el siglo XVII su peso fue mayor, pues el convento tenía capacidad para albergar a más de veinte frailes y siempre había alguno destinado a la lectura en la Universidad $^{23}$. Cabe señalar, como un rasgo significativo, que Lérida, como Universidad más antigua de la Corona, no fue el destino de los dominicos más sobresalientes, que solían acudir a los Estudios Generales de la Orden de las capitales de Reino (Zaragoza, Valencia, Barcelona y Palma), así como también a los Estudios Generales municipales de dichas ciudades, o a las Universidades de la Orden (Tortosa, Orihuela o Solsona).

En cambio, sobre todo, en el siglo XVI y en la primera mitad del XVII, hallamos una presencia muy destacada de los agustinos ${ }^{24}$, que a la sazón fungían como capellanes del Estudio ${ }^{25}$. En la Crónica de los Agustinos de Jaime

22 AHN, Códices, L. 573, f. 9v.

23 A. Collell, “Ayer de la provincia dominicana de Aragón”, Analecta Sacra Tarraconensia, 39 (1966), pp. 217-255. La cita es de la p. 224. "El convento de Predicadores de Lérida fue fundado antes del año 1230, porque es mas antiguo que el de Mallorca, que fue fundado ese año; tiene de todo. Recibe en dinero cada año 1.200 libras fm. 220 cuarteras de trigo, 80 de ordio y 800 cántaros de vino. Puede sustentar 25 frailes, y hoy tiene 20, es a saber: 11 sacerdotes, 4 profesos clérigos, 3 frailes legos y 2 novicios. Hay dos lectores de Teología y tres estudiantes; un lector de artes y dos estudiantes”.

24 La proyección universitaria de los agustinos durante esta época puede verse en G. Díaz, "La escuela agustiniana desde 1520 hasta 1650", La Ciudad de Dios, 176 (1963), pp. 63-84.

25 J. Jordán, Historia de la provincia de la corona de Aragon de la sagrada orden 
Jordán se indica que Fr. Vicente Montañez, valenciano, había sido catedrático de Teología a mediados del siglo XVI²6; y que Fr. Miquel Maiques había leído Filosofía, Cánones y Teología durante muchos años en Lérida ${ }^{27}$.

La gran mayoría de órdenes religiosas tenían casas en Lérida: entre ellas destacan los agustinos, los dominicos, los carmelitas y, muy especialmente, las congregaciones monásticas. El Colegio de San Bernardo fue fundado al amparo de una Bula de Martín V, el 10 de abril de 1419. La Orden cisterciense costeó un nuevo edificio, de piedra picada, entre 1568 y 1570. Como veremos, entre 1640 y 1644 residieron en él las bernardas de Sant Hilari hasta que, por orden de Felipe IV, el Colegio fue derribado en $1646^{28}$. Cabe señalar también que en virtud de una Bula de Clemente VIII, de 13 Agosto de 1592, se erigió un Colegio de la Orden de San Benito en Lérida ${ }^{29}$, que fue objeto de diversas protecciones $^{30}$.

No tenemos una nómina exacta de profesores y es muy díficil proceder explicando la evolución de ambas Facultades, ya que desconocemos muchos datos. Creemos que es mejor agrupar a los profesores de Artes y de Teología en una exposición que permita al lector hacerse cargo de las particularidades y vicisitudes de la Universidad de Lérida, siguiendo un hilo cronológico. No nos vamos a detener de nuevo en los aspectos institucionales de la Universidad que ya hemos expuesto en el capítulo anterior.

de los ermitaños de nuestro gran padre San Augustin: compuesta de quatro reynos, Valencia, Aragon, Cataluña, y las islas de Mallorca y Menorca, y dividida en quatro partes, Tomo I, Valencia, Joseph Garcia, 1704, p. 494.

26 Ibidem, p. 486.

27 Idem, p. 257.

28 E. Zaragoza Pascual, Catàleg dels monestirs catalans, p. 132.

29 ACL, P7_M2_P3_Co3, n. 12.

30 Por ejemplo, en 1612, los Diputados y Oidores de cuentas del General fueron a visitar al Lugarteniente y le rogaron que para las abadías vacantes postulara a los benedictinos, señalando que en las ternas provinciales podían contar con los alumnos del Colegio de Lérida, puesto que, si estos veían posibilidades de promoción, estudiarían con más ahínco. Véase DGC, IV, p. 32. "E també supplican a sa excel-lència que en lo de les ternes farà ací de les abbadias vaccants, per enviar en cort de sa magestat per ésser proveïdes aquelles, sie servit en fer-los mercè de anomenar y posar en dites ternes provincials de dit orde de sant Benet, per haver-n·i de doctes y de moltes parts y qualitats y tenir-ne un col-legi cèlebre en Leyda, lo que serà donar gran ànimo en què passen avant en sos studis y vigílias y no permètrer $\mathrm{s} \cdot \mathrm{i}$ posen persones estranyas y fora de dita religió provincial que, a més que és de molta equitat y justícia, dits supplicants ho rebran a singular gràcia y mercè”. 


\subsection{De Felipe II a Felipe IV}

Retomemos aquí el relato histórico en el punto en que habíamos concluido el capítulo primero. Cabe recordar que, antes de la reforma de Antonio Agustín, el catedrático de Prima de Teología era Francesc de la Torre, mientras que Pere Sales leía la cátedra de Conchillos. Desde 1578 hasta 1610, el Dr. Antoni Maní ocupó la cátedra de Conchillos y la de Prima de Teología. Sabemos que Antoni Sellés (o Cellers) era asimismo catedrático de Teología ${ }^{31}$, al igual que Pere Batlle ${ }^{32}$.

Massot cita como profesor de Teología al agustino Fr. Francisco Aguilar, que en 1584 había sido Prior en Huesca ${ }^{33}$ y que fue también Prior del Convento de Lérida y catedrático de Prima ${ }^{34}$. Jaime Jordán indica que su correligionario Fr. Miquel Antolí había sido catedrático de Escritura ${ }^{35}$ y que Fr. Pedro Medina, natural de Alcoy, se opuso a una cátedra de Teología en $1589^{36}$.

En 1599, Antoni Maní, catedrático y beneficiado de la Catedral de Lérida, accedía al beneficio de San Ivo, fundado en el Aula mayor de la Universidad $^{37}$, porque el de la Catedral era de menguadas rentas. Falleció el 11 de diciembre de 1610 y al día siguiente fue sepultado en la Catedral. Fue un gran protector de los jesuitas y había solicitado al P. General de la Compañía en 1603 que se hiciese cargo de las escuelas de Gramática de la Universidad ${ }^{38}$. El General respondió que en aquel momento no podían ocuparse de ello, pero que si tuviese suficiente gente lo haría. No se tardó mucho en lograrlo, como veremos seguidamente.

Massot indica que Fr. Andreu Estrada ${ }^{39}$, agustino natural del Valle de Arán,

31 F. Esteve Perendreu, "La docència de la teologia a Lleida...”, p. 160.

32 J. Lladonosa, Història de Lleida, II, p. 323.

33 C. Alonso, La Reforma tridentina en la provincia agustiniana de la Corona de Aragón: 1568-1586, Valladolid, Ed. Agustiniana, 1984, p. 127.

34 J. Massot, Compendio Historial de los Hermitaños de nuestro Padre San Agustín..., p. 252.

35 J. Jordán, Historia de la provincia de la corona de Aragon de la sagrada orden de los ermitaños de nuestro gran padre San Augustin, Vol. 1, Tomo II, Valencia, Antonio de Bordazar, 1712, p. 60.

36 Ibidem, p. 120.

37 F. Esteve Perendreu, Mestrescoles i rectors..., p. 155.

38 R. Gayá Massot, Los Jesuitas en la Universidad de Lérida, p. 33-34.

39 J. Massot, Compendio Historial de los Hermitaños de nuestro Padre San Agustín..., p. 97. 
era catedrático de Artes. En 1601 tenemos constancia de que Antonio Cabeza, dominico de Barcelona ${ }^{40}$, era Doctor en Artes $^{41}$. En 1602 ya era catedrático Antonio Galipienso ${ }^{42}$, presbítero natural de Sangüesa, que escribió la aprobación y censura de muchas obras de la época (Antonio Daza, Lope de Vega...)

En 1603 aparece como catedrático de Teología Fr. Pedro Vega ${ }^{43}$, de la Orden de Predicadores. Fr. Pedro de la Vega y de la Puente (más conocido como Fr. Pedro Vega), nació en Bubierca en 1560. Ingresó en el Convento de San Pedro Mártir de Calatayud en 1576, y profesó en 1577. Cuando Pedro Cerbuna, fundador de la Universidad de Zaragoza, estaba en trance de muerte, Fr. Pedro de la Vega, a la sazón catedrático de Durando en la Universidad de Zaragoza, fue enviado por el entonces Rector a la Corte como Síndico de la Universidad ${ }^{44}$. Fue confesor de la reina Margarita de Austria, esposa de Felipe III. Fue elegido Obispo de Cartagena de Indias el 19 de julio de 1614 y allí falleció en 1616.

Sentado lo anterior, hay que constatar que las cátedras de Gramática estaban en un estado decadente desde la marcha del obispo Antonio Agustín. Como hemos visto en el primer capítulo, su gestión estaba sujeta, al igual que el resto de las cátedras, al gobierno de la Ciudad. Sin embargo, como se ha indicado, había ya muchas voces que clamaban a favor de un cambio y se consideraba que los jesuitas, con su pedagogía eficaz, desempeñada en diferentes Colegios ${ }^{45}$, supondrían un importante revulsivo para la enseñanza humanística, y darían una formación sólida que redundaría en beneficio de toda la Universidad ${ }^{46}$.

Finalmente, el 17 de octubre de 1605 se llevó a cabo una concordia entre la Universidad y la Compañía de Jesús, autorizada por los Paheres ${ }^{47}$. Gayá

40 F. Diago, Historia de la prouincia de Aragon de la orden de predicadores, desde su origen y principio hasta el año de mil y seyscientos, Barcelona, impressa por Sebastian de Cormellas en Sancta Catherina martyr de Barcelona, a costa de la prouincia, 1599, p. 153.

41 F. Esteve Perendreu, Mestrescoles i rectors..., p. 158.

42 Ibidem, p. 158 y 210.

43 Idem, p. 160.

44 G. Borao, Historia de la Universidad de Zaragoza, [s.l.] [s.n.], p. 78.

45 F. J. Palao, "Los jesuitas y las universidades en la Corona de Aragón”, en L. E. Rodríguez San Pedro Bezares y J. L. Polo Rodríguez (coord.), Universidades hispánicas: colegios y conventos universitarios en la Edad Moderna, XV Coloquios Alfonso IX, (I), Salamanca, Universidad de Salamanca, 2009, pp. 159-188.

46 R. Gayá Massot, Los Jesuitas en la Universidad de Lérida, pp. 35-37.

47 AHUB, Universidad de Cervera, Caja 147, leg. 1224, n. 4. 
Massot resume así los pactos acordados: 1) que la Compañía podía gobernar por sí misma y a su modo las aulas de Gramática, y que con ello quedaba libre de la jurisdicción de la Ciudad y del Estudio; 2) que la Gramática, las Humanidades y la Retórica no pudieran enseñarse en otro lugar que no fuese las escuelas del Colegio de la Compañía; 3) que dichas escuelas, o lecturas, se concedían con carácter perpetuo a favor del Colegio de los jesuitas; 4) que el Estudio General subvencionaría al Colegio con la cantidad de $400 £$ anuales, pagaderas por mitad el 24 de junio y el 25 de diciembre; 5) que el Estudio incorporaba las Escuelas de Gramática al Colegio de la Compañía y le comunicaba todos sus privilegios en cuanto a lo que le resultase favorable ${ }^{48}$. En este sentido cabe afirmar que el Colegio de la Compañía pasaba a formar parte del Estudio de Lérida ${ }^{49}$.

El propio Gayá Massot se hacía eco de las garantías que se reservaba el Estudio General: 1) que la Compañía tenía que poner tres maestros; 2) que los maestros debían examinar a los estudiantes antes de pasar a las otras Facultades; 3) que los colegiales debían estar matriculados en la Universidad; 4) que la Universidad conservaría la jurisdicción sobre los Colegiales; 5) que la corrección de las faltas graves quedaba en manos de los Paheres y el Consejo de la Ciudad, y 6) que si los maestros de la Compañía no leyesen como convenía, el Estudio podía acudir a los superiores y, si se cesase la lectura, se dejaría de percibir la cantidad consignada ${ }^{50}$.

El 18 de octubre de 1605, es decir, un día después de la reforma de la Concordia, la Compañía empezó a leer Gramática. Los primeros maestros fueron el P. Miguel Torres (mayores), el P. Bartomeu Molines (medios) y el Hno. Jaume Puig (menores) ${ }^{51}$. Estos tres maestros fueron, mediado el tiempo, personajes muy destacados en la ciudad, por su pedagogía y saber.

Apoyaron fervientemente la concordia con los jesuitas tanto el obispo, Francesc Virgili, que al poco tiempo reformó la Universidad, como el maestrescuela Antoni Gallart i Traginer, nacido en Valencia en 1558, y que, tras largas consultas, el 11 de marzo de 1609 sería nombrado obispo de Elna ${ }^{52}$ y después, en 1612, de Vic.

48 R. Gayá Massot, Los Jesuitas en la Universidad de Lérida, p. 39.

49 Ibidem, p. 47,

50 Idem, p. 39.

51 Idem, p. 50.

52 ACA, Consejo de Aragón, leg. 268, n. 66. 
Gallart fue sustituido en la Maestrescolía con polémica ${ }^{53}$, pues fue recusado $^{54}$ el Dr. Baltasar de Victoria, aragonés, Arcediano de Ansó (Obispado de Jaca $^{55}$. Felipe II escribió al lugarteniente en 1612:

"He tenido por bien, no embargante lo alegado por los diputados, que el despacho se le entregue al dicho doctor Victoria - como se ha hecho- para que acuda con él a Roma con sus bullas, y junctamente por igualar la sangre entre aragoneses y cathalanes y para que los unos y los otros se desenganyen de que han de ser comunes de entrambas naciones y reynos los beneficios de la dicha iglesia de Lérida, pues como está dicho los frutos della se reciven en las dos provincias y la mayor parte en Aragón, he proveido en el doctor Francisco Monfar, cathalán, cathedrático en la universidad de Lérida, el arcedianato de Ribagorça, no obstante que és prebenda de Aragón, y también el canonicato que vaccare en aquella iglesia de Lérida por la promoción del doctor Sentís al priorato de Santa Anna de Barcelona... ${ }^{6 "}$

La Diputación del General no se mostró satisfecha con esta provisión del Rey, porque consideraban que Victoria no era catalán, tal y como se exigía. Felipe III tuvo que escribir el 20 de julio de 1613 a los diputados, a fin de que no estorbasen la toma de posesión de Baltasar de Victoria ${ }^{57}$.

Sabemos que en 1606 fueron destinados como lectores al Convento de los dominicos de Lérida Fr. Miquel Vergés y Tomàs Valero ${ }^{58}$, aunque no tenemos constancia de que leyesen en la Universidad. En 1607 aparece como catedrático de Teología el Dr. Antoni Claramunt, natural de la villa de Tous (de la

53 La maestrescolía había sido provista a Fr. Pere Sancho, de la Abadía de la Portella. Ello contravenía el derecho, puesto que era menorquín. Véase DGC, IV, pp. 63-64 y DGC, III, p. 669, que citamos seguidamente: "Los deputats del General del principat de Cathalunya nos han ordenat representassen a vostra excel·lència com han entès que sa magestat ha proveït la mestrescolia de Leyda en persona de (...) Victorian natural del regne de Aragó la qual provisió és feta contra la constitució 2, en lo títol de Studis Generals en les Corts de 1585 en la qual se conté que.ls mestrescuelas del studi de Leyda haja de ser cathalà, y contra moltes altres constitucions y assenyaladament contra la onzena y tot lo títol que los officials en Cathalunya hajan de ésser Cathalans per tenir, lo dit mestrescuelas, jurisdicció ordinària privative [ad alios] ordinarios y ferme contencions com ordinari, lo qual no podrie fermar sinó tingués jurisdicció ordinària y també és contra contra les constitucions y títol que los strangers no pugan tenir beneficis ecclesiàstic”.

54 ACA, Generalitat, Serie V, 242, n. 414.

55 ACA, Consejo de Aragón, leg. 268, n. 32.

56 DGC, IV, pp. 48-49.

57 ACA, Generalitat, Serie V, 242, n. 456.

58 AHN, Códices, L. 573, f. 22 r. 
diócesis de Vic). Ese año tomó posesión como Rector de la Iglesia Parroquial de San Juan de Lérida ${ }^{59}$.

Beltrán de Heredia ${ }^{60}$ mencionó como profesores de la Universidad de Lérida a los dominicos Jaime Rebullosa, Miguel Chález y Jacinto Vallejo de Santa Cruz, sin que podamos confirmarlo documentalmente ${ }^{61}$.

En 1610 cabe citar al agustino portugués Agustín Ozorio (Osorio) ${ }^{62}$, como catedrático de Teología ${ }^{63}$. Recibió el grado de Doctor en Artes en la Universidad de Tarragona el 4 de agosto de $1600^{64}$. Fue catedrático de la Universidad tarraconense entre 1600 y $1602^{65}$, y allí recibió el doctorado en Teología el 14 de junio de $1602^{66}$. Desempeñó otros cargos en su Orden así como sobresalió como predicador ${ }^{67}$.

En estas fechas encontramos también como catedrático a Fr. Juan Mur, dominico, que había profesado en la Orden en 1595, logrado el grado de Maestro en Artes en la Universidad de Tortosa en $1602^{68}$, y recibido el grado de presentado en $1611^{69}$. Mur, que también fue Síndico de la Universidad, solicitó al Rey en 1610 su intercesión ante el papa Paulo V, para que éste les concediese la gracia de que los catedráticos que fuesen clérigos pudiesen percibir sus beneficios y prebendas mientras estuviesen ocupados al servicio de

59 F. Esteve Perendreu, Mestrescoles i rectors..., p. 164.

60 V. Beltrán de Heredia, "Los dominicos y la enseñanza de la teología en el Reino de Aragón”, Miscelánea Beltrán de Heredia. Colección de artículos sobre Historia de la Teología española, II, Salamanca, 1972, p. 613.

61 Lo tomó de A. Fernández, Historia y anales de la deuocion y milagros del Rosario: desde su origen hasta año mil y seis cientos y veinte y seis, Madrid, por Iuan Gonzales, 1627, lib. IX, p. 20v. "El Maestro fray Pedro de la Vega, Catedratico de sagrada Escritura, y Lector de la Catedral de Lerida, sucediole el Maestro fray Miguel Lopez, a quien sucedió el Maestro fray Iayme Rebullosa, que era Lector de la Catedral de Vrgel, donde le sucedió el Presentado fray Iuan Valero".

62 J. Massot, Compendio Historial de los Hermitaños de nuestro Padre San Agustín..., p. 99.

63 F. Esteve Perendreu, Mestrescoles i rectors..., p. 167.

64 AMT, Ms. Historia del Estudio de Tarragona..., f. 253.

65 S. Capdevila, "Documents per a la Història...", p. 229.

66 AMT, Ms. Historia del Estudio de Tarragona..., f. 242.

67 R. Lazcano, Agustinos españoles escritores de María, Guadarrrama, Madrid, 2005, pp. 225-226.

68 BC, Ms. 3918, Libro de la Universidad..., f. 34r.

69 A. Collell, "Ayer de la provincia dominicana...", p. 249. 
la Universidad ${ }^{70}$. Esta petición fue cursada por Felipe III en $1617^{71}$. Cuando Juan Mur fue nombrado Provincial, en 1613, era Prior del Convento de San Pedro Mártir de Calatayud, si bien aparece como "S. Theologiae Professor, In Universitate Ilerdensi Vespertinae Theologorum Cathedrae moderator emeritus $^{72 "}$ " En 1615 aparece aún como catedrático de la Universidad ilerdense $^{73}$ y en 1627 figura como "Cathedratico de la Cathedra Primera de Visperas de Theologia"4".

Según Esteve, Joan Antoni Agustín consta como catedrático de Teología en $1613^{75}$. Ese año, el obispo Virgili reformó los Estatutos de la Universidad ${ }^{76}$ y hubo los primeros conflictos entre los jesuitas y las autoridades. Según Gayá Massot, "lo que realmente se pretendía, en esta etapa era una sola cosa: que la Compañía pasase a leer la Gramática en las aulas o ámbito de la Universidad 77 ”. En dichos Estatutos se preceptuaba que el catedrático de Filosofía de primer año tenía que leer el Compendio desde el día de San Lucas hasta Navidad y desde el dos de enero hasta el mes de agosto, la lógica ${ }^{78}$. El 6 de mayo de 1615, Antoni Castellnou, catedrático de Teología y beneficiado de la Catedral, fue enterrado en la Seu Vella ${ }^{79}$ y Pere Llorenç, estudiante, también beneficiado de la catedral y catedrático, falleció el 12 de mayo de dicho año ${ }^{80}$.

En 1623 tenemos noticia de varios profesores y doctores en Teología ${ }^{81}$ : Dr. Antonio Galipienso, catedrático de Prima; Fr. Joan Mur, dominico, de Vísperas; Fr. Gaspar de Sorribas i Grau, Doctor en Teología y Prior del Convento de San Agustín; Josep Pere ${ }^{82}$, Doctor en Teología; Fr. Tomàs Nadal,

70 F. Esteve Perendreu, Mestrescoles i rectors..., p. 167.

71 Ibidem, p. 179.

72 AHN, Códices, L. 573, f. 108r.

73 J. López, Quarta parte de la Historia general de Santo Domingo y de su Orden de Predicadores, Valladolid, por Francisco Fernandez de Cordoua, 1615, p. 950.

74 F. de Villalva, Avisos de padre y rosario de nuestra señora, [s.l.] 1629, aprobación.

75 F. Esteve Perendreu, Mestrescoles i rectors..., p. 175.

76 ACA, Cancillería, Ms. 4895, ff. 83r-125v.

77 R. Gayá Massot, Los Jesuitas en la Universidad de Lérida, p. 72.

78 F. Esteve Perendreu, El Régimen jurídico..., p. 202.

79 F. Esteve Perendreu, "La docència de la teologia a Lleida...”, p. 160.

80 F. Esteve Perendreu, Mestrescoles i rectors..., p. 177.

81 Ibidem, p. 189.

82 Sobre este personaje, J. Lladonosa Pujol, La Suda, parròquia de la Seu de Lleida: problemàtica arqueològica i urbanística d'una antiga ciutadella, Lleida, Institut d'Estudis Ilerdencs, 1979, p. 30. 
dominico, Doctor en Teología; Fr. Tomàs Roger, dominico e hijo de Lérida ${ }^{83}$, catedrático de Teología; Fr. Antoni Croses, Doctor en Teología; Fr. Joan Vicenç Pellicer, dominico, Doctor en Teología; Francesc Orcau, Doctor en Teología y Francesc Navés, también Doctor en Teología y canónigo de la Catedral de Lérida.

Fr. Gaspar de Sorribas era natural de la Seu d'Urgell. En 1612 se doctoró en Teología en la Universidad de Barcelona. En el Capítulo de 1611 fue electo Visitador de la Provincia agustiniana, y en 1617 fue escogido Prior en Seo de Urgel, y el cabildo le nombró Lector de la Catedral. Falleció en $1629^{84}$.

Fr. Tomàs Nadal fue instituido presentado en el Capítulo provincial de los dominicos, celebrado en Barcelona en $1629^{85}$. Consta como profesor en diversas sedes ${ }^{86}$ y años después fue Rector del Colegio de Orihuela y Canciller de la Universidad (1638-1640). Recibió todos los grados de Teología en $1638^{87}$. En cuanto a Fr. Tomàs Roger, fue profesor de Artes en el Colegio de Solsona desde 1617 a $1618^{88}$. Fr. Antonino Croses, hijo del Convento de Gerona, profesó en la Orden de Predicadores en 1595, fue Rector del Colegio de Solsona en $1620^{89}$ y de la Universidad de Tortosa (en la que se doctoró en Teología en $1622^{90}$ ) en los períodos 1621-1623 y 1629-163291.

En el Consejo General de la Ciudad de 6 de agosto de 1623, los Paheres mostraron su descontento con los jesuitas, porque leían la Gramática en lengua castellana, utilizaban libros muy nuevos, y los maestros no eran aptos. Para ello proponían que los Padres de la Compañía dejasen de leer Gramática en su Colegio y que lo hiciesen en la Universidad, que leyesen en catalán, que adoptasen los libros nuevos, de Nebrija, Cicerón, Virgilio..., que los Paheres pudieran supervisar a los lectores jesuitas y que, si no se hacía así, se les quitase la lectura de la Gramática y se proveyese por oposición pública mediante edictos ${ }^{92}$.

83 J. Lladonosa i Pujol, Història de Lleida, vol. II, p. 431.

84 J. Massot, Compendio Historial de los Hermitaños de nuestro Padre San Agustín..., p. 336.

85 AHN, Códices, L. 573, f. 99r.

86 A. Collell, "Ayer de la provincia dominicana...”, p. 254.

87 R. Ramis Barceló y P. Ramis Serra, "Los primeros grados de la Universidad de Orihuela...”, p. 256.

88 V. Beltrán de Heredia, "Catálogo de los colegiales...", p. 130.

89 Ibidem, p. 134.

90 ACBE, Sign. 1651, Registrum doctorativi et baccalaurenti..., s.f.

91 BC, Ms. 3918, Libro de la Universidad..., f. 86v y f. 87r.

92 R. Gayá Massot, Los Jesuitas en la Universidad de Lérida, pp. 83-85. 
En realidad, estas medidas no contaban con el completo consenso de los profesores universitarios, de los Paheres, ni tampoco de la población ilerdense. Había asimismo numerosas dudas legales acerca de estas disposiciones, que fueron planteadas en diferentes sesiones. El Rector del Colegio de los jesuitas se negó a aceptar estos términos y en un Consejo celebrado el 9 de septiembre de 1623 se ordenó que los hijos de San Ignacio dejasen de leer Gramática93. Los jesuitas elevaron un memorial al Rey. Este hecho todavía recrudeció más los ánimos y se encaró un pleito. No hubo unanimidad en las acciones a emprender por parte de los Paheres ${ }^{94}$, pero se hizo frente al pleito. Finalmente, el 6 de noviembre fueron nombrados algunos profesores interinos de Gramática: Miquel Arrufat, Bachiller en Teología, sería el profesor de mayores; Domingo del Rey, presbítero, enseñaría a los medianos; y Francesc Julià, estudiante de Teología, sería el maestro de los pequeños ${ }^{95}$.

Sabemos que, mientras tanto, los dominicos hicieron en el Capítulo Provincial de Zaragoza de 1625 una detallada provisión de maestros para el Convento de Lérida: el ya citado Fr. Joan Mur tenía que ser regente; Fr. Joan Vicenç Pellicer, Lector de Prima del convento; Fr. Tomàs Villanueva era segundo Lector; quedaba como Maestro de Estudiantes Fr. Jacint Minguet, y Fr. Jacinto Solinera era Lector de Artes ${ }^{96}$. El 26 de noviembre de 1625 fallecía el Dr. Antoni Claramunt, catedrático de Segunda de Teología97.

Tras una intensa toma de posiciones y alegatos a favor y en contra ${ }^{98}$, al final, en 1628, la Real Audiencia falló a favor del Estudio ilerdense en su pleito contra los jesuitas, y devolvió la lectura de Gramática a la Universidad, como una defensa de los privilegios de la institución. El Consejo General ilerdense acogió con júbilo la resolución ${ }^{99}$ y, con ello, pudo gestionar el pago de las cátedras a los maestros seculares que leían Gramática ${ }^{100}$.

Los jesuitas quedaron muy contrariados, y buscaron otra manera de atraerse a los jóvenes estudiantes a su órbita. Lo hicieron a través de la cátedra de Teología moral, que ya hemos citado en el capítulo anterior. Fue inaugurada

93 AML, Reg. 438, Llibre d'Actes (1622-1628), ff. 67r-70.

94 AML, Reg. 438, Llibre d'Actes (1622-1628), ff. 70-73r.

95 AML, Reg. 438, Llibre d'Actes (1622-1628), f. 73v.

96 AHN, Códices, L. 573, f. 83v.

97 F. Esteve Perendreu, Mestrescoles i rectors..., p. 191.

98 R. Gayá Massot, Los Jesuitas en la Universidad de Lérida, pp. 103-121.

99 AML, Reg. 438, Llibre d'Actes (1622-1628), ff. 237v-238r.

100 AHUB, Universidad de Cervera, Caja 147, leg. 1224, n. 4. 
en octubre de 1629 y su regente más afamado fue el P. Baltasar Gracián, entre 1631 y $1633^{101}$. Por las circunstancias antes expresadas, no puede decirse que Gracián fuera profesor de la Universidad de Lérida, aunque esa cátedra era el trampolín que tenía el Colegio de la Compañía para reivindicar su saber ante los maestros de la Universidad y los Paheres.

Mientras tanto, el 29 de septiembre de 1629 se graduó como Doctor en Teología Francesc de Maranyosa i Toló y regentó una cátedra. Sabemos que falleció en $1638^{102}$. Según Massot, el agustino Fr. Miquel Andreu, del Rosellón, se doctoró en Teología en la Universidad ilerdense en 1629 y ganó una cátedra ${ }^{103}$, que ocupó hasta 1632, cuando fue electo visitador de las islas de Mallorca y Menorca ${ }^{104}$.

Las autoridades de la Universidad se quejaron de la actuación del Maestrescuela Francesc Pastor y de la competencia que hacían las demás universidades ${ }^{105}$. La reforma de la Universidad debía basarse en dieciséis puntos, que aparecen extractados en un manuscrito de esta época. Las solicitudes eran las siguientes: 1) que se quitasen las demás Universidades de la Corona; 2) clarificar la jurisdicción del Rector y del Maestrescuelas; 3) que el cargo de Rector tuviera duración bienal; 4) que se regulase nuevamente la forma de leer los catedráticos, y el tiempo y puntualidad con la que debían hacerlo; 5) establecer la forma mediante la cual se podían sustituir los catedráticos; 6) regular acerca de cómo se habían de proveer las cátedras y que todas tuvieran que vacar a su tiempo sin que existiera perpetuidad en ellas; 7) que no hubiera jubilaciones, aunque a la sazón hubiese muchos catedráticos con muchos años de lectura; 8) disponer cómo y cuándo se habían de juntar el Rector y el Consejo de la Universidad; 9) que hubiera una normativa acerca de la sujeción de los notarios y bedeles de la Universidad; 10) establecer una regulación de cómo se tenían que dar los grados de los doctores, y la petición de "que se redusca el Corte dellos y el modo como se han de votar los doctorantes"; 11) reivindicar el valor de las cátedras y de la necesidad que hay de darles a los catedráticos el salario competente; 12) que se diese salario al Rector y al alguacil del Maestrescuelas y que quedara claro de dónde habían

101 R. Gayá Massot, Los Jesuitas en la Universidad de Lérida, pp. 130-133.

102 F. Esteve Perendreu, Mestrescoles i rectors..., p. 197.

103 J. Lladonosa, Història de Lleida, II, p. 536.

104 J. Massot, Compendio Historial de los Hermitaños de nuestro Padre San Agustín..., p. 252.

105 ACA, Consejo de Aragón, leg. 282, n. 48/5. 
de salir los fondos; 13) tener en cuenta lo que se señaló en 1585 sobre la Universidad [acerca del Maestrescuela]; 14) detallar una petición para remediar las necesidades que tenía la Universidad; 15) que se fundara un colegio; y 16) establecer una disposición acerca del modo de alterar estas directrices cuando la necesidad lo pidiese ${ }^{106}$.

Todas estas quejas tenían como telón de fondo el auge de las demás universidades, especialmente la de Huesca. La sede oscense mantuvo unas cifras elevadas en graduados en Artes durante el primer tercio de la centuria: fueron 193 los Bachilleres en el período 1600-1610; 165 en la década de 1610-1620 y 129 en el lapso 1620-1630. En cambio los teólogos fueron bastante pocos: 19 en la década de $1600-1610,14$ en la siguiente y 16 en la de $1620-1630^{107}$. La verdadera pujanza, como hemos visto en el capítulo anterior, se dio entre los graduados en Derecho.

Una circunstancia que se sumó a lo anterior fue a partir del 1629 el Colegio de Poblet empezó a sufrir presiones para que los estudiantes dejasen Lérida y pasaran a Huesca. El Vicario General de la Orden, Fr. Miquel Escartín ${ }^{108}$, quien años después fue obispo de Lérida, quería reunificar en aquel momento a todos los estudiantes del Císter en Huesca, donde se hallaba el Colegio de la Congregación Cistercenciense de la Corona de Aragón. Para ello presionó al Abad de Poblet para que no enviase a los estudiantes a Lérida, sino a Hues$\mathrm{ca}^{109}$. Ello dio lugar, como veremos, a cierta polémica.

En 1631 aparece como catedrático el Dr. Domènec Rovira, canónigo de la Catedral de Lérida ${ }^{110}$, y sabemos que el 15 de abril el Duque de Segorbe comunicó a los Paheres que para la cátedra de Artes que había obtenido Fr. Josep Sanz, "se podra graduar este religioso para que a su tiempo tenga efecto la oposicion ${ }^{111}$ ". No queda claro quien era este personaje. Cabe la posibilidad que fuese el homónimo cisterciense, de origen valenciano, que entre 1652 y 1656 fue abad de Poblet. Sabemos que fue admitido como novicio en Poblet en 1627 y que al año siguiente hizo la profesión perpetua. Hay que

106 ACA, Consejo de Aragón, leg. 282, n. 48/3.

107 J. M. Lahoz Finestres, "Un estudio sobre los graduados de la Universidad de Huesca”, p. 281.

108 J. M. Lahoz Finestres y L. García Torrecilla, "Graduados en teología en la Universidad de Huesca”, pp. 240-241.

109 A. Altisent, Història de Poblet, pp. 489 y 498-499.

110 A. Agustí, Llengua i Església a la Lleida del XVI al XVIII, Lleida, Universitat de Lleida, 1995, p. 254.

111 AML, Reg. 851, Cartes Reials, s.f. 
pensar que de allí pasó al Colegio de Poblet de Lérida, donde se educaban los novicios ${ }^{112}$.

El 15 de abril del año siguiente se mandó el sobreseimiento de las cátedras doctorales ${ }^{113}$. El Síndico de la Universidad comunicó lo siguiente:

"El sindico del estudio general de Leride dise que este año vacan todas las cathedras de dicha uniuersidat y se proueeen por concurso el primero de majo segun regias reformasiones y estatutos della y son bien sine carta de su magestad del año 17 que manda no se entrometa el uisorei de Cataluña en la prouision de dixas cathedras asta que tenga otra orden.

Ase sacado carta del S. Duque de Segorbe visorei en que manda se alargue la prouision de dixas Cathedras y esto lo an proueido algunos por intereses particulares a fin que sin concurso las puedan alcansar. Lo cual amas de ser contra los decretos de su Magestad es gran perjuisio de la universidat opositores i estudiantes ${ }^{114}$ ".

Gayá Massot indica que el período de regencia municipal de las cátedras de Gramática (1628-1643) debe entenderse como una época de completa decadencia ${ }^{115}$. El éxodo de los estudiantes a la Universidad de Huesca fue continuo ${ }^{116}$, y los Paheres y el Rey tuvieron que tomar cartas en el asunto, a fin de evitar tal estado de postración. De hecho, el maestrescuela Jaume Magre se dirigió en 1637 a los Paheres para pedir que los jesuitas volviesen a regentar las cátedras de Gramática. El 12 de mayo de 1637 se decidió que se devolviese a los jesuitas la lectura, aunque sólo por tres años ${ }^{117}$.

En enero de 1637, una comisión del Consejo de la Universidad, encabezada por el catedrático de Teología Mateu Companys, se personó ante los Paheres para pedirles que se construyera un paraninfo para poder colacionar los grados y para los demás actos literarios, pues no tenían lugar adecuado para celebrarlos y debían hacerlo en la Sala Capitular de la Catedral. La Ciudad respondió afirmativamente, indicando cómo se tenía que proceder ${ }^{118}$.

Se conserva un curso fechado en Lérida en 1637 de Resolutiones dilucide institutionum dialecticarum copiado por el estudiante Rafael Mollet, de las

112 E. Toda i Güell, La Davallada de Poblet: Poblet als Segles XVII i XVIII, [Poblet], Abadia de Poblet, 1997, pp. 164-170.

113 AML, Reg. 851, Cartes Reials, s.f.

114 ACA, Consejo de Aragón, leg. 282, n. 48/7.

115 R. Gayá Massot, Los Jesuitas en la Universidad de Lérida, pp. 123-130.

116 AML, Reg. 439, Llibre d'Actes (1630-1636), ff. 165-166v.

117 AML, Reg. 439, Llibre d'Actes (1636-1639), ff. 41-42.

118 F. Esteve Perendreu, Mestrescoles i rectors..., pp. 203-205. 
lecciones dictadas por el maestro Josep Cortés, del cual no tenemos más noticias $^{119}$. De Rafael Mollet han quedado en el mismo manuscrito dos cursos más, sobre filosofía aristotélica: unos Commentaria in octo libris phisicorum Aristotelis cum dubiis et questionibus his nostris temporibus egitare solitis ${ }^{120}$ y unos Commentarii in duos libros Aristotelis De Ortu et interitu, sive de generatione et corruptione $e^{121}$.

Como hemos visto en el capítulo anterior, en noviembre de 1638, a fin de atajar los problemas del Estudio, el Rey comunicó a los Paheres que había comisionado a Pau Duran, Obispo de Urgell, para la reforma del Estudio ${ }^{122}$. Duran informó a los Paheres acerca de las irregularidades detectadas en a la administración hecha por los clavarios de la Ciudad en lo tocante a la Universidad, durante los últimos veinticinco años ${ }^{123}$. De la reforma preparada por Duran quedó un ejemplar en posesión de Gayá Massot, cuyas rúbricas reproducimos de nuevo aquí, sin desarrollar, porque no hemos podido consultar la copia:

"I. De la vaccació de les càthedres y en que temps se hauran de provehyr y del termini y forma dels edictes.

II. Dels pretenents y oppositors a les càthedres y qui seran àbils pera opposarse.

III. Del ordre y modo que se ha de observar en donar los punts y en quins llibres y del modo que se ha de guardar en lo legir dels oppositors.

IV. Del modo y forma que se ha de guardar en la abilitació dels votants y dels qui seran àbils pera concorrer a poder votar y calitats de aquells.

V. De les provisions de les càthedres y de la forma y modo que se ha de tenir y observar en elles ${ }^{124 "}$.

Las actuaciones y reformas ${ }^{125}$ de Pau Duran tuvieron, como hemos visto

119 BC, Ms. 2899/1, ff. 1-114v.

120 BC, Ms. 2899/1, ff. 121-222v.

121 BC, Ms. 2899/3, ff. 223-247v

122 AML, Reg. 851, Cartes Reials, s.f. y ACA, Consejo de Aragón, leg. 281, n. 101.

123 AML, Reg. 851, Cartes Reials, s.f.

124 R. Gayá Massot, "Provisión de cátedras...”, p. 276.

125 Ibidem, leemos la siguiente síntesis de la reforma: "Las catedras de Prima de teología, canones, leyes y medicina se declaran perpetuas. Las demas se proveerán cada tres años, excepto la de Sexto, que se ha de crear, y la de Instituta, que lo haran de dos en dos años; también seran perpetuas, sólo para sus titulares, las catedras de facultades mayores tenidas en propiedad por los doctores que hayan leído doce años consecutivos o interpolados, «porque no sería justo que los catedraticos que hayan leído y trabajado por largo 
en el capítulo anterior, un efecto muy notable en la configuración del claustro universitario. De hecho, hubo turbas y algarabías, pero el Conde de Santa Coloma se mantuvo firme y respaldó las reformas del Obispo visitador ${ }^{126}$.

En 1639 falleció el Dr. Antonio Galipienso, catedrático de Prima, y su compañero de cátedra, el dominico Fr. Tomàs Roger predicó un sermón, que ha quedado impreso $^{127}$. Sabemos también que el 14 de septiembre de dicho año, Felipe IV nombró Presidente del Convento de San Agustín de Lérida a Fr. Josep de Enguita, lector jubilado y Maestro en Teología de la Universidad ${ }^{128}$. Sabemos también que los dominicos habían enviado, en el Capítulo provincial de 1636, como Lector de los textos de Santo Tomás del convento de Lérida a Fr. Climent Cisteller ${ }^{129}$.

\subsection{La Guerra dels Segadors}

La Universidad de Lérida escribió continuamente al virrey Dalmau Queralt, Conde de Santa Coloma, y a su sucesor, en un tenso intercambio epistolar ya comentado en el capítulo anterior. Añadamos aquí las quejas trasladadas por el Vicerrector de la Universidad en 1641, cuando hacía tres años de las reformas que había introducido Pau Duran:

"Jayxi en satisfaccio del que V.S. en dita carta mane lo Vicerrector de dita universitat diu que les Catredes de aquella, son triennals, excepto les de prima, que aquet any vaquen totes per concurs ordinari. Que ha tres anys que non se han provehit, per avero impedit Lo Bisbe de Urgell, qui ab un pretes titol de Visitador, contrafent les constitucions del Principat, remogue scandols tan notoris que los studiants estan quexosos, de veurer que les lectures vajen per substituts; los quals may satisfan a la obligasion que tenen, per no ser la cosa propria. Que lo temps de la prouisio de les catredes es lo mes de Maig, posant

tiempo en la Universidad estén toda la vida sujetos a competencias y consiguientemente a poner en concurso la reputación adquirida con tanto esfuerzo»; en las catedras de Prima de las cuatro facultades mayores solamente podran tomar parte los opositores que sean doctores por esta Universidad o por las de Barcelona y Zaragoza”.

126 AML, Reg. 851, Cartes Reials, s.f.

127 T. Roger, Sermón en las honras del venerable sacerdote e insigne doctor Antonio Galipienço, cathedrático de Prima de Theologia en la Universidad de Lérida. Predicado por el maestro fr. Thomás Roger, de la orden de Predicadores, cathedrático de Santo Thomás en la mesma Universidad. Dirigido al muy Illustre Dean, y Cabildo de la S. Iglesia Cathedral de Lerida, Lerida, Enrique Castañ, 1639.

128 AML, Reg. 851, Cartes Reials, s.f.

129 AHN, Códices, L. 573, f. 126r. 
edictes generals, als 2 de aquell, en força de una carta Real inconcissament observada. Que los Predicadors no estan exortant altre per los pulpits, que lo reparo de dita Universitat. Que la primera pedra es asentar los Mestres perque altrament no se agafaran los dexeples a cursar.

Per estes rahons en dies pasats lo Rector de dita Universitat proposa al Consell la prouisio de les catredes, y fou uniforme la resolusio, que posasen edictes, segons statuts, y regles reformes en 2 de Maig han de votar les dites catredes los studiants, de les facultats respectivaments per indults Apostolics, y privilegis reals, y esta es la observança. No te atendencia als pocs, o als molts studiants, que aso dependeix dels infortunis del temps, sols more si los que concorren a votar tenen les calitats degudes segons regies reformes, y ordinations del Studi: de les quals conexen los Habilitadors ab iudici tan absolut, que no admet appellaçio, no al alter nos, ni regia audiencia, no dols quant al afecte suspensiu, pero ni quant al deuolutiu.

Es inconuenient dilatar les provisions altre temps perque en lo estiu no ya studi, no studiants, y los oppositors, gasten sos patrimonis en enviar a sercar los vots. Allargar a Sant Lluch es occasionar inquietuts entre los studiants, an ques diuerteixen de son studi, y esgarrant lo curs mes principal, y finalment es treurer la Universitat de sos quicis, y pervertir tot lo orde natural de son curs.

Los exemplars que a V. S. han intentat proposar en contrari son de informacio falsa perque ans be en lo any 1632 mana lo Lloctinent General que nos prouehissen les catredes perque lo Rey venie a corts, y no obstant dita suspensio se pasa auant quant y mes, que quant fossen, no auien de ser trets en consequensia per ser exemplars de abusos.

Ayxi mateyx han celat la veritat de dir que dilatanse dita provisio, y aura mes vots, perque segons statuts, y regies reformes sols concorren a votar, los que son estat presents en lo discurs del any. Ni poden replicar de que en lo present no se ha llegit perque tot lo any se han perseguit les lectures, exeptat lo segons curs per los continuos rebatos, y auui se proseguexen; y es gran desconsuelo que los studiants, que han assistit a sos Mestres, y an lo amor de aprofitarse, y saber, han atropellat los perills de la guerra, y desmereixquen lo premi y honra que per statut sels deu, es desalentarlos en extrem ${ }^{130}$ ".

Asimismo, el Rector del Estudio, y en su nombre el Vicerrector ordinario, el licenciado Diego Vilaformiu ${ }^{131}$, escribió a los Diputados del General el día 1 de mayo de 1641 sobre el tema de las cátedras, rogándoles que respetasen los privilegios apostólicos y reales de la Universidad ${ }^{132}$.

Lladonosa escribió que Fr. Gaspar Sala persistía activamente desde su cá-

130 ACA, Generalitat, Correspondencia del virrey Conde de Santa Coloma, carta n. 12381, s.f.

131 Fue consejero clérigo del Rosellón, bajo los auspicios de Luis XIV. Véase M. A. Martínez Rodríguez, Felip IV i Catalunya, p. 166.

132 ACA, Generalitat, Correspondencia del virrey Conde de Santa Coloma, carta n. 12380 , s.f. 
tedra en la Universidad en escribir a favor de Richelieu ${ }^{133}$. Tras analizar diversos textos impresos del agustino Fr. Gaspar Sala i Berart, hay que subrayar que no podemos afirmar que fuera catedrático de Teología de la Universidad de Lérida, sino de la de Barcelona, aunque era también Lector Magistral de la Catedral de Lérida. Por tanto, pese a la influencia que ejerció Sala en la ciudad del Segre, no podemos demostrar documentalmente que hubiese leído en su Estudio General, sino en el de Barcelona.

Cuando Lérida aceptó la soberanía francesa, se exiliaron algunos profesores de la Universidad de orientación felipista, entre los que hallamos algunos catedráticos de Teología ${ }^{134}$. En el Archivo de la Corona de Aragón se conservan algunos de sus memoriales, solicitando ayuda económica a Felipe IV. De esta forma podemos saber algunos nombres y trayectorias.

Conocemos el caso del Dr. Juan Francisco de Orcau, natural de Monzón, canónigo de la Catedral de Zaragoza y catedrático de Teología en Lérida hasta su exilio. El rey le hizo merced de doscientos escudos y Orcau solicitó, en septiembre de 1642, que se le dieran en plata en la ciudad de Zaragoza ${ }^{135}$.

Se conserva también el memorial que escribió, en junio de 1643, Fr. Pere Moliner, trinitario catalán, catedrático que fue de Vísperas de Teología en la Universidad ilerdense, en el que solicitaba al Rey una pensión por los servicios prestados, con pérdida de sus bienes ${ }^{136}$. Fr. Pere Moliner había escrito varios opúsculos apologéticos, favorables al rey Felipe $\mathrm{IV}^{137}$, entre los que destaca Apologia in orationem Reverendissimi Episcopi Lamarca Galli contra Hispaniarum Regem apud Gotholanum Clerum declamantis (Tarragona, 1644), contra Pèire de Marca ${ }^{138}$.

En la documentación aparecen también varios manuscritos de 1643 y 1645

133 J. Lladonosa i Pujol, Història de Lleida, II, p. 469.

134 F. Esteve Perendreu, Mestrescoles i rectors..., p. 212.

135 ACA, Consejo de Aragón, leg. 291, n. 42.

136 ACA, Consejo de Aragón, leg. 291, n. 81.

137 E. Miralles, "Els escriptors catalans en una Europa en conflicte: la propaganda política impresa de la Guerra dels Segadors", Caplletra, 52 (2012), pp. 199-200.

138 S. Baluze, Sancti Agobardi archiepiscopi Lugdunensis Operum, Vol. II, Parisiis, apud Franciscum Muguet, 1665, p. 27, hace un juicio crítico de esta obra: "Caeterum adversus hanc orationem Marcae, puerilem admodum declamatiunculam eodem anno Tarracone edidit frater Petrus Moliner Trinitarius magister, theologiae doctor ac vespertinus cathedraticus in Ilerdensi Lycaeo. His enim se titulis ornavit homo opinione sua doctus et eloquens; sed, quantum ex ipsius declamatiuncula colligi potest, Musis non tam invisus, quam ignotus". 
referentes al maestro Fr. Francesc Reguer i de Soldevila, natural de Balaguer y a la sazón Provincial de los Carmelitas de Cataluña. En ellos, el interesado informaba al Rey de que era Lector perpetuo de la Catedral de Lérida y catedrático perpetuo de Escritura de la Universidad. Sabemos que Reguer, tras haber leído como Bachiller, había sido catedrático de Filosofía de la Universidad de Gerona desde el 27 de agosto de $1629^{139}$, por espacio de un bienio. Aparece también un escrito de Jacint Reguer i de Soldevila, en el que indicaba que era caballero, al igual que su hermano, y que ambos solicitaban socorro de alimentos y otras mercedes ${ }^{140}$. Por lo visto, Francesc de Reguer fue desterrado a Génova ${ }^{141}$; ambos hermanos recibieron novecientos ducados ${ }^{142}$.

En 1642 la lectura de las humanidades volvió a manos de los jesuitas ${ }^{143}$. El 10 de junio la Ciudad aprobó la Concordia con la Compañía, que fue firmada el 22 de febrero de $1643^{144}$. Las cláusulas eran bastante parecidas a las que se habían rubricado en 1605, si bien quedaban más claros algunos de los puntos conflictivos, como por ejemplo la elección de los libros para estudiar. En contrapartida, los maestros se hallaban exentos de toda jurisdicción por parte del Rector, si bien al comienzo de curso estos maestros tendrían que pronunciar una oración panegírica en defensa de la Latinidad. Una de las concesiones más importantes para los jesuitas era que "ningun studiant que eixira de dita Gramatica no puga esser admes en la Universitat del General Studi de la present Ciutat per a ohir ninguna de les facultats que se lligen, en que no sia portant una bolleta de aprovacio feta y firmada per lo dit Pare Perfecto [sic $]^{145 "}$.

La Ciudad debía, en enero de 1643, los pagos atrasados. A tal efectó solicitó su entrega el catedrático de Prima de Teología, Mateu Companys ${ }^{146}$, junto con

139 AMG, Llibre d'actes o manual d'acords del Consell de la ciutat (1628), Reg. 17721, f. 149 .

140 ACA, Consejo de Aragón, leg. 293, n. 15.

141 A. Simón i Tarrés, "Los desterrados catalanes en Italia durante la Guerra de Separación de Catalunya (1640-1652)”, Investigaciones Históricas, 33 (2013), p. 105.

142 ACA, Consejo de Aragón, leg. 294, n. 49.

143 AHUB, Universidad de Cervera, Caja 147, leg. 1224, n. 4. Véase R. Gayá Massot, Los Jesuitas en la Universidad de Lérida, pp. 139-144.

144 AML, Reg. 442, Llibre d'Actes (1642-1644), ff. 131-133.

145 AML, Reg. 442, Llibre d'Actes (1642-1644), ff. 50v-57r.

146 Era Vicario del Cabildo de Lérida y desde 1637 pasó a ser Rector de la Iglesia Parroquial de San Juan. Véase F. Esteve Perendreu, Mestrescoles i rectors..., p. 110. 
los otros catedráticos de Prima ${ }^{147}$. Mientras tanto, se ocupaban las aulas de la Universidad para almacenar la pólvora y la munición para la guerra ${ }^{148}$. Los Paheres acordaron la contratación, el 4 de diciembre de 1643, de un maestro de primeras letras, por óbito del que había ${ }^{149}$.

En septiembre de 1643, llegó Felipe IV con su ejército a las puertas de la ciudad y mandó destruir todas las huertas vecinas a fin de franquearse el paso. El gobernador francés, M. de Rogles, para impedir la entrada del Rey ordenó quemar todas las casas del arrabal, así como los conventos y monasterios de extramuros: la Casa de Montserrat de los benedictinos y la Casa de los cartujos, así como también los conventos de los trinitarios, agustinos y dominicos, que se contaban entre los más grandes de la ciudad. Este hecho supuso un grave problema, puesto que todas estas comunidades necesitaban un lugar donde realojarse, y apenas dispusieron de ello, durante décadas. Asimismo se perdió el cenobio de Sant Hilari, de las bernardas, que fueron realojadas en el Colegio universitario de San Bernardo ${ }^{150}$, que poco después también tuvo que ser derribado. De hecho, los novicios cistercienses, al no tener Colegio en Lérida, se trasladaron desde 1653 a Huesca ${ }^{151}$.

Esta situación afectó muy negativamente al progreso de la Universidad, a la que todas estas comunidades, particularmente los agustinos y las órdenes monásticas, proporcionaban estudiantes y maestros. Los dominicos pidieron en febrero de 1644 que se les dejara colocar las piedras que habían quedado de la demolición de su convento en el claustro de la Universidad y el Consejo de la Ciudad aceptó que se guardasen allí, siempre y cuando no resultaran un estorbo ${ }^{152}$. El gobernador francés se incautó del Aula de Lógica en la Universidad, a fin de convertirla en un depósito de munciones, hasta que un día los estudiantes violaron la puerta para sacar las armas y la pólvora que allí se guardaba. Señala Lladonosa que la queja ante el Consejo General de 26 de enero de 1644 conllevó la detención de veinte estudiantes de Artes ${ }^{153}$.

Entre tanto, el Papa había nombrado maestrescuela al Dr. Ramon de Magarola el 16 de agosto de 1641, pero el inicio de la guerra había impedido que

147 AML, Reg. 442, Llibre d'Actes (1642-1644), f. 124v.

148 F. Esteve Perendreu, Mestrescoles i rectors..., p. 216.

149 AML, Reg. 442, Llibre d'Actes (1642-1644), f. 184r.

150 J. Lladonosa, Lleida durant la Guerra dels Segadors, pp. 22-25.

151 E. Toda i Güell, La Davallada de Poblet, p. 140.

152 AML, Reg. 442, Llibre d'Actes (1642-1644), ff. 159v-160.

153 J. Lladonosa, Lleida durant la Guerra dels Segadors, p. 27. 
tomara posesión ${ }^{154}$. Magarola debió de esperar para entrar junto a Felipe IV, en agosto de 1644, cuando presentó la bula de provisión de la maestrescolía ${ }^{155}$.

El 16 de octubre de 1644, los Paheres acordaron el cobro de todas las pensiones debidas ${ }^{156} \mathrm{y}$ al día siguiente, los jesuitas rindieron cuentas ante los Paheres de los libros que iban a leer y de los maestros que enseñarían en ese curso: el P. Josep Vinyas sería el maestro de los pequeños, y se dedicaría a leer los primeros libros de la Retórica, las conjugaciones, las declinaciones...; no sabemos el nombre del lector de medios, si bien Gayá explica que debía leer la Sintaxis de Torroella y las epístolas más difíciles de Cicerón y de Ovidio; y para el tercer año el lector era el P. Albino Abella y tenía que seguir las oraciones de Cicerón, los progimnasmata de Nunyes y otras obras ${ }^{157}$.

En las vacaciones de verano de 1645 se ocupó nuevamente la Universidad con artillería. El Rector y el Claustro solicitaron al Rey que las desocupara. El 18 de agosto de ese año, el Rey dictó una orden en la que confirmaba en su cátedra de la Universidad de Lérida a Fr. Agustín Villarin, monje de San Victorián ${ }^{158}$.

Esteve indica la nómina de profesores que acudieron al Consejo General de 1646, entre los que destacan Josep Vilaplana, catedrático de Teología, Rector de la Iglesia parroquial de Sant Andreu ${ }^{159}$; y Joaquim Latorre, Maestro en Artes y Filosofía; a los que debe añadirse el Dr. Jaume Cases i Perisans, catedrático de Teología de la cátedra de Santo Tomás y Rector de la Iglesia parroquial de Santa Magdalena ${ }^{160}$. Massot informa que Josep Ballester, agustino natural de Barcelona, se doctoró en Teología en Lérida y fue catedrático de Prima en la Universidad en 1642 hasta $1648^{161}$.

Sabemos también que el Obispado de Lérida se comprometió a pagar cien escudos cada año para el catedrático de Filosofía. El último posesor de la mitra ilerdense fue el agustino Fr. Pedro de Santiago, que ya había fallecido el

154 ACA, Consejo de Aragón, leg. 292, n. 36.

155 F. Esteve Perendreu, Mestrescoles i rectors..., pp. 86-88.

156 AML, Reg. 443, Llibre d'Actes (1644-1651), f. 18.

157 R. Gayá Massot, Los Jesuitas en la Universidad de Lérida, pp. 226-227.

158 ACA, Consejo de Aragón, leg. 294, n. 77.

159 F. Esteve Perendreu, "La docència de la teologia a Lleida...”, p. 161.

160 F. Esteve Perendreu, Mestrescoles i rectors..., pp. 220-221.

161 J. Massot, Compendio Historial de los Hermitaños de nuestro Padre San Agustín..., p. 210. Otras fuentes indican que Fr. Josep Ballester (1610-1668) fue muy estimado como orador sagrado. Véase F. Martín Verdejo, "La vida y la biblioteca de Bernabé García, boticario rural del siglo XVIII", Asclepio. Revista de Historia de la Medicina y de la Ciencia, 56/2 (2004), p. 157. 
26 de mayo de 1650. Los Paheres indican que se había que pagar el salario a Fr. Francesc Tapioles, carmelita descalzo, Presentado y Calificador del Santo Oficio $^{162}$, catedrático de Teología, que no había percibido la nómina de San Juan de $1649^{163}$. De todo ello se informó al Nuncio, Arzobispo de Tarso, el 20 de junio de $165 \mathrm{O}^{164}$, quien recalcó que las deudas contraídas en el pontificado del difunto Obispo tenían que abonarse.

Desde 1647 hasta 1650 puede decirse que la Universidad estuvo totalmente cerrada. Aunque nominalmente figurase un claustro de profesores, lo cierto es que desde 1643 hasta 1654 prácticamente no hubo clases regulares, a causa de la guerra. Los Paheres escribieron el 6 de agosto de 1648 al Obispo indicando que "per les calamitats del temps y les desdiches que posse en si la guerra han sesat fins vuy la lectura de les cathedres de esta universitat en totes les Facultats ${ }^{165}$ ".

Aún en 1650 las aulas estaban ocupadas por material de guerra, si bien se hicieron reuniones para examinar los pasos a seguir para volver a la normalidad académica. En un consejo celebrado el 29 de junio de 1650 aparece el Dr. Pere Mallada como catedrático de Teología y en otro celebrado el 12 de abril de 1651 figuran el Dr. Mallada, Fr. Plácido García de Vera ${ }^{166}$, que era a la sazón Lector de la Catedral'167, y Fr. Josep de Villamajor, todos ellos Doctores en Teología ${ }^{168}$.

Tras la peste que asoló la ciudad, en el Consejo de la Universidad, reunido el 30 de junio de 1652, se dieron cita el Dr. Francesc Mallada (a la sazón Rector de la Iglesia de San Juan y catedrático de Prima de Teología ${ }^{169}$ ), Fr. Plácido García de Vera, Fr. Luis de Castilla (dominico y catedrático de Durando ${ }^{170}$ ),

162 J. C. de Vargas Machuca, Decisiones vtriusq[ue] supremi..., p. 50.

163 Más adelante fue Provincial. Véase B. Velasco Bayón, Historia del Carmelo español: Provincias de Cataluña y Aragón y Valencia, 1563-1835, Roma, Institutum Carmelitanum, 1954, p. 177.

164 AML, Reg. 856, Correspondencia, f. 258r.

165 AML, Reg. 856, Correspondencia, ff. 202r-v.

166 Identificamos este personaje con un religioso cisterciense denominado "Plácido de Vera", del que se dice "que ha sido de la Congregación de Aragón”, en la crónica de Fr. Tomás Gómez, En reino extraño. Relación de la visita del Real monasterio de Valldigna. Autobiografía, vida cotidiana y lucha política en la España de Carlos II, Valencia, Universitat de Valencia, 2008, p. 789.

167 F. Esteve Perendreu, "La docència de la teologia a Lleida...”, p. 162.

168 F. Esteve Perendreu, Mestrescoles i rectors..., pp. 226-227.

169 J. C. de Vargas Machuca, Decisiones vtriusq[ue] supremi..., p. 50.

170 Ibidem. 
y Bernardo de Aranda ${ }^{171}$, Doctor en Artes $^{172}$, todos ellos catedráticos. En las sucesivas reuniones se pedía la retirada del material de guerra, a fin de poder reanudar las clases y el abono de los salarios a los catedráticos ${ }^{173}$.

\subsection{Lenta recuperación}

El 15 de junio de 1653 sabemos que era catedrático de Filosofía Fr. Tomás de Salafranca, dominico ${ }^{174}$. Nacido en 1624 en Zaragoza, procedía de una familia destacada. Tomó el hábito en el Convento de Zaragoza, cursó sus estudios en la Universidad de Lérida y en 1656 fue Prior del Convento ilerdense. Fue asimismo catedrático de Vísperas ${ }^{175}$. Viajó a Roma al Capítulo General como socio de Fr. Blas del Fau. Fue un reputado orador ${ }^{176}$.

También sabemos, por un sermón pronunciado en $1662^{177}$, que el agustino Fr. José Antonio de Urrea había sido poco antes catedrático de Sagrada Escritura en la Universidad de Lérida.

En 1654, el Dr. Mateu Companys seguía siendo el catedrático de Prima de Teología y figuraba como Prior de la Villa de Castelló de Farfanya ${ }^{178}$. Ese mismo año los Paheres, haciendo previsiones para el nuevo curso, resolvieron que no habría dinero ni se daría permiso a la Religión claustral de San Benito para que construyese un Colegio nuevo. También admitieron que sería imposible que para San Lucas pudiera haber tres catedráticos de Filosofía ${ }^{179}$ para completar el ciclo trienal. A la sazón, el Vicerrector del Colegio de la Compañía en Lérida era el P. Ignacio Lucas Herrera ${ }^{180}$.

171 Le identificamos con un agustino homónimo, que fue luego Prior del Convento de Zaragoza y examinador del arzobispado. Véase Constituciones, y ordinaciones de la muy ilustre Congregación y Confradia del glorioso S. Pedro Martyr: de ministros de la Inquisicion de Aragon, Zaragoza, por Francisco Moreno, 1746, p. 147.

172 F. Esteve Perendreu, Mestrescoles i rectors..., p. 228.

173 AML, Reg. 851, Cartes Reials, s.f.

174 F. Esteve Perendreu, Mestrescoles i rectors..., p. 231.

175 J. C. de Vargas Machuca, Decisiones vtriusq[ue] supremi..., p. 50.

176 F. de Latasa, Biblioteca nueva de escritores aragoneses, III, Pamplona, En la Oficina de Joaquín Domingo, 1799, p. 445.

177 J. A. de Urrea, Sermon de la Inmaculada Concepcion de Nuestra Señora, Barcelona, Antonio Lacavalleria, 1662.

178 F. Esteve Perendreu, "La docència de la teologia a Lleida...”, p. 161.

179 AML, Reg. 856, Correspondencia, f. 290.

180 J. C. de Vargas Machuca, Decisiones vtriusq[ue] supremi..., p. 50. 
El 26 de octubre de 1654 comparecieron en el Consejo de la Universidad algunos de los profesores ya citados, así como Fr. Domingo López ${ }^{181}$ y Fr. Juan de Beaumonte, dominico, Doctores en Artes y Filosofía, catedráticos de la Universidad ${ }^{182}$. Asimismo se solicitó al Virrey, Duque de Monteleón, que se embargasen las rentas que el obispado de Lérida tenía en Aragón para el pago de las $1000 £$ de pensión que la Universidad tenía sobre aquella mitra, petición que fue concedida el 21 de noviembre ${ }^{183}$.

Se inició a la sazón un conflicto con los monjes benedictinos de la Casa de Monserrat, que se mostraron muy descontentos con la decisión de los Paheres, que no habían permitido que construyesen un Colegio nuevo. En 1657, el Consejo de la Ciudad constataba que los benedictinos querían dejar la casa que tenían en Lérida y transferir el Colegio a Barcelona ${ }^{184}$. Ello suponía no solo una afrenta al Estudio, sino un intento de pasar a la pujante Ciudad Condal, que tenía, de facto, una fama cada vez más consolidada. No obstante, tras examinar la petición, el Rey ordenó que continuasen en Lérida ${ }^{185}$. En 1661, los benedictinos, enfrentados con la Universidad ilerdense, manifestaron su voluntad de pasar a la Universidad de Huesca ${ }^{186}$, que estaba floreciendo. El Rey nuevamente se opuso a dicho traslado ${ }^{187}$.

En 1657, Fr. Tomás de Salafranca era ya Doctor en Teología y catedrático de Vísperas, al tiempo que se desempeñaba como Prior de los dominicos de Lérida $^{188}$. En el Consejo de la Universidad de 2 de abril de 1658 hallamos a Pere Francesc Mallada, catedrático de Prima de Teología; Fr. Joan Beaumonte; José Campi ${ }^{189}$, Doctor en Filosofía; y Josep Melianta, Bachiller en Filosofía ${ }^{190}$.

181 Ibidem.

182 F. Esteve Perendreu, Mestrescoles i rectors..., p. 232.

183 ACA, Consejo de Aragón, leg. 220, n. 40.

184 AML, Reg. 856, Correspondencia, f. 342.

185 E. Zaragoza Pascual, Història de la Congregació Benedictina Claustral Tarraconense i Cesaraugustiana (1215-1835), Montserrat, Abadia de Montserrat, 2004, p. 185.

186 AML, Reg. 863, Correspondencia, f. 13v-14.

187 E. Zaragoza Pascual, Història de la Congregació Benedictina..., p. 187.

188 F. Esteve Perendreu, Mestrescoles i rectors..., p. 236, n. 742.

189 AAVV, Biografía eclesiástica completa, Tomo III, Madrid, Eusebio Aguado, 1850, p. 240. José Campi y Abenia era aragonés. En paralelo a su actividad como profesor, obtuvo el cargo de examinador sinodal en su diócesis y en 1680 la canongía penitenciaria de Tarazona. Se conservan varias obras suyas. Era, al parecer, un poeta agradable y ameno.

190 F. Esteve Perendreu, Mestrescoles i rectors..., pp. 235-236. 
Tras continuas quejas por parte del Estudio y también de los Paheres, el 29 de abril de 1659, el Consejo de Aragón se pronunció sobre las pensiones que el Obispo adeudaba a la Universidad, adjuntando una copia de la bula de la pensión ${ }^{191}$. Asimismo solicitaron al Rey que pudieran admitirse colegiales en el Colegio de la Concepción, como sucedía antes de la Guerra, pues en aquel momento estaban instaladas allí las bernardas y no había sitio para los colegiales $^{192}$. El memorial indicaba que el Colegio Nuevo, antes de las guerras, no tenía más que cuatro colegiales y que, como el convento de las bernardas fue derribado, se las realojó allí. Se solicitaba que los colegiales que fuesen nombrados pudiesen ser acomodados en el Colegio.

En 1660 tenemos constancia de que figuraban como catedráticos de Teología Pere Mallada, que detentaba la cátedra de Prima, y Francesc Crespo, benedictino. Este último personaje fue uno de los más importantes hijos de San Benito del siglo XVIII. Natural de Calatayud, tras haber leído en diferentes Colegios de la Orden, se graduó y fue Lector en la Universidad de Irache en $1638^{193}$. Tras haber sido Abad de Montserrat (1653) ${ }^{194}$ y de Sant Pere de Bages (1657-1660), fue catedrático en la Universidad de Lérida y Abad de San Victorián (1660-1668) ${ }^{195}$.

En 1660, Joan Beaumonte seguía como catedrático de Filosofía ${ }^{196}$, así como el ya citado Fr. Josep Ballester, lector jubilado de la Provincia de Aragón ${ }^{197}$. En 1659 figura como catedrático del Estudio Fr. Ramon Font, que en 1653 había sido Lector de Artes en el Convento de Cervera ${ }^{198}$, y en 1661, tenemos constancia de la lectura de Fr. Tomàs Font, dominico como el anterior ${ }^{199}$.

La reforma de los Estatutos de la Universidad de Lérida propuesta por Fr. Miguel Escartín se aprobó el 12 de mayo de $1662^{200}$. Este hecho tuvo inciden-

191 ACA, Consejo de Aragón, leg. 267, n. 117.

192 AML, Reg. 856, Correspondencia, f. 363, pliego intercalado.

193 AGN, n. 542, Registro y Libro de Grados mayores y menores, f. 332v.

194 En 1653, la comunidad de Montserrat, encabezada por Crespo, hizo solemne voto concepcionista. Véase F. X. Altés i Aguiló et alt., Cinc-cents anys de Publicacions de l'Abadia de Montserrat, Barcelona, Abadia de Montserrat, 2005, p. 46.

195 E. Zaragoza Pascual, Catàleg dels monestirs catalans, pp. 26, 29, 156. También E. Zaragoza Pascual, Història de la Congregació Benedictina..., pp. 378-379.

196 F. Esteve Perendreu, Mestrescoles i rectors..., p. 239.

197 Ibidem, p. 240.

198 AHN, Códices, L. 573, f. 171v.

199 F. Esteve Perendreu, "La docència de la teologia a Lleida...”, p. 162.

200 ACA, Consejo de Aragón, leg. 314, n. 80. 
cia en una oposición en la que participaba el Dr. José Campi, pues la aplicación de los nuevos Estatutos obligaba a que la provisión de cátedras se hiciese a puerta cerrada y que ningún seglar pudiese entrar en ella, con armas o sin ellas $^{201}$. También el Maestrescuela vio confirmada su facultad de nombrar al Alguacil, confirmando a Joaquim de Montserrat, que había desempeñando este cargo ${ }^{202}$.

Francesc Esteve aporta el nombre de más profesores de Filosofía y Teología durante los años 1663-1665: Fr. Ángel Valentín, cisterciense, hijo del Monasterio de Rueda ${ }^{203}$, figuraba como catedrático de Vísperas de Teología, y Francesc Ardilla era Doctor en Filosofía ${ }^{204}$; el canónigo Josep Puigvert i Martí, natural de Tortosa, era catedrático de Sagrada Escritura; y Fr. Àngel Filbet, Provincial de los carmelitas calzados desde $1656^{205}$, era catedrático de Teología de Santo Tomás ${ }^{206}$. Sabemos que este último solicitó ese mismo año al Papa que se dignase definir el Dogma de la Inmaculada Concepción ${ }^{207}$.

Los Paheres pidieron el 26 de enero a 1665 la fundación de otra cátedra de $\operatorname{Artes}^{208}$, un tema que había sido recurrente durante toda la década. Sin embargo, la situación económica no permitía la dotación. Los Paheres constataron ese mismo año muchas dificultades para el pago de los salarios de las cátedras ${ }^{209}$. El 14 de mayo de 1665 se llevó a cabo otra concordia entre los Paheres y el Colegio de la Compañía, en virtud de la cual se ajustaron algunos aspectos de la lectura de la Gramática ${ }^{210}$.

Como solía pasar en momentos de carestía, había más tumultos y alborotos. En 1666, en el marco de la votación de una catedrilla de Leyes y una cátedra de Filosofía hubo pasiones entre los estudiantes y al final la Ciudad tuvo que intervenir para evitar ulteriores problemas ${ }^{211}$.

201 F. Esteve Perendreu, Mestrescoles i rectors..., pp. 242-244.

202 AML, Reg. 863, Correspondencia, f. 91.

203 Angel Valentín de Jaca aparece como censor de M. R. Zapater, Cister militante en la campaña de la Iglesia contra la sarracena furia, Zaragoza, por Agustin Verges, 1662.

204 F. Esteve Perendreu, Mestrescoles i rectors..., p. 247.

205 B. Velasco Bayón, Historia del Carmelo español, p. 221.

206 F. Esteve Perendreu, Mestrescoles i rectors..., p. 248.

207 Índice de la colección de don Luis de Salazar y Castro, tomo V, Madrid, Real Academia de la Historia, 1951, p. 294.

208 ACA, Consejo de Aragón, leg. 308, n. 13.

209 AML, Reg. 863, Correspondencia, f. 102v.

210 AHUB, Universidad de Cervera, Caja 147, leg. 1224, n. 4.

211 AML, Reg. 863, Correspondencia, f. 117, pliego intercalado. 
Al final, el 20 de diciembre de 1666, al recibir una nueva petición de fundación de una tercera cátedra de Filosofía, los Paheres deliberaron que se dieran $60 £$ al año al Estudio para que pudiese leerse un curso trienal de filosofía completo $^{212}$.

El Dr. Mateu Companys, catedrático que fue de Prima de Teología, fue designado Vicario General de la diócesis de Tortosa por el obispo Josep Fageda, su tío ${ }^{213}$. Desde 1666 fue nombrado Maestrescuela de la Catedral de Lérida. Falleció en Tortosa en $1668^{214}$. En 1666 pereció Baudili Galí ${ }^{215}$, Doctor en Teología, arcediano de Ribagorza y canónigo de la Catedral de Lérida, que en otro tiempo había detentado la cátedra de Sagrada Escritura en la Universidad $^{216}$.

El 14 de mayo de 1666 hubo oposiciones para la cátedra de Teología de Durando, a la que concurrieron el Dr. José Campi, que había sido catedrático de Filosofía y de Teología, y el bachiller Martín Trallero, sobrino, al parecer, del gobernador de la Plaza. Campi alegaba que, por ser Doctor, tenía que leer primero. Tras una serie de incidentes, el 14 de julio, el Rector y el Consejo de la Universidad resolvieron que el Dr. Campi no fuese admitido como Doctor en los actos literarios de la Universidad, lo que llevó a Campi a interponer una demanda ante la Real Audiencia de Cataluña ${ }^{217}$. Fue nombrado relator de la causa Alejo de Tristany, antiguo estudiante de las Universidades de Lérida y de Barcelona ${ }^{218}$.

Parece ser que Martín Trallero resultó vencedor, puesto que el 3 de diciembre de 1667 figuraba como catedrático de Teología de Durando ${ }^{219}$. De todas formas, José Campi, que había tomado posesión de la rectoría de la Parroquia de San Juan el 1 de enero de 1667, fue catedrático más adelante de Sagrada Escritura y alcanzó la cátedra de Prima de Teología. Con pos-

212 AHUB, Universidad de Cervera, Caja 147, leg. 1224, n. 33.

213 A. de Trilla, Perfecto practicante medico y nueua Luz de facil enseñança, Toledo, por Agustin de Salas Zaço, 1677, p. 6v.

214 F. Esteve Perendreu, Mestrescoles i rectors..., pp. 110-113.

215 Hay un personaje homónimo que figura como canónigo electo de Gerona en J. P. Fontanella, Tractatus de pactis nuptialibus siue e capitulis matrimonialibus: duobus tomis diuisus, Lugduni, sumptibus Horatii Boissat et Georgii Remeus, 1667, p. 446.

216 F. Esteve Perendreu, "La docència de la teologia a Lleida...”, p. 162.

217 F. Esteve Perendreu, Mestrescoles i rectors..., pp. 250-252.

218 ACL, P7_M2_P3_Co6, s.f. Fue creado doctor por beneplácito regio: ACA, Cancillería, Reg. 5498, f. 210 .

219 F. Esteve Perendreu, Mestrescoles i rectors..., p. 110. 
terioridad fue designado canónigo penitenciario en la Catedral de Tarazo$\mathrm{na}^{220}$.

A fin de mejorar la enseñanza, los Paheres se reunieron en 1667 con el Rector de la Universidad, Josep Valls, así como con Pere Mallada, canónigo y catedrático de Prima de Teología; Joan Pau Molner, Vicario General y catedrático de Prima de Cánones; Joan Enciso, catedrático de Segunda de Cánones; Jaume Biosca, catedrático de Prima de Leyes; Ramon Queraltó, catedrático de Decreto; y Josep Bayona, catedrático de Medicina. Entre otros temas, trataron de nuevo la necesidad de crear definitivamente una nueva cátedra de Filosofía, a fin de que los estudiantes estuviesen mejor preparados al llegar a las Facultades superiores ${ }^{221}$.

El Dr. Joan Gabriel Surch, catedrático de Filosofía, falleció el 9 de enero de 1669 y fue enterrado en la Iglesia Parroquial de San Juan ${ }^{222}$. Al año siguiente figuraba como catedrático de Teología el dominico Fr. Pere Màrtir Oller ${ }^{223}$, que había leído Artes en el Colegio de Solsona en $1655^{224}$, fue instituido Presentado en el Capítulo provincial de Zaragoza de $1674^{225}$ y Maestro en el Capítulo de Barcelona de $1676^{226}$. En 1669 tomó posesión de la maestrescolía el Dr. Josep Puigvert i Martí, que hasta el momento había sido catedrático de Teología. Se desempeñó como Maestrescuela hasta su fallecimiento, acaecido en $1679^{227}$. Como sucesor en la cátedra, propuso al Dr. Campi ${ }^{228}$.

El Definitorio de los benedictinos de 1672 acordó que el Colegio se trasladase a Barcelona, aunque el monarca no lo aceptón 229 . Sin embargo, el Prior de los dominicos de Santa Catalina Mártir de Barcelona admitió a los benedictinos juniores en el curso de Filosofía, junto a sus estudiantes. Los Paheres

220 Sermon que predico el Doctor Josef Campi y Avenía, Canonigo Penitenciario de la Santa Iglesia Cathedral de Tarazona; Antes cathedratico de Prima de Theologia en la Universidad de Lérida. Dia del nacimiento de San Juan Bautista, en dicha Santa Iglesia, en Zaragoça, por los herederos de Diego Dormer, 1676.

221 AML, Reg. 447, Llibre d'Actes (1665-1676), f. 38v.

222 F. Esteve Perendreu, Mestrescoles i rectors..., p. 258.

223 Ibidem, p. 259.

224 V. Beltrán de Heredia, “Catálogo de los colegiales...”, p. 130.

225 AHN, Códices, L. 573, f. 233 v.

226 AHN, Códices, L. 573, f. 252r.

227 F. Esteve Perendreu, Mestrescoles i rectors..., p. 115.

228 Ibidem, pp. 113-114.

229 E. Zaragoza Pascual, Història de la Congregació Benedictina..., p. 193. 
se percataron de esta situación ${ }^{230}$ y de que los cinco monjes de Sant Cugat se habían trasladado a Barcelona, para estudiar en el Convento de Santa Catalina Mártir. Tras haber formalizado su protesta, las autoridades contestaron a los Paheres que estos monjes estaban en Barcelona con las rentas del Colegio de Lérida ${ }^{231}$. Vista la situación, la Ciudad intentó que los benedictinos construyesen una nueva casa en Lérida, con la promesa de ayudarles. Finalmente, los benedictinos decidieron construir allí un nuevo Colegio.

Con todo, la relación con la Universidad de Lérida no fue fácil tampoco desde entonces, pues los benedictinos claustrales consideraban que el Estudio estaba en gran decadencia y que sólo daban clases seis meses, con muchos días feriados, y ello iba en perjuicio de la formación de los monjes. La Congregación decidió pedir a Carlos II que se trasladase el Colegio a Barcelona "ubi studia valde florent ${ }^{232}$ ". También se prohibió que los colegiales estudiasen Leyes y Cánones antes de haber acabado los cuatro años de estudios teológicos.

El 10 de septiembre de 1673 el Dr. Melcior Serra, presbítero, consta como catedrático de Sagrada Escritura ${ }^{233}$. Asimismo, los Paheres, recién empezado el curso, acordaron que, para arreglar las aulas que se estaban derrumbando, mandasen a los clavarios que se gastase para repararlas ${ }^{234}$.

El 1 de agosto de 1678 figura el Dr. Joan Ferrusola, Rector de la Iglesia Parroquial de San Juan, como catedrático de Escritura ${ }^{235}$. En enero de 1679 falleció el Dr. Pere Francesc Mallada i Gavàs, catedrático jubilado de Prima de Teología. Recordemos que ya en 1650 constaba como catedrático de Prima. En 1669 figuraba como canónigo, catedrático de Prima y Vicario General del obispo Josep Ninot $^{236}$. Por óbito de este prelado, Mallada fue administrador apostólico y realizó la visita pastoral en $1673^{237}$.

El 17 de agosto de 1680 consta que el ya citado Dr. Melcior Serra era catedrático de Teología de Santo Tomás. Fue beneficiado en la Iglesia parroquial de San Juan y obtentor del beneficio de Sant Ramon de Penyafort en la Iglesia parroquial de Sant Andreu ${ }^{238}$. Fr. Tomàs Carreter, dominico hijo del convento

230 AML, Reg. 863, Correspondencia, ff. 210v-211r.

231 AML, Reg. 863, Correspondencia, f. 224.

232 E. Zaragoza Pascual, Història de la Congregació Benedictina..., p. 208.

233 F. Esteve Perendreu, Mestrescoles i rectors..., p. 263.

234 AML, Reg. 447, Llibre d'Actes (1665-1676), ff. 273v-274v.

235 F. Esteve Perendreu, Mestrescoles i rectors..., p. 267.

236 F. Esteve Perendreu, "La docència de la teologia a Lleida...”, pp. 160-161.

237 A. Agustí, Llengua i Església a la Lleida del XVI al XVIII, p. 210.

238 F. Esteve Perendreu, Mestrescoles i rectors..., p. 268. 
de Perpiñán, Prior del convento de Santo Domingo ${ }^{239}$, y catedrático de Sagrada Escritura, obtuvo en 1680 la cátedra de Santo Tomás con una duración de cuatro años. Carreter fue instituido Presentado en el Capítulo provincial de $1684^{240}$, Maestro en el capítulo de $1696^{241}$ y fue nombrado Provincial de Aragón en 1708.

El abad Josep Tresánchez (1684-1688), natural de Balaguer y antiguo alumno del Colegio de Lérida, decidió restablecer en la ciudad el Colegio de Poblet. Tresánchez dispuso que para el curso 1685-1686 varios estudiantes y maestros se trasladasen a Lérida, a fin de constituir la primera comunidad. Pese a la oposición del Vicario General de la Orden, el Colegio pronto se consolidó. Los dos maestros lectores enviados fueron Baltasar Sayol y Gregori Ramon $^{242}$. En 1686, la Orden de San Bernardo compró una casa que sería la definitiva ubicación de los cistercienses en Lérida. Desde entonces hasta la transferencia de la Universidad a Cervera tuvieron una presencia muy destacada en el Estudio ${ }^{243}$.

Tenemos constancia del nombre de algunos profesores de Filosofía y Teología en 1683: el Dr. Miquel Vila, Vicario que fue de la Iglesia de Sant Pere, era el catedrático de Prima de Teología; Fr. Josep Gatell, de la Orden de Predicadores, instituido presentado en el Capítulo de $1696^{244}$, era catedrático de Teología ${ }^{245}$; Fr. Jaume Teixidó, benedictino, era catedrático de Filosofía; Fr. Bernat Gavàs, cisterciense, era también catedrático de Filosofía ${ }^{246}$.

Bernat Gavàs (o Gabás), natural de Sopeira, era hijo del Monasterio de Lavaix, del que fue años después Abad ${ }^{247}$. Tuvo gran fama como orador y dejó impresos algunos sermones ${ }^{248}$. Sabemos asimismo que Fr. Tomàs Carreter, que había ganado la cátedra de Sagrada Escritura por cuatro años, solicitó que su cátedra fuese perpetua, circunstancia a la que el monarca, previo informe del

239 AHN, Códices, L. 573, f. 272r.

240 AHN, Códices, L. 574, f. 136r.

241 AHN, Códices, L. 574, f. 221v.

242 E. Toda i Güell, La Davallada de Poblet, p. 181.

243 J. Lladonosa Pujol, Lérida y sus relaciones..., pp. 15-17.

244 AHN, Códices, L. 574, f. 222r.

245 Figura como Doctor en Teología en un documento de 1688. Véase I. Puig Sanchís, “D’Arquitectura i Mestres de Cases a la Lleida del segle XVIII: Els Biscarri”, Urtx, 16 (2003), p. 191.

246 F. Esteve Perendreu, "La docència de la teologia a Lleida...", p. 165.

247 E. Toda i Güell, La Davallada de Poblet, p. 204.

248 R. Muñiz, Biblioteca Cisterciense española, Burgos, Joseph de Navas, 1793, p. 147. 
Virrey, accedió. El Rector, desobedeciendo la orden regia, decidió poner edictos en 1684 para que los interesados se opusieran a dicha cátedra, lo cual fue impugnado por Fr. Tomàs Carreter. Parece ser que se respetó la orden regia ${ }^{249}$.

El Consejo General de la Ciudad tomó en cuenta también la necesidad de arreglar las aulas del Estudio ${ }^{250}$. La situación era muy inestable y precaria. A ello se sumaron nuevos problemas con el Colegio de San Bernardo, que mandó un largo memorial ${ }^{251}$, frente al cual la Ciudad tuvo que enviar una misiva al Nuncio ${ }^{252}$, explicando los problemas de dicho Colegio con la Universidad y la propia Orden, que poco a poco tendieron a apaciguarse durante la última década del siglo XVII.

Jaime Pueyo, natural de Tolva (Huesca), nació en 1650 y, tras doctorarse en Filosofía y en Teología en el Estudio de Lérida, en 1684 consta como catedrático de Filosofía ${ }^{253}$. De 1685 podemos proporcionar la nómina completa de los catedráticos de Teología: Dr. Miquel Vila, de Prima; Francesc Ferrusola, de Sagrada Escritura; Josep Gatell, de Santo Tomás; y Juan Navarro, mercedario, que fue Provincial de Aragón y examinador sinodal del Arzobispado de Zaragoza $^{254}$, era catedrático de Vísperas. Navarro fue consagrado Obispo de Albarracín en 1704, dignidad que detentó hasta su fallecimiento en $1727^{255}$.

En 1687 sabemos que el Dr. Francesc Colí era catedrático de Filosofía y que Fr. Gregori Ramon, cisterciense, era catedrático de Teología ${ }^{256}$. En 1688 figura como catedrático el Dr. Francesc Vives, que era Rector de Santa Magdalena ${ }^{257}$.

El 4 de noviembre de 1686, el Rector fijó un edicto en el cual ordenaba que en un plazo de tres días los estudiantes debían matricularse. Algunos

249 F. Esteve Perendreu, Mestrescoles i rectors..., p. 273.

250 AML, Reg. 450, Llibre d'Actes (1681-1687), ff. 193v-194r.

251 AML, Reg. Lletres (1685-1686), ff. 49v-61v.

252 AML, Reg. Lletres (1685-1686), ff. 75v-77r.

253 F. Esteve Perendreu, Mestrescoles i rectors..., p. 268, n. 854.

254 F. de Neyla, Gloriosa fecundidad de Maria en el campo de la Catolica Iglesia: Descripcion de las excelencias è ilustres hijos del Real Convento de San Lazaro de la ciudad de Zaragoça del Real y Militar Orden de Nuestra Señora de la Merced Redencion de Cautivos, por Rafael Figuerò, Barcelona, 1698, p. 382.

255 V. Sánchez Gil, "La teología española hasta la Ilustración 1680-175o”, en M. Andrés (ed.), Historia de la teología en España, 1470-1570: Desde fines del siglo XVI hasta la actualidad, Madrid, Fundación Universitaria Española, 1987, p. 377.

256 F. Esteve Perendreu, Mestrescoles i rectors..., p. 279.

257 J. Lladonosa, Història de Lleida, vol. II, p. 578. 
alumnos le dijeron al Rector que el P. Prefecto del Colegio de la Compañía no les quería examinar de Latinidad, por el hecho de no haber cursado en dicho Colegio un año de Retórica. Los estudiantes alegaban que sabían suficiente latín para poder hacer el examen y matricularse de primero de Filosofía, pero que el P. Prefecto no quería examinarles. El Rector mandó que dos catedráticos de la Universidad, Fr. Josep Gatell y el Dr. Francesc Colí, examinasen de Latinidad a los estudiantes que quisieran y, en el caso de que aprobasen, que se pudieran matricular de Filosofía ${ }^{258}$.

$\mathrm{Al}$ conocer el hecho el Maestrescuela, Esteve Caselles, el 8 de noviembre se personó en el aula de primero de Filosofía para ordenar que los estudiantes que no se hubiesen examinado con el P. Prefecto, lo hiciesen, y que si no querían, abandonaran la Universidad de inmediato ${ }^{259}$. Al día siguiente, el Rector mandó que nadie fuera a matricularse con el Prefecto y que el curso siguiera con normalidad. La situación fue radicalizándose hasta que el Virrey mandó que suspendiesen las actuaciones confrontadas entre ambos hasta que Carlos II resolviera. El Maestrescuela resolvió radicarse entretanto en Barcelona, de manera que no se podían conceder los grados de Doctor y los que le correspondían de Bachiller.

Las alegaciones del Maestrescuela fueron impresas y en ellas recalcaba especialmente su autoridad y la facultad de hacer observar los Estatutos. Como hemos explicado en el capítulo anterior, el Maestrescuela quería vindicar ante todo sus derechos. Su juicio sobre las cátedras de Filosofía era desolador:

"Esta relaxacion, y desorden nace de los Cathedraticos, que para conservarse cada vno, y á los de sequito, procuran numero de estudiantes, para tener mas votos a su devocion, y assi quien aun no sabra gramatica, en el primer año de curso votaria en las cathedras de Philosophia, y con la misma ignorancia prosiguen las facultades, con tanto descredito de la Vniversidad, y con perdida vana del tiempo, y patrimonio de sus casas ${ }^{260 ”}$.

258 Seguimos a F. Esteve Perendreu, Mestrescoles i rectors..., pp. 118-129.

259 E. Casellas, Iurisdiccion regia, p. 4: "en el libro de statutos y Regia reforma de dicha Vniversidad esta un statuto regio, que manda, que para matricularse, y ser admitido en el primer año de curso de Philosophia el estudiante, que quiziere cursar, haya primero de ser examinado, y aprobado por el Prefecto de las Escuelas de gramatica, y traher sedula, y fe de dicho Prefecto, que habilite al estudiante para empeçar la Philosophia. Mas ay otro estatuto, que manda, que ni Retor, su Consejo, ni otro de la Vniversidad pueda interpretar, ni dispensar en estatutos, sino que quando se ofresca dificultad en estatuto, le acuda a Vuestra Magestad, o al Visitador si se huviere".

260 Ibidem, p. 8. 
En el texto también se exponen algunos detalles sobre las oposiciones y la violencia escolar:

"El año 1680 en el dia que se habilitavan los votos para la provision de la Cathedra de Philosophia, porque se temian desordenes de armas, siendo Retor el Dotor Joan Olives, aora Canonigo de la Santa Iglesia de Lerida, subio el Maestre-Escuelas a la Vniversidad con sus Officiales y con su presencia dentro los patios della, i se desaparecieron las inquietudes, se temian; y desto fue instado. [...] En el mismo año por la mañana, que lehian de oposicion de Philosophia el Dotor Jayme Pueyo, y el Dotor Fray Balthazar Sayol, en el patio de la Vniversidad hizo capturar dos estudiantes, que el dia antes havian rompido la cabeça con una piedra a un pobre hombre, y fueron encarcelados en la carcel de la Vniversidad. Otra ocasion hizo entrar sinco en la misma carcel por inquietos, y el Dotor Fr. Gavaz, intercedia por algunos dellos, y otros por otros, y esto sin las muchas vezes como queda dicho, que por sus Alguaziles ha exercitado su jurisdicion, y todas dentro de la Vniversidad. Sinco vezes diferentes a mandado fixar editos concernientes a su jurisdicion, y todas dentro de la Vniversidad ${ }^{261}$ ".

En la reforma de 1693 se preceptuó que el curso de Filosofía tenía que ser trienal y que los catedráticos no tenían que avanzar más en el escribir que en el explicar. La primera cátedra que vacase tenía que ser destinada a la opinión tomista, mientras que la segunda, a la oponión suarista. La tercera, debía ser destinada alternativamente a cada una de ambas opiniones. Era necesario tener aprobados tres cursos de Filosofía para graduarse de Bachiller. Se preceptuó asimismo la creación de una catedrilla de Teología, con las mismas condiciones que los catedráticos de Instituta ${ }^{262}$.

En estos años, el dominico Antonio Iribarren detentó la cátedra de Sagrada Escritura y Lector magistral de la Catedral ${ }^{263}$. Había nacido en Calatayud en 1655, y obtuvo el grado de Doctor en Teología en la Universidad de Zaragoza. Fue Examinador de la Nunciatura y sinodal del Arzobispado de Zaragoza. Falleció en el Colegio de San Vicente en $1710^{264}$.

Consta también como catedrático de Teología desde 1693 Fr. Feliu (Félix) Genover, cisterciense ${ }^{265}$. Genover había sido autorizado para seguir leyendo

261 Idem, p. 22.

262 F. Esteve Perendreu, El Régimen jurídico..., pp. 233-234.

263 F. de Neyla, Alpha y omega sacro, discursos evangelicos, morales, y panegiricos..., Zaragoça, por Pasqual Bueno, 1691, aprobacion.

264 Latassa, F. de, Biblioteca nueva de los Escritores Aragoneses florecieron desde el año de 1689 hasta el de 1753, Vol. IV, Pamplona, Joaquín Domingo, 1800, pp. 241-242.

265 E. Toda i Güell, La Davallada de Poblet, p. 225, "L'abat Feliu Genover fou el 
Teología hasta completar doce años en la cátedra. En 1699 recibió la conformidad del Abad para oponerse a una cátedra de Derecho canónico, que no debió de vencer. En 1700 ya había acabado su período de lectura en la Universidad, y era Rector del Colegio de Poblet cuando publicó su tratado sobre el sacrificio de la Misa ${ }^{266}$, cuya censura hizo el Dr. Vila, catedrático de Prima. Siendo ya Abad de Poblet (1728-1732), Genover dio a la imprenta sus disputaciones sobre teología moral ${ }^{267}$, siguiendo las opiniones de Santo Tomás, que dan fe de su amor a la ciencia.

Hay que indicar que varios cistercienses del Colegio de Poblet habían recibido autorización para participar en las cátedras de la Universidad de Lérida: Agustí Oliva, Josep Queralt, Feliu Genover, Miquel Escuder, Joan Baptista Vendrell, Joan Baptista Cànoves y Romuald Ferriol ${ }^{268}$. Sólo hemos obtenido noticia de algunos de ellos, pues otros no llegaron a presentarse a las oposiciones o no las vencieron.

En 1696, tenemos constancia de la nómina de dos catedráticos de Filosofía: Francesc Colí, presbítero, y Baltasar Pellicer. Esteve indica que Pellicer, procedente Verdú (Solsona), en 1690 era acólito y Doctor en Filosofía y tomó posesión del Beneficio de San Ivo en la Universidad de mano de Francesc Colí, Doctor en Filosofía y beneficiado de la Catedral ${ }^{269}$.

En 1697, sabemos que Fr. Baltasar Sayol (1656-1738), cisterciense, era Rector del Colegio de San Bernardo de Lérida y catedrático de Sagrada Escritura, puesto que ocupó por espacio de doce años ${ }^{270}$. Se trata de uno de los personajes más ilustres que pasaron por las aulas del Segre en esta época. Vistió la cogulla en Poblet el 1671 y recibió los grados de Doctor en Artes y en Teología por la Universidad de Lérida. Fue nombrado Prior de Nazaret de Barcelona y desde 1705 fue Lector en el Colegio de la Orden en Huesca. $\mathrm{Su}$ apoyo a Felipe V le valió ser elegido tres veces Abad cuatrienal de Poblet

monjo més inquiet i d'història més moguda que existí en cap de les comunitats pobletanes en el curs de la vida del monestir. Fou home prou interessant per a que l'exposem en tots sos caires. Nasqué a Vilanant, lloc veí a Figueres, en 1688 [sic], i professà en 1692".

266 Succinta, praeclara ac perutilis resolutio, cujusdam peculiaris difficultatis, circa sacrosancti Missae Sacrificii applicationem occurrentis Ilerdae, excudebat Dominicus Simon, 1700.

267 Selectae disputationes miscellaneae, in moralem theologiam juxta tutissima, et inconcussa Div. Thomae Aquinatis dogmata, Cervariae, per Thomam Senant, 1730.

268 E. Toda i Güell, La Davallada de Poblet, p. 191.

269 F. Esteve Perendreu, Mestrescoles i rectors..., p. 294.

270 F. Esteve Perendreu, "La docència de la teologia a Lleida...", p. 165. 
(1716-20, 1724-28 y 1732-36). Es autor de algunos sermones, de comentarios latinos y obras históricas ${ }^{271}$.

\subsection{De la alternativa de cátedras a la extinción de la Universidad}

En 1698, los Paheres se dirigieron a Carlos II, a fin de que fundara tres nuevas cátedras de Filosofía, de modo que hubiera tres cátedras tomistas y tres suaristas, lo cual muestra la pujanza de las doctrinas de la Compañía de Jesús, también en Lérida. Como es sabido, el Rey, para dar margen al pensamiento jesuítico, quería que hubiese alternativa de cátedras, a la que se oponían firmemente las Universidades mayores y otras, como la de Barcelona ${ }^{272}$. Los Paheres aprovecharon para pedir al monarca que doblase el número de cátedras, a fin de que se diese una alternativa perfecta, con tres de ellas dedicadas a Santo Tomás y tres a Suárez:

"Y porque seria en vano dar mejor providencia en las provisiones de las Cathedras, si al mismo tiempo no se aplicaren medios para aumentar el concurso de Estudiantes, que ha descaecido, desde que por el contratiempo de las Guerras del año 1640 en que fue Lérida frontera, y antemural de estos Reynos, y teatro de batallas, fue preciso cerrar por algunos años las Escuelas, para lograr, Señor, este concurso. Suplica la Ciudad a V. Magestad se digne honrarla con la fundacion de tres nuevas Cathedras de Philosophia; de suerte, que con las tres ya fundadas, tenga la Universidad seis Cathedras de Artes, siendo tres de opinion Thomista, y las otras tres de opinion Suarista, y se comineçen cada año dos cursos, uno de opinion Thomista, y el otro de opinion Suarista, lograndose por este medio, a mas de llamar el concurso de oyentes de todas las opiniones, mayores progressos, con el calor de disputas, y argumentos: y para assegurar siempre mas ardiente, y vigorosa la contrariedad de opiniones, se discurre conveniente el assignar una de las Cathedras Thomistas a la Religion de Santo Domingo, y otra Catedra Suarista a la Religion de la Compañía de Jesus, dexando a los Provinciales de la Provincia de Aragon de dichas Religiones el nombrar los sugetos que huvieren de Regentar las Cathedras; los quales, para obtenerlas, deben matricularse, y recibir el grado de Bachiller de Philosophia de esta Universidad, teniendo voto en el Consejo de ella, y en todo los demas Cathedraticos; pero en el tiempo que no recibieren el grado de Doctor, se sienten en el ultimo lugar entre los Cathedraticos Doctores de Philosophia; y para que en las quatro Cathedras, que quedan, y debieran proveerse por votos de Estudiantes, no suceda que siendo en mas en numero los votos de una opinion, elijan para la contraria sugetos menos idoneos, a fin de deslustrarla, debiera prevenirse

271 R. Muñiz, Biblioteca Cisterciense española, pp. 314-315.

272 Véase A. Alonso García, "Del tomismo al suarismo: la cuestión de la 'alternativa de cátedras' del Estudi General de Barcelona durante el inicio del reinado de Felipe V", Pedralbes, 30 (2010), pp. 267-282. 
que a las dos Cathedras tomistas, tuvieran voto solo los Estudiantes Thomistas, y al contrario a las otras dos Suaristas, los Suaristas ${ }^{273 "}$.

La idea de introducir seis cátedras de Filosofía en Lérida era una emulación de lo que sucedía en la Universidad de Barcelona. En el Estudio General barcelonés empezaban, en efecto, dos cursos trienales cada año, si bien en en la Ciudad Condal todos los maestros eran tomistas, y el suarismo no tenía adeptos en la Universidad, sino en el vecino Colegio de Cordelles. Las autoridades defendían que las cátedras de la Universidad de Barcelona fuesen libres, de manera que no se viesen afectadas por esta pendencia entre tomistas y suaristas ${ }^{274}$.

Una querella similar se había producido en Zaragoza años antes. Había en la Universidad zaragozana tres cátedras de Filosofía: una tomista, afectada a la Orden de Predicadores, y dos de ellas de carácter indiferente, apetecidas a la sazón por los franciscanos y los jesuitas, que querían una consagración del escotismo y del suarismo con cátedra propia en la Universidad ${ }^{275}$. Los jesuitas lograron que, de las dos indiferentes, una fuera para la doctrina suarista y la otra quedase libre para el concurso de todas las opiniones. Al final, tras muchos conflictos, Carlos II acabó sancionando, en una Real Cédula de 14 de marzo de 1692, esta solución de la alternativa de cátedras entre suaristas y tomistas para los cursos de Artes en la Universidad de Zaragoza ${ }^{276}$.

Dicho lo anterior, volvamos el desarrollo de los acontecimientos en Lérida. El 26 de abril de 1700, el rector Baltasar Pepió publicaba edictos para la provisión de una cátedra de Filosofía, que hacía doce años que leía el Dr. Baltasar Pellicer. La cátedra la obtuvo el licenciado Ramon Gort, y el Dr.

273 F. Esteve Perendreu, Mestrescoles i rectors..., pp. 408-409.

274 DGC, X, p. 1338. "Quando la ciudad y Universidad formaron en el año 1638 la ordenansa para la enseñansa de philosofía no les ocurrió la distincción de thomista y suaristas, si sólo que se comentasse a Porphirio y Aristóteles con comentos y pareceres no uniformes, no haviendo tenido por blanco una ni otra de las dos opiniones, si sólo la exposición de estos autores con la discordancia en la interpretación en que jusgaron assigurado el fruto de la enseñansa. La experiencia lo ha manifestado en todas edades en aquélla y otras Universidades, pues no teniéndose aún en la República Litteraria noticia de opinión suarista, salieron consumados maestros para la universal enseñansa, y la Universidad de Barcelona no ha conocido su falta por espacio de muchos años en la enseñansa de la philosofía, haviendo tenido, como de presente tiene, consumados maestros que con singular aplauso y conocido fruto regentan las seys cáthedras”.

275 G. Borao, Historia de la Universidad de Zaragoza, pp. 93-97.

276 C. M. Ajo, Historia de las universidades Hispánicas, IV, Ávila, CSIC, p. 131. 
Pellicer, opositor a la misma cátedra, reclamó ante el Rector por irregularidades en la votación. El Rector consideró que se tenía que proceder a una nueva votación, algo que no se hizo, y el Dr. Pellicer tuvo que impugnarla ante el Rey ${ }^{277}$.

El 29 de mayo de 1701, el Rector recibía un Real Despacho en el que se ordenaba que la cátedra de Filosofía impugnada por el Dr. Pellicer tenía que ser nuevamente votada. Gort, prescindiendo de las órdenes regias, pidió la conducción de la cátedra y la admisión para graduarse de Doctor. El Maestrescuela ordenó al catedrático de Filosofía Fr. Jeroni Castañeda, trinitario ${ }^{278}$, que presidiese el grado, fungiendo como padrino y le conminó a llevar a cabo la colación, bajo pena -si se negase- de voz activa y pasiva y de los honores de la Facultad. Castañeda impugnó el mandato del Maestrescuela y éste, sabiendo que había votado en contra de Gort, le prohibió acudir a la colación al grado, y lo mismo hizo al Dr. Francesc Colí, catedrático de Filosofía. Finalmente, Gort fue graduado de Doctor en Filosofía ${ }^{279}$.

Sabemos que el P. José Martínez, jesuita y destacado escritor, era a la sazón el catedrático de Retórica y Fr. Francisco Bielsa, Rector del Colegio de la Merced, era el sustituto en la cátedra de Durando que poseía Fr. Miguel Zugarramurdi, también mercedario ${ }^{280}$. El Rector, a la vista de que el titular había faltado a la lectura más de treinta días, impidió la lectura de Bielsa, hecho que protestó el interesado ante el Rector ${ }^{281}$. Recordemos que Fr. Miguel Zugarramurdi y Arriola era Presentado, Rector del Colegio de la Merced en Lérida, Secretario de la Provincia de Aragón de la Merced y Teólogo de la Nunciatura de España ${ }^{282}$.

Volviendo al pleito de la cátedra de Filosofía del Dr. Gort, el Rey volvió a ordenar que se votase nuevamente. En el escrutinio salió por mayoría Ramon Gort y se le declaró catedrático titular de Filosofía. Tras una nueva impugnación del Dr. Pellicer, el tribunal, sin perjuicio de ulterior recurso ante el Rey, validó la provisión que se había hecho de la cátedra ${ }^{283}$.

277 F. Esteve Perendreu, Mestrescoles i rectors..., p. 299.

278 J. Lladonosa i Pujol, Història de Lleida, II, p. 571, n. 60.

279 F. Esteve Perendreu, Mestrescoles i rectors..., p. 300.

280 F. Esteve Perendreu, "La docència de la teologia a Lleida...", p. 167.

281 F. Esteve Perendreu, Mestrescoles i rectors..., p. 305.

282 Hizo la aprobación de las obras de Quevedo que fueron editadas en Barcelona en 1702, dedicadas a la Academia de los Desconfiados. Véase Obras de D. Francisco de Quevedo Villegas, Barcelona, Por Jayme Suri, 1702, aprobación.

283 F. Esteve Perendreu, Mestrescoles i rectors..., p. 305. 
En cuanto a las cátedras de Teología del momento, Francesc Esteve informa de que Fr. Joan Tardà, dominico, figuraba en febrero de 1701 como catedrático de Santo Tomás ${ }^{284}$. Hemos localizado a Tardà como examinador en la Universidad de Solsona en agosto de $1701^{285}$.

Esteve Perendreu se hace eco de un documento de 8 de enero de 1701, en el que Fr. Agustí Vilar, monje de Poblet, indica que había leído en el Colegio de San Bernardo y en la Universidad tres cursos de Teología ${ }^{286}$. Este personaje fue partidario del abad Tresánchez y participó en el Capítulo provincial de Aragón en $1717^{287}$. Asimismo, Torres Amat y Lladonosa denominan a Fr. Joaquim Pujol, monje cisterciense del monasterio de Lavaix, "Dr. teólogo de la Universidad de Lérida ${ }^{288}$ ", aunque no tengamos mayores detalles que nos permitan saber si fue un egresado o si enseñó en el Estudio.

El 24 de septiembre de 1701, Felipe V fue recibido en Lérida con gran entusiasmo. La Universidad se implicó mucho en el recibimiento regio. El Rey mandó instrucciones para modificar la estructura de las cátedras de Filosofía y el 19 de junio de 1703 los Paheres indicaron que no habían podido obedecer las órdenes regias en el tema ${ }^{289}$. Poco tiempo después volvieron a escribir al Rey indicando su disponibilidad en cooperar "en hacer efectivos los medios para restituir la Universidad a su antiguo estado 290 ”. En realidad, el principal interés regio residía en limitar el predominio del tomismo, estableciendo definitivamente una cátedra tomista para los dominicos y una suarista para los jesuitas. El 2 de agosto de 1703, la Pahería tomó en consideración el mandato regio de afectar una cátedra tomista para la religión de Santo Domingo y otra suarista a la Compañía de Jesús ${ }^{291}$. Las religiones de San Francisco de Asís y de San Agustín escribieron el 18 de agosto de 1703 manifestando que no pensaban hacer oposición a la cátedra de Artes y que se diese las cátedras

284 Ibidem, pp. 305-306

285 R. Ramis Barceló y P. Ramis Serra, "Los últimos grados de la Universidad de Solsona...”, p. 328.

286 F. Esteve Perendreu, "La docència de la teologia a Lleida...", p. 166.

287 E. Toda i Güell, La Davallada de Poblet, pp. 141 y 197.

288 F. Torres Amat, Memorias para ayudar a formar un diccionario critico de los escritores catalanes y dar alguna idea de la antigua y moderna literatura de Cataluña, Barcelona, Imprenta de J. Verdaguer, 1836, p. 515.

289 AML, Reg. 873, Correspondencia, f. 32r.

290 AML, Reg. 873, Correspondencia, f. 45r.

291 AML, Reg. 873, Correspondencia, ff. 53-54. 
a los dominicos y a los jesuitas ${ }^{292}$. El P. Marimon remitió en la misma fecha un memorial sobre el estado de la Universidad ${ }^{293}$.

El 5 de septiembre de 1702, falleció el Dr. Miquel Vila, natural de Mora, canónigo penitenciario y catedrático de Prima de Teología ${ }^{294}$. En 1704 figura como Vicerrector y catedrático de Vísperas de Teología el Dr. Francesc Colín ${ }^{295}$. La nómina de profesores que se desprende del Consejo General de la Universidad, celebrado en 1705, contempla a los siguientes catedráticos de Teología: Fr. Bernat Gavàs, catedrático de Prima; Dr. Francesc Colí, de Vísperas; Fr. Francesc Bielsa, y el Dr. Llorenç Salvà, presbítero, que el 10 de junio de 1704 había obtenido la cátedra de Teología de Santo Tomás, y posteriormente fue Lector de la Catedral. Y los catedráticos de Filosofía eran Fr. Jeroni Castañeda y Fr. Miquel Escuder, a la sazón Doctor en Teología, Rector del Colegio de Sant Bernat de Lérida ${ }^{296}$, que con posterioridad fue Abad de Poblet (17131716), disidente luego de la comunidad y, por mandato real, Abad de Escarp (1720-1722) ${ }^{297}$. El tercer catedrático era el ya citado Dr. Ramon Gort.

Casi toda Cataluña pasó a la obediencia del archiduque Carlos. La elección de Rector en 1705 estuvo fuertemente condicionada por la oposición del Obispo al candidato Domènec Adamet y por la excomunión del catedrático de Vísperas, Dr. Colí. Todo ello implicó una serie de problemas en la provisión de la cátedra de Sagrada Escritura, que Fr. Josep Queralt, monje de Poblet, detentaba desde hacía cuatro años. Queralt era natural de Conesa, y dejó manuscritas algunas obras, entre ellas una Relacion historica de la religion benedictina, congregacion cisterciense y real monasterio de Poblet ${ }^{298}$. Dicha cátedra de Escritura finalmente fue provista y la obtuvo Fr. Tomàs Antimor, dominico ${ }^{299}$, a la sazón Prior del Convento de Lérida ${ }^{300}$, que sería instituido Presentado en el Capítulo provincial de la Orden en $1716^{301}$ y Maestro en el

292 AML, Reg. 873, Correspondencia, f. 58r.

293 AML, Reg. 873, Correspondencia, f. 6or.

294 F. Esteve Perendreu, "La docència de la teologia a Lleida...", p. 165.

295 F. Esteve Perendreu, Mestrescoles i rectors..., p. 309.

296 Ibidem, p. 312.

297 E. Zaragoza Pascual, Catàleg dels monestirs catalans, pp. 95 y 177; y E. Toda i Güell, La Davallada de Poblet, p. 141.

298 R. Muñiz, Biblioteca Cisterciense española, p. 270.

299 F. Esteve Perendreu, Mestrescoles i rectors..., pp. 312-318.

300 J. Lladonosa, Història de Lleida, vol. II, p. 578.

301 AHN, Códices, L. 575, f. 13r. 
Capítulo de $1722^{302}$. En la Biblioteca de Catalunya se conserva un manuscrito del curso teológico dictado por Antimor ${ }^{303}$.

Según Esteve, en febrero de 1706 Francesc de Guiu i Martí, aristócrata y miembro de una ilustre familia de Lérida ${ }^{304}$, era catedrático de Teología de Santo Tomás ${ }^{305}$. Tenemos constancia de un sermón ${ }^{306}$ predicado por el Dr. Llorenç Salvá, en el que figura como catedrático de Teología de Santo Tomás, Lector que fue de la Catedral y Examinador sinodal de la misma ciudad y obispado de Lérida ${ }^{307}$.

Tras un largo asedio, las tropas filipistas entraron en Lérida el 12 de octubre de $1707 \mathrm{y}$ la ciudad fue saqueada: muchos edificios fueron destruidos y no pocos habitantes perecieron. El Convento del Roser, de los dominicos, fue quemado. Casi todos los religiosos que sobrevivieron fueron expulsados. Aprovechando la situación, el P. Joan Baptista Pujals, Rector del Colegio de la Compañía en Lérida, envió una carta a Felipe V, en la cual aparecen cuestiones de gran interés. Informa el jesuita

"que en el año de 1707 quando las Victorosas Armas de V. Magestad entraron por Asalto en la Ciudad de Lerida, el Sr. Duque de Orleans desterró de aquella Ciudad a todos los Religiosos que hauia en ella, y mandó su Alteza que quedasen solo los Jesuitas para asistir a las Tropas en los Ministerios proprios de su Instituto [...] Y no obstante la mucha falta de medios para mantener a los Religiosos que se ocupan en estos Ministerios tan del servicio de Dios y de V. Magestad pues todo este tiempo casi se han mantenido y mantienen de

302 AHN, Códices, L. 574, f. 23 r.

303 BC, Ms. 790, ff. 1-128v. "Tractatus de actibus humanis sub utroque ese iuxta miram angelici preceptoris". Hay otro curso: "Tractatus de sacramento matrimonii juxta miram angelici preceptis D. Thomae Aquinatis Doctrina" (ff. 131-220), aunque no consta la autoría.

304 J. M. Clarisó Martí, La economía de la nobleza..., p. 302.

305 F. Esteve Perendreu, Mestrescoles i rectors..., p. 322.

306 L. Salvá, Perenne Monumento, y funebres lamentos que en las Exequias, translacion, y Entierro en la Iglesia del Oratorio de San Felipe Neri de esta Ciudad se erigió al [...] Dr. Francisco Garrigó, Barcelona, por Francisco Guasch, 1715.

307 En la aprobación del sermón se puede leer, s.f.: “Todos los que havemos logrado la ditxa de tratar de cerca al Orador, quando à un mismo tiempo Cathedratico de Theologia en la de Santo Thomàs de la Real Universidad de Lerida, y Lector de su Santa Iglesia, en la Cathedra exponia lo mas sutil en questiones Scholasticas; Y en el pulpito panegirista, y missionario hermanava los distantes extremos de elegante, y doctrinal; profundo, è inteligible; fervoroso, y eloquente; solido, y sutil, para plantar virtudes y arrancar vicios [...] podemos dezir, sin riesgo de exageracion que el Doctor Salvà solo, vale por muchos predicadores”. 
limosnas; viendo que se perdia la Jubentud por falta de educazion, aumentaron de sujetos para ocurrir a esta necesidad, poniendo otra vez Maestros de Gramatica que con conocida utilidad de aplican a la enseñanza de sus Discipulos; pero perdiendose muchos de estos hauiles ya en el latín, por faltarles Maestros que les enseñen las facultades Maiores de filosofia, y theologia, por no hauerlas en aquella Ciudad, no tener la Compañía medios para mantenerles, pues están oi las Rentas de aquel Colegio tan acauadas, que apenas bastan para mantener dos sujetos, manteniendose los demas de Limosnas. Pareze seria combeniente el señalar medios para mantener estos Maestros, y otros dos sacerdotes, que se empleen en el exercicio Santo de las Missiones en los Lugares de aquel Partido, lo que resultará sin duda en Grande Servicio de Dios, y de V. Magestad por la grande ignorancia de la Doctrina Christiana que se experimenta, y relaxacion de Costumbres que se ha introducido con la Livertad de la Guerra ${ }^{308}$ ".

Tras pedir fondos para llevar a cabo estas empresas, el P. Pujals abordó la cuestión central:

“... ha parezido al Suplicante representar a V. Magestad que desde el año 1707 en que se conquistó aquella Ciudad ha faltado la Lectura de las Cathedras de aquella Uniuersidad, y por consiguiente todos los Cathedraticos y demas Ministros que hauia en ella para su buen Gouierno, de suerte que ni el nombre ni Sombra de unibersidad queda; administrandose las Rentas de ella por un Ministro Subdelegado del Intendente de Cataluña; por lo que parece que sin el grauamen del Real erario de V. Magestad se podian aplicar dichas rentas con sus atrasos, en el interin que V. Magestad da prouidencia para el restablezimiento de la unibersidad, al Collegio de la Compañia para el fin de mantener sujetos para Maestros de filosofia y theologia y dos missioneros, con lo que en parte se da providencia, a la gran falta de educacion de aquella Jubentud, y al vien espiritual de aquellos Pueblos, y se atiende al Christiano Zelo de V. Magestad. Lo que espera el suplicante de la gran piedad de V. Magestad ${ }^{309 " . ~}$

El Vicerrector y el Consejo de la Universidad de Lérida solicitaron en 1712 que se volviera a establecer la sede universitaria ${ }^{310}$. La Ciudad de Lérida expuso una serie de motivos para restablecer las lecturas, que dieron lugar a un informe de la Real Junta de Gobierno y Justicia de Cataluña ${ }^{311}$.

Como hemos indicado en el capítulo anterior, la Universidad fue transferida definitivamente a Cervera en Octubre de 1717, pese a las protestas de las autoridades ilerdenses. Rubió mostró que en la minuta del Decreto de supre-

308 AHUB, Universidad de Cervera, Caja 147, leg. 1224, n. 3.

309 AHUB, Universidad de Cervera, Caja 147, leg. 1224, n. 3.

310 F. Esteve Perendreu, Mestrescoles i rectors..., pp. 420-421.

311 AHUB, Universidad de Cervera, Caja 1, leg. 4727. 
sión había algunos párrafos que revelaban el espíritu de venganza de Felipe V, circunstancia de la que se ha hecho eco toda la bibliografía ${ }^{312}$.

No hay duda de que el rey Felipe quería represaliar a las ciudades catalanas que no le habían sido afectas. Con todo, en un borrador manuscrito de "Motivos que persuaden con la aprobacion Pontificia de la Universidad de Cervera", escrito por diversas manos y con múltiples tachones, aparecen también otras circunstancias, que deben tenerse en cuenta. Nos centramos ahora en analizar la justificación legal y canónica de la voluntad del monarca:

"Felipe Quinto despues de hauer reduzido à su justo dominio que obediencia el Principado de Cathaluña en el año 1714 mando cerrar las Universidades de Lerida, Barcelona, Tarragona, y Vique, que por las turbaciones del Pays, y excessos de años antes, estauan totalmente relaxadas, y en su ultima dissolution. Y para restaurar el estudio de las buenas letras, y exigir un Emporio de todas las Ciencias, en aquel Principado, planto una Universidad en la Ciudad de Cervera, lugar sano, y sin presidio militar, en que se lograsse mejorado el estado de la enseñança publica ${ }^{313 "}$.

Tras indicar que había conferido a los maestros y estudiantes de Cervera los mismos privilegios que las cuatro universidades mayores de España (Salamanca, Alcalá, Valladolid y Huesca) ${ }^{314}$, y una total exención de tributos, indicaba que se estaba concluyendo un edificio "sin igual en toda Europa", y un seminario para ochenta escolares procedentes de las diversas diócesis de toda Cataluña ${ }^{315}$, manteniendo las rentas propias de la Escuela,

312 M. Rubió y Borrás, Historia de la Real y Pontificia..., p. 113. "La tenaz resistencia de los catalanes contra la debida sujeción a mi legítimo dominio que desconoció su Perfidia, en que se inducieron muchos sujetos notables de las Universidades Literarias de aquel País, provocó mi justicia y obligó mi providencia a mandar se cerrasen las Universidades, que eran fomento de maldades cuando debían serlo de virtudes...” Al margen había una nota, de letra distinta, que decía: "Parece que este principio se debe moderar y explicar con otros términos más templados”. Sobre las reformas de Felipe V en Cataluña y sus consecuencias, hay una amplia bibliografía: desde diversas ópticas, véase C. Martínez Shaw y M. Alfonso Mola, Felipe V, Madrid, Arlanza, 2001; J. Albareda, Felipe Vy el triunfo del absolutismo. Cataluña en un conflicto europeo (1700-1714), Barcelona, Generalitat de Catalunya, 2002; y R. Fernández Díaz, Cataluña y el absolutismo borbónico: historia y política, Barcelona, Crítica, 2014.

313 AHUB, Universidad de Cervera, Caja 1, leg. 4773.

314 A. de Trilla, Perfecto practicante medico..., p. 6v, escribía asimismo, en 1677: “... la Real y Antiquissima Vniversidad de Lerida, vna de las quatro primeras de España...”

315 Tachado aparece "diez estudiantes de cada obispado de los ocho de Cataluña". 
"en quienes se ha recogido lo mas selecto de la disciplina Academica, mirando por singular escopo, el formar los Estudiantes, igualmente virtuosos, que por Letrados; para corregir los abusos, que padecia en las uniuersidades Cathaluña; pues en sus mas principales Escuelas, se conferian grados a los indignos, siendo tal el desorden de los cursantes, y coniuencia del Govierno, que la misma impunidad, era el mas seguro asylo de sus excessos ${ }^{316 "}$.

Felipe V ordenó que el Maestrescuela de la Catedral de Lérida pasase a Cervera y dispuso crecidísimas sumas para la fábrica de la Universidad con el fin de asistir "a mas de ducientos estudiantes pobres con la racion de pan diario, que se da a un soldado", y le otorgó una pensión de 4500£, sobre las rentas del Arzobispado de Tarragona, y otra de $1400 £$ sobre las del Obispado de Gerona, ambas confirmadas por la Santa Sede. El Rey, de su Real Patrimonio, le hizo gracia de 600o£ anuas, y le agregó también los réditos de las Universidades que mandó cerrar en el Principado. Estos réditos, en su mayoría, eran eclesiásticos y el Memorial indicaba que "pareze justissima su incorporacion, por el gran favor que mereze la causa publica de los Estudios". Apoyándose en el P. Mendo y en Escobar, consideraba que

"puede el Principe por si mismo trasnferirlas de una Uniuersidad a otra: Y por mas que sean Ecclesiasticos, quando el fin no es la absoluta extincion o suppresion de las Universidades, sino su traslacion, por justas causas, y relevantes motivos a la utilidad del Estado, passan essos mismos bienes a la Universidad principal a quien se unen o incorporan las otras [...] Deste principio se colije, que, aunque alguna de las dichas Universidades, en sus dotalias y fundacion, huviese prevenido caso de substitucion, en el que de quedar extinta, no podria entrar esta, por durar aun el fin primero de los fundadores, en fuerça de la nueva traslacion, pues el mudar lugar, no es destruir la sustancia de las Universidades, como lo suponen los mismos autores, antes bien mejorarla, segun las circunstancias de la traslacion ${ }^{317}$.

En realidad, el Memorial, en una nota al margen, consideraba que la decadencia de las universidades catalanas provenía de su multiplicidad, pues "florecieron en su mayor auge los estudios cerca de dos centuras, que fue unica la de Lerida, y empeçaron a desmayar y a descaezer con la misma numerosidad de Uniuersidades ignobles ${ }^{318}$ ". Concluía el texto indicando que:

"Esto pareze lo mas congruente para solicitar de la Santa Sede la aprobacion de la Uniuersidad erigida, la incorporacion en sus rentas de las mandadas cerrar, la traslacion de la

316 AHUB, Universidad de Cervera, Caja 1, leg. 4773.

317 AHUB, Universidad de Cervera, Caja 1, leg. 4773.

318 AHUB, Universidad de Cervera, Caja 1, leg. 4773. 
maestrescolia de Lerida, y la de los dos Collegios seglares, que tuvo aquella Ciudad, pues a todo son adaptables los motiuos de S. M. y los principios y fundamentos, que se apuntan: pues probablemente bastan para que lo hiziera el Principe de su propria Autoridad: Y aun juntos son el mas viuo alliciente para una plenissima Concession de priuilegios de la Santa Sede; porque esta acostumbra no ser menos liberal en promouer que fauorezer la Causa publica de los Estudios, igualmente necessarios al regimen de una y otra Republica, que los mismos Principes Fundadores ${ }^{319}$.

En efecto, el 20 de noviembre de 1717, Felipe V decretó el traslado a Cervera del Maestrescuela de la Catedral de Lérida. Este fue el único honor que cupo a la más antigua sede universitaria de Cataluña y tenía una función meramente estratégica: defender que la Universidad de Cervera heredaba el estatuto pontificio de la ilerdense ${ }^{320}$. El 25 de junio de 1718, Francesc de Queralt i Reart, Maestrescuela, hizo devolver las alhajas de plata de la Universidad de Lérida a la de Cervera, indicando que las mazas estaban en posesión aún de Josep Voltes, el último Rector, que a la sazón vivía en Barcelona ${ }^{321}$.

Como premio a los jesuitas, en Lérida se aplicaron $680 £$ de la pensión de la mitra episcopal al Colegio de la Compañía de Jesús, para la enseñanza de la Gramática $^{322}$. Las $800 £$ restantes procedentes de las $1400 £$ de la mitra ilerdense iban destinadas a la Universidad de Cervera ${ }^{323}$. Esta circunstancia fue un quebradero de cabeza, porque Felipe V había asignado, en 1715, las rentas de la mitra de Lérida a la Universidad de Cervera y sólo después, el 2 de julio de 1718, ordenó que se hiciese ese reparto definitivo con la Compañía de Jesús, que dejó insatisfechas a ambas instituciones: en Cervera se consideraba que se tenían que aplicar todas las rentas del Estudio de Lérida (muchas de ellas, de origen eclesiástico, y con intención universitaria) a la Universidad cervariense, mientras que los jesuitas consideraban que se debía favorecer el progreso de su Colegio y que incluso podían reclamar parte de las rentas del período transcurrido entre 1715 y 1718.

Como los breves papales para la erección de la Universidad cervariense se retrasaran, la Compañía, apoyándose en la liberalidad de Felipe V para

319 AHUB, Universidad de Cervera, Caja 1, leg. 4773.

320 Sobre las dificultades para conseguir la bula se tuvo que esperar a 1731. Las vicisitudes pueden verse en J. Prats, La Universitat de Cervera i el reformisme borbònic, pp. 138-153.

321 AHUB, Universidad de Cervera, Caja 147, leg. 1224, n. 18.

322 AHUB, Universidad de Cervera, Caja 1, leg. 4768.

323 AHUB, Universidad de Cervera, Caja 147, leg. 1224, n. 15. 
con ella, mostró repetidamente sus pretensiones sobre las demás rentas del Estudio General de Lérida, que quería aplicar a su Colegio. El 9 de julio de 1719, el agustino Francisco Olaso Hipenza, Obispo de Lérida, ponía en conocimiento a Luis Curiel, Ministro protector de la Universidad de Cervera, de que tenía las rentas eclesiásticas correspondientes a la Universidad ilerdense, si bien esperaba los breves pontificios para entregárselas ${ }^{324}$. Esto implicó que durante los primeros años, los catedráticos de Cervera no pudieran cobrar sus salarios debidamente ${ }^{325}$.

Así como Lérida fue particularmente castigada, las otras Universidades catalanas conservaron algún pequeño rescoldo de su docencia filosófica y teológica. En la Universidad de Barcelona se ordenó que hubiera cuatro maestros de Artes a cargo de la Compañía de Jesús ${ }^{326}$ y se dejó en la Ciudad Condal buena parte de la enseñanza de la Medicina. En Gerona, en 1717, se autorizó lectura de la Gramática y de la Retórica a cargo de los jesuitas ${ }^{327}$. Y en 1724 se dio permiso para que en Tarragona se enseñara Gramática, Filosofía y Teología a los naturales de la Ciudad y de su Campo, aunque tenían la obligación de graduarse en Cervera ${ }^{328}$.

Poco a poco se fue desmantelando la estructura colegial de Lérida. En 1723 se ordenó el traslado del Colegio de la Concepción a Cervera. En 1730 Felipe

324 AHUB, Universidad de Cervera, Caja 147, leg. 1224, n. 26. La misiva, escrita con no poca altivez, indicaba que: “...me manda su Majestad buelba a correr por mi quenta el recobro de las rentas eclesiasticas que tenia la Univercidad de Lerida, y que dichas rentas esten en seguro deposito hasta que vengan los breves de su santidad tambien estoy cierto, que dichos breves vendran como el Rey los pide, pero tambien lo estoy en que no nececito de Thesorero porque ninguno mejor que Yo: pues ninguno dara mejor quenta al Rey que yo mismo, y ninguno con mas desinteres, asi se lo tengo escrito a Vs. con resolucion de no nombrar thesorero ninguno hasta que el Rey me lo mande. Y advierto a Vs. que la pencion que toca a la Universidad de Cerbera y los oncenillos que assimismo paga la mitra estaran siempre seguros en mi poder, pero la cobranza del Arziprestazgo de Ager que lo que unicamente costara alguna cosa, se atrasa, pues aunque Yo no les he hablado palabra, han respondido a la Universidad que no pagaran sin orden mia porque solo a mi me reconocen por Thesorero de esas rentas y porque me parece que Vs. no me reconoce por tal no he dado paso en orden a su cobranza, ni lo dare hasta o que, el Rey me lo mande o Vs. me reconosca por unico thesorero de dichas rentas..."

325 AHUB, Universidad de Cervera, Caja 147, leg. 1224, n. 27.

326 M. Rubió y Borrás, Historia de la Real y Pontificia..., p. 97.

327 AMG, Llibre d'actes o manual d'acords del Consell de la ciutat (1717), Reg. 17471, f. 175 .

328 M. Rubió y Borrás, Historia de la Real y Pontificia..., pp. 135-136. 
V mandó que el Colegio de Poblet hiciese lo propio. El abad Genover, excatedrático de la Universidad de Lérida, dio cumplimiento a la orden ${ }^{329}$. También los benedictinos decidieron trasladar en 1746 su Colegio desde Lérida a Cervera $^{330}$.

En fin, se estableció un Colegio en Cervera con capacidad para ochenta estudiantes de toda Cataluña. Felipe V concedió en 1728, para la enseñanza común de los naturales del Principado de Cathaluña, 63800£ catalanas de pensiones perpetuas repartidas entre les obispados de Barcelona, Vic, Solsona, Urgel, Lerida y Tortosa, de las cuales 13600 correspondían a Lérida ${ }^{33}$.

Tras una larga negociación, Clemente XII promulgó el 4 de diciembre de 1730 la Bula apostólica Imperscrutabiles Divinorum, que aprobaba los Estatutos de la Universidad de Cervera, al tiempo que le concedía las rentas de algunas de las Universidades catalanas suprimidas, el privilegio privativo de la impresión de los libros de enseñanza, la incorporación definitiva de los Colegios de la Asunción y de la Concepción... Al final, no se erigió una universidad nueva, sino que acabó imperando el criterio jurídico de la traslación de la sede universitaria de Lérida a Cervera, alegando su "utilidad 332 ", algo que conllevó otros problemas con las rentas ilerdenses.

Los jesuitas de Lérida siguieron exigiendo sus pretendidos derechos, incluso después de la Bula que confirmaba los Estatutos de la Universidad de Cervera. Otra Bula apostólica, expedida el 12 de agosto de 1732, determinó que se aplicara al Colegio de la Compañía en Lérida una pensión de 228 ducados de oro de cámara y 9 julios de moneda de Roma, a razón de 17 julios cada ducado. Con ello se obligaba perpetuamente a mantener cinco sacerdotes: dos para leer Teología moral, dos para hacer misiones por el obispado y uno para predicar, adoctrinar y confesar a la guarnición de la plaza ${ }^{333}$.

Pese a todo, los jesuitas siguieron reclamando a la Universidad de Cervera una parte de las rentas del Estudio de Lérida para el sostenimiento de su Colegio, pues la enseñanza de Gramática de dicho Colegio, dependía legalmente de la Universidad de Lérida, que no había sido suprimida, sino transferida a Cervera. Al final, tras una costosa negociación, se hizo una concordia en Madrid entre el P. Josep Rigal, Procurador de la Provincia de la Compañía

329 A. Altisent, Història de Poblet, pp. 583 y 590.

330 E. Zaragoza Pascual, Història de la Congregació Benedictina..., p. 234.

331 AHUB, Universidad de Cervera, Caja 1, leg. 4772.

332 J. Prats, La Universitat de Cervera i el reformisme borbònic, pp. 157-164.

333 AHUB, Universidad de Cervera, Caja 147, leg. 1224, n. 2. 
de Jesús y Francisco de Arias, Apoderado de la Universidad de Cervera. La concordia, firmada el 28 de febrero de 1735, declaraba que las diferencias entre ambas partes por la percepción de las rentas entre 1715 y 1718 quedaban remitidas, al igual que las $40 £$ que le correspondían al Colegio del Arca de la Universidad, así como también sus atrasos. En cuanto a las $100 £$ anuales que tenía que percibir el Colegio de las rentas de la Universidad de Lérida, los jesuitas se conformaban con cobrar $85 £$ y recibir las cartas de pago o recibos atrasados en forma de finiquito ${ }^{334}$.

En definitiva, fue una victoria en toda regla de la Compañía de Jesús, que pasaba a ocupar el puesto más destacado en la enseñanza universitaria y colegial catalana. El Colegio de los jesuitas en Lérida fue el centro de referencia para la enseñanza en la ciudad. Pese a las vacilaciones de Felipe V en la ejecución y a las complicaciones sobrevenidas, el monarca dejó sin universidades a las grandes ciudades catalanas y los jesuitas establecieron en ellas prácticamente un monopolio de la enseñanza media.

Lérida fue rehaciéndose muy lentamente de las ruinas de la guerra. Los catedráticos religiosos fueron expulsados de Lérida y los seculares naturales de la Ciudad -que sobrevivieron- siguieron con las demás ocupaciones de sus cargos y prebendas, hasta su muerte. Sabemos, en fin, que el Dr. Baltasar Pellicer, presbítero y rector parroquial, expiró el 21 de julio de 1725 y que el 7 de abril de 1734 falleció "Llorens Salva, Dr. en Drets y Canonge de la Cathedral fou una mort repentina encara que avia rebut los Sagraments pero despues asta algo convalescent y era fora casa ${ }^{335}$ ".

\section{Conclusiones}

En comparación con la Facultad de Leyes y Cánones, las de Artes y Teología fueron de menor entidad, al igual que la de Medicina. La Ciudad no se preocupó de que la enseñanza gramatical, filosófica y teológica fuese una prioridad, al revés de lo que sucedía en las demás universidades catalanas. El prestigio de los estudios jurídicos en Lérida acabó eclipsando a los demás.

La enseñanza de Latinidad quedó en manos de la Compañía de Jesús desde 1605, circunstancia que -en comparación con otras universidades, como Gerona o Barcelona- permitió una relación más tranquila de la Ciudad y la Universidad con los jesuitas, aunque hubo algunas tensiones que forzaron a

334 AHUB, Universidad de Cervera, Caja 147, leg. 1224, n. 10.

335 F. Pifarré San Agustín, Aspectes sanitaris..., s.f. 
hacer nuevas concordias. La incorporación del Colegio de la Compañía a la Universidad fue la base que facultó a los jesuitas a exigir las rentas del Estudio, cuando éste fue transladado a Cervera.

Para la enseñanza de Filosofía, la dotación de dos cátedras era insuficiente, y con ello no se podía establecer un curso filosófico trienal completo. Tras la Guerra dels Segadors, y después de vencer numerosas dificultades, se dotó finalmente una tercera cátedra. En cuanto a la Teología, el número de cátedras era parecido al que había en el resto de universidades municipales vecinas. Frente a Barcelona y Vic, la orientación de la Universidad de Lérida no era tan marcadamente tomista.

Gracias al concurso de las órdenes religiosas y del clero local, se pudieron cubrir las cátedras filosóficas y teológicas. La presencia de agustinos, dominicos, carmelitas y mercedarios fue especialmente destacada, al igual que los Colegios de los benedictinos y cistercienses proporcionaron alumnos y catedráticos. La Orden de Predicadores se involucró menos en la Universidad de Lérida que en las universidades de las capitales de Reino, en las que tenían los Estudios Generales de la Provincia de Aragón, aunque muchos dominicos leyeron por un breve lapso en Leyda.

El nivel de los profesores era solo aceptable, pues la lectura de las cátedras se entendía bien como una labor propedéutica antes de pasar a mayores empeños, bien como una responsabilidad compatible con otros cargos. Resultaba más prestigioso enseñar en Huesca, Zaragoza o en Barcelona, y algunos leyeron en Lérida antes de pasar a estas sedes. Es cierto que muchos de los que en su juventud fueron catedráticos llegaron a desempeñar importantes cargos en sus órdenes religiosas (abades, priores, provinciales, visitadores...) o en el clero regular (canónigos, rectores...) y que algunos de ellos incluso brillaron por su afición al estudio. Pocos dejaron testimonio escrito de su saber. Deben mencionarse los casos de Pere Moliner o Feliu Genover. Sin embargo, los nombres más relevantes de la Filosofía y la Teología hispánica del momento deben buscarse en otras Universidades.

El desempeño de las cátedras de Teología fue más duradero para los seculares que para los regulares, pues los primeros tenían a menudo beneficios en la propia ciudad, que resultaban compatibles con la docencia. Desde luego, la estabilidad profesoral y el prestigio fueron superiores a los de otras universidades de menor entidad, como Gerona o Tarragona.

La competencia de las Universidades de Huesca -denominada Universidad mayor en un manuscrito transcrito en las páginas anteriores- y de Barce- 
lona hizo que Lérida perdiese mucho alumnado y cediese ante su empuje. Los conflictos con los colegios de los cistercienses y benedictinos es una muestra evidente de la decadencia ilerdense, frente a la pujanza de estas dos universidades. La competencia ilegítima que llevó a cabo la Universidad de Solsona tampoco ayudó a cimentar los estudios filosóficos y teológicos en Lérida, del mismo modo que las Universidades de Tarragona, Vic y Gerona dieron satisfacción, mal que bien, a la necesidad de formación de los eclesiásticos de las diócesis y no hubo tanta movilidad como en el siglo XVI.

Como se ha dicho en el capítulo anterior, las guerras tampoco favorecieron la estabilidad del Estudio. Tardó varios lustros en reponerse de las consecuencias de la Guerra dels Segadors, y ello supuso una regionalización de la Universidad, que antes había tenido un carácter más amplio, con presencia abundante de aragoneses y mallorquines. La Guerra de Sucesión acabó por destrozar la Ciudad y la Universidad, poniendo fin a un período de frágil recuperación, alentada por los nuevos Colegios de las órdenes monásticas.

En definitiva, los estudios filosóficos y teológicos no contaron con tantas cátedras como los jurídicos y la Ciudad les prestó una menor atención. Pese a todo, algunos profesores tuvieron después carreras eclesiásticas dignas de mención. La competencia de las demás universidades fue muy dura y, a veces, desleal. Los Paheres y los catedráticos asistieron -a menudo con impotenciaa la decadencia de la Universidad ilerdense, cuya antigüedad no fue, en el siglo XVII, timbre suficiente para dar el lustre debido a sus Facultades. 


\section{RELACIÓN DE LOS PRINCIPALES CATEDRÁTICOS CITADOS}

\begin{tabular}{|c|c|c|}
\hline Nombre & AfILIACIÓN & FACULTAD/ES \\
\hline Aguilar, Francisco & O.S.A. & Teología \\
\hline Agustín, Juan Antonio & Pbro. & Teología \\
\hline Andreu, Miquel & O.S.A. & Teología \\
\hline Antimor, Tomàs & O.P. & Teología \\
\hline Antolí, Miquel & O.S.A. & Teología \\
\hline Aranda, Bernardo de & O.S.A.? & Artes \\
\hline Ballester, Josep & O.S.A. & Teología \\
\hline Batle, Pere & Pbro. & Teología \\
\hline Beaumonte, Juan de & O.P. & Artes \\
\hline Bielsa, Francisco & O. de M. & Teología \\
\hline Campi, José & Pbro. & Artes - Teología \\
\hline Carreter, Tomàs & O.P. & Teología \\
\hline Cases, Jaume & Pbro. & Teología \\
\hline Castellnou, Antoni & Pbro. & Teología \\
\hline Castañeda, Jeroni & O.SS.T. & Artes \\
\hline Castilla, Luis de & O.P. & Teología \\
\hline Claramunt, Antoni & Pbro. & Teología \\
\hline Coli, Francesc & Pbro. & Artes - Teología \\
\hline Companys, Mateu & Pbro. & Teología \\
\hline Crespo, Francesc & O.S.B. & Teología \\
\hline Enguita, Josep de & O.S.A. & Teología \\
\hline Escuder, Miquel & O. Cist. & Artes \\
\hline Estrada, Andreu & O.S.A. & Artes \\
\hline Ferrusola, Joan & Pbro. & Teología \\
\hline Filbet, Ángel & O. Carm. & Teología \\
\hline Font, Ramon & O.P. & Teología \\
\hline Galí, Baudili & Pbro. & Teología \\
\hline Galipienso, Antonio & Pbro. & Teología \\
\hline García de Vera, Plácido & O. Cist.? & Teología \\
\hline Gatell, Josep & O.P. & Teología \\
\hline Gavàs, Bernat & O. Cist. & Artes - Teología \\
\hline Genover, Feliu & O. Cist. & Teología \\
\hline
\end{tabular}




\begin{tabular}{|c|c|c|}
\hline Gort, Ramon & Pbro. & Artes \\
\hline Guiu, Francesc & Pbro. & Teología \\
\hline Iribarren, Antonio & O.P. & Teología \\
\hline López, Domingo & O.P. & Artes \\
\hline Llorens, Pere & Pbro. & Artes? \\
\hline Maiques, Miquel & O.S.A. & Teología \\
\hline Mallada, Francisco & Pbro. & Teología \\
\hline Maní, Antoni & Pbro. & Teología \\
\hline Maranyosa, Francesc de & Pbro. & Teología \\
\hline Medina, Pedro & O.S.A. & Teología \\
\hline Moliner, Pere & O.SS.T. & Teología \\
\hline Montañez, Vicente & O.S.A. & $\begin{array}{c}\text { Filosofía - Cánones - } \\
\text { Teología }\end{array}$ \\
\hline Mur, Juan & O.P. & Teología \\
\hline Navarro, Joan & O. de M. & Teología \\
\hline Orcau, Juan Francisco de & Pbro. & Teología \\
\hline Ozorio, Agustín & O.S.A. & Teología \\
\hline Pellicer, Baltasar & Pbro. & Artes \\
\hline Pueyo, Jaime & Pbro.? & Artes \\
\hline Puigvert, Josep & Pbro. & Teología \\
\hline Queralt, Josep & O. Cist. & Teología \\
\hline Ramon, Gregori & O. Cist. & Teología \\
\hline Reguer Soldevila, Francesc & O. Carm. & Teología \\
\hline Roger, Tomàs & O.P. & Teología \\
\hline Rovira, Domènec & Pbro. & [Teología $]$ \\
\hline Salafranca, Tomàs de & O.P. & Artes - Teología \\
\hline Salvà, Llorenç & Pbro. & Teología \\
\hline Sanz, Josep & O. Cist.? & Artes \\
\hline Sayol, Baltasar & O. Cist. & Teología \\
\hline Sellés, Antoni & Pbro. & Teología \\
\hline Serra, Melcior & Pbro. & Teología \\
\hline Sorribas, Gaspar de & O.S.A. & Teología \\
\hline Surch, Joan Gabriel & Pbro. & Artes \\
\hline Tapioles, Francesc & O. Carm. & Teología \\
\hline Tardà, Joan & O.P. & Teología \\
\hline
\end{tabular}




\begin{tabular}{|l|c|c|}
\hline Teixido, Jaume & O.S.B. & Artes \\
\hline Trallero, Martín & Pbro.? & Teología \\
\hline Torre, Francesc de la & Pbro. & Teología \\
\hline Valentín, Ángel & O. Cist. & Teología \\
\hline Vega, Pedro & O.P. & Teología \\
\hline Vila, Miquel & Pbro. & Teología \\
\hline Vilaplana, Josep & Pbro. & Teología \\
\hline Vilar, Agustí & O. Cist. & Teología \\
\hline Villarín, Agustín & O.S.B. & Teología \\
\hline Vives, Francesc & Pbro. & - \\
\hline Zugarramurdi, Miguel & O. de M. & Teología \\
\hline
\end{tabular}




\section{EPÍLOGO}

Quisiéramos acabar el libro con unas reflexiones sobre la Universidad de Lérida, cuya historiografía no ha podido hacer justicia a su dilatada historia. La falta de fuentes ha obligado a enmudecer; la falta de vestigios ha silenciado su importante pasado. Los historiadores locales se han dedicado a reconstruir los perfiles del antiguo Estudio, en un ejercicio casi más arqueológico que historiográfico, por la dificultad de hilvanar los datos dispersos en fuentes muy dispares, que a menudo han llegado a nuestros días en un estado deficiente.

Repetimos que, sin el concurso de los esfuerzos de Gayá Massot, Lladonosa y Esteve Perendreu, así como también de otros especialistas en historia universitaria como Cándido Ajo y Mariano Peset, no se hubiera podido escribir este libro. Nuestro principal propósito ha sido estudiar la Universidad de Lérida no desde la historia local, sino desde la perspectiva de la historia de las universidades, la cual quizás permite mostrar su relieve con más precisión. Las relaciones entre poderes, las carreras de los profesores, las transformaciones de las cátedras y la vida académica son analizadas en el amplio marco de las universidades catalanas y de la Corona de Aragón.

No hay duda de que la erección del Estudio General de Lérida obedeció a un momento de esplendor de la ciudad y que fue el modelo por excelencia de las demás Universidades de la Corona de Aragón. Sin embargo, era difícil que llegase al mismo nivel que tuvo Salamanca, por varias razones.

La más destacada era la cercanía de otras sedes, tanto o más afamadas: Toulouse y Montpellier gozaron de un gran atractivo para los estudiantes de la Corona de Aragón, al igual que las universidades italianas, con las cuales había fuertes conexiones marítimas. No pocos alumnos catalanes, aragoneses o baleares iniciaron sus estudios en Lérida, para concluirlos en las Universidades del sur de Francia o en sedes como Bolonia, Pavía, Roma o Pisa. En cambio, Salamanca -alejada, con la excepción de Valladolid, de otras ciudades universitarias- fue, en Castilla, la sede de referencia durante siglos, sin que hubiera rivales directas.

La segunda razón es que los monarcas de la Corona de Aragón no mantuvieron una misma política universitaria: se optó progresivamente por un modelo descentralizado, con la creación de las Universidades de Perpiñán y de Huesca (en el siglo XIV), y los privilegios para la erección de los Estudios de Gerona, Barcelona, Palma, Zaragoza... en la centuria siguiente. El mapa 
fue complementado, en los siglos XVI y XVII, con creaciones de cuño local y diocesano (Tarragona, Tortosa, Vic...), que significaron una devastadora competencia para Lérida.

Los monarcas mostraron una política vacilante: los Trastámara, en vez de proteger el Estudio ilerdense, contentaron a las oligarquías locales y a los cabildos. Hemos visto en los capítulos anteriores que Carlos I y Felipe II tuvieron una visión muy diferente acerca de la Universidad de Lérida. Al final, con los Austrias Menores, el poder local, los cabildos y los conventos de los dominicos ganaron la partida al centralismo universitario.

La última razón, y no menos importante, es el emplazamiento de Lérida en un lugar equidistante de todos los Reinos, aunque de un valor estratégico fundamental. Si la intención era buena, no es menos cierto que Lleida, por su ubicación y condición de plaza fuerte, fue un objetivo básico en todas las contiendas. Estaba muy expuesta y era, militarmente, una ciudad demasiado importante, algo que no les sucedía a Montpellier, Alcalá o Salamanca.

Si dejamos de lado el caso leridano, ¿cuál fue la sede de la Corona de Aragón que congregó a graduados de todas las "naciones" durante la época moderna? Sin duda, fue la Universidad de Tortosa, que sirvió para dar títulos de Artes y Teología a candidatos catalanes, aragoneses, valencianos y mallorquines, casi en las mismas proporciones. Su emplazamiento quizás hubiera sido el idóneo para un Estudio General para toda la Corona de Aragón. En todo caso, Tortosa era un pequeño Convento-Universidad y no tuvo estudios ni confería grados de Medicina, Leyes y Cánones, que se colacionaron, sin embargo, en muchas universidades vecinas.

El ascenso de Huesca y Zaragoza, por un lado, y el de Barcelona, por otro, fueron parejos a la decadencia de Lérida, que tuvo en el episcopado de Antonio Agustín la última época de esplendor. La (in)competencia de Solsona, que devaluó por completo los títulos, y el lánguido declinar de Tarragona o Gerona eran sin duda, exponentes del decaimiento de un modelo basado en la inflación de grados y una menguada disposición académica. El Estudio de Lérida, ofendido por tal vulgarización, sobrevivió con grandes dificultades a la proliferación de émulos durante el Barroco y se sintió preterido por el poder, que se concentraba cada vez más en la Ciudad Condal.

Las Universidades de Barcelona, Huesca, Zaragoza y Valencia crecían en prestigio, mientras que la Lérida no podía hacer frente a las numerosas dificultades que se sobreponían en su camino. La Guerra de Sucesión fue la ocasión perfecta para castigar a las ciudades rebeldes y para reorganizar el 
postrado sistema universitario catalán. Con todo, Barcelona y Lérida eran, a principios del siglo XVIII, los dos únicos reductos universitarios de cierta entidad en el Principado ${ }^{1}$.

El "experimento de Cervera", como lo denominaron los hermanos Peset $^{2}$, fue un laboratorio en el que se inciaron reformas que luego se acabaron implantando en los territorios de la extinta Corona de Aragón y en Castilla. Si los Austrias menores cedieron ante los municipios, los canónigos y los dominicos, Felipe $\mathrm{V}$ hizo lo propio con los jesuitas, que habían sido una quinta columna del monarca y esperaban su momento. Habían copado hasta entonces la enseñanza media y estaban ampliando su red de influencia hasta llegar a la enseñanza superior.

Hemos subrayado el caso del Colegio de la Compañía en Lérida como un paradigma del nuevo modelo borbónico: en la Ciudad del Segre permaneció este centro como único legado del antiguo Estudio. Durante el reinado de Felipe $\mathrm{V}$, los jesuitas se apoderaron, prácticamente sin competencia, de la enseñanza en las ciudades en las que no había universidad. El caso de Barcelona, pese a la resistencia que opuso la Ciudad, es muy elocuente.

Cabe preguntarse por qué en Barcelona se conservaron estudios de Medicina y de Gramática (éstos, en manos de los jesuitas) y, en cambio, en Lérida se borró de forma tan abrupta la vida universitaria. Hay que pensar que, para Felipe V, tenía que desaparecer cualquier vestigio de la Universidad en Lérida. Había sido trasladada, a todos los efectos. Jurídicamente, no se había erigido

1 El juicio de A. del Arco, La antigua Universidad de Tarragona, p. 107, pese a su antigüedad, no deja de ser interesante: "Bien es verdad, y justo es consignarlo, que si se exceptúan las Universidades de Barcelona y Lérida, las demás de Cataluña arrastraban una Vida misérrima que había anulado casi por entero su actuación; y aunque no deja de ser cierto, como lo consignó Felipe V en la Cédula o Real Decreto de supresión, que la multiplicidad de Universidades había acarreado una Verdadera plétora de sabios inútiles, con perjuicio de las Artes, la Industria y el Comercio, ramas estas de la general cultura que habían de menester mayor apoyo en una región como Cataluña, emporio siempre de las Artes industriales y del Comercio marítimo, hubiera, sin embargo, tenido Verdadera satisfacción este fundamento del real mandato, si al suprimirse las Universidades se hubiesen creado Escuelas de Bellas Artes, Industriales y de Comercio que compensaran la falta de centros universitarios y encauzaran la enseñanza por el camino apropiado a los intereses catalanes. No se hizo esto por Felipe V, y la crítica imparcial no puede hallar justificación a un acto de represalia que cercenó, despiadadamente, la Vida intelectual de Cataluña”.

2 M. Peset y J. L. Peset, La Universidad española (siglos XVIII y XIX). Despotismo ilustrado y revolución liberal, Madrid, Taurus, 1974, p. 65. 
ninguna universidad nueva, sino que se habían transferido las universidades catalanas a Cervera. A falta de Bula, el Estudio General de Lérida aportaba el estatus canónico a la sede de Cervera, trasladando simbólicamente a ella su jurisdicción con la figura del Maestrescuela.

Por ello, el rey Felipe quiso desmantelar totalmente la Universidad de Lérida, con sus colegios anejos y sus rentas, y trasladarlos a Cervera, a fin de que se diese una transferencia física y jurídicamente completa. Llevando al extremo el argumento, puede decirse que Felipe V cambió de sitio la Universidad de Lérida, radicándola en Cervera, y extinguiendo el resto de universidades, con pequeñas concesiones, que no se podía permitir en la Ciudad del Segre. Los jesuitas quedaron allí como premio a su colaboración y sello de instauración de un nuevo orden.

No hay que insistir en lo humillante que fue para Lérida ese final y esa transferencia a una ciudad relativamente cercana, aunque menor. Cervera acabó ensombreciendo en el siglo XVIII a Lérida, como luego -en el siglo XIX- Barcelona eclipsó a Cervera. ¿Acabó siendo, jurídicamente y en último extremo, la Universidad de Barcelona la heredera de los privilegios de Lérida, fungiendo Cervera como mediadora? Dejemos simplemente apuntada aquí esta reflexión.

Desde luego, la Universidad de Cervera ha tenido una tradición historiográfica acorde con el abundante material que de ella se conserva. La historiografía catalana ha sido muy reacia a estudiar sus universidades durante la época de los Austrias. No deja de extrañar que de una época tan analizada como, por ejemplo, la Guerra dels Segadors o la Guerra de Sucesión, se desconozca (e interese tan poco) la vida universitaria. Resultan sorprendentes las lagunas historiográficas no solamente del caso de Gerona, Vic o Tortosa, sino también del Estudio General de la Barcelona del Barroco. Son carencias que deberían solventarse, a fin de poder trazar una historia completa de las universidades de la Corona de Aragón.

En fin, Lérida, pese a haber tenido más de cuatrocientos años de vida universitaria, no puede conocer con exactitud su pasado por falta de fuentes. Este libro perfila y proporciona una explicación general, aunque necesariamente incompleta, de algunas Facultades del Estudio General desde el pontificado de Antonio Agustín hasta la Guerra de Sucesión. Tal vez con estas páginas el lector pueda evocar con mayor nitidez la historia de un pasado que merece ser conocido. 


\section{BIBLIOGRAFÍA}

AAVV, Biografía eclesiástica completa, tomo III, Madrid, Eusebio Aguado, 1850.

Acuña, S. de, Dissertaciones sobre el orden que los medicos deben observar en las juntas para evitar discordia, y conservar la autoridad, y prerrogativa, de que goza cada uno; en defensa de las Universidades de España, del Real ProthoMedicato, de los Medicos de Camara de su Magestad y de los de su Real Familia, Madrid, Librerìa de Luis de Correa, 1746.

[Aguiló, M.], Catálogo de obras en lengua catalana impresas desde 1474 hasta el presente, s.l, 1865 .

Agustí i Farreny, A., "Els concilis de la Tarraconense. Algunes aportacions a la història de la llengua catalana", en Miscel-lània Jordi Carbonell, Barcelona, Abadia de Montserrat, 1993, pp. 53-94.

Agustí, A., Llengua i Església a la Lleida del XVI al XVIII, Lleida, Universitat de Lleida, 1995.

Ajo, C. M., Historia de las universidades hispánicas: orígenes y desarrollo desde su aparición hasta nuestros días, Ávila, CSIC, 1957-1979, 11 vols.

Albareda, J., Felipe Vy el triunfo del absolutismo. Cataluña en un conflicto europeo (1700-1714), Barcelona, Generalitat de Catalunya, 2002.

Albertí, S., "Esquema històric del llinatge Pedrolo", Urtx, 7 (1995), pp. 49-88.

Alcina Rovira, J. F., "Los inicios del ramismo en España”, en J. Pérez Dura y J. M. Estellés (eds.), Los humanistas valencianos y sus relaciones con Europa, Valencia, Ajuntament de Valencia, 1998, pp. 117-136.

Alcina Rovira, J. F., "Antonio Agustín y el índice de libros prohibidos del Concilio de Trento (Roma, 1564)”, Calamvs renascens: Revista de humanismo y tradición clásica, 3 (2002), pp. 7-14.

Alcina Rovira, J. F., "El Humanismo de Antonio Agustín", en A. Egido y J. E. Laplana (coord.), Mecenazgo y Humanidades en tiempos de Lastanosa: Homenaje a Domingo Ynduráin, Zaragoza, Institución Fernando el Católico e Instituto de Estudios Altoaragoneses, 2008, pp. 31-50.

Alegacion en derecho contra el D. Francisco Martí y Viladamor... en justificación de los procedimientos hechos por el muy Illustre, y noble Lugarteniente de Bayle General, y su Consistorio, a peticion del Procurador Fiscal del R.Patrimonio de la B.G., Barcelona, por la Viuda Déu, 1647.

Alins Rami, L., "La nueva fábrica de la Universidad Sertoriana (1690)", Argensola: Revista de Ciencias Sociales del Instituto de Estudios Altoaragoneses, 92 (1981), pp. 267-278. 
Alonso García, A., "Del tomismo al suarismo: la cuestión de la 'alternativa de cátedras' del Estudi General de Barcelona durante el inicio del reinado de Felipe V", Pedralbes, 30 (2010), pp. 267-282.

Alonso Romero, M. P., "Catedráticos salmantinos de Leyes y Cánones en las Chancillerías y Audiencias regias durante el siglo XVII”, en Salamanca, escuela de juristas, Madrid, Dykinson, 2012, pp. 375-398.

Alonso, C., La Reforma tridentina en la provincia agustiniana de la Corona de Aragón: 1568-1586, Valladolid, Ed. Agustiniana, 1984.

Altés i Aguiló, F. X. et alt., Cinc-cents anys de Publicacions de l'Abadia de Montserrat, Barcelona, Abadia de Montserrat, 2005.

Altisent, A., Història de Poblet, Tarragona, Abadia de Poblet, 1974.

Antón Pelayo, J. y Jiménez Sureda M., "Francisco Martí i Viladamor: un profrancés durante la guerra dels Segadors", Manuscrits, 9 (1991), pp. 289-304.

Antonii Augustini archiepiscopi Tarraconensis Opera omnia, Vol. 7, Lucae, Typis Josephi Rochii, 1772.

Arco, A. del, La antigua Universidad de Tarragona: apuntes y documentos para su historia, Tarragona, Tip. de F. Sugrañes, 1918.

Ayala Martínez, J., "La admiración de Baltasar Gracián por San Agustín”, Ciudad de Dios, 217/1 (2004), pp. 261-281.

Aynsa y de Iriarte, F. D. de, Fundacion, excelencias, grandezas, y cosas memorables de la antiquissima ciudad de Huesca, assi en lo temporal, como en lo espiritual, Huesca, por Pedro Cabarte, 1619.

Bada i Elias, J., “Aportacions doctrinals d'Antoni Agustín a la tercera etapa del Concili de Trento (1562-1563)", Revista Catalana de Teologia, 12/1 (1987), pp. 125139.

Bada i Elias, J., "L'ensenyament superior a Catalunya en el segle XVII", Ausa, 143 (1999), pp. 499-518.

Balasch, E. (coord.), Antoni Agustí, bisbe de Lleida i arquebisbe de Tarragona, 15171586: aportacions entorn el marc sòcio-cultural de Catalunya en la seva època, Lleida, Publicacions dels Amics de la Seu Vella, 1995.

Baluze, S., Sancti Agobardi archiepiscopi Lugdunensis Operum, Vol. II, Parisiis, apud Franciscum Muguet, 1665.

Barbeito Díez, M. P. Pedro Juan Núñez, humanista valenciano, Madrid, Universidad Complutense, [Tesis doctoral], 1996.

Beltrán de Heredia, V., "Catálogo de los colegiales, lectores y rectores del Colegio de San Miguel de Solsona (1615-1835)”, Analecta Sacra Tarraconensia, 31 (1958), pp. 125-137.

Beltrán de Heredia, V., "Los dominicos y la enseñanza de la teología en el Reino de 
Aragón”, Miscelánea Beltrán de Heredia. Colección de artículos sobre Historia de la Teología española, II, Salamanca, 1972, pp. 601-621.

Blasco de Lanuza, V., Historias eclesiasticas y seculares de Aragon, desde el año 1556 hasta el de 1618, Vol. II, En Çaragoça, por Iuan de Lanaia y Quartanet, 1622.

Blasco y Lanuza, F., Respuesta al presente mandato, con sus erratas a la margen, [s.l.], [1654].

Borao, G., Historia de la Universidad de Zaragoza, [s.l.], [s.n.].

Bover, J. M., Biblioteca de autores baleares, vol. 2, Palma, Gelabert, 1868.

Busqueta, J. J. (ed.), Llibre de les Constitucions i Estatuts de l'Estudi General de Lleida, Lleida, Universitat de Lleida, 2000.

Busqueta, J. J., "Oligarquia urbana i ensenyament superior: Lleida, del bidell al canceller de l'Estudi General”, en F. Sabaté i Curull (coord.), L'edat mitjana: món real i món imaginari, Catarroja-Barcelona, Editorial Afers, 2012, pp. 163-169.

Cadenas y Vicent, V. de, Extracto de los Expedientes de la Orden de Carlos III. 17711847, Tomo IV, Madrid, Hidalguía, 1982.

Camón y Tramullas, I., Memorias Literarias de Zaragoza, II, en Zaragoza, imprenta de Francisco Moreno, 1768.

Canet Aparisi, T., "Entre la visita y la sucesión. La resistencia a la virreinalización administrativa en Valencia entre Carlos V y Felipe II", Estudis. Revista de Historia Moderna, 28 (2002), pp. 205-240.

Capdevila, S., "La Seu de Tarragona”, Analecta Sacra Tarraconensia, 10 (1934), pp. 1-192.

Capilla, A., Libro llamado Consuelo de Nuestra Peregrinación de grande utilidad y consolaciòn para todos los fieles, en que se trata de la dignidad y exellencia de la Religión Christiana, Lerida, Pedro de Nobles y Juan de Villanueva, 1574.

Carbonell i Manils, J., Epigrafia i numismàtica a l'epistolari d'Antonio Agustín (15511563), Bellaterra, Universitat Autònoma de Barcelona, [Tesis doctoral], 1992.

Carbonell i Manils, J., "La relación epistolar inédita entre Antonio Agustín y el Papa Gregorio XIII”, Faventia, 22/2 (2000), pp. 121-138.

Carrió-Invernizzi, D., "Los catalanes en Roma y la iglesia de Santa María de Montserrat (1640-1670)”, Pedralbes, 28 (2008), pp. 571-584.

Casals Bergés, Q., Polítics de Lleida. El poder local i les seves mutacions a través del temps (1716-1868), Lleida, Pagès, 2014.

Casellas, E., Iurisdiccion regia y pontificia que sobre la Universidad y Estudios Generales de Lerida y singulares personas de aquella, tiene el maestre-escuelas de dicha Universidad, s.n., 1687?.

Cassanyes Roig, A. y Ramis Barceló, R., "Graduados en Leyes y Cánones en la Uni- 
versidad Luliana y Literaria de Mallorca (1692-1831)", e-legal history review, 16 (2013), pp. 1-62.

Castellví, F. de, Narraciones Históricas desde el año 1700 hasta el año 1725, III, Madrid, Fundación Francisco Elías de Tejada y Erasmo Pèrcopo, 2002.

Cerro Nargánez, R., "Los alcaldes mayores del corregimiento de Lérida en el siglo XVIII", Cuadernos dieciochistas, 2 (2001), pp. 37-72.

Cerro Nargánez, R., "Assessors del veguer i alcaldes majors: una transició problemàtica per a Barcelona (1714-1720)", Barcelona. Quaderns d'Història, 7 (2002), pp. 119-135.

Cerro Nargánez, R., "Los alcaldes mayores del corregimiento de Tarragona (17171808)", Cuadernos de investigación histórica, 20 (2003), pp. 299-324.

Cisteller, D., Memorial, en defensa de la lengua catalana, para que se predique en ella en Cataluña, dedicado a los Muy Illustres Señores Diputados del Principado de Cataluña, padres de la Patria, Tarragona, en casa Gabriel Roberto, 1636.

Clarisó Martí, J. M., La economía de la nobleza de Lleida en el siglo XVIII, Madrid, UNED, [Tesis doctoral], 2015.

Collell, A., "Ayer de la provincia dominicana de Aragón", Analecta Sacra Tarraconensia, 39 (1966), pp. 217-255.

Constituciones, y ordinaciones de la muy ilustre Congregación y Confradia del glorioso S. Pedro Martyr: de ministros de la Inquisicion de Aragon, Zaragoza, por Francisco Moreno, 1746.

Constitutions fetes per la S.C.R. Magestat del Rey Don Phelip Segon, Barcelona, en casa de Gabriel Graels y Giraldo Dotil, 1603.

Constitutions fetes per la Sacra Catholica Real Magestat del Rey Don Phelip..., Barcelona, Casa de Damia Bages, 1586.

Constitutions y altres drets de Cathalunya..., Barcelona, en casa de Joan Pau Marti y Joseph Llopis, 1704.

Cortiada, M. de, Decisiones cancellarii et sacri regii senatus Cathaloniae siue Praxis contentionum et competentiarum, tomo III, Lugduni, sumptibus Anisson et Posuel, 1699.

Decreta Regia pro reformatione Universitatis Studii Generalis Illerdae, edita in illius visitatione de anno M.DC.XIII, Apud Ludouicum Manescal, 1614.

Despuig y Dameto, A., Vida de la beata Catalina Tomás, Mallorca, Imprenta de Felipe Guasp, 1816.

Diago, F., Historia de la prouincia de Aragon de la orden de predicadores, desde su origen y principio hasta el año de mil y seyscientos, Barcelona, impressa por Sebastian de Cormellas en Sancta Catherina martyr de Barcelona, 1599.

Díaz, G., "La escuela agustiniana desde 1520 hasta 1650", La Ciudad de Dios, 176 (1963), pp. 63-84. 
Durán Gudiol, A., "Notas para la historia de la Universidad de Huesca en el siglo XVI", Hispania Sacra, 21 (1968), pp. 87-150.

Elliott, J. H., La revolta catalana, 1598-1640: Un estudi sobre la decadència d'Espanya, [1963], València, Universitat de València, 2011.

Esteve Perendreu, F., "El doctor Francisco Perandreu Maestrescuela del Estudio General de Lérida" en Miscel-lània. Les Terres de Lleida al segle XVII, Lleida, Institut d'Estudis Ilerdencs, 1984, pp. 165-214.

Esteve Perendreu, F., "Jurisdicció del bisbe sobre el mestrescola i eclesiàstics de l'Estudi General de Lleida" en VVAA, Església i societat a la Catalunya del segle XVIII, Cervera, UNED, 1990, vol. II, pp. 183-197.

Esteve Perendreu, F., El Régimen jurídico del Estudio General de Lleida: s. XIII/ XVIII, Lleida, Publicacions de l'Estudi General de Lleida-Pagès, 1992.

Esteve Perendreu, F., "La docència de la teologia a Lleida, la càtedra del bisbe Conchillos i les altres càtedres teològiques de l'Estudi General" en X. Company (ed.), $E l$ bisbe Jaume Conchillos, l'humanisme a Catalunya, Lleida, Amics de la Seu Vella, 1993, pp. 141-179.

Esteve Perendreu, F., "Rentas y reformas del Estudio General de Lérida", Analecta Sacra Tarraconensia, 69 (1996), pp. 29-86.

Esteve Perendreu, F., "El tribunal de coltellades de Lleida. Procediment i dictàmens mèdics", Gimbernat, 30 (1999), pp. 165-174.

Esteve Perendreu, F., "Llibreria jurídica de Joan Pau Molner, catedràtic de l'Estudi i ardiaca de la Seu", en Seu Vella. Anuari d'Història i Cultura, 3, Lleida, Amics de la Seu Vella, 2001, pp. 325-358.

Esteve Perendreu, F., “Joan Josep Casanoves, el final d'una època”, en X. Eritja et alii (coords.), Lleida al segle XVIII: el naixement d'una nova ciutat, Lleida, Ateneu Popular de Ponent, 2002, pp. 75-116.

Esteve Perendreu, F., Mestrescoles i rectors de l'Estudi General de Lleida (1597-1717), Lleida, Edicions de la Universitat de Lleida, 2007.

Esteve Perendreu, F., El Col-legi universitari de l'Assumpció de Santa Maria de Lleida (segles XIV-XIX), Lleida, Universitat de Lleida, 2010.

Falcón Pérez, M. I., Motis Dolader, M. A., Procesos criminales en el Arzobispado de Zaragoza, Zaragoza, Gobierno de Aragón, 2000.

Felipo Orts, A., La Universidad de Valencia durante el siglo XVI (1499-1611), Valencia, Universidad de Valencia, 1993.

Felipo Orts, A., "La actitud institucional ante el proceso de beatificación de Francisco Jerónimo Simón durante el siglo XVII", Estudis: Revista de historia moderna, 23 (1997), pp. 117-148.

Felipo Orts, A. y Callado Estela, E., Entre la cátedra y el púlpito. Los pavordes de 
la Universidad de Valencia (siglos XVI-XVII), Valencia, Universitat de València, 2016.

Felipo Orts, A., Peris Felipo, F. J., Miralles Vives, F., Estudiantes y probanzas de cursos en la Universidad de València (1561-1707), Valencia, Universitat de València, 2013.

Fernández, A., Historia y anales de la deuocion y milagros del Rosario: desde su origen hasta año mil y seis cientos y veinte y seis, Madrid, por Iuan Gonzales, 1627.

Fernández Díaz, R., Cataluña y el absolutismo borbónico: historia y política, Barcelona, Crítica, 2014.

Fernández Luzón, A., La Universidad de Barcelona en el siglo XVI, Barcelona, Universitat de Barcelona, 2005.

Ferreres Nos, J., "El bandolerisme català dels segles XVI i XVII a les terres del Maestrat Vell de Montesa”, Recerca, 9 (2005), pp. 67-104.

Finestres y de Monsalvo, J., Historia del Real Monasterio de Poblet, vol. 4, Tarragona, Joseph Barber, 1756.

Flores Sellés, C., Epistolario de Antonio Agustín, Salamanca, Universidad de Salamanca, 1980.

Fontanella, J. P., Tractatus de pactis nuptialibus siue e capitulis matrimonialibus: duobus tomis diuisus, Lugduni, sumptibus Horatii Boissat et Georgii Remeus, 1667.

Fuente, V. de la, Historia de las universidades, colegios y demás establecimentos de enseñanza en España, Madrid, La viuda e hija de Fuentenebro, 1884-1887, 3 vols.

Fuster, J. P. Biblioteca Valenciana de los escritores que florecieron hasta nuestros dias, vol. 1, Valencia, Ximeno, 1827.

Gallego Salvadores, J., "La metafísica en España durante el siglo XVI”, en Repertorio de las ciencias eclesiásticas en España, VII, Salamanca, UPSA, 1979, pp. 142-234.

Galobart i Soler, J., "Les actes de visita dels abats de Montserrat al monestir de Sant Benet de Bages. I. 1627-1725”, Studia monastica, 45/1 (2003), pp. 73-187.

García Trobat, P., "Los grados de la universidad de Gandía (1630-1772)", en AAVV, Universidades españolas y americanas, Valencia, Universidad de Valencia, 1987, pp. 175-186.

García Trobat, P., "La Universidad de Gandía”, en M. Peset; M. F. Mancebo; M. Martínez Gomis; P. García Trobat, Historia de las universidades valencianas, II, Alicante, Instituto Juan Gil-Albert, 1993, pp. 153-221.

Gayá Massot, R., Los Valencianos en el Estudio General de Lérida, Valencia, CSICPatronato José María Quadrado, 1950.

Gayá Massot, R., Cancilleres y rectores del Estudio General de Lérida, Lérida, La Editora Leridana, 1951. 
Gayá Massot, R., Los jesuitas en la Universidad de Lérida, Lérida, La Editora Leridana, 1954 .

Gayá Massot, R., “Las Rentas del Estudio General de Lérida”, Analecta Sacra Tarraconensia, 25 (1954), pp. 293-338.

Gayá Massot, R., "Provisión de cátedras en el Estudio General de Lérida”, Analecta Sacra Tarraconensia, 30 (1958), pp. 233-296.

Gayá Massot, R., "Influencia de la Universidad de Salamanca en la de Lérida”, Analecta Sacra Tarraconensia, 31 (1959), pp. 101-124.

Genover, F., Succinta, praeclara ac perutilis resolutio, cujusdam peculiaris difficultatis, circa sacrosancti Missae Sacrificii applicationem occurrentis Ilerdae, excudebat Dominicus Simon, 1700.

Genover, F., Selectae disputationes miscellaneae, in moralem theologiam juxta tutissima, et inconcussa Div. Thomae Aquinatis dogmata, Cervariae, per Thomam Senant, 1730.

Gómez García, V. T., “Aportación del convento dominicano de Santa Catalina de Barcelona a la evangelización de América y el Extremo Oriente" en J. Barrado Barquilla (coord.), Actas del II Congreso Internacional sobre los Dominicos y el Nuevo Mundo, Salamanca, 28 de marzo-1 de abril de 1989, Salamanca, San Esteban, 1990, pp. 917-938.

Gómez, T., En reino extraño. Relación de la visita del Real monasterio de Valldigna. Autobiografía, vida cotidiana y lucha política en la España de Carlos II, Valencia, Universitat de Valencia, 2008.

Gort Riera, R., L'Estudi General de Lleida al segle XIV, Lleida, Edicions de la Universitat de Lleida, 2016.

Gras de Esteva, R., La Paheria de Lérida. Organización municipal 1149-1707, Lleida, Imprenta y litografía Sol y Benet, 1909.

Grau, F., Las Retóricas de Pedro Juan Núñez, Valencia, Universidad de Valencia, [Tesis doctoral], 1994.

Gudiol i Cunill, J., La Universitat Literària de Vic, Vic, Patronat d’Estudis Osonencs, [1924], 1991.

Guiso, P., Historia de las Heroycas virtudes, relacion de los portentosos milagros: Vida, muerte, y culto del B. Salvador de Horta..., Caller, en Santo Domingo, 1732.

Gutiérrez, C., Trento, un problema: la última convocación del concilio (1552-1562), V, Madrid, Universidad Pontificia de Comillas, 2000.

Hernández Palmés, A., "Matriculatio legistarum Universitaris Generalis Studii Ilerdensis (1607-1624)", en AAVV, Miscelánea de Trabajos sobre el Estudio General de Lérida, vol. II, Lérida, Editora Leridana, 1950, pp. 71-178. 
Iglesies, J., Pere Gil, S.I. (1551-1622) i la seva Geografia de Catalunya, Barcelona, Institut d'Estudis Catalans, 2002.

Índice de la colección de don Luis de Salazar y Castro, tomo V, Madrid, Real Academia de la Historia, 1951.

Jané Checa, O., “Aspectes de la relació identitària de Catalunya amb França a l'època de Lluís XIV”, Manuscrits, 19 (2001), pp. 103-136.

Jordà Fernández, A., "Un humanista del derecho. Antonio Agustín (1516-1517?-1586) y su obra jurídica”, e-SLegal history review, 25 (2017), pp. 1-63.

Jordán, J., Historia de la provincia de la corona de Aragon de la sagrada orden de los ermitaños de nuestro gran padre San Augustin: compuesta de quatro reynos, Valencia, Aragon, Cataluña, y las islas de Mallorca y Menorca, y dividida en quatro partes, Tomo I, Valencia, Joseph Garcia, 1704.

Jordán, J., Historia de la provincia de la corona de Aragon de la sagrada orden de los ermitaños de nuestro gran padre San Augustin, Vol. 1, Tomo II, Valencia, Antonio de Bordazar, 1712.

Kagan, R. L., Universidad y sociedad en la España moderna, Madrid, Taurus, 1981.

Lahoz Finestres, J. M., Las Facultades de Leyes y Cánones de la Universidad de Huesca, siglos XIV a XIX, 3 vols., Zaragoza, Universidad de Zaragoza, [Tesis doctoral], 1994 .

Lahoz Finestres, J. M., "Graduados catalanes en las facultades de Leyes y Cánones de la Universidad de Huesca”, Estudis històrics i documents dels arxius de protocols, 15 (1997), pp. 167-220.

Lahoz Finestres, J. M., "Esbozo de los graduados de la universidad de Huesca (15411845)", en AAVV, Aulas y Saberes, vol. II, Valencia, Universidad de Valencia, 2003, pp. 29-43.

Lahoz Finestres, J. M., "Un estudio sobre los graduados de la Universidad de Huesca”, Argensola: Revista de Ciencias Sociales del Instituto de Estudios Altoaragoneses, 115 (2005), pp. 245-282.

Lahoz Finestres, J. M. y García Torrecilla, L., "Graduados en teología en la Universidad de Huesca”, Miscelánea Alfonso IX. Centro de Historia Universitaria, Salamanca, Universidad de Salamanca, 2001, pp. 207-288.

Lario, D. de, "La variante catalana” en Al hilo del tiempo. Controles y poderes de una España imperial, Valencia, Universidad de Valencia, 2004, pp. 141-147.

Lario Ramírez, D. de y García Martín, J., “La impermeabilización ideológica de Felipe II: cronología de una coyuntura (1558-1571)”, Estudis: revista de historia moderna, 40 (2014), pp. 31-70.

Latassa, F. de, Biblioteca Nueva de los escritores aragoneses: que florecieron desde el año de 1500 hasta 1599, Vol. 1, Pamplona, en la oficina de Joaquín Domingo, 1798. 
Latassa, F., Biblioteca nueva de los escritores aragoneses: que florecieron desde el año de 1600 hasta 1640, Vol. 2, Pamplona, Joaquín Domingo, 1799.

Latasa, F. de, Biblioteca nueva de escritores aragoneses, Vol. 3, Pamplona, En la Oficina de Joaquín Domingo, 1799.

Latassa, F. de, Biblioteca nueva de los Escritores Aragoneses florecieron desde el año de 1689 hasta el de 1753, Vol. 4, Pamplona, Joaquín Domingo, 1800.

Lazcano, R., Agustinos españoles escritores de María, Guadarrrama, Madrid, 2005.

Lladonosa, J., Lérida y sus relaciones con el Monasterio de Poblet, Lleida, Tipografia Selecta, 1954 .

Lladonosa, J., Anecdotari de l'antiga Universitat de Lleida, Barcelona, Barcino, 1957.

Lladonosa, J., La Facultat de Medicina de l'antiga Universitat de Lleida, Barcelona, Rafael Dalmau, 1969.

Lladonosa, J., L'Estudi General de Lleida del 1430 al 1524, Barcelona, Institut d'Estudis Catalans, 1970.

Lladonosa, J., "Humanisme i reformes a l'Estudi General de Lleida durant el segle XVI”, VIII Congreso de Historia de la Corona de Aragón, T. III, Vol. II, 1973, Valencia, Sucesor de Vives Mores, 1973, pp. 87-106.

Lladonosa, J., Lérida medieval. Tomo II (siglos XIV-XV), Lleida, Dilagro, 1975.

Lladonosa, J., Història de Lleida, II, Tàrrega, F. Camps Calmet, 1975.

Lladonosa, J., Lérida moderna. Epoca de los Austrias, Lleida, Dilagro, 1977.

Lladonosa, J., La Suda, parròquia de la Seu de Lleida: problemàtica arqueològica i urbanística d'una antiga ciutadella, Lleida, Institut d'Estudis Ilerdencs, 1979.

Lladonosa, J., Lérida moderna. Epoca de los Borbones, Lleida, Dilagro, 1980.

Llaquet de Entrambasaguas, J. L., La Facultad de Cánones de la Universidad de Cervera (ss. XVIII-XIX), Barcelona, Universidad de Barcelona, [Tesis doctoral], 2001.

López, J., Quarta parte de la Historia general de Santo Domingo y de su Orden de Predicadores, Valladolid, por Francisco Fernandez de Cordoua, 1615.

Madurell Marimon, J. M., "Luis Juan Vileta”, Analecta Sacra Tarraconensia, 37 (1964), pp. 19-76.

Maranyosa, T. de, Pro syndico et clavario civitatis Barcinonae contra rectorem et operarios termini et parrochiae Sancti Martini de Provensals territorij Barcinone, s.f., s.d.

Marqués, A., Cataluña defendida de sus emulos illustrada con sus hechos fidelidady servicios a sus reyes, Lérida, por Enrique Castañ, 1641.

Marqués, S., "L’Estudi General de Girona”, en J. J. Busqueta Riu y J. Pemán Gavín (coords.), Les universitats de la Corona d’Aragó, ahir i avui..., pp. 125-146. 
Martín Verdejo, F., "La vida y la biblioteca de Bernabé García, boticario rural del siglo XVIII", Asclepio. Revista de Historia de la Medicina y de la Ciencia, 56/2 (2004), pp. 113-168.

Martínez del Villar, M., Tratado del Patronado, antiguedades, gouierno, y varones illustres de la ciudad, y Comunidad de Calatayud, y su Arcedianado, Çaragoça, Lorenço de Robles, 1598.

Martínez Gomis, M., La universidad de Orihuela (1610-1807): un centro de estudios superiores entre el Barroco y la Ilustración, Alicante, Universidad de Alicante, 1986.

Martínez Rodríguez, M. A. “Linaje y poder en la Cataluña foral: la actividad política de los Copons”, Cuadernos de Historia Moderna, 22 (1999), pp. 11-31.

Martínez Rodríguez, M. A., "Els oïdors de la Sala Tercera de l’Audiència de Catalunya a la segona meitat del segle XVII", Estudis històrics $i$ documents dels Arxius de Protocols, 20 (2002), pp. 205-228.

Martínez Rodríguez, M. A., "Els assessors del governador de Catalunya als segles XVI i XVII", Pedralbes, 23 (2003), pp. 95-111.

Martínez Rodríguez, M. A., "Los regentes la Cancillería en la Cataluña de los últimos Austrias", Manuscrits, 23 (2005), pp. 109-130.

Martínez Rodríguez, M. A., Felip IV i Catalunya, Lleida, Pagès, 2013.

Martínez Shaw, C., y Alfonso Mola, M., Felipe V, Madrid, Arlanza, 2001.

Massot, J., Compendio Historial de los Hermitaños de nuestro Padre San Agustín del Principado de Cataluña, Barcelona, Juan Jolis, 1699.

Memorial en fet per la ciutat de Barcelona conrta [sic] Geronym Pintor, Barcinone, apud Sebastianum et Iacobum Matevat..., 1638.

Miralles, E., "Els escriptors catalans en una Europa en conflicte: la propaganda política impresa de la Guerra dels Segadors", Caplletra, 52 (2012), pp. 181-205.

Molas, P., "El bisbe Antoni Agustí: política i erudició al segle XVI”, en M. Esther Balasch (coord.), Antoni Agustí..., pp. 13-19.

Molas, P., “'Aragón’ en el Consejo de Castilla”, Cuadernos dieciochistas, 2 (2001), pp. 13-35.

Molini, F., De brachio seculari Ecclesiae praestando et mutuis iudicum auxiliis celeberrimi commentarij: in tres libros distincti; his accessit liber singularis De sacra homicidio amittenda immunitate nec ne, Barcelona, Ioannem Simon, 1607.

Molini, F., Tractatus celebris, et insignis de ritu nuptiarum, et pactis in matrimonio conuentis, Barcelona, Laurentij Déu, 1617.

Morales Roca, F. J., Próceres habilitados en las Cortes del Principado de Cataluña, siglo XVII: 1599-1713, Vol. 1, Madrid, Hidalguía, 1983.

Morales Roca, F. J., Ciudadanos y burgueses honrados habilitados como Síndicos 
del Brazo Real en las Cortes del Principado de Cataluña: dinastías de Trastámara y de Austria, siglos XV y XVI, 1410-1599, Madrid, Hidalguía, 1995.

Morales Roca, F. J., "Officialium Catalonia, IV, Regidores del Ayuntamiento de Lérida, Dinastía de Borbón, 1716-1833”, Hidalguía, 316-317 (2006), pp. 441-472.

Muñiz, R., Biblioteca Cisterciense española, Burgos, Joseph de Navas, 1793.

Narváez Cases, C., "El patronatge de les noves oligarquies urbanes a l'art català dels segles XVI i XVII", Recerques, 51 (2005), pp. 5-25.

Neyla, F. de, Alpha y omega sacro, discursos evangelicos, morales, y panegiricos..., Zaragoça, por Pasqual Bueno, 1691.

Neyla, F. de, Gloriosa fecundidad de Maria en el campo de la Catolica Iglesia: Descripcion de las excelencias è ilustres hijos del Real Convento de San Lazaro de la ciudad de Zaragoça del Real y Militar Orden de Nuestra Señora de la Merced Redencion de Cautivos, por Rafael Figuerò, Barcelona, 1698.

Obras de D. Francisco de Quevedo Villegas, Barcelona, Por Jayme Suri, 1702.

Oleart, O., "Diputación del General y libros jurídicos en Cataluña (siglos XVI-XVIII): la publicación de las Decisiones del doctor Miquel de Cortiada", en M. Á. González de San Segundo (coord.), Un jurista aragonés y su tiempo. El doctor Juan Luis López, primer marqués del Risco (1644-1703), Zaragoza, Gobierno de Aragón, 2007, pp. 505-591.

Palao, F. J., "Los jesuitas y las universidades en la Corona de Aragón”, en L. E. Rodríguez San Pedro Bezares y J. L. Polo Rodríguez (coord.), Universidades hispánicas: colegios y conventos universitarios en la Edad Moderna, XV Coloquios Alfonso IX, (I), Salamanca, Universidad de Salamanca, 2009, pp. 159-188.

Passola Tejedor, A., Oligarquia i poder a la Lleida dels Austria: una elit municipal catalana en la formació de l'estat modern, Lleida, Pagès, 1997.

Pemán Gavín, J., "Los estatutos fundacionales de la antigua universidad Ilerdense (año 1300)", en J. J. Busqueta (ed.), Llibre de les Constitucions i Estatuts de l'Estudi General de Lleida, Lleida, Universitat de Lleida, 2000, pp. 25-53.

Pérez Santamaría, A., "L'escultor guixolenc Domènec Rovira (1608-1678)", Estudis del Baix Empordà, 31 (2012), pp. 83-104.

Peset, M., "La fundación y el fuero universitario de Lérida”, Hispania, 199 (1998), pp. 515-536.

Peset, M. y Menegus Bornemann, M., "Localización y espacio de las universidades hispánicas”, Cuadernos del Instituto Antonio de Nebrija, 3 (2000), pp. 189-232.

Pifarré San Agustín, F., Aspectes sanitaris de l'arxiu parroquial de Sant Joan de Lleida, segles XVIII $i$ XIX, Lleida, [Tesis doctoral], 2007.

Piquer i Jover, J. J., Abaciologi de Vallbona (1153-1977), Santes Creus, Fundació Roger de Ballfort, 1978. 
Planas Rosselló, A., La Real Audiencia de Mallorca en la época de los Austrias (15711715), Barcelona, Publicacions de la Universitat Pompeu Fabra, 2010.

Planas Rosselló, A., y Ramis Barceló, R., La Facultad de Leyes y Cánones de la Universidad Luliana y Literaria de Mallorca, Madrid, Dykinson, 2011.

Poch, J., "Del Estudio General de la Universidad de Lérida. Carta de los Paheres a Felipe 11 (17 agosto 1574)”, Ciudad, 26 (1974), pp. 119-120.

Poch, J., "El rectorado del Estudio General de Lérida en la anualidad 1573-1574”, Ciudad, 27 (1975), s.n.

Prats, J., La Universitat de Cervera i el reformisme borbònic, Lleida, Pagès, 1993.

Puig Sanchís, I., "D’Arquitectura i Mestres de Cases a la Lleida del segle XVIII: Els Biscarri”, Urtx, 16 (2003), pp. 165-214.

Querol Coll, E., L'Antiga Universitat a Tortosa (1529-1824), Tortosa, Antena Cultural Tortosa-Universitat Rovira i Virgili, 2013.

Ramis Barceló, R., "Estudiantes hispanos de leyes y cánones en la Universidad de Pisa (1543-1665)”, Glossae. European Journal of Legal History, 10 (2013), pp. 524-544.

Ramis Barceló, R., "Las cátedras tomistas de la Universidad Luliana y Literaria de Mallorca (1692-1824)”, Archivum Fratrum Praedicatorum, 83 (2013), pp. 345368.

Ramis Barceló, R., "La política universitaria de los Austrias en la Península Ibérica” en G. P. Brizzi y A. Mattone (ed.), Le origini dello Studio Generale sassarese nel mondo universitario europeo dell'eta moderna, Bolonia, CLUEB, 2013, pp. 103116.

Ramis Barceló, R., "Las cátedras lulianas de la Universidad de Mallorca (1692-1824)”, Bolletí de la Societat Arqueològica Lul-liana, 70 (2014), pp. 185-205.

Ramis Barceló, R., "Peregrinatio academica: Legistas y canonistas de la Corona de Aragón en las Universidades italianas durante el Renacimiento", Miscellanea historico-iuridica, 12 (2014), pp. 35-66.

Ramis Barceló, R., "Las cátedras suaristas de la Universidad Luliana y Literaria de Mallorca (1692-1767)”, Archivum Historicum Societatis Iesu, 164/2 (2014), pp. 399-426.

Ramis Barceló, R., “Aristotelismo, lulismo y ramismo en Barcelona durante el siglo XVI: Joan-Lluís Vileta y sus discípulos”, Cauriensia, 10 (2015), pp. 385-407.

Ramis Barceló, R., "Las cátedras escotistas de la Universidad Luliana y Literaria de Mallorca (1692-1824)”, Archivum Franciscanum Historicum, 108/1-2 (2015), pp. 301-317.

Ramis Barceló, R., "Los grados en teología en la Universidad de Barcelona durante el siglo XVI", Anuario de Historia de la Iglesia, 24 (2015), pp. 291-309. 
Ramis Barceló, R., “Los graduados en Leyes y Cánones de la Universidad de Barcelona durante el siglo XVI", Anuario de Historia del Derecho Español, 85 (2015), pp. 475-496.

Ramis Barceló, R., "Sobre los privilegios de la Universidad de Solsona y los grados en leyes, cánones y medicina durante el siglo XVII”, Glossae. European Journal of Legal History, 12 (2015), pp. 661-678.

Ramis Barceló, R., “Apuntes sobre los grados en leyes y cánones en la Universidad de Barcelona a comienzos del siglo XVII”, en A. Murillo Villar, A. Calzada González y S. Castán Pérez-Gómez (eds.), Homenaje al Profesor Armando Torrent, Madrid, Dykinson, 2016, pp. 753-763.

Ramis Barceló, R., "Estudiantes y grados en la Universidad de Tortosa durante el siglo XVII”, en J. M. Calderón Ortega, M. Casado Arboniés, A. Díez Torre (coord.), Historia universitaria de España y América, Alcalá, Universidad de Alcalá de Henares, 2016, pp. 253-268.

Ramis Barceló, R., "La Facultad de Leyes y Cánones de la Universidad de Barcelona a comienzos del siglo XVIII”, Anuario de Historia del Derecho Español, 86 (2016), pp. 385-408.

Ramis Barceló, R., "Grados mayores en la Universidad de Tarragona (1580-1624)", Analecta Sacra Tarraconensia, 90 (2017), pp. 131-155.

Ramis Barceló, R., "La Facultad de Leyes y Cánones de la Universidad de Orihuela en el siglo XVII”, Cuadernos de historia del derecho, 24 (2017), pp. 161-185.

Ramis Barceló, R., "La Facultad de Teología de la Universidad de Barcelona a comienzos del siglo XVIII", Revue d'Histoire Ecclésiastique, 112/1-2 (2017), pp. 185-214.

Ramis Barceló, R., "La Universidad de Lérida durante el pontificado de Antonio Agustín (1561-1576)”, Cauriensia, 12 (2017), pp. 599-626.

Ramis Barceló, R., Doctores hispanos en Leyes y Cánones por la Universidad de la Sapienza de Roma (1549-1774), Madrid, Dykinson, 2017.

Ramis Barceló, R., "La defensa del tomismo frente al suarismo: la Facultad de Artes y Filosofía de la Universidad de Barcelona a comienzos del siglo XVIII”, Espíritu, 155 (2018), pp. 81-106.

Ramis Barceló, R., "La Universidad de Salamanca vista desde La Sapienza en el siglo XVII", en J. Correa Ballester (ed.), Universidad y Sociedad: Historia y pervivencias, Valencia, Publicaciones de la Universidad de Valencia, 2018, pp. 513-525.

Ramis Barceló, R. y Ramis Serra, P., "Los primeros grados de la Universidad de Orihuela (1610-1643)”, Estudis. Revista de Historia Moderna, 43 (2017), pp. 235-260.

Ramis Barceló, R. y Ramis Serra, P. "Los últimos grados de la Universidad de Solsona (1701-1715)”, Historia. Instituciones. Documentos, 44 (2017), pp. 313-349.

Ramis Barceló, R. y Ramis Serra, P., "Grados de la Universidad de Irache (16131620)", Studia monastica, 6o/1 (2018), pp. 119-180. 
Redondo Veintemillas, G., "La Universidad de Zaragoza”, en J. J. Busqueta Riu y J. Pemán Gavín (coords.), Les universitats de la Corona d’Aragó, pp. 239-287.

Responsum pro Petro Francisco Agramunt D.D. Cathedratico Primario Canonum Vniversi[tatis] gener[alis] studij Ilerden[sis]: contra oppositionem Ioachimi Frigola, Illerdae, apud Ludouicum Manescal, 1619.

Rial i Carbonell, R., L'Ensenyament superior a la Catalunya central entre els segles XVII $i$ XIX: de la Universitat literària de Vic (1599-1717) al Seminari Conciliar de Vic (1749-1868), Barcelona, Facultat de Teologia de Catalunya, 2003.

Ribera, E., "Figuras del Estudio General de Lérida en el Archivo Parroquial de San Juan Bautista”, en AAVV, Miscelanea de Trabajos sobre el Estudio General de Lérida, Lleida, Institut d'Estudis Ilerdencs, I, 1949, pp. 65-120.

Ribera, M. M. de, Centuria primera del Real y Militar Instituto de la inclita religion de Nuestra Señora de la Merced Redempcion de Cautivos christianos, Barcelona, por Pablo Campins, 1726, s.f.

Riquer, M. de, Quinze generacions d'una família catalana, Barcelona, Quaderns Crema, 1998.

Rodríguez-Sampedro Bezares, L. E., La Universidad salmantina del Barroco, periodo 1598-1625, Tomo II, Salamanca, Universidad de Salamanca, 1986.

Rodríguez-Sampedro Bezares, L. E., "La Corona de Aragón en la Universidad de Salamanca: siglos XVII y XVIII”, en Aulas y Saberes: VI Congreso Internacional de Historia de las universidades hispánicas, vol. II, Valencia, Universidad de Valencia, 2003, p. 399-417.

Roger, T., Sermón en las honras del venerable sacerdote e insigne doctor Antonio Galipienço, cathedrático de Prima de Theologia en la Universidad de Lérida. Predicado por el maestro fr. Thomás Roger, de la orden de Predicadores, cathedrático de Santo Thomás en la mesma Universidad. Dirigido al muy Illustre Dean, y Cabildo de la S. Iglesia Cathedral de Lerida, Lerida, Enrique Castañ, 1639.

Rubió y Borrás, M., Historia de la Real y Pontificia Universidad de Cervera, I, Barcelona, Librería Verdaguer, 1915.

Ruiz, E., “Los años romanos de Pedro Chacón”, Cuadernos de Filología Clásica, 10 (1976), pp. 189-247.

Sainz de Baranda, P., España Sagrada, T. XLVII, Madrid, Imprenta de la Real Academia de la Historia, 1850.

Salvá, L., Perenne Monumento, y funebres lamentos que en las Exequias, translacion, y Entierro en la Iglesia del Oratorio de San Felipe Neri de esta Ciudad se erigió al [...] Dr. Francisco Garrigó, Barcelona, por Francisco Guasch, 1715.

Sanahuja, P., "La Universidad de Lérida y los franciscanos", Archivo Ibero-americano, 7 (1947), pp. 167-242.

Sánchez Gil, V., “La teología española hasta la Ilustración 1680-1750”, en M. Andrés 
(ed.), Historia de la teología en España, 1470-1570: Desde fines del siglo XVI hasta la actualidad, Madrid, Fundación Universitaria Española, 1987, pp. 359-442.

Sánchez-Lauro Pérez, S., "L’Estudi General de Lleida davant un moment històric d'inflexió renovadora: peticions locals d'intervenció regi a Felip II”, Revista de Dret Històric Català, 9 (2009), pp. 253-269.

Sermon que predico el Doctor Josef Campi y Avenía, Canonigo Penitenciario de la Santa Iglesia Cathedral de Tarazona; Antes cathedratico de Prima de Theologia en la Universidad de Lérida. Dia del nacimiento de San Juan Bautista, en dicha Santa Iglesia, en Zaragoça, por los herederos de Diego Dormer, 1676.

Serra i Puig, E., Els Llibres de l’Ànima de la Diputació del General de Catalunya (1493-1714), Barcelona, IEC, 2015.

Simón i Tarrés, A., Del 1650 al 1705. L'autogovern de Catalunya i la classe dirigent catalana en el joc de la política internacional europea, València, Universitat de València, 2011.

Simón i Tarrés, A., "Los desterrados catalanes en Italia durante la Guerra de Separación de Catalunya (1640-1652)”, Investigaciones Históricas, 33 (2013), pp. 89105 .

Solís, J., "Las Juntas de secuestros y confiscaciones del Archiduque Carlos en Cataluña, Aragón y Valencia”, Anuario de Historia del Derecho Español, 69 (1999), pp. 427-462.

Solís, J., "La magistratura austracista en la Corona de Aragón”, Manuscrits, 23 (2005), pp. 131-150.

Solís, J., "La organización del Santo Oficio y el nombramiento de Inquisidor General por el archiduque Carlos (1709-1715)", Hispania, 65/2 (2005), pp. 515-542.

Toda i Güell, E., La Davallada de Poblet: Poblet als Segles XVII i XVIII, [Poblet], Abadia de Poblet, 1997.

Torres Amat, F., Memorias para ayudar a formar un diccionario critico de los escritores catalanes y dar alguna idea de la antigua y moderna literatura de Catalu$\tilde{n} a$, Barcelona, Imprenta de J. Verdaguer, 1836.

Torroella, J. B., El Estudi general ó Universitat Literaria de Girona. Ensaig histórich-crítich, Girona, Impr. P. Torres, 1906.

Trilla, A. de, Perfecto practicante medico y nueua Luz de facil enseñança, Toledo, por Agustin de Salas Zaço, 1677.

Urrea, J. A. de, Sermon de la Inmaculada Concepcion de Nuestra Señora, Barcelona, Antonio Lacavalleria, 1662.

Vargas Machuca, J. C. de, Decisiones vtriusq[ue] supremi tribunalis Regni Aragoniae, placitis et sententiis supremorum tribunalium Regni Neapolis, Neapoli, Typis et expensis Aegidii Longo, 1676. 
Vázquez Janeiro, I., "Repertorio de franciscanos españoles graduados en teología durante la Edad Media”, en Repertorio de Historia de las Ciencias Eclesiásticas de España, vol. 3: Siglos XIII- XVI, Salamanca, UPSA, 1971, pp. 255-320.

Velasco Bayón, B., Historia del Carmelo español: Provincias de Cataluña y Aragón y Valencia, 1563-1835, Roma, Institutum Carmelitanum, 1954.

Vilalta i Escobar, M. J., "La societat de Lleida en l'època moderna”, en C. Martínez Shaw (coord.), Historia Moderna, Historia en construcción, Vol. II, Lleida, Milenio, 1999, pp. 329-350.

Vilaplana, A. de, Proposiciones Christianas y iuridicas, Barcelona, Iacinto Andreu, 1679.

Villalva, F. de, Avisos de padre y rosario de nuestra señora, [s.l.], 1629.

Villanueva, J., Viage literario a las iglesias de España, T. XVII, Madrid, Imprenta de la Real Academia de la Historia, 1851.

Viola i González, R., "Un testament canonical (16 d'agost de 1561)”, Analecta Sacra Tarraconensia, 71 (1998), p. 907-920.

Zapater, M. R., Cister militante en la campaña de la Iglesia contra la sarracena furia, Zaragoza, por Agustin Verges, 1662.

Zaragoza Pascual, E., Catàleg dels monestirs catalans, Montserrat, Abadia de Montserrat, 1997.

Zaragoza Pascual, E., Abaciologi benedictí de la Tarraconense, Barcelona, Ed. Balmes, 2002.

Zaragoza Pascual, E., Història de la Congregació Benedictina Claustral Tarraconense i Cesaraugustiana (1215-1835), Montserrat, Abadia de Montserrat, 2004. 


\section{PROGRAMA HISTORIA DE LAS UNIVERSIDADES \\ PUBLICACIONES \\ ISSN: $1886-0710$}

1. Estado de la Universidad de Alcalá (1805), estudio preliminar de José Luis Peset, edición de Diego Navarro, Madrid 1999, 120 pp.

http://hdl.handle.net/10016/7875

2. La investigación en la universidad, edición de Carmen Merino, Madrid 1999, $217 \mathrm{pp}$.

http://hdl.handle.net/10016/7876

3. Aurora Rivière Gómez, Orientalismo y nacionalismo español. Estudios árabes y hebreos en la Universidad de Madrid (1843-1868), Madrid 2000, 143 pp.

http://hdl.handle.net/10016/7905

4. Manuel Martínez Neira, El estudio del derecho. Libros de texto y planes de estudio en la universidad contemporánea, Madrid 2001,318 pp.

http://hdl.handle.net/10016/7877

5. Daniel Comas Caraballo, Autonomía y reformas en la Universidad de Valencia (1900-1922), Madrid 2001, 334 pp.

http://hdl.handle.net/10016/7878

6. Carolina Rodríguez López, La Universidad de Madrid en el primer franquismo: ruptura y continuidad (1939-1951), Madrid 2002, 490 pp.

http://hdl.handle.net/10016/7879

7. Ramon Aznar i Garcia, Cánones y leyes en la universidad de Alcalá durante el reinado de Carlos III, Madrid 2002, 349 pp.

http://hdl.handle.net/10016/7880

8. Enrique Villalba Pérez, Consecuencias educativas de la expulsión de los jesuitas de América, Madrid 2003, 246 pp.

http://hdl.handle.net/10016/7881

9. Archivos universitarios e historia de las universidades, edición de José Ramón

Cruz Mundet, Madrid 2003, 345 pp.

http://hdl.handle.net/10016/7882

10. La enseñanza del derecho en el siglo XX. Homenaje a Mariano Peset, edición de Adela Mora Cañada, Madrid 2004, 578 pp.

http://hdl.handle.net/10016/7883 
11. Manuel Martínez Neira / José M. ${ }^{a}$ Puyol Montero / Carolina Rodríguez López, La universidad española 1889-1939. Repertorio de legislación, Madrid 2004, 389 pp. http://hdl.handle.net/10016/7884

12. Hacia un modelo universitario: la Universidad Carlos III de Madrid, edición de Adela Mora Cañada y Carolina Rodríguez López, Madrid 2004, 365 pp. http://hdl.handle.net/10016/7885

13. Manuales y textos de enseñanza en la universidad liberal, edición de Manuel Ángel Bermejo Castrillo, Madrid 2004, 750 pp.

http://hdl.handle.net/10016/7886

14. Susana Guijarro González, Maestros, escuelas y libros. El universo cultural de las catedrales en la Castilla medieval, Madrid 2004, CD + 349 pp.

http://hdl.handle.net/10016/7887

15. Filosofía para la universidad, filosofía contra la universidad, edición de Faustino Oncina Coves, Madrid 2008, 360 pp.

http://hdl.handle.net/10016/3506

16. Manuel Martínez Neira / José María Puyol Montero, El doctorado en derecho. 1930-1956, Madrid 2008, 340 pp.

http://hdl.handle.net/10016/3386

17. Germán Perales Birlanga, El estudiante liberal. Sociología y vida de la comunidad escolar universitaria de Valencia. 1875-1939, Madrid 2009, 326 pp.

http://hdl.handle.net/10016/4376

18. Alfons Aragoneses, Un jurista del Modernismo. Raymond Saleilles y los orígenes del derecho comparado, Madrid 2009, 259 pp.

http://hdl.handle.net/10016/5778

19. Antonio López Vega, Biobibliografía de Gregorio Marañón, Madrid 2009, 187 pp. http://hdl.handle.net/10016/6178

20. Pio Caroni, La soledad del historiador del derecho. Apuntes sobre la conveniencia de una disciplina diferente, Madrid 2010, 225 pp.

http://hdl.handle.net/10016/6560

21. Francisco Crosas López, De enanos y gigantes. Tradición clásica en la cultura medieval hispánica, Madrid 2010, 169 pp.

http://hdl.handle.net/10016/8346

22. Manuel Martínez Neira / Natividad Araque Hontangas, El marqués de Morante y la Universidad de Madrid, Madrid 2011, 277 pp.

http://hdl.handle.net/10016/10578 
23. Antonio Planas Rosselló / Rafael Ramis Barceló, La facultad de leyes y cánones de la Universidad Luliana y Literaria de Mallorca, Madrid 2011, 186 pp. http://hdl.handle.net/10016/11325

24. Francisco Ayala / Eduardo L. Llorens / Nicolás Pérez Serrano, El derecho político de la Segunda República, estudio preliminar, edición y notas de Sebastián Martín, Madrid 2011, CLXXXIX + 396 pp.

http://hdl.handle.net/10016/11365

25. Pablo Campos Calvo-Sotelo, La evolución histórica del espacio físico de la universidad. Impulsos conceptuales, paradigmas arquitectónicos, estrategias institucionales y propuestas recientes de innovación, Madrid 2011, 236 pp.

http://hdl.handle.net/10016/12017

26. Andry Matilla Correa, Los primeros pasos de la ciencia del Derecho Administrativo en Cuba. José María Morilla y el Breve tratado de Derecho Administrativo (1847), Madrid 2011, 329 pp.

http://hdl.handle.net/10016/12033

27. José María Puyol Montero, La autonomía universitaria en Madrid (1919-1922), Madrid 2011, 545 pp.

http://hdl.handle.net/10016/12289

28. Manuel Cachón Cadenas, Historias de procesalistas, universidades y una guerra civil (1900-1950), Madrid 2012, 681 pp.

http://hdl.handle.net/10016/14588

29. María Paz Alonso Romero, Salamanca, escuela de juristas. Estudios sobre la enseñanza del derecho en el Antiguo Régimen, Madrid 2012, 722 pp.

http://hdl.handle.net/10016/15129

30. Carlos Nieto Sánchez, San Clemente de Bolonia (1788-1889): el fin del Antiguo Régimen en el último colegio mayor español, Madrid 2012, 480 pp.

http://hdl.handle.net/10016/15708

31. Natividad Araque Hontangas, Manuel José Quintana y la Instrucción pública, prólogo de Jean-Louis Guereña, Madrid 2013, 427 pp.

http://hdl.handle.net/10016/17196

32. La Universidad Central durante la Segunda República: Las Ciencias Humanas y Sociales y la vida universitaria, edición de Eduardo González Calleja y Álvaro Ribagorda, Madrid 2013, 376 pp.

http://hdl.handle.net/10016/17394

33. Manuel Martínez Neira, La creación del cuerpo de catedráticos de universidad (1812-1857). Estudio histórico-jurídico, Madrid 2013, 358 pp.

http://hdl.handle.net/10016/18077 
34. Luis Enrique Otero Carvajal (dir.), La Universidad nacionalcatólica. La reacción antimoderna, Madrid 2014, 1098 pp.

http://hdl.handle.net/10016/18911

35. Manuel Martínez Neira, La regulación de las oposiciones a cátedras universitarias: $1845-1931$, Madrid 2014, $146 \mathrm{pp}$.

http://hdl.handle.net/10016/19338

36. Aulas modernas. Nuevas perspectivas sobre las reformas de la enseñanza secundaria en la época de la JAE (1907-1939), edición de Leoncio López-Ocón, Madrid 2014, $364 \mathrm{pp}$.

http://hdl.handle.net/10016/19883

37. María Ángeles Longás Lacasa, Historia de la Biblioteca de la Universidad de Mallorca (1767-1829), Madrid 2015, 437 pp.

http://hdl.handle.net/10016/21552

38. Fernando Liendo Tagle, Pablo de Olavide y la nueva planta de los estudios, Madrid 2016, 176 pp.

http://hdl.handle.net/10016/23895

39. Rafael Ramis Barceló, Doctores hispanos en leyes y cánones por la Universidad de La Sapienza de Roma (1549-1774), Madrid 2017, 274 pp.

http://hdl.handle.net/10016/24015

40. Julián Gómez de Maya, De Al-Ricotí al rector Sabater: estudios históricos sobre la Universidad de Murcia y sus antecedentes, Madrid 2017, 388 pp.

http://hdl.handle.net/10016/24848

41. Luigiaurelio Pomante, A Great Research Lab on University History and Higher Education in Spain: Instituto Antonio de Nebrija de Estudios sobre la Universidad (1997-2009), Madrid 2017, 253 pp.

http://hdl.handle.net/10016/25309

42. Pablo Campos Calvo-Sotelo / Laura Luceño Casals, Las formas de la educación. Vínculos entre dimensión docente y dimensión arquitectónica en disciplinas creativas, como expresión de innovación universitaria, Madrid 2018, 169 pp.

http://hdl.handle.net/10016/26594

43. Rafael Ramis Barceló / Pedro Ramis Serra, Los primeros grados de la Universidad de Baeza (1549-1580), Madrid 2018, 234 pp.

http://hdl.handle.net/10016/27079

44. Víctor Guijarro Mora, Artefactos y acción educativa. La cultura del objeto científico en la enseñanza secundaria en España (1845-1930), Madrid 2018, 273 pp.

http://hdl.handle.net/10016/27200 
45. Javier Carlos Díaz Rico (ed.), Oposiciones a cátedras de derecho (1847-1943), Madrid 2018.

http://hdl.handle.net/10016/27454

46. Rafael Ramis Barceló, Estudios sobre la Universidad de Lérida (1561-1717), Madrid 2018, 190 pp.

http://hdl.handle.net/10016/27465 